\title{
Electronics and Electrical Engineering Laboratory
}

\section{Program Plan}

Supporting Technology for U.S. Competitiveness in Electronics

Prepared by:

Electronics and Electrical Engineering Laboratory

U.S. DEPARTMENT OF COMMERCE Technology Administration National Institute of Standards and Technology

Eectronics and Electrical Engineering Gaithersburg, MD 20899 


\section{Electronics and Electrical Engineering Laboratory}

\section{Program Plan}

Supporting Technology for U.S. Competitiveness in Electronics

Prepared by:
Electronics and Electrical
Engineering Laboratory

U.S. DEPARTMENT OF COMMERCE Technology Administration National Institute of Standards and Technology

Eectronics and Electrical Engineering Gaithersburg MD 20899

August 1993

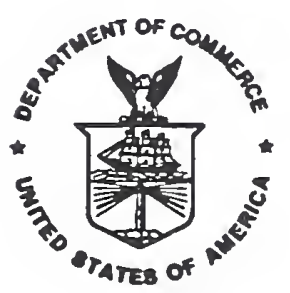

US. DEPARTMENT OF COMMERCE Ronsid H. Brown, Secretary

TECHNOLOGY ADMINISTRATION

Mary L Good, Under Secretery for Technolgy MATIONAL INSTIUUTE OF STANDARDS NND TECHNOLOOY

Ared Probhelces, Director 


\section{ELECTRONICS AND ELECTRICAL ENGINEERING LABORATORY Program Plan}

\section{TABLE OF CONTENTS}

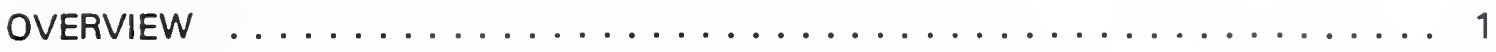

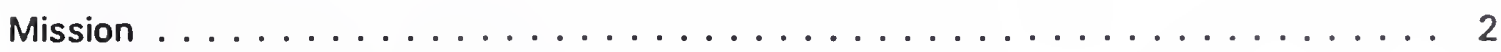

Means of Delivery $\ldots \ldots \ldots \ldots \ldots \ldots \ldots \ldots \ldots \ldots \ldots \ldots$

Resources and Planning $\ldots \ldots \ldots \ldots \ldots \ldots \ldots \ldots \ldots$

Response to Strategic Plan ...................... 6

OfFICE OF MICROELECTRONICS PROGRAMS $\ldots \ldots \ldots \ldots \ldots \ldots \ldots$

OFFICE OF LAW ENFORCEMENT STANDARDS $\ldots \ldots \ldots \ldots \ldots \ldots$

ELECTRICITY DIVISION .......................... 37

Applied Electrical Measurements Group . . . . . . . . . . . . . . . . 38

Electronic Instrumentation and Metrology Group . . . . . . . . . . . 66

Electrical Reference Standards Group . . . . . . . . . . . . . . 81

Fundamental Electrical Measurements Group . . . . . . . . . . . . . . . 92

SEMICONDUCTOR ELECTRONICS DIVISION ............... 101

Materials Technology Group . . . . . . . . . . . . . . . . . . . . 102

Device Technology Group . . . . . . . . . . . . . . . . . . . . . . . . 114

IC Technology Group . . . . . . . . . . . . . . . . . . . . . . . . . 124

ELECTROMAGENTIC FIELDS DIVISION . . . . . . . . . . . . 133

Microwave Metrology Group . . . . . . . . . . . . . . . . . . . 134

Broadband Microwave Metrology Group . . . . . . . . . . . . . . . . 151

Fields and Interference Metrology Group . . . . . . . . . . . . 161

Antenna Metrology Group . . . . . . . . . . . . . . . . . . . . . . 170

ELECTROMAGNETIC TECHNOLOGY DIVISION . . . . . . . . . . 183

Optical Electronic Metrology Group . . . . . . . . . . . . . . . . . . 184

Cryoelectronic Metrology Group . . . . . . . . . . . . . . . . . 199

Superconductor and Magnetic Measurements Group . . . . . . . . . . . 211 
$\cdots$ 


\section{OVERVIEW}

\section{INTRODUCTION}

The Electronics and Electrical Engineering Laboratory (EEEL), working in concert with other NIST Laboratories, is providing supporting technology that is critical to the competitiveness of the U.S. electronics industry and the U.S. electrical equipment industry. Among U.S. manufacturing industries, the electronics industry is the largest employer (1.9 million in 1991) and is comparable in product shipments (\$271 billion in 1991) to the other largest manufacturing industry, the chemical industry ( $\$ 275$ billion in 1991). ${ }^{1}$ The electronics industry exerts extraordinary influence on the performance of every other U.S. industry. For the electrical-equipment industry, U.S. shipments are $\$ 48$ billion (1990). ${ }^{2}$ Among the products included is the equipment used by the electric utilities. They provide $\$ 186$ billion of electricity annually (1992). ${ }^{3}$

\section{International Challenge}

Both the electronics industry and the electrical-equipment industry face significant and continuing challenges to their international competitiveness. Trade activity for both industries is high, indicating the sensitivity of their competitive position to continued good performance. Trade activity, as measured by exports plus imports, divided by U.S. shipments, is about 55 percent for the electronics industry ${ }^{4}$ and perhaps half that level for the electrical-equipment industry. For the electronics industry, the overall balance of trade is negative (1991). ${ }^{5}$ The single most significant contributor to this negative balance is consumer electronics. Performance in consumer electronics is widely regarded as an important indicator of a nation's ability to manufacture competitive electronic products more broadly. Computers have the largest positive balance of trade among U.S. electronic products.

Both the electronics and the electrical equipment industries are employing increasingly advanced technology in new products, and both are outstripping available supporting measurement capability. In response, the Electronics and Electrical Engineering Laboratory of NIST has developed this program of measurement support for industry.

\section{Role of This Program Plan}

The Program Plan shows how EEEL is implementing its program. The relationship of this plan to other planning documents developed by EEEL is summarized in Table 1. EEEL begins with a detailed definition of the industries

that it serves. It assesses the measurement needs of those industries and looks for those needs that require NIST's assistance and that will have the greatest economic impact if successfully addressed. EEEL develops a Strategic Plan that describes the broad response needed by industry from NIST as a whole, without limitation by NIST's current resources. Then EEEL develops the Program Plan to describe EEEL's own response to the Strategic Plan at a level consistent within currently available EEEL resources. In the Program Plan, EEEL's plans for five years forward are described, with emphasis on plans for the current year; accomplishments for the past year are also described.
Table 1: EEEL's PLANNING DOCUMENTS

Measurements for Competitiveness in Electronics assessments of measurement needs of industries served for 10 years forward; definitions of industries served

Strategic Plan strategic plan for NIST's response for 10 years forward

\section{Program Plan}

operational plan for EEEL's response for 5 years forward with emphasis on current year completed EEEL work in past year and new impact information
Accomplishments and Impact 
Finally, EEEL evaluates the accomplishments and impact of its work. At this time, formal documents addressing these steps are in place, except for Accomplishments and Impact. However, several impact studies have been completed and others are underway to provide the basis for this last document, as discussed further below in connection with Table 6.

\section{Fields Addressed}

In EEEL's Strategic Plan, the fields of electronics that EEEL has identified, to date, as needing NIST support are shown in Table 2. They include electronic, electrical, optical, and magnetic technologies, and combinations of them. Increasingly, these fields mutually depend on one another.

Of the fields in Table 2, there are several that EEEL presently does not support but plans to support in the future; they are marked " $\mathrm{f}$ ". Also, EEEL does not address the architecture and other broader aspects of computers and information networks; they are addressed by NIST's Computer Systems Laboratory. Rather, EEEL contributes support for electronic components, through its support of the other fields. In the table, several fields are the subject of formal collaboration between EEEL and other NIST Laboratories; those fields are marked " $c$ ". All seven of the other NIST Laboratories are represented, with 61 collaborative efforts of varying sizes in place. The cross-cutting fields at the bottom of the table address challenges that are common to many of the fields at the top of the table.

\section{MISSION}

The Electronics and Electrical Engineering Laboratory improves U.S. economic competitiveness, Government operations, and health and safety by providing essential supporting technology, generic technology, and fundamental research to industry, government, and educational institutions. The primary supporting-technology deliverables are measurement capability (for absolute accuracy and reproducibility) and materials reference data. These are realized through development of measurement methods, supporting theory, measurement reference standards (including the national primary standards for electricity, and materials reference standards), and calibration and other measurement services to assure measurement traceability. These deliverables support electronic and electrical products in all forms, including materials, components, equipment, and

Table 2: FIELDS OF ELECTRONICS

Fields

semiconductors

high-density silicon integration $c$ compound-semiconductor integration

magnetics

high-density magnetic

information storage

magnetic sensing

advanced materials

superconductors

low temperature

high temperature

microwaves

individual components

integrated components

lightwaves

Lasers

optical-fiber communications c

high-density optical

information storage

optical signal processing

and computing

optical-fiber sensors

computers

information networks

power networks

power transmission

power control

video

high-resolution vision

high-speed signal processing $c$

high-data-rate transmission

high-density information

storage

bigh-resolution displays

Cross-Cutting Fiolds

electromagnetic compatibility

complex-system description

complex-system testing

high efficiency

high accuracy

$\mathrm{c}=$ collaborative with other NIST Laboratories

$f=$ future EEEL support anticipated

systems, operating over the frequency range from dc to light. The deliverables serve research and development, manufacturing, marketplace exchange, and support (installation, operation, and maintenance). 
In fulfilling this mission, EEEL's strives to serve as the world's best source of fundamental and industrial measurement methods and reference standards with high leverage for the U.S. electronics industry, and to deliver these resources to industry and Government in support of national goals.

EEEL expresses its mission priorities within three principal categories: national goals served, customers served, and deliverables pursued for those customers, as shown in Table 3. The entries under each of the three main headings in Table 3 are in priority order. EEEL addresses all of the elements in the table but distributes its resources to reflect these priorities.

\section{National Goals}

EEEL pursues, as its top priority goal, the strengthening of the U.S. economy, primarily through improved competitiveness. EEEL also supports improved Government operations and health and safety by providing needed technical support. For health and safety, EEEL provides both direct support (e.g., electric-fields measurements for biological researchers) and indirect support since virtually every electronic device with a health or safety function is advanced by EEEL's deliverables.

\section{Customers}

EEEL serves industry, other government agencies (Federal, state, and local), and educational institutions. The general public has not been listed as a customer in Table 3 because virtually all of EEEL's services that support the general public are provided through one of the three other customers listed. EEEL serves the research community wherever it is located - in industry, government agencies, or educational institutions.

\section{Deliverables}

EEEL provides deliverables that yield high leverage in

Table 3: MISSION

National Goals

strengthen U.S. economy improve industry's competitiveness improve Government operations improve bealth and safety

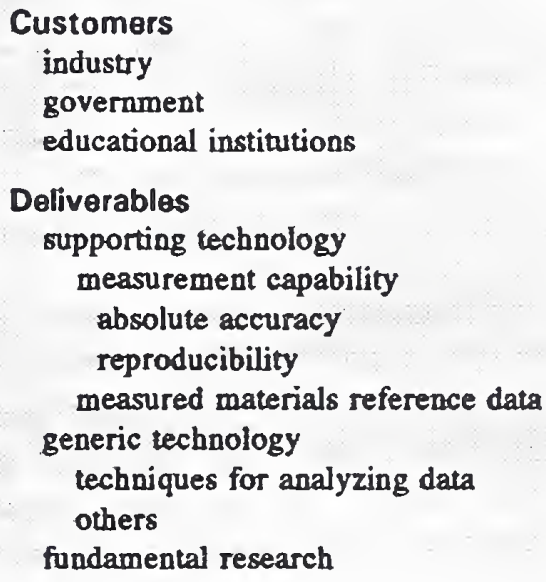

achieving the specified national goals and that are consistent with NIST's broad legislated authority. As shown in Table 3, EEEL provides three principal categories of deliverables: supporting technology, generic technology, and fundamental research. EEEL places its top priority on supporting technology, with a special emphasis on measurement capability. This emphasis reflects a combination of the high leverage of measurement capability on competitiveness, and other key factors (such as NIST's unique role). Leverage, in this case, means the economic impact per dollar of NIST investment. EEEL's emphasis on measurement capability reflects the broad impact of measurements on the rapid commercialization of new technology. Rapid commercialization is widely accepted as a key competitiveness challenge of the U.S. electronics industry, as opposed to access to new technology or to additional fundamental research. Other agencies, principally NSF, DOD, and DOE, invest billions of dollars in new technology and fundamental research that is supportive of electronics; additional investment by EEEL would be small in comparison. Further, NIST has a unique responsibility to meet critical national measurement needs which cannot be met by individual companies and other agencies. For the electronics industry, those needs are both vast and urgent. 
Measurement capability. EEEL places the highest priority on delivering absolute accuracy, in keeping with NIST's unique role as the national reference laboratory for measurements. Absolute accuracy may require a documented measurement method (and/or a special measurement device), a supporting reference standard, and a means of delivery such as a measurement assurance program or a calibration service. EEEL also provides reproducible measurement capability. Virtually every fundamental advance that EEEL makes in measurement capability requires new knowledge and therefore intensive fundamental research. Key generic-technology development is often required to put measurement capability into a deliverable form. Thus EEEL conducts a considerable amount of generic-technology development and fundamental research in direct support of its measurement mission.

Measured materials reference data. EEEL develops reference data on the electronic properties of materials if NIST's special measurement skills are needed for development, or if NIST's evaluation and imprimatur are needed for wide acceptance. However, whenever possible, EEEL prefers to provide industry with measurement capability that industry can use to develop the data for itself, maximizing EEEL's leverage.

Techniques for analyzing measured data. EEEL develops generic technology in the form of techniques for analyzing measured data. Examples include test strategies for complex electronic systems, and expert system analyses for semiconductor process lines. These techniques, together with measurement capability and materials reference data, are EEEL's measurement-related deliverables.

Other generic technology and fundamental research. EEEL develops other generic technology as well. An example is process technology for superconducting and semiconducting integrated circuits. Another example is complex-systems descriptions that include standardized descriptions of the functional and physical characteristics of products in digital form for automated manufacturing. ${ }^{6}$ EEEL also conducts fundamental research, other than that required for its measurement-related deliverables, if targets of unusual opportunity present themselves; usually this research requires measurement capability available only at NIST. A key example is EEEL's work on determining the values of fundamental physical constants, such as the fine-structure constant and the gyromagnesic ratio of the proton.

\begin{tabular}{|c|c|}
\hline Communications & $\begin{array}{r}\text { FY92 } \\
223\end{array}$ \\
\hline software requests & 276 \\
\hline talks & 242 \\
\hline consultations & 1488 \\
\hline visits & 193 \\
\hline visitors & 839 \\
\hline meetings & \\
\hline attendees & $>2000$ \\
\hline contributors & 66 \\
\hline \multicolumn{2}{|l|}{$\begin{array}{l}\text { Joint Activities } \\
\text { standards organizations }\end{array}$} \\
\hline staff participating & 51 \\
\hline memberships & $>100$ \\
\hline professional societies & \\
\hline memberships & 203 \\
\hline cooperative research & 81 \\
\hline consartia (incl forming) & 8 \\
\hline research associates & 3 \\
\hline guest scientists & 43 \\
\hline \multicolumn{2}{|l|}{ Paid Services } \\
\hline $\begin{array}{l}\text { custom measurement } \\
\text { development }\end{array}$ & 138 \\
\hline standard reference materials & 55 \\
\hline \multicolumn{2}{|l|}{ calibration services } \\
\hline tests & $>4000$ \\
\hline customers & 473 \\
\hline training courses & 28 \\
\hline
\end{tabular}

\section{MEANS OF DELIVERY}

EEEL provides its deliverables by three principal means. as shown in Table 4: communications, joint activities, and paid services. FY 1992 levels of activy are shown in the table. These means of delivery require regular interactions with industry, government agencies, and universities. The interactions are essential to planning as well as to delivery. Over the past three years, the levels of activity associated with the various means of delivery have varied up and down but not with distinct trends. All continue to be important to effective delivery. An examination of the workload on the 
staff indicates that the staff has reached capacity in the number of technology-transfer activities that it can handle at its present size.

\section{RESOURCES AND PLANNING}

\section{Resources}

The fiscal and staff resources that EEEL brings to bear on its program are characterized in Table 5. EEEL expects that funding from the Congress will provide about 55 percent of the estimated $\$ 44.3$ million of total resources required for FY 1992. The balance will be made up of funding from other agencies, from reimbursements from industry and other Government agencies for calibrations and other services, and from funding from NIST's Advanced Technology Program (ATP) for activities supportive of the thrusts of that program. To improve its direct funding, EEEL is pursuing increases through the President's Budget for FY 1994. EEEL hopes to be able to reduce its

\begin{tabular}{|lrr|}
\hline \multicolumn{3}{|c|}{ Table 5: RESOURCES } \\
Funding Level (1993) & $\$ 4.3$ million \\
Funding Sources (1993) & \\
direct from Congress & $55 \%$ \\
other agencies & $36 \%$ \\
calibrations, other services & $5 \%$ \\
Advanced Technology Program & $\frac{4 \%}{100 \%}$ \\
total & & \\
Staff (FY 1992) & & 354 \\
paid & 300 & \\
$\quad \begin{array}{l}\text { full-time permanent } \\
\text { other }\end{array}$ & 54 & \\
unpaid & 46 \\
$\quad$ guest scientists & 43 & \\
$\quad$ research associates & 3 & \\
total & & 400 \\
\hline
\end{tabular}
dependency on funding from other agencies to 30 percent in coming years.

\section{Planning}

EEEL attaches considerable importance to planning. Key efforts are outlined in Table 6.

EEEL is developing assessments of industry's measurement needs and is publishing them periodically to obtain feedback from industry and government. The most recent publication is Measurements for Competitiveness in Electronics (April, 1993). The longterm goal of this project is to develop measurement needs assessments for every economically significant sector of the U.S. electronics and electrical equipment industries. The assessments published through FY 1993, and the new or updated assessments planned for publication in future fiscal years, are marked " $a$ " in Table 6. For selected assessments, EEEL has solicited reviews (" $r$ ") by industry experts and has revised the assessments according to their responses. Underlined letters in the table, " $\mathrm{a}$ ", " $\mathrm{I}$ ", and " $\mathrm{i}$ ", indicate planned work, rather than completed work.
Table 6: PLAN FOR PLANNING DOCUMENTS

Fields semiconductors

magnetics

superconductors

microwaves

lightwaves

lasers

optical-fiber communications

optical information storage

optical processing/computing

optical-fiber sensors

computers

information networks

power networks

video

Cross-Cutting Fields

electromagnetic compatibility

complex-system description

complex-system testing

high efficiency

high accuracy

$\mathrm{a}=$ assessment of industry's measurement needs, $\mathrm{a}=$ planned

$r=$ review of needs assessment by industry, $I=$ planned

$s$ : = survey of industry's measurement needs

$i=$ impact study, $\underline{i}=$ planned, $i \hat{i}=$ two in one year 
EEEL has also conducted a number of surveys ("s"), employing either questionnaires or coordinated contacts with industry at both technical and managerial levels. Underway at present is a survey of the measurement needs for optical techniques for characterizing semiconductor materials, including both silicon and compound semiconductors.

Finally, EEEL and the NIST Program Office have conducted a number of impact analyses (" $i$ "), employing both EEEL staff and outside experts to determine how completed work affected industry. Recently completed studies address the impact of EEEL's measurement capability on optical fibers for communications systems, electromagnetic compatibility, electromigration in integrated circuits, and superconductivity. ${ }^{7}$ EEEL is presently conducting one additional impact study, focused on the impact of EEEL calibration services for electrical power and energy. ${ }^{8}$

\section{RESPONSE TO STRATEGIC PLAN}

The pages that follow describe in detail EEEL's plan for response to its 1991 Strategic Plan. The material is organized into a series of projects. The description of each project contains two pages of text that state the objective and significance of the project in general terms, the major accomplishments for the past fiscal year, FY 1992, and the major plans for the current year, FY 1993. After each two-page description, a chart, called the Five-Year Plan, indicates the timing for the completion of major plans from FY 1993 to FY 1997. The presence of an arrow $(\rightarrow)$ under FY 1997 means that the planned work is expected to continue beyond FY 1997.

The projects are arranged according to EEEL's organizational structure. EEEL is organized into four Divisions, each of which is subdivided into Groups. In addition, EEEL contains two Offices that fund and manage, but do not conduct, programs. One is the Office of Microelectronics Programs (OMP). It manages a NIST-wide program in support for the semiconductor indus: Part of its program is conducted within the various Divisions of EEEL and part within the D. so s of other NIST Laboratories. In the attached descriptions of the projects of the Divisions, the aruvtation "OMP" appears next to work funded by that Office. The other Office is the Office of Law Enforcement Standards. It manages a NIST-wide program in support of the law enforcement community. At present virtually all of its program is conducted within the various Divisic of EEEL. This Office is supported entirely by funding from other Federal agencies.

Table 7 shows the crosswalk between the programmatic structure of EEEL's Strategic Plan and the organizational structure of the Program Plan. 


\begin{tabular}{|c|c|c|}
\hline $\begin{array}{l}\text { EEEL STRATEGIC PLAN: } \\
\text { FIELDS OF TECHNOLOGY }\end{array}$ & $\begin{array}{l}\text { EEEL PROGRAM PLAN: } \\
\text { PROJECTS }\end{array}$ & PAGE \\
\hline SEMICONDUCTORS & $\begin{array}{l}\text { Plesme chemistry - plasme processing [see also Plasma } \\
\text { processing and chemicel vepor deposition, page 12] } \\
\text { MBE growth technology } \\
\text { Characterization and eveluation of HGCdTe IR detectors } \\
\text { Electricel characterization } \\
\text { Opticel cherecterizetion } \\
\text { Thir-film SRMs } \\
\text { SOI material and device measurements } \\
\text { Power device and thermal measurements } \\
\text { Integrated measurement systems } \\
\text { Test structures for reliability } \\
\text { Test structures for IC manufacturing } \\
\text { Intelligent test structure metrology }\end{array}$ & $\begin{array}{l}56 \\
102 \\
104 \\
108 \\
110 \\
114 \\
116 \\
119 \\
122 \\
124 \\
126 \\
128\end{array}$ \\
\hline SUPERCONDUCTORS & $\begin{array}{l}\text { Cryoelectronic metrology } \\
\text { Superconducting motrology } \\
\text { Far-infrared technology } \\
\text { High-temp. superconducting films and olectronic devices } \\
\text { Superconductor standards } \\
\text { Conductor systems } \\
\text { Supereonductor strueture and properties }\end{array}$ & $\begin{array}{l}199 \\
202 \\
205 \\
208 \\
211 \\
214 \\
221\end{array}$ \\
\hline MAGNETICS & Magnetics & 217 \\
\hline MICROWAVES & $\begin{array}{l}\text { Power standards and measurements } \\
\text { Impedance, attenuation, voltage standards and meas. } \\
\text { Network analysis and measurements } \\
\text { MMIC standerds and measurements } \\
\text { Electromagnetic properties of materials } \\
\text { Noise measurements and standards } \\
\text { Antenne measurements, theory, and applications } \\
\text { Metrology for antenna, RCS, and space systoms } \\
\text { Special tests, measurements, and calibrations \{antennas\} }\end{array}$ & $\begin{array}{l}134 \\
138 \\
143 \\
147 \\
151 \\
156 \\
170 \\
175 \\
179\end{array}$ \\
\hline LGHTWAVES & $\begin{array}{l}\text { Optoelectronic/electrooptic tochnology } \\
\text { Optical-fiber measurement systems and standards } \\
\text { Laser power and energy measurements } \\
\text { Characterization of sources and dotectors } \\
\text { Integrated optoolectronics } \\
\text { Optical-fiber sensors }\end{array}$ & $\begin{array}{c}78 \\
184 \\
187 \\
190 \\
193 \\
196\end{array}$ \\
\hline POWER NETWORKS & $\begin{array}{l}\text { Powerlenergy and ACIOC high-voltage and-current moas. } \\
\text { Liquid diolectrics and portial-dischargo rosearch } \\
\text { Power quality } \\
\text { Pulsed power measurements } \\
\text { Gasoous dielectrics research }\end{array}$ & $\begin{array}{l}41 \\
44 \\
50 \\
53 \\
59\end{array}$ \\
\hline VIDEO & Digital information processing & 47 \\
\hline ELECTROMAGNETIC COMPATIBILTYY & $\begin{array}{l}\text { Electric and magnetic field measurement } \\
\text { Emission and immunity metrology } \\
\text { Standard EM fields and trensfer probe standerds }\end{array}$ & $\begin{array}{c}38 \\
161 \\
165 \\
\end{array}$ \\
\hline COMPLEX SYSTEM DESCRIPTION & Automated oloctronic manufacturing & 62 \\
\hline COMPLEX SYSTEM TESTING & $\begin{array}{l}\text { Meesurements for complex electronic systems } \\
\text { Weveform acquisition devices and standerds } \\
\text { Generation and meesurement of precise signels } \\
\text { Phese angle and power/energy standards } \\
\text { AC-DC difference standards and measurement techniques } \\
\text { Calibration services for basic electrioat quentities } \\
\text { Resistance standards and measurememt methods } \\
\text { Impedance standerds ond measurement mothods } \\
\text { DC voltage standards and measurement methods } \\
\text { SI Farad and Ohm and the quantum Hall offect } \\
\text { SI Ampere and gyromagnetic patio of the proton }\end{array}$ & $\begin{array}{l}86 \\
69 \\
72 \\
75 \\
81 \\
84 \\
86 \\
89 \\
92 \\
95 \\
98\end{array}$ \\
\hline
\end{tabular}




\section{ENDNOTES}

1. Electronic Market Data Book, Electronic Industries Association, pp. 2, 120 (1992). U.S. Industrial Outlook 1993, International Trade Administration, U.S. Department of Commerce, p. 11-1 (January 1993). The value for the chemical industry is product shipments, that is, shipments of all chemical products, whether by the chemical industry or by other industries. The value of industry shipments, that is, of all shipments by the chemical industry, whether chemical products or not, is $\$ 296$ billion for 1991 .

2. Measurements for Competitiveness in Electronics, Chapter 3, "Overview of U.S. Electronics and Electrical Equipment Industries", Electronics and Electrical Engineering Laboratory, National Institute for Standards and Technology, U.S. Department of Commerce, p. 38 (April 1993).

3. Courtesy of Barbara Brough, Edison Electric Institute, Washington, DC (April 1993). The quantity of electricity sold in the U.S. in 1992 was 2.7 trillion kilowatt hours, that is $2.7 \times 10^{12}$ kilowatt hours.

4. Electronic Market Data Book, Electronic Industries Association, pp. 2, 111, and 113 (1992).

5. Electronic Market Data Book, Electronic Industries Association, p. 113 (1992).

6. Industry calls this effort PDES, or Product Data Exchange Using STEP, where STEP is Standards for the Exchange of Product Model Data.

7. Albert N. Link, Estimates of Economic Impact of NIST Research in Electromagnetic Compatibility/Interference (EMC/EMI) Metrology (December, 1991). Albert N. Link, Economic Impact of NIST-Supported Standards for the U.S. Optical Fiber Industry: 1981 - Present (February, 1992). Albert N. Link, Economic Impact on the U.S. Semiconductor Industry of NIST Research in Electromigration (January, 1992). Dr. Link is a consulting economist. Robert L. Peterson, An Analysis of the Impact on U.S. Industry of the NIST/Boulder Superconductivity Programs (to be published in 1993).

8. John D. Ramboz, Economic and Technical Impacts and Value of the NIST Calibration Services for Electrical Power and Energy (to be completed in 1993). 
OFFICE OF MICROELECTRONICS PROGRAMS

$-9-$ 


\section{Project: FEATURE-SIZE MEASUREMENTS FOR MICROELECTRONICS}

FY 92 Fund Sources: STRS, IBM Corp., SDI, OMP

Staff (5.5 staff-years)

\begin{tabular}{|l||l|l|l|l|}
\hline Professional & R.D. LARRABEE & M.T. POSTEK & J.E. POTZICK & W.J. Keery" \\
\cline { 2 - 5 } & C.F. Vezzetti" & J.R. Lowney* & A. Vladar & \\
\hline Technician & S.N. Jones & & & \\
\hline
\end{tabular}

name in capital letters $=$ project leader; $=$ person works on project part time

Objective: 1) Develop the basic metrology, standards, and associated techniques for accurately measuring the size of submicrometer features on photomasks, X-ray masks, integrated circuits, and other structures of industrial interest by optical, electron-beam, or scanning-probe techniques, and 2) disseminate the results of this work not only through Standard Reference Materials, but also through publications, formal presentations, seminars, tutorials, workshops, visits, and personal contacts.

Significance: As the critical dimensions continue to evolve to smaller dimensions, the problem of accurately measuring feature sizes for quality control purposes becomes both more critical for effective quality control and more difficult to achieve in practice. In the mid-1970's, NIST led the way to accurate metrology of photomask features, in the mid-1980's it led the way to awareness and solutions of the problems of accurate submicrometer metrology in the scanning electron microscope, and in the mid1990 's it plans to lead the way in solving the problems of accurate submicrometer metrology using scanning-probe techniques.

\section{FY 92 Accomplishments}

- Completed SRM 473, NIST's first submicrometer photomask linewidth standard which extends the linewidth range to $0.5 \mu \mathrm{m}$ from $1 \mu \mathrm{m}$.

- Held second annual optical modeling workshop as part of the 1992 SPIE Symposium on Microlithography.

- Made significant improvements in our proposed transmission SEM method of measuring submicrometer feature sizes on $\mathrm{X}$-ray masks.

- Acquired 20 prototype SEM magnification standard artifacts from the National Nanofabrication Facility at Cornell for use in an interlaboratory comparison study.

\section{FY 93 Plans}

- Issue SRM 473 and continue construction of a new ultraviolet-light calibration system for use on the next generation photomask standards.

- Complete the interlaboratory study of the prototype magnification standards and prepare technical paper detailing the results.

- Complete the "best effort" calibration of $\mathrm{x}$-ray mask standards for IBM and deliver both masks and documentation to IBM. 
- Initiate project to develop a more robust sharpness (or resolution) standard for the SEM.

\section{Impact}

- The industry has long awaited the issuance of the new SRM 473 and is now awaiting an improved version with greater accuracy and still smaller linewidths.

- The tentative results of the SEM magnification standard interlaboratory study clearly show the need for calibration on every magnification level and, perhaps, in real time for critical measurements.

- Our work with the transmission mode of SEM for metrology has resulted in its incorporation into at least two custom instruments currently under construction.

\section{Recognition}

- Dr. M.T. Postek is the current chairman of the Integrated Circuit Metrology, Inspection and Process Control Conference of the 1992 and 1993 SPIE Symposium on Microlithography. He is also chairman of one of the technical sessions as are Dr. R.D. Larrabee and Mr. J.E. Potzick. In addition, Dr. Larrabee has initiated and is organizing and running two separate workshops at the Symposium.

- Dr. M.T. Postek received the DoC Silver Medal for his work in basic SEM metrology.

\section{Related Developments}

- As the device scale continues to evolve to smaller dimensions as predicted by Moore's law, the need for new and improved dimensional metrology techniques becomes ever more acute. This generates a continuing need for new and expanded NIST measurement services and standards that probably will not be satisfied at the current and presently projected levels of effort.

- SEMATECH funding for collaboration in areas of common interest has not been forthcoming despite continued recommendations for such funding and collaboration by the Metrology Focus TAB Committee consisting of member company representatives. 


\section{Project: PLASMA PROCESSING AND CHEMICAL VAPOR DEPOSITION}

\section{FY 92 Fund Sources: STRS, OMP}

\section{Staff (4.5 staff-years)}

\begin{tabular}{|l||l|l|l|l|}
\hline Professional & $\begin{array}{l}\text { J.R.WHETSTONE } \\
\text { (CSTL) }\end{array}$ & $\begin{array}{l}\text { R. J. Van Brunt } \\
\text { (EEEL) }\end{array}$ & $\begin{array}{l}\text { J. K. Olthoff } \\
\text { (EEEL) }\end{array}$ & $\begin{array}{l}\text { J. R. Roberts } \\
\text { (PL) }\end{array}$ \\
\cline { 2 - 5 } & $\begin{array}{l}\text { M. A. Sobolewski } \\
\text { (CSTL) }\end{array}$ & $\begin{array}{l}\text { R. W. Davis } \\
\text { (CSTL) }\end{array}$ & $\begin{array}{l}\text { E. F. Moore } \\
\text { (CSTL) }\end{array}$ & $\begin{array}{l}\text { M. R. Zachariah } \\
\text { (CSTL) }\end{array}$ \\
\hline
\end{tabular}

name in capital letters = project leader: " = person works on project part time

Objective: Develop basic reference data, reference plasma discharge cells, advanced measurement methods and predictive models applicable to plasma etching and chemical vapor deposition (CVD) reactors, using advanced measurement techniques for model validation and process control and computational models employing fundamental thermochemical and kinetics data.

Significance: Improved process models and sensors are critical to the achievement of $0.12 \mu \mathrm{m}$ device geometries. The predictive models required will be based on semi-empirical to fully fundamental methods by the beginning of the next century. Validation of these will rely heavily upon a knowledge base describing the basic physical and chemical mechanisms controlling thin film etching and deposition reactors. The measurements and data necessary include kinetic-energy distributions, densities, and species concentrations of ions and electrons in plasmas. Validated ab-initio models will provide methods for estimating chemical thermodynamics and kinetics data and particle formation mechanisms and trajectories in CVD reactors to support equipment design for CVD reactors. To advance plasma processing techniques, reference discharges such as the Gaseous Electronics Conference (GEC) rf Reference Cell have been developed to test diagnostic measurements, plasma chemistry models of the process, and determine the inherent physical characteristics that determine the limits of reproducibility.

\section{FY 92 Accomplishments}

- Measured kinetic energy distributions of ions sampled from $\mathrm{Ar} / \mathrm{O}_{2}$ and $\mathrm{Ar} / \mathrm{He}$ if discharges in the GEC rf reference cell under various plasma conditions.

- Compared electrical data from six GEC cells; results accepted for publication in The Review of Scientific Instruments. Parasitic if impedance effects in the GEC cell, or other plasma reactors, have major effects $6:$ the measured currents and voltages. A simple model of these parasitics and an inductive shunt circuit provided the means to achieve interlab comparability below the $10 \%$ level.

- Improved accuracy of electrical measurements in RF discharges by calibrating voltage and current probes and developing characterization methods for parasitics to allow differences in the electrical characteristics of plasmas in reactors to be separated from measurement errors.

- A full two-dimensional model for flow and particle dynamics in a axisymmetric rotating-disk chemical vapor depositin (CVD) reactor was developed and validated using experimental data from Sandia National Lab:- A global particle contamination parameter was identified which specifies the particle siz alow which no impacts will occur regardless of particle location in the reactor.

- JC SEMATECH/NIST workshop on the Chemistry of CVD Processes in miconductor N. respements, and state-of-the-art experimental and ab-initio estimation methods for thermochemical data. Recommendations for future industrial thermal CVD technology needs were developed.

- Developed a cluster growth model as an iristiation mechanism for particulate formation. Molecular 
dynamics methods were used to follow cluster-cluster collision and agglomeration dynamics affecting the formation of larger particles in CVD and etching reactions. Results given in an archival paper.

- Ab-initio molecular orbital calculations coupled with reaction rate theory to simulate silane oxidation showing subsequent formation of $\mathrm{SiO}$ polymerized into planar rings. The technique allows investigation of chemical reaction pathways of thermal CVD reactions. Archival paper published.

- Measured kinetic-energy distributions for ions sampled from diffuse, high $\mathrm{E} / \mathrm{N}$, dc discharges in argon and nitrogen. For lower $\mathrm{E} / \mathrm{N}(<9 \mathrm{kTd})$, distributions agree with predictions from measured cross sections. Higher $\mathrm{E} / \mathrm{N}$ distributions exhibit a non-Maxwellian distribution. Results on the argon discharges were included in a conference paper presented at the 1992 Gas Discharge Conference.

- Measured space- and time-resolved optical emission data for argon and argon/hydrogen plasmas. Spectral line profiles of hydrogen $\mathrm{H}_{\alpha}$, both time-integrated and time-resolved, show that differing ratios of fast and slow hydrogen atoms are greatly influenced by the amount of argon in the plasma.

- Completed evaluation and submitted a report to SEMATECH of a Langmuir probe system. Also evaluated a commercially available probe systems and found the single probe characteristics not to be analyzable due to the lack of frequency compensation for applied rf voltage.

FY 93 Plans

- Prepare archival paper documenting results of ion kinetic energy measurements, made with a new mass spectrometer system, by sampling through the grounded electrode of the GEC reference cell.

- Complete measurements of kinetic-energy distributions for ions sampled from diffuse argon and nitrogen high $\mathrm{E} / \mathrm{N}$, dc discharges and of $\mathrm{K}+$ ion energy distributions in the uniform-field drift tube and compare with results of Monte-Carlo simulations. Continue investigations of ion kinetic-energy distributions and attempt to delineate the effects of surface charging on the plasma.

- Continue studies of the application of if electrical measurements and langmuir probe measurements to process monitoring of critical plasma etching parameters, e.g., total ion flux, plasma sheath potentials, surface conditions and charging.

- Pursue collaboration with SEMATECH to develop improved thermochemical data bases supporting advanced process chemistry models as part of engineering design tools for thermal CVD equipment.

\section{Impact}

- NIST has played a leading role in development and evaluation of the reference discharge-cell concept. The GEC cell at NIST is now an object of investigation in numerous research laboratories in the U.S., including Sandia National Laboratory, University of New Mexico, Air Force Aeropropulsion Laboratory, AT\&T Bell Laboratories, IBM T.J. Watson Research Center, University of Michigan, University of California, Massachusetts Institute of Technology, and University of Illinois.

- NIST has been providing support to the industry through SEMATECH and via interactions with various manufacturers in the implementation of advanced plasma diagnostics.

- NIST has worked closely with SEMATECH in assessing the needs in the CVD modeling community. The recent example of this occurred in FY-92 with the joint workshop on the status and capabilities needed for thermochemical and chemical kinetic data for next generation CVD systems.

\section{Recognition}

- R. J. Van Brunt was elected Secretary of the Gaseous Electronics Conference which will be held at NIST in 1994. 


\section{Additional Information for Accomplishments and Plans}

\section{FY 92 Accomplishments}

- The lack of reproducibility in semiconductor etching processes has long been a problem in microelectronic production. The inability to reproduce a particular etching plasma in different plasma reactors hinders the transfer of processing techniques, and points to a dramatic lack of understanding of which parameters actually affect the plasma and the etching process. To improve our understanding of these problems, 5 identical research if reactors were fabricated and operated at different laboratories, NIST, Sandia, Wright-Patterson Laboratories, Univ. of Michigan, and the Univ. of New Mexico. A comparison of voltage and current waveforms measured for a wide range of plasma conditions indicated that the variation in plasmas was significant, even for "identical" reactors. Further study indicated that the plasmas were strongly affected by external circuitry, different power supplies, the inductance and capacitance of the reactors, cable types and lengths, and other undetermined parameters. Further research is planned to determine how to minimize these effects.

Investigation of questions about the accuracy of the initial electrical measurements on the GEC reference cell involved several assumptions about cell parasitics and the current and voltage probes that were not justified. These resulted in an increase in the apparent size of cell-to-cell variations. In response to these difficulties, methods for calibrating the probes and a general technique to characterize the parasitics in the cell were developed. In addition development of a general technique characterizing the effects of stray impedance on measurements of electrical characteristics of if discharges that assures accurate results with specified uncertainties is needed. Error analysis demonstrated that large gains in the precision are obtained by using an inductive shunt circuit with the plasma reactor. These results are based on if current and voltage waveform observations and fourier analyses to accurately predict I-V values at the electrode surfaces contacting the plasma. Realtime data acquisition and analysis make these measurements suitable for sensing and control applications in plasma reactors. These methods allow differences in the plasmas in different cells to be distinguished from random and systematic measurement errors. These techniques are applicable to future GEC cell comparisons and to commercial plasma etching reactors and have been published in two archival papers. 


\section{Project: INTELLIGENT TEST STRUCTURE METROLOGY}

\section{FY 92 Fund Sources: STRS, STRS-OMP; (D)ARPA MIMIC}

Staff (1.9 staff-years)

\begin{tabular}{|l||l|l|l|l|}
\hline \multirow{2}{*}{ Professional } & L. LINHOLM* & R. Allen* & M. Cresswell* & D. Khera* \\
\cline { 2 - 5 } & M. Zaghloul* & & & \\
\hline Technician & L. Buck* & C. Ellenwood* & J. Owen* & \\
\hline
\end{tabular}

name in capital letters = project leader; $=$ person works on project part time

Objective: Design, develop, and evaluate integrated-circuit test structures and expert-system-based diagnostic analysis techniques for use in rapidly and accurately determining selected semiconductor process parameters required for improving the parameter control, yield potential, and manufacturing throughput of complex integrated circuits.

Significance: Increased complexity of integrated circuits for both military and civilian applications makes complete performance testing impractical or impossible and intensifies the need for measurements that can verify design, performance, and fabrication processes and equipment operation. Integratedcircuit test structures coupled with thoroughly evaluated diagnostic expert systems and machine-learning codes provide a powerful metrological means for meeting this need. Needed are improved structures thoroughly validated as to capabilities, limitations, and interferences, as well as innovative expert system analysis tools for improving test coverage. Competent and unbiased development by NIST is necessary to assure equity between buyer and seller and to enable improved technology transfer between manufacturers.

\section{FY 92 Accomplishments}

- Developed and delivered an initial prototype expert system for determining the feasibility of applying expert system methodology to capacitance-voltage curve diagnosis; developed rules for the system based on heuristic knowledge from industrial and NIST experts. Incorporated revisions to system following reviews. Received support from industrial partner in form of purchase of license for NIST copy of advanced expert system shell software. [collaboration with industry] (OMP)

- Completed initial evaluation of linewidth measurements by a variety of techniques: optical, electrical, and scanning electron microscopy (SEM). Arranged for manufacturer to fabricate initial specimens for these tests, polysilicon on silicon and titanium on quartz; incorporated quartz substrate to enable linewidth measurement via highly accurate optical techniques at NIST. Analyzed initial results and found agreement between SEM and optical methods to be less than $90 \mathrm{~nm}$. Arranged for fabrication of second set of test specimens having improved edge quality. [collaboration with industry and Precision Engineering Division, Manufacturing Engineering Laboratory] (OMP)

- Installed replacement wafer probe station; following training and qualification testing, declared it to be operational in June 1992. (OMP)

\section{FY 93 Plans}

Note: In FY 93, this project will be combined with the Test Structures for IC Manufacturing and Test Structures for Reliability Projects to form the Advanced Test Structure Metrology Project. 
- Continue collaboration with industry to establish correlation between optical and electron-beam-based linewidth metrologies and electrical techniques. (OMP)

- Identify a selection of rules for a capacitance-voltage diagnostic expert system by coupling an MOS model to neural network and/or other classification algorithms. (OMP)

\section{Impact}

- A major U.S. semiconductor manufacturer reports using NIST-developed cross-bridge test structures. SEMATECH is utilizing NIST staff to assist in defining yield management strategies.

- NIST staff members Linholm and Cresswell assisted SEMATECH in developing the concept for planning and organizing a Yield Management Workshop, April 14-15, 1992 (results of the Workshop can be found in SEMATECH publication 92051108A-WS).

\section{Recognition}

- Linholm is serving on the GOMAC Steering Committee as Awards Chairman, for the 1992 IEEE International Conference on Microelectronic Test Structure (ICMTS) as Local Arrangements and Steering Committee Chairman, for the 1993 ICMTS as U.S. Representative and Steering Committee Chairman, and as NIST representative to DoD Advisory Group on Electron Devices Working Group B: Microelectronics.

- Linholm and Allen have been invited to participate in an IEEE Workshop describing NIST test structure development at 1993 International Conference on Microelectronic Test Structures.

- Linholm was invited to make presentation to a major computer manufacturer on NIST test-structure research. 


\section{Project: TEST STRUCTURES FOR IC MANUFACTURING}

FY 92 Fund Sources: STRS-OMP; (D)ARPA

Staff (3.0 staff-years)

\begin{tabular}{|l||l|l|l|l|}
\hline Professional & M. CRESSWELL* & R. Allen* & L. Linholm* & \\
\hline Technician & L. Buck* & C. Ellenwood* & J. Owen* & \\
\hline
\end{tabular}

Objective: Develop test structures and related measurement processing algorithms for extracting critical dimensions of replicated features in the manufacture of advanced integrated circuits and mask reticles. Extend development of a test structure for the measurement of overlay capabilities of advanced lithographic systems approaching the $0.01-\mu \mathrm{m}$ level. Determine feasibility of contactless test-structure metrology in a manufacturing environment. Provide leadership to the (D)ARPA X-Ray Lithography Program Mask Standards Committee.

Significance: Without an accelerated effort, metrology capability will lag the semiconductor industry's stated needs through the year 2000 . In lithography, a critical requirement is feature placement metrology for primary pattern generator electron-beam tools. Measurements capable of distinguishing $10 \mathrm{~nm}$ are needed for control of critical dimensions and overlay during photo-imaging. In pattern transfer, plasma etch process development requires linewidth measurement to $0.12 \mu \mathrm{m}$, with $0.01-\mu \mathrm{m}$ precision and accuracy. In defect control, techniques for measuring the incidence of particles less than $0.1 \mu \mathrm{m}$ in size will be needed for the competitive manufacture of devices such as gigabit memories. NIST is developing advanced test structures for industry use in meeting these needs.

\section{FY 92 Accomplishments}

- Used a modified voltage-dividing potentiometer structure for feature-placement metrology and demonstrated that systematic errors resulting from asymmetrical inside corner rounding can be eliminated by having voltage taps extend across the current bridge. Developed a model of the intersection of two lines with asymmetric inside corner rounding and developed and experimentally verified a measurement technique that extracts the model parameters. Published paper on modeling the effects of asymmetrical inside corner rounding in Solid State Electronics; reported that the resulting test structure performed with better than $7-\mathrm{nm}$ uncertainty. Filed two related applications for U.S. Patents. (OMP)

- Demonstrated that a mathematical model yielded excellent agreement with measurements extracted from a 1000:1 scaled-up capacitively coupled linewidth bridge over the frequency range $10 \mathrm{kHz}$ to $5 \mathrm{MHz}$. Collaborated with an instrument manufacturer in developing a successful proposal to (D)ARPA for applying to fabrication with cluster tooling a noncontact test structure for linewidth measurement via cross-bridge resistor. Developed and documented noncontact approaches using

(a) infrared diffraction grating test structures and (b) resonant inductive/capacitive radiofrequency circuits in preparation for patent application purposes. Also proposed an interdigitated planar capacitor with linewidth-dependent capacitance which may be extracted by capacitative or inductive coupling. (OMP)

- Developed a technique for low-cost feature-placement metrology featuring a test structure that is partially defined with a reusable artifact calibrated with the NIST nanometer-scale coordinate 
measuring system. [collaboration with Precision Engineering Division, Manufacturing Engineering Laboratory] (OMP)

- Revised the proposal on Test Structures for IC Manufacturing and submitted it to SEMATECH. Assisted SEMATECH in the planning and execution of a Yield Management Workshop in Austin.

\section{FY 93 Plans}

Note: In FY 93, this project will be combined with the Intelligent Test Structure Metrology and Test Structures for Reliability Projects to form the Advanced Test Structure Metrology Project.

- Develop a robust, low-cost, electrical test-structure metrology for primary pattern feature placement and overlay with calibration that is traceable to atomic spacings. [collaboration with Precision Engineering Division] (OMP)

- Model candidate architectures of noncontact radiofrequency test structures for extraction of critical dimensions of replicated features. (OMP)

- Continue present strategy to license the particle sensor patent to the clean-room industry.

- Obtain agreement between the major players in the U.S. X-ray lithography industry infrastructure on the dimensions of a standard membrane support ring.

\section{Recognition}

- The project has been invited to use the services of SEMI-SEMATECH to investigate the use of the project's particle detector invention in photographic, pharmaceutical, and environmental areas.

- Cresswell serves as Chairman of the (D)ARPA X-Ray Program Mask Standards and Resist Modeling Standards Committees, and was General Chairman of the 1992 IEEE International Conference on Microelectronic Test Structures. He has been appointed to the Semiconductor Research Corporation Lithography Thrust Evaluation Team of the Manufacturing Process Sciences Technical Advisory Board and serves on SEMATECH's X-Ray Lithography's Working Group.

- The paper, "Voltage-Dividing Potentiometer Enhancements For High-Precision Feature Placement Metrology," received a Best Paper Award at the IEEE International Conference on Microelectronic Test Structures in March 1992.

\section{Related Developments}

- The NIST-led and -organized (D)ARPA X-Ray Program Mask Standards Committee has agreed upon mask dimensional standards for the manufacturing of ICs by means of X-ray lithography. 


\section{Project: TEST STRUCTURES FOR RELIABILITY}

\section{FY 92 Fund Sources: STRS-OMP; (D)ARPA MIMIC}

Staff (4.5 staff-years)

\begin{tabular}{|l||l|l|l|l|}
\hline \multirow{2}{*}{ Professional } & H. SCHAFFT & J. Suehle & S. Witczak* & C. Schuster \\
\cline { 2 - 5 } & J. Albers* & S. Mayo* & & \\
\hline Technician & L. Buck* & C. Ellenwood* & & \\
\hline
\end{tabular}

Objective: Develop test methodology needed by industry and government for assuring reliability of complex integrated circuits related primarily to electromigration and oxide integrity. Specifically, develop and promote new concepts for achieving reliability, develop new models for analyzing accelerated stress test data, support and work with industrial standards organizations, and seek to remove existing measurement ambiguities that interfere with the assurance of product reliability. Provide (D)ARPA MIMIC program with guidance in using test structures for reliability assessment in the fabrication of monolithic microwave integrated circuits.

Significance: Electromigration failure of metallization interconnects and failure of oxide integrity are two of the most critical reliability concerns facing the electronics industry for microelectronic devices. Both concerns become more important as feature sizes continue to decrease. Electromigration has been called the "big fear" for the 1990s and is reported to be the primary reliability problem in state-of-the-art memory chips. Competent and unbiased development by NIST is necessary to assure equity between buyer and seller and to enable improved technology transfer between manufacturers.

\section{FY 92 Accomplishments}

- Revised the ElA's Joint Electron Device Engineering Council Standard on measuring and using temperature coefficient of resistance (TCR) of a metallization. (OMP)

- Evaluated a surface-temperature probe and found its performance to meet needs for improved temperature measurement capability identified in first TCR interlaboratory experiment. Purchased a probe and a portable readout system to be sent for calibration purposes with test specimen to each participant in the second interlaboratory experiment. [collaboration with Rennselaer Polytechnic Institute] (OMP)

- Oversaw the completion of an economic impact study of the electromigration work at NIST, which indicated a substantial saving to industry (see Impact section).

- Showed that the classical electromigration stress test can be used at ultra-high stress levels, but an enhancement, predicted in earlier work, represents a significant interference to making a correlation to use conditions. Discovered an unusually large enhancement of conductor lifetime under pulsed dc stress that depends on current density and oxide thickness.

- Developed a document for Wafer-Level Testing of Thin Dielectrics which was accepted as a EIA/JEDEC Standard. (OMP)

- Characterized the power lognormal distribution for modeling electromigration failure-time data which 
include a quantification of the length dependence and of a worst-case estimate of the early reliability of conductor lines. (OMP)

- Assembled a library, NISTGAAS, consisting of approximately 134 GaAs microwave and millimeterwave test-structure designs developed under the (D)ARPA MIMIC Program.

- Set up a new measurement system and wrote software to perform constant-current injection experiments which indicated that the breakdown behavior of SIMOX (separation by implantation of oxygen) oxides is different from that of conventional thermal oxides.

- Developed the first monolithic tin oxide gas sensor realized with commercial CMOS by silicon micromachining. [collaboration with the Process Measurements Division, Chemical Science and Technology Laboratory]

- Designed and tested a sensor for in-situ monitoring of the deposition of metallization.

- Developed and used tester code to measure alignment-related test structures on the Wright Laboratory high-density, test-structure wafers and analyzed resulting data.

\section{FY 93 Plans}

Note: In FY 93, this project will be combined with the Intelligent Test Structure Metrology and Test Structures for IC Manufacturing Projects to form the Advanced Test Structure Metrology Project.

- Conduct experiment on unpassivated metallization for evaluating the power lognormal distribution to model electromigration failure times. (OMP)

- Continue to promote the application of the Building-In Reliability (BIR) Approach in the industry and in NIST. (OMP)

- Conduct second JEDEC interlaboratory experiment to determine the precision of the JEDEC TCR measurement method when a common temperature calibration is available.

- Measure the thermal conductivity of selected oxide films as a function of film thickness and temperature using refined measurement and data analysis techniques.

\section{Impact}

- Impact study of NIST electromigration work showed that an investment of approximately $\$ 1.6$ million by NIST reaped an estimated total cost savings of over $\$ 26.6$ million for semiconductor producers.

\section{Recognition}

- Schafft served as organizer and General Chair of the 1992 Wafer Level Reliability Workshop, and served as the corresponding member of the Technical Program Committee of the 1992 European Symposium on Reliability of Electron Devices, Failures, and Physical Analysis. He presented invited talks on BIR in France and Germany.

- Suehle was asked to assist a manufacturer in replicating the NIST pulsed electromigration test station. Suehle was author/coauthor of three invited papers which appeared in print. 


\section{Project: THERMOSET CURE IN MICROELECTRONIC PACKAGING}

\section{FY 92 Fund Sources: OMP}

Staff (1.0 staff-years)

\begin{tabular}{||l||l|l|l|l|}
\hline Professional & B. DICKENS* & G.T. Davis* & A.S. DeReggi* & F.I. Mopsik* \\
\hline & S.C. Roth* & & & \\
\hline
\end{tabular}

name in capital letters $=$ project leader; $+=$ person works on project part time

\section{Objective:}

Assess the need to measure extent of cure of polyimide films as a function of depth in the film when the film is on a substrate. Investigate the feasibility of measuring cure of such polyimide films.

\section{Significance:}

Polyimide films are used as dielectrics in electronic packaging. The film is applied in the form of polyamic acids and then cured to produce a much more inert film of lower dielectric constant. The cure process does not proceed to equilibrium and hence is very variable. Polyimide films with a range of dielectric parameters are produced and their coefficient of thermal expansion is not optimum. It is difficult to optimize the cure when the cure is ill-defined and is not attained reproducibly and it is not known which parameters should be measured. Therefore, the significant parameters in the cure process will be identified and methods of quantifying them will be investigated.

\section{FY 92 Accomplishments}

- Discerned from external contacts what the significant problems are perceived to be as far as the polyimide film is concerned. Current problems are: variability in the coefficients of thermal expansion (certain polyimide films can be made to be anisotropic), build-up (during cooling from the cure temperature) of unacceptable stress in the films which causes lack of adhesion to the substrate, variability in material properties, and difficulty in optimizing cure because cure can not be quantified and measured. Future problems include: degradation of signals at transmission rates above $100 \mathrm{MHz}$, and crosstalk between signal lines.

- Selected photo-acoustic spectroscopy as a reasonable diagnostic technique to use to investigate cure in polyimide films of 25 micrometers or so thick. A $\$ 10,000$ PAS cell and a $\$ 1500$ lock-in amplifier were purchased. The NIST Physics Laboratory had, fortuitously for us, just purchased a $\$ 100,000$ FTIR spectrometer which could perform the needed measurements.

- Information on the design and synthesis of polyimides and their precursors was collected. Clearly, this information, which is almost entirely chemistry, is not known to the engineers in the field.

\section{FY 93 Plans}

- Install oven to allow controlled cure of polyimide films by varying temperature rate and oxygen content of atmosphere. An $\$ 18,000$ furnace has been designed, specified and ordered and should be delivered in May, 1993.

- Bring PAS experiments to the stage where a conclusion can be made concerning the possible utility of the technique in monitoring cure in polyimide films on a substrate. 
- Assemble the information on polyimide design and synthesis into a review article, which may not be finished by the end of FY93.

- Investigate feasibility of measuring third dimension thermal expansion coefficient of a polyimide film on a substrate as a function of temperature using a capacitive technique, which is expected to give precise measurements. The stability of the sample holder will be a major problem. Eventually, a $\$ 20,000$ automatic precision capacitance bridge will have to be procured. A temperature-controlled precision capacitance cell will cost $\$ 50,000$. These items will be added to future procurement lists and will not be available in FY93.

- Investigate incorporating a capacitance meter into a custom-made apparatus to provide meaningful measurements of the dielectric constant at frequencies from $\mathrm{DC}$ to $1 \mathrm{GHz}$ of polyimide films cured under various conditions.

\section{Impact}

- Ability to measure cure of polyimide films in meaningful ways would allow optimization of cure for a given set of constraints and would also allow process control to be carried out during manufacture. Process control is especially important in microelectronics because each item typically contains many components, all of which must function for the device to work.

- Use the information gained by curing polyimide films under a variety of conditions in the furnace to establish which of the parameters important in the cure of polyimide films in principle are important in practice also.

- One function of the polyimide film when used as a dielectric is to allow a signal (a series of pulses in an electric conductor) to propagate without change and without influencing neighboring signals. The dielectric measurements to $1 \mathrm{GHz}$ will reveal how well and in which range polyimide films cured in various ways perform that function.

\section{Recognition}

- None

\section{Related Developments}

- None 


\section{Project: SOLDERABILITY MEASUREMENTS AND OPTIMIZATION}

\section{FY 92 Fund Sources: STRS, OMP}

\section{Staff (1.2 staff-years)}

\begin{tabular}{|l||l|l|l|l|}
\hline Professional & J.R. MANNING* & W.J. Boettinger* & R.J. Fields* & $\begin{array}{l}\text { C.A. } \\
\text { Handwerker }\end{array}$ \\
\cline { 2 - 5 } & M.E. Williams* & & & \\
\hline \hline
\end{tabular}

name in capital letters $=$ project leader; $=$ person works on project part time

Objective: Determine the effect that the reactions that occur between $\mathrm{Pb}-\mathrm{Sn}$ solders and copper have on solderability measurements and the soldering process. The goal is to optimize solder joint reliability and decrease reject rates. Reactions between liquid solder and $\mathrm{Cu}$ at high temperatures, occurring during the soldering process, and solid state reactions at room temperature, occurring during the storage of solder-coated $\mathrm{Cu}$ wires, each cause $\mathrm{Cu}_{3} \mathrm{Sn}$ and $\mathrm{Cu}_{6} \mathrm{Sn}_{5}$ intermetallic compounds to form between copper and $\mathrm{Pb}-\mathrm{Sn}$ solder. Current emphasis has been on determining the effect of these intermetallics on solderability and on tests designed to measure solderability.

Significance: Improved measurement and understanding of solderability of electronic components are becoming increasingly urgent as the dimensions of electronic devices decrease in size and surface-mount solder joints replace through-hole connections. These industrial developments place new demands on the soldering process and the mechanical strength of the solder joints. Moreover, to form consistently good solder joints without rework is an important industrial goal. Poor solder joints and their re-work are estimated currently to cost industry $\$ 0.5 \mathrm{~B}$ to $\$ 1 \mathrm{~B}$ per year.

\section{FY 92 Accomplishments}

- Analyzed the mechanisms that control wetting and spreading of solder, particularly as these affect the area-of-spread and wetting-balance methods of measuring solderability.

- Analyzed the effects of heat flow, fluid flow, interdiffusion, and intermetallic formation that are important during the spreading of $\mathrm{Pb}-\mathrm{Sn}$ solder on copper, including analysis of the time scales over which each process is expected to control wetting.

- Demonstrated the importance of $\mathrm{Cu}_{3} \mathrm{Sn}$ and $\mathrm{Cu}_{6} \mathrm{Sn}_{5}$ intermetallic compounds and their surface oxides to the wetting of $\mathrm{Cu}$ by $\mathrm{Pb}-\mathrm{Sn}$ solder. Performed wetting balance measurements and area-of-spread tests on bulk samples of the intermetallics $\mathrm{Cu}_{3} \mathrm{Sn}$ and $\mathrm{Cu}_{6} \mathrm{Sn}_{5}$. These tests indicated that intermetallics impede wetting only if they are oxidized.

- Determined the effect of heterogeneities in the wetted surface on contact angles for wetting and their effect on the area of spread measured. For this purpose, model surfaces with a controlled area fraction of nonwettable patches were prepared, in addition to surfaces of $\mathrm{Cu}-\mathrm{Sn}$ intermetallic with controlled amounts of surface oxide.

- Determined the ternary phase diagram for the $\mathrm{Cu}-\mathrm{Pb}-\mathrm{Sn}$ system through thermodynamic calculations and phase equilibration experiments. This diagram provides, for any soldering temperature of interest, the compositions of solder in equilibrium with the various intermetallics and can be used to predict the growth rate of the intermetallics during soldering or storage. 
- Collaborated with the National Center for Manufacturing Sciences (NCMS) in forming a broad-based consortium on the development of $\mathrm{Pb}$-free solder alloys.

\section{FY 93 Plans}

- Examine reactions at the contact line between solder and substrate in $\mathrm{Cu}-\mathrm{Pb}-\mathrm{Sn}$. Chemical changes at this contact line lead to instabilities in the fluid flow which affect solderability measurements and optimization of the soldering process.

- Calculate phase diagrams for $\mathrm{Pb}$-free systems.

- Extend models of reactive wetting to Pb-free systems.

- Investigate bulk intermetallic compounds that form between $\mathrm{Cu}$ and $\mathrm{Pb}$-free solder systems.

- Perform wetting and physical property measurements for application to soldering processes and solder joint reliability questions.

\section{Impact:}

- NIST has analyzed the fundamental processes involved in reactive wetting and spreading and supplied this to industry as a chapter in a state-of-the-art book on solder spreading. This book, sponsored by the U.S. Army, was written for industry representatives responsible for manufacturing solderability assessments.

- NIST was a major participant in meetings organized by industry to plan a cooperative program on lead-free solders.

\section{Recognition}

- NIST scientists were asked to present invited talks on solder wettability at two major national meetings on solder science and technology.

- NIST has been asked by an industrial/government consortium to study the wettability of candidate systems for lead-free solders, calculate the multi-component phase diagrams to determine the temperature ranges over which soldering can be performed and the composition ranges in which brittle intermetallic phases form, and measure the mechanical, thermal, and chemical properties of these materials.

\section{Related Developments}

- The impending legislation on the removal of $F:$ from solder alloys makes it imperative that new solder alloy systems be developed that meet manufacturing and performance standards, as well as environmental standards. Under the leadership of the National Center for Manufacturing Sciences, an industrial/government consortium has been organized to investigate candidate lead-free systems. In addition to NIST, members of the consortium include IBM, AT\&T, Rockwell, Texas Instruments, Ford, GM-Hughes, GM-Delco, Microfab, Motorola, United Technologies Research Center, RPI, and Sandia National Laboratories. 


\section{Project: MICROMECHANICAL MEASUREMENTS FOR RELIABILITY OF ELECTRONIC PACKAGING AND INTERCONNECTS}

FY 92 Fund Sources: STRS, NASA, Air Force, Army, Navy, OMP

Staff (0.9 staff-years)

\begin{tabular}{|l||l|l|l|l|}
\hline Professional & D.T. READ & J.W. Dally * & E.S. Drexler & \\
\hline
\end{tabular}

name in capital letters $=$ project leader; $*=$ person works on project part time

Objective: Develop micromechanical measurement techniques to provide input data and verification of analytical predictions of mechanical reliability of packaging and interconnects in advanced microelectronic devices. Specifically: 1) Develop techniques for unambiguous measurement of the elastic modulus, yield and ultimate strength, and elongation to failure of metal and polymer thin films.

2) Develop experimental mechanics techniques to verify analytical predictions by direct observation of local displacements, strains, and stresses, in specially prepared specimens taken from actual devices.

Significance: Packaging and interconnects link integrated circuits to other integrated circuits and to the outside world. These structures must conduct electrical signals and heat, and are subjected to repeated thermomechanical stresses arising from differential thermal expansion. The measurement techniques will allow manufacturers and critical users of electronic devices to supplement empirical tests of reliability with solid-mechanics-based predictive analyses. As devices become smaller, they challenge packaging and interconnect designs and materials ever more, because they contain more interfaces and generate more heat in smaller volumes.

\section{FY 92 Accomplishments}

- Developed and demonstrated a new technique for mechanical testing of thin metal films. Reported data for yield strength, ultimate strength, and elongation to failure of titanium-coated aluminum films. Found that the tensile elongation was small compared to that of bulk aluminum.

- Extended technique to produce tension-tension fatigue data for aluminum thin films. Fatigue behavior at low cycle lives is similar in character to bulk sheet metal, but data to date shows shorter lives at equivalent stress levels.

- Developed electron-beam-moiré technique to examine local displacements, from which local stresses and strains can be deduced.

- Applied electron-beam-moire to a glass-fiber-reinforced plastic. The capability for detailed observation of the progress of local failure modes was shown.

\section{FY 93 Plans}

- Measure tensile properties of copper.

- Improve accuracy of tensile test apparatus so that the elastic modulus can be measured.

- Learn how to make and test smaller specimens. 
- Investigate the possibility of collaboration with Harry Schafft's measurements of electromigration resistance. We would like to correlate mechanical properties with electrical behavior in a single film.

- Observe thermal strains in a plated through hole, to show the effect of the out-of-plane thermal expansion of the PCB.

\section{Impact}

- These programs attempt to anticipate industry needs. Their impact will be to help industry implement a more quantitative, analysis-based approach to designing for improved reliability.

\section{Recognition}

- This program received NIST Director's Reserve funding for FY 93 to examine the cause of the low ductility in metal thin films.

\section{Related Developments}

- J. W. Dally of the University of Maryland Mechanical Engineering Department spent most of FY 92 with us on sabbatical. He was instrumental in making the accomplishments listed above.

- A transmission electron microscope is being installed in Division 853 in Boulder, and will be used mainly for studies of electronic packaging materials. 


\section{Project: ELECTRICAL CHARACTERIZATION}

FY 92 Fund Sources: STRS-OMP, WCT-SRMP; NOAA; (D)ARPA

Staff (6.0 staff-years)

\begin{tabular}{|l||l|l|l|l|}
\hline \multirow{2}{*}{ Professional } & J. EHRSTEIN & J. Kim & J. Kopanski* & S. Mayo* \\
\cline { 2 - 5 } & J. LOWNEY* & D. Seiler* & W. Thurber* & D. Novotny* \\
\hline Technician & D. Ricks* & R. Russell* & J. Thomas & \\
\hline name in capital letters = project leader; * person works on project part time
\end{tabular}

Objective: Develop methods, tools, and artifacts to improve the state of the art in electrical-characterization metrology for semiconductor materials. Specifically, provide silicon device manufacturers with bulk resistivity standards with better than $1 \%$ accuracy, and implant dose/sheet resistance standards with $1 \%$ accuracy. Provide compound-semiconductor device manufacturers with improved metrology and models to enhance device performance and reliability.

Significance: The yield and reliability of semiconductor devices depend critically on the characteristics of the materials and processes that are used to manufacture them. The electronics industry needs the methodology provided by NIST to evaluate these materials and processes. Industry also needs standard measurement methods and artifacts to make verifiable measurements of materials parameters as a wafer is processed. As an example, resistivity is one of the most important parameters for silicon, and in response to industrial needs, NIST is providing state-of-the-art resistivity SRMs. Improved materials understanding and evaluation techniques are needed by the compound-semiconductor industry to make useful and reliable devices.

\section{FY 92 Accomplishments}

- Developed small-diameter silicon resistivity SRMs having characteristic radial variation of resistivity reduced to about $2 \%$ (previous material had spikes to $5 \%$ ); certified 140 wafers of improved uniformity having resistivities of 180 or $1 \mathrm{ohm}-\mathrm{cm}$.

- Received a custom-built chamber and refurbished an existing cold-chuck and adapted it to the patterned-contact, resistivity micro-mapping instrument; upgrades enable mapping over a range of temperatures so that carrier activation may be studied. Demonstrated the fine detail that can be obtained on $\mathrm{HgCdTe}$ with room-temperature maps on wafers supplied by a manufacturer with patterned contacts. Began work on mapping GaAs wafers and on silicon patterned with implanted resolution stripes. [industrial collaboration]

- Prepared detailed specifications for a scanning tunneling/atomic force microscope for scanning capacitance microscopy (SCM); the microscope will be one of the first to be made with a large sample stage, compatible with semiconductor wafers with diameters to $250 \mathrm{~mm}$. Began development of the capacitance-sensitive circuit and theoretical modeling of the SCM measurement (delivery and installation expected in early December 1992). (OMP)

- Developed and applied to both $\mathrm{HgCdTe}$ and III-V test samples a general technique for analyzing multicarrier conduction. Made extensive Hall and resistivity measurements on several GaAs-based HEMT structures for a paper on multicarrier characterization methods. 
- Wrote computer codes to enable analysis of high-field magneto-transport measurements of thin semiconductor layers, such as the accumulation layers of $\mathrm{HgCdTe}$ detectors.

- Demonstrated by capacitance-voltage measurements that characteristics of SiC MOS capacitors were as good as those obtainable on silicon, and that a degree of activation for ion-implanted boron into commercially supplied $\mathrm{SiC}$ (having $6 \mathrm{H}$ crystal structure) was greater than previously observed. This latter observation may encourage use of boron, rather than aluminum, as the preferred p-type dopant for SiC microelectronics.

- Completed the survey on characterization techniques used by the $\mathrm{HgCdTe}$ community for various material parameters, analyzed data, and prepared paper for the 1992 Workshop on Measurement Techniques for Characterization of $\mathrm{HgCdTe}$ Materials, Processing and Detectors in Danvers, Mass.

\section{FY 93 Plans}

Note: In FY 93, portions of this project will be combined with the Optical Characterization Project to form the Semiconductor Characterization Technology Project, and portions combined with the Molecular Beam Epitaxy and GOES Projects to form the Nanoelectronics Project.

- Certify and deliver sufficient quantities of $100-\mathrm{mm}$ silicon resistivity SRMs to meet industry's needs; publish documentation of the certification process.

- Develop improved understanding of the industry's needs for silicon or compound semiconductor-based SRMs, and improve collaboration with the industry for more effective development of such SRMs.

- Extend resistivity-mapping capability to low temperature and develop system and theory for scanning capacitance microscopy. Apply to silicon, $\mathrm{HgCdTe}$, and III-V wafers. (OMP)

- Install and bring on line superconducting magnet system for magneto-transport and magneto-optical measurements on semiconductors. (OMP)

\section{Impact}

- As a result of Kopanski's confirmation of higher electrical activation for boron implanted into $\mathrm{SiC}$, renewed study of boron as a p-type dopant in $\mathrm{SiC}$ has been stimulated at two major manufacturers. NIST's help has been acknowledged in letters from one of these.

\section{Recognition}

- Kopanski was invited to write a chapter on Oxidation of $\mathrm{SiC}$ for a commercial publisher.

\section{Related Developments}

- The Defense Procurement Act Title III authorization for very-high-purzty silicon and other activities was passed by the Legislative Branch at the end of FY 1992. In anticipation, preparations were made for very-high-purity silicon characterization under Title III during FY 1993.

- Ehrstein received a letter from a manufacturer exprsing interest in fabricating samples and performing auxiliary measurements to aid the developm:=, of ion implant dosimetry SRMs.

- The lon-Implant Users Group has provided recommendations for a standard process for dosis $y$ reference material; to date, two instrument manufacturers have expressed interest in supporting the R\&D effort. 


\section{Project: OPTICAL CHARACTERIZATION}

\section{FY 92 Fund Sources: STRS-ATP; (D)ARPA}

Staff (5.5 staff-years)

\begin{tabular}{|l||l|l|l|}
\hline Professional & P. AMIRTHARAJ & D. Chandler-Horowitz & N. Nguyen \\
\cline { 2 - 4 } & J. Marchiando & D. McKeown* & B. Rennex* \\
\cline { 2 - 4 } & D. Seiler & & \\
\hline \hline
\end{tabular}

name in capital letters $=$ project leader; $=$ person works on project part time

Objective: Develop optical characterization measurements geared to addressing key materials, processing, and device issues in the semiconductor industry while improving standards needed by the industry. Specifically, establish a state-of-the-art spectroscopic facility for a high-resolution and high-sensitivity Fourier transform photoluminescence (FTPL) system for quantitative and impurity-specific analysis of trace levels of impurities in high purity $\mathrm{Si}$, with concentrations of the order of $10^{10} / \mathrm{cm}^{3}$, which are beyond the analytical range of electrical measurements. Establish Raman, conventional photoluminescence, modulation and absorption spectroscopies, and ellipsometry for materials characterization, in order to provide industry with needed standards and improved measurement methods.

Significance: Spectroscopic techniques are both powerful and attractive for semiconductor materials characterization since they are nondestructive, contactless, and possess spatial-mapping capability and near-surface-region sensitivity. There is an immediate need for quantitative detection of impurities in high-purity silicon for the fabrication of power devices, and FTPL is the major tool for fulfilling it. NIST will use its facility to help industry adapt, improve, and optimize the FTPL technique and to provide standards. Also, the use of photoreflectance (PR) in the semiconductor industry as a routine characterization tool will be significantly advanced by the developments at NIST. Direct inputs are being provided to both the users of PR and the manufacturers of PR measurement equipment.

\section{FY 92 Accomplishments}

- Completed installation of high-resolution Fourier transform photoluminescence system and initiated measurements in high-purity Si (doped with $\mathrm{P}$ at $10^{12} \mathrm{~cm}^{-3}$ ).

- Optimized (noise, repeatability and stability) high-stability Fourier transform infrared absorption system for SRM measurements.

- Mailed to major semiconductor companies the OMB-approved questionnaire regarding the use of optical characterization techniques for materials and device analysis by the semiconductor industry (responses are being collected).

- Provided (D)ARPA with metrologic support for the X-ray lithography mask program and expert consultation and optical characterization for the infrared materials program.

- Completed Raman scattering measurements and analysis on CdTe as a function of temperature to obtain the first set of reliable optical phonon frequencies, needed to understand impurity-related vibrational behavior for infrared detector materials. 
- Observed effects of interface roughness in short-period GaAs/AlAs superlattices using spectroscopic ellipsometry for the first time.

- Observed in real time, using spectroscopic ellipsometry, the growth of thin native oxide on MBEgrown GaAs layers. Applied the near-monolayer sensitivity to follow the initial stages of native oxide growth on MBE GaAs. Found that the oxide growth followed a logarithmic law for the first 1500 minutes to a thickness of $1.4 \mathrm{~nm}$, followed by a power-law growth behavior.

- Upgraded the spectroscopic ellipsometer with ultraviolet grade polarizers to expand the energy range to $6 \mathrm{eV}$, which substantially increases the ability to study surface-related effects in most semiconductors.

- Completed and tested double-modulation system to perform photoreflectance measurements; method significantly adds to the in-house capability for PR measurements by extending the range of materials that can be examined.

\section{FY 93 Plans}

Note: In FY 93, this project will be combined with portions of the Electrical Characterization Project to form the Semiconductor Characterization Technology Project.

- Develop PL, FTIR, and Raman methods for material and impurity analysis in Si and compound semiconductors. (OMP)

- Develop the system and theory for a new double modulation photoreflectance technique for the characterization of microstructures and compound semiconductors.

- Improve the understanding of the optical properties of $\mathrm{SiO}_{2}$ on $\mathrm{Si}$ thin oxides and interfaces and improve the measurement accuracy for thin layer thicknesses ( $<15 \mathrm{~nm}$ ). (OMP)

- Complete survey and analysis of optical characterization techniques used in the semiconductor industry.

- Complete invited chapter on "Optical Properties of Semiconductors" for the Handbook of Optics.

- Complete certification of oxygen-in-silicon SRMs and continue to improve accuracy of Group's Fourier transform infrared spectrometer.

\section{Impact}

- Computer software developed by Marchiando is reported by several companies to enhance their use of ellipsometric data in process evaluation; at least one company has incorporated NIST codes in its ellipsometric system designed and built to assist in the manufacture of electronic components.

\section{Recognition}

- Chandler-Horowitz was invited to present a tutorial review of ellipsometric analysis at DEC, Inc., in Hudson, Mass. and will serve on the International Scientific Committee tor the First International Conference on Spectroscopic Ellipsometry, to take place in Paris, January 11-14, 1993.

- SEMI Compound Semiconductor Committee and ASTM F1.15 Compound Semiconductor Subcommittee are becoming active in the development of measurement techniques and artifacts for characterization of compound semiconductors; SEMI Committee has requested NIST involvement. 


\section{Project: ROUND ROBIN CORRELATION OF GAS FLOW CALIBRATION FACILITIES}

FY 92 Fund Sources: SEMATECH and STRS

Staff (1.7 man-years)

\begin{tabular}{|l||l|l|l|l|}
\hline \multirow{2}{*}{ Professional } & G. MATTINGLY* & W. G. Cleveland* & G. Baumgarten* & D. E. Hess* \\
\cline { 2 - 5 } & P. I. Espina* & & & \\
\hline Technician & J. M. Allingham* & & & \\
\hline
\end{tabular}

Objective: Establish a gas flow measurement assurance program (MAP) that is capable of producing, for specific fluid and flow conditions, realistic traceability for the critical gas flow calibration facilities used in the semiconductor producing industries in the U.S.

Significance: Semiconductor production is critically dependent upon the performance of Mass Flow Controllers (MFCs). These devices are critical links in the chains of events that produce semiconductor elements. MFC performance is based upon the data taken for a wide range of calibration facilities. Validated calibration facilities are essential to MFC credibility. The proposed program is the best and most realistic way to establish and maintain the desired traceability

\section{FY 92 Accomplishments}

- Designed and built the appropriate gas flow measurement artifact.

- Reported the gas flow measurement performance characteristics of the artifact.

- Arranged and conducted a dry-run test program for the artifact and test procedure improvements.

- Reported the dry-run results and the resulting artifact and test procedure improvements.

\section{FY 93 Plans}

- Designed improvements to the artifact and test procedures.

- Arranged and currently conduct the round robin tests among the 25 laboratories listed by SEMATECH.

- Will report round robin results.

- Will establish the gas flow measurement artifact as a standard available though NIST and provide the associated calibration service. Will report results.

\section{Impact}

- NIST staff have participated in several SEMATECH committee meetings to write standards for Mass Flow Controller (MFC) performance. These efforts have produced drafts which currently are in review among MFC manufacturers and users.

- MFC variability is one of the three most prevalent factors perceived as the causes of semiconductor process variability. Improved calibration traceability should significantly reduce MFC variability. 


\section{Recognition}

- Dr. G.E. Mattingly is a chairman or a member of a number of national and international committees on flow measurements. He is the American Editor of an international journal, Flow Measurement and Instrumentation.

- Mr. G.P. Baumgarten has been involved in gas flow measurement at NIST for over 30 years.

\section{Related Developments}

- There is a continuing trend in fluid flow measurement toward the establishment of realistic traceability for a wide range of conditions.

- Round robin flow testing programs generally uncover systematic calibration errors that exceed imprecision uncertainties by a factor of 10 . 
OFFICE OF LAW ENFORCEMENT STANDARDS 


\section{Project: LAW ENFORCEMENT TECHNOLOGY}

\section{FY 92 Fund Sources: OA: NU, NHTSA, FBI}

Staff (6.0 staff-years)

\begin{tabular}{|l||l|l|l|l|}
\hline \multirow{2}{*}{ Professional } & L.K. ELIASON & N.J. Calvano & D.E. Frank & A.G. Lieberman \\
\cline { 2 - 5 } & J.A. Worthey & & & \\
\cline { 2 - 5 } & & & & \\
\hline Technician & N.E. Waters & & & \\
\hline
\end{tabular}

name in capital letters $=$ project leader; $=$ person works on project part time

Objective: To apply the resources of the Electronics and Electrical Engineering Laboratory and NIST overall to the technological needs of law enforcement, conducting research to enable manufacturers to develop equipment and systems suitable for such use. Specifically, to develop performance standards for promulgation by the National Institute of Justice (NIJ) and the National Highway and Traffic Safety Administration (NHTSA); to prepare tutorial guidelines on specific law enforcement equipment and systems; to prepare reports on topics of interest to law enforcement personnel based upon NIST research; to develop analytical techniques and standard reference materials for forensic science application; to assist NIJ/NHTSA in the implementation of testing programs and in establishing consumer product lists of equipment that complies with their performance standards.

Significance: Law enforcement agencies continue to enhance the efficiency and effectiveness of their operations through the application of emerging technologies in electronics, materials, analytical analysis, and weapons. The private sector has recognized that law enforcement personnel are increasing their capabilities to apply sophisticated equipment and systems, and many companies are expanding their product lines to include equipment specifically for law enforcement use. In many instances, such manufacturers utilize the NIJ/NHTSA standards, developed by OLES, as the basis of product design.

The law enforcement adoption of the products of emerging technologies, unlike private sector application, often involves critical issues having both safety and legal ramifications. Inadequate equipment performance can adversely affect the general population when it increases public safety costs, precludes arrests, or results in evidence found to be inadmissible in court. The standards developed by OLES for other-agency promulgation enable the cost-effective procurement of equipment that meets the unique needs of law enforcement.

\section{FY 92 Accomplishments}

- Completed a limited experiment to investigate whether the physical size of body armor samples influences ballistic test results; published results.

- Issued SRM 2390 for DNA quality assurance testing.

- Drafted a report on instrumentation to measure the forces on a holster when a handgun is withdrawn.

- Completed the development of the standard for dialed-number recorders and published a report.

- Initiated projects to develop standards for photoradar and laser speed-measuring systems. 
- Provided technical assistance to the FBI in the development of integrated services digital network systems.

- Completed the first phase (experimental design) of a project to develop standards for locks for detention and corrections facilities.

- Completed the development of test methods to evaluate the resistance of armor to sharp instrument slashing and thrust attack.

- Issued AutoBid computer program for 1992 vehicle year; program permits law-enforcement agencies to relate their specific needs to vehicle specifications to support purchase decisions.

\section{FY 93 Plans}

- Complete the development of test methods/standards for sharp instrument penetration resistant armor.

- Complete the development for a standard for the flammability of mattresses for detention and correction facilities.

- Develop test methods for photoradar speed-measuring devices and complete preliminary tests of these systems.

- Initiate tests of laser speed-measuring devices.

- Complete a preliminary draft of a minimum performance standard for integrated services digital network intercept systems.

- Initiate efforts to develop standard reference materials for DNA profiling employing Polymerase Chain Reaction Technique.

\section{Impact}

- Body armor manufacturers continued to participate in the NIJ compliance testing program. As of the end of FY 92, more than 800 models of armor have been tested in the program; a major manufacturer credited the use of body armor with sparing 174 officers from serious injury during calendar year 1992.

- The first radar speed-measuring device operating in the $\mathrm{Ka}$ band frequency range was tested by the International Association of the Chiefs of Police and found to comply with the NHTSA standard, based on NIST work. In addition, 1000 units were subjected to critical performance testing for quality assurance purposes.

\section{Related Developments}

- The Office of Technology Assessment (OTA) report, Police Body Armor Standards and Testing, presents OTA's findings concerning issues of contention between NU and the manufacturing community. The OTA presents a number of options concerning the NIJ standard and testing program for NIJ consideration, many of which will require research by OLES if NIJ wishes to implement the OTA suggestions.

- The appointment of a new director of the NIJ science and technology division can be expected to have a major effect on the long-term future and direction of the technical support OLES provides to NI. 
$-36-$ 
ELECTRICITY DIVISION

$-37-$ 


\section{Project: ELECTRIC AND MAGNETIC FIELD MEASUREMENT}

\section{FY 92 Fund Sources: STRS; OA: DOE; NTP; EPRI}

Staff (0.8 staff-years)

\begin{tabular}{|l||l|l|l|l|}
\hline Professional & M. MISAKIAN* & M. Fulcomer & & \\
\hline name in capital letters = project leader; & person works on project part time
\end{tabular}

Objective: Develop the calibration and measurement techniques required to characterize the electrical environment (electric and magnetic fields, ion density, etc.) near ac and dc power lines and in biological exposure facilities designed to simulate the power line environment.

Significance: The work provides an essential basis for determining accuracy of measurements of electrical parameters used in U.S. bioeffects research sponsored by government and private sector agencies (about $\$ 20$ million per year is funded) and for relating this research to development of safe, efficient electric power systems. Economic impact estimated to be near $\$ 1$ billion.

\section{FY 92 Accomplishments}

- Provided measurement support and consultation for bioeffects studies supported by DOE, FDA, NTP, EPRI and EPRI-PEAC to insure electrical parameters are adequately characterized.

- Prepared manuscript of IEEE working group paper describing a spot measurement protocol for residential magnetic fields. Paper will be published in IEEE Transactions on Power Delivery.

- Participated in review of IEEE Standard 644-1987 (measurement of electric and magnetic fields near ac power lines). NIST has lead role in this activity which will extend into 1993.

- Edited and made revisions of contributions from coauthors for primer on in vitro studies with ELF electric and magnetic fields. Manuscript has been accepted for publication in Bioelectromagentics.

- Served on advisory panels for the NCI and the California Department of Health Services (both agencies are supporting epidemiological studies on possible health effects of power-frequency magnetic fields).

- Served on research planning committee for Health Effects Institute and participated in ad hoc NIH review panels. Both activities addressed questions related to EMF biological effects.

\section{FY 93 Plans}

- Provide consultation and measurement support to DOE, FDA, NTP, EPRI, and EPRI-PEAC to insure that electrical parameters are adequately characterized.

- Calculate uncertainties for measuring the magnetic (dipole) fields from electrical appliances by means of coil probes; prepare manuscript and submit to journal; incorporate information into new draft standard.

- Prepare in collaboration with task force ( and working group (IEEE ELF Working Group/SCC 28-Subcommittee 1) two iterations of new draft standard on instrumentation for measuring ELF fields. 
- Prepare conference paper on ELF field measurement methods for 1993 IEEE Symposium on EMC; present invited talk.

- Serve on advisory panels for California Dept. of Health Services and National Cancer Institute to consult on cancer epidemiology studies.

- Take lead role in review of IEEE Std 644-1987.

- Update contributions to NCRP report on ELF field effects (NCRP Scientific Committee 89-3).

\section{Impact}

- The present national (IEEE) and international (IEC) standards for measurement of electrical parameters near ac and dc power lines result from NIST technical development and leadership. NIST has materially contributed to the credibility of results from U.S. bioeffects studies by providing on-site consultation and characterization of electrical parameters in biological exposure systems as part of a quality-control effort since 1978.

\section{Recognition}

- At the invitation of IEEE SCC28/Subcommittee 1, M. Misakian has become chairman of a new working group on ELF measurements and instrumentation. He also serves as task force leader in the IEEE AC Fields Working Group (PES) which is preparing a draft of a new standard on ELF field measuring instrumentation. He was invited to participate in the Department of Energy Science and Engineering Workshop which is developing a national EMF research and communication program. Misakian continues to serve on panels for the California Department of Health Services, the National Cancer Institute, and the National Council for Radiation Protection and Measurements.

\section{Related Developments}

- A $\$ 65$ million EMF research and communication measure included in the U.S. Energy Bill is approved by Congress and the President. The legislation provides for an Interagency Committee for purposes of planning and providing recommendations. NIST will be represented on this committee.

- Pennsylvania's Public Utility Commission (PUC) administrative law judge rules that a new 230-kV transmission line should not be energized until the PUC sets EMF exposure standards.

- The cost of uncertainty surrounding possible health effects from exposure to power frequency electric and magnetic fields is estimated to exceed \$1 billion annually [Science, vol. 257, 468 (1992)].

- A report prepared by a committee of the Health Council of the Netherlands concludes that "There is at present insufficient proof that chronic exposure to ELF EMF with low field strengths...results in adverse bealth effects."

- Following the conclusion of two new epidemiological studies, Sweden's National Board for Industrial and Technical Development announced that it "...will act on the assumption that there is a connection between exposure to power-frequency magnetic fields and cancer, in particular childhood cancer."

- A wrongful death claim has been filed against Pacific Gas \& Electric (PG\&E) by the family of a former employee. The family charges that the death from leukemia resulted from EMF exposure while working at PG\&E.

- The National Institute of Environmental Health Sciences awarded \$8 million to the IIT Research Institute to study possible bealth effects in rats exposed to $60-\mathrm{Hz}$ magnetic fields. 


\section{Project: ELECTRIC AND MAGNETIC FIELD MEASUREMENT}

\begin{tabular}{|c|c|c|c|c|c|}
\hline FISCAL YEARS & 93 & 94 & 95 & 96 & 97 \\
\hline \multicolumn{6}{|l|}{ AC ELECTRIC AND MAGNETIC FIELDS } \\
\hline \multirow{2}{*}{\multicolumn{6}{|c|}{$\begin{array}{l}\text { Provide measurement support for } \\
\text { DOE/EPRI/NTP sponsored field effect } \\
\text { studies. [STRS, OA-EPRI,OA-NTP] }\end{array}$}} \\
\hline & & & & & \\
\hline \multicolumn{6}{|l|}{$\begin{array}{l}\text { Calculate uncertainty due to probe area } \\
\text { when coil probes are used to measure } \\
\text { appliance magnetic fields. [STRS, OA- } \\
\text { DOE] }\end{array}$} \\
\hline \multicolumn{6}{|l|}{$\begin{array}{l}\text { Participate in review of IEEE Standard } \\
644-1987 .[\text { [STRS, OA-DOE] }\end{array}$} \\
\hline \multicolumn{6}{|l|}{$\begin{array}{l}\text { Prepare draft of new IEEE standard for } \\
\text { instrumentation used to measure ELF } \\
\text { magnetic and electric fields. ISTRS, OA- } \\
\text { DOE] }\end{array}$} \\
\hline \multicolumn{6}{|l|}{$\begin{array}{l}\text { Serve on advisory panels for } \mathrm{NCl} \text { and } \\
\text { California Dept. of Health Service. [STRS] }\end{array}$} \\
\hline \multicolumn{6}{|l|}{ DC FIELDS AND ION MEASUREMENTS } \\
\hline $\begin{array}{l}\text { Measurement support for DOE. ISTRS, } \\
\text { OA-DOE] }\end{array}$ & & & & & \\
\hline
\end{tabular}




\section{Project: POWER/ENERGY AND AC/DC HIGH-VOLTAGE AND HIGH-CURRENT MEASUREMENTS}

\section{FY 92 Fund Sources: STRS; Calibrations}

Staff (2.5 staff-years)

\begin{tabular}{|l||l|l|l|l|}
\hline Professional & T. L. NELSON & W. E. Anderson* & G. J. FitzPatrick* & M Misakian* \\
\cline { 2 - 5 } & J. K. Olthof** & J. Ramboz* & E. Simmon* & R. Turgel* \\
\hline \multirow{2}{*}{ Technician } & J. Chandler* & J.Pitt* & A. Secula & \\
\hline
\end{tabular}

name in capital letters $=$ project leader; $=$ person works on project part time

Objective: To maintain the U.S. calibration facility for power and energy measurements and to provide services for instrument manufacturers, utilities, and regulatory agencies. To develop and disseminate techniques to measure steady-state voltages and currents at levels above 1000 volts and above 100 amperes. Present activities include: assessing the need for improved electrical measurements in electric power systems; reducing uncertainties in HVDC measurements; developing techniques to characterize optical current and voltage sensors.

Significance: Metering all electrical energy used throughout the U.S. with a revenue of more than $\$ 176$ billion is directly traceable to calibrations performed at NIST. Bulk sales of electricity, quality control and efficiency tests, and acceptance tests for utility equipment are all based on high-voltage and current measurements. This work supports these applications and is the primary NIST activity in steady-state, high-voltage, and current measurements.

\section{FY 92 Accomplishments}

- Completed modernization of power and energy laboratory.

- Evaluated and calibrated the high- and mid-range current comparators for high-frequency performance up to $1 \mathrm{kHz}$, each on the 1200-A to 5-A ranges. Use was made of the new 54-kVA power sources in the recently operational Current Transformer Calibration Facility. Tests were made using the NIST designed amplifier-aided two-stage current comparator as a reference.

- Characterized performance of high-frequency current comparator for a special calibration of a 5000:1 ampere current-transformer standard at frequencies up to $5 \mathrm{kHz}$. Tested at secondary currents as low as $4 \mathrm{~mA}$. Examined methods for increasing useable current range at higher frequencies where circuit reactance is the limiting factor.

- Analyzed responses from the Power and Energy Impact Study questionnaires. Completed analysis of all data from the electric utilities and Public Utility Commissions. Projected economic impact on a national scale by three different methods; based on energy sales, on revenue, and on number of customers. (The study was completed in April 1993).

- Completed cooperative consultations with a manufacturer of electronic watthour meters and standards to assist the company in upgrading its calibration capability to provide a better accuracy base for company products. Carried out extensive calibration services for same company [see related item in Impact section].

\section{FY 93 Plans}

- Perform a nonsinusoidal power calibration to help a company solve a customer dispute. 
- Construct a transportable power bridge for international comparisons.

- Complete EEEL Impact Study for the electric power and energy calibration service and report results. Motivation includes information for planning.

- Complete extension of dc calibration service to $1 \mathrm{kV}$ (calibrations in the range of 1 to $10 \mathrm{kV}$ are presently not supported at NIST).

- Develop measurement support for optical current sensors (see Pulse Power Project) critical for industry acceptance of this new technology.

- Continue evaluation efforts for the characterization of high-frequency performance of current transformers.

\section{Impact}

- As a direct result of NIST guidance and assistance to a manufacturer of electronic watthour meters and standards, the company can now offer a new high-accuracy NIST-traceable calibration service.

- Approximately 110 devices were calibrated during FY 92 resulting in revenues of $\$ 196 \mathrm{k}$. Of these there were 28 current and voltage transformers, 45 watthour standards, 18 MAPs, and 16 dividers. These services have exceptionally high leverage - for example, industry calibrates about 10 million watthour meters per year.

\section{Recognition}

- R. S. Turgel is Chairman of the American National Standards Committee on Electricity Metering (C12) which sets acceptable performance standards for watthour meters and related instruments. Turgel is also the Technical Advisor to the U.S. National Committee of the IEC for Technical Committee $\mathbf{8 5}$ which is responsible for international standards of indicating meters. Turgel was also selected to be President of IEEE's Instrumentation and Measurement Society. 


\section{Project: POWER/ENERGY AND AC/DC HIGH-VOLTAGE AND HIGH-CURRENT MEASUREMENTS}

\begin{tabular}{|c|c|c|c|c|c|}
\hline FISCAL YEARS & 93 & 94 & 95 & 96 & 97 \\
\hline \multicolumn{6}{|l|}{ NEW POWER/ENERGY SYSTEM } \\
\hline \multicolumn{6}{|l|}{$\begin{array}{l}\text { Modify hardware to extend ranges of } \\
\text { current comparator bridges. [STRS] }\end{array}$} \\
\hline \multicolumn{6}{|l|}{ CALIBRATION SERVICES } \\
\hline \multirow{2}{*}{\multicolumn{6}{|c|}{$\begin{array}{l}\text { Upgrade equipment and methods for } \\
\text { calibration services. [STRS, OA- } \\
\text { Calibrations] }\end{array}$}} \\
\hline & & & & & \\
\hline \multicolumn{6}{|l|}{ POWER SYSTEM MEASUREMENT NEEDS } \\
\hline \multicolumn{6}{|l|}{$\begin{array}{l}\text { Develop higher dynamic range calibration } \\
\text { techniques for current transformers. } \\
\text { [STRS] }\end{array}$} \\
\hline \multicolumn{6}{|l|}{$\begin{array}{l}\text { Develop measurement support for optical } \\
\text { voltage and current measurements. } \\
\text { [STRS, OA] }\end{array}$} \\
\hline \multicolumn{6}{|l|}{$\begin{array}{l}\text { Develop calibration service for current } \\
\text { transformers to } 5 \mathrm{Khz} \text { and } 5 \mathrm{kA} \text {. [STRS] }\end{array}$} \\
\hline \multicolumn{6}{|l|}{$\begin{array}{l}\text { Develop calibration capability to support } \\
80-\text { Ka circuit breaker test sets. [STRS, } \\
\text { OA] }\end{array}$} \\
\hline \multicolumn{6}{|l|}{$\begin{array}{l}\text { Improve range and accuracy of DC High } \\
\text { Voltage measurements. [STRS] }\end{array}$} \\
\hline \multicolumn{6}{|l|}{$\begin{array}{l}\text { Extend watthour calibrations range to } \\
\text { lower levels. [STRS] }\end{array}$} \\
\hline $\begin{array}{l}\text { Develop methods for non-sinusoidal } \\
\text { quantities for metering. [STRS] }\end{array}$ & & & & & \\
\hline
\end{tabular}




\section{Project: LIQUID DIELECTRICS AND PARTIAL DISCHARGE RESEARCH}

FY 92 Fund Sources: STRS; OA: Berkeley Res. Assoc.

Staff (1.5 staff-years)

\begin{tabular}{|l||l|l|l|l|}
\hline Professional & K. STRICKLETT & E. Cernyar* & R. J. Van Brunt* & P. von Glahn* \\
\hline Technician & J. Pitt* & & & \\
\hline
\end{tabular}

name in capital letters $=$ project leader; $=$ person works on project part time

Objective: Advance measurement methods for the detection and characterization of partial discharges; investigate the initiation, growth, and stochastic properties of partial discharges in liquid, solid, and gaseous materials; and develop techniques for the measurement of parameters significant to the evaluation of liquid dielectric materials.

Significance: The nation is critically dependent on the reliability of its electric power distribution grids; this work addresses concerns about the reliability of insulation. Partial discharge measurement has become a standard tool for quality assurance during the manufacture of high-voltage equipment. The presence of partial discharges within electrical equipment limits its useful voltage range and power, and results in the degradation of electrical insulation and thus contributes to premature equipment failure. Moreover, the concern with insulation failures extends beyond the electric-power utilities and operators of high-voltage equipment. There is increasing interest in improving insulation integrity and test methods for electronic components and low-voltage systems, especially those used in remote or inaccessible environments such as nuclear power plants and space craft.

\section{FY 92 Accomplishments}

- Prepared and submitted a major archival paper documenting modifications made to the Stochastic Analyzer for Pulsating Phenomena (SAPP) to extend its measurement capability to ac-generated partial discharges.

- Summarized and reported measurements of prebreakdown and breakdown behavior in perfluorinated polyether (HT-40), ditolyl ether (DTE), and dibenzyl and benzyl toluene (C101).

- Reported experimental results on partial discharge in phenylxylyl ethane (PXE) and hexanes to the 1992 International Symposium on Electrical Insulation.

- Prepared the first draft of a major archival paper describing the instrumentation developed for research on partial-discharge in liquids.

- Reported initial findings from a study of the high-voltage oil switch used in the Aurora accelerator to the 1992 Conference on High Energy Beams.

- Reported results from an experimental investigation into the stochastic properties of partial discharges generated in point-dielectric gaps at the 1992 IEEE International Symposium on Electrical Insulation.

- Gave two invited talks describing partial discharge research at NIST: presentations were given at the Second International Workshop on Partial Discharge Measurements and Their Traceability and at the 1992 Gordon Conference on Dielectric Phenomena. 
- Completed an experimental investigation of electro-optic mapping of highly divergent electric fields.

\section{FY 93 Plans}

- Complete tests of Monte Carlo simulation of the stochastic behavior in partial discharges and document the results.

- Complete measurements of the stochastic properties of partial discharge in a point-dielectric gap for ac generated discharges and document the results.

- Investigate partial discharge in commercial dielectric liquids including transformer oil and castor oil.

- Conduct a collaborative experimental investigation of triggered oil gaps.

\section{Impact}

- A Cooperative Research and Development Agreement was formed with Berkeley Research Associates, who currently manage the Aurora facility at Harry Diamond Laboratories in Silver Spring, MD. The work has included high-speed photography of the high-voltage oil switch used in the facility. As a result of this collaboration, staff of the facility have been able to evaluate more definitively modifications made to reduce the jitter in the time of switch closure. With this cooperation, NIST-developed technology significantly impacted the pulse power and nuclear effects generation field.

- Organized and hosted workshop on Advanced Partial Discharge Measurements; prepared summary and distributed it to more than seventy representatives of industrial, governmental, and academic institutions (initial response to the report has been positive).

\section{Recognition}

- The dielectrics community has shown keen interest in research on partial discharge at NIST. This interest has led to several invited presentations in the last year: R. J. Van Brunt gave the keynote presentation at The Second International Workshop on Partial Discharge Measurements and Their Traceability and participated in a panel session devoted to partial discharge measurement at the 1992 IEEE International Symposium on Electrical Insulation. Additionally, K. L. Stricklett gave a presentation describing partial discharge in liquids to the 1992 Gordon Conference on Dielectric Phenomena.

- NIST hosted the fall meeting of the Society of Automotive Engineers (SAE) Propulsion Ignition Systems Committee. The committee is currently reviewing the methods for measurement of the spark energy in jet engine ignitors. The meeting included a review of recent round robin test results and presentations by NIST staff on impulse voltage and current measurements, optical current sensors, and gas-phase electrical discharge. The Committee's practices are likely to be impacted by the NIST-developed HV transient measurements and diagnostic techniques. 


\section{Project: LIQUID DIELECTRICS AND PARTIAL DISCHARGE RESEARCH}

\begin{tabular}{|c|c|c|c|c|c|}
\hline FISCAL YEARS & 93 & 94 & 95 & 96 & 97 \\
\hline $\begin{array}{l}\text { Develop a monte carlo stochastic pulse } \\
\text { generator. [STRS] }\end{array}$ & & & & & \\
\hline $\begin{array}{l}\text { Apply the SAPP measurement concept to } \\
\text { liquids. [STRS] }\end{array}$ & & & & & \\
\hline $\begin{array}{l}\text { Develop methods for low-level light } \\
\text { detection. [STRS] }\end{array}$ & & & & & \\
\hline $\begin{array}{l}\text { Develop methods for imaging low-level } \\
\text { light signals. [STRS] }\end{array}$ & & & & & \\
\hline $\begin{array}{l}\text { Apply the SAPP instrumentation to } \\
\text { materials studies. [STRS] }\end{array}$ & & & & & \\
\hline
\end{tabular}




\section{Project: DIGITAL INFORMATION PROCESSING}

FY 92 Fund Sources: STRS; ATP; OA: DARPA

Staff (3.0 staff-years)

\begin{tabular}{|l||l|l|l|l|}
\hline Professional & B. F. FIELD & C. P. Fenimore & E. F. Kelley & \\
\hline
\end{tabular}

name in capital letters = project leader; $*$ = person works on project part time

Objective: To develop the measurement support needed by domestic industry and the U.S. Government to process and transmit digital information. Support (D)ARPA contractors developing advanced video imaging systems to reduce system development time and cost, and contribute to the development of industry-wide, interoperable standards by using the Princeton Engine. Develop and test video-conversion algorithms and video-quality metrics. Improve the ability of American manufacturers to become competitive in the flat-panel display market by contributing to modeling and simulation of flat panel displays and the technical development of photometric-based standards for flat panel displays (no such standards or testing procedures presently exist in industry).

Significance: National goals include the development of information highways. The capability offered by the Princeton Engine (a massively parallel video supercomputer) permits NIST to provide support for industry and (D)ARPA contractors developing advanced video imaging systems. Further, progress in imaging requires advances in measurement technology. In response, this project will develop the measurement expertise to contribute to standards development for imaging products (the number of laboratories presently qualified to perform tests and measurements in this area is extremely limited). Effective modeling and simulation of flat panel displays will permit manufacturers to subjectively evaluate potential display characteristics using a "what if" scenario to optimize the design for the intended application. The development of a set of industry accepted photometric standards and procedural tests will provide the crucial link between flat panel display manufacturers and users.

\section{FY 92 Accomplishments}

- Gave an invited talk to the IEEE Visual Signal Processing and Communication Workshop to report the availability of the Princeton Engine at NIST and to solicit interested users. Gave invited talk to the IEEE Society for Instrumentation and Measurement and presented a paper entitled "An Analysis of Frame Interpolation in Video Compression and Standards Conversion" to the 1992 IEEE/NASA Data Compression Conference.

- Prepared and held a seminar at NIST with presentations by NIST and DSRC personnel to over 40 industry and government researchers to demonstrate the capabilities of the Princeton Engine.

- Participated in meetings and working teleconferences of the Task Force on Digital Image Architecture of the Society of Motion Picture and Television Engineers (SMPTE). The Task Force is charged with developing criteria for the interoperability and extensibility of the high-definition television systems (HDTV) that have been proposed to the FCC (NIST plans to use the Princeton Engine to demonstrate frame and scan rate conversion to illustrate interoperable concepts proposed by the Task Force).

- Developed a collaborative program with the University of Maryland to use the Princeton Engine to investigate the effectiveness of parallel processing architectures as applied to data compression using the Discrete Cosine Transform Algorithm. 
- Installed and tested new programming tools including a Princeton Engine $C$ compiler and a FORTRAN 90 compiler to reduce code development time and to permit transportable code to be developed with less reliance on the specific machine architecture. Completed training courses at David Sarnoff Research Center.

- Continued a collaboration with the Public Broadcasting Service (PBS) for the evaluation of video compression systems. Implemented and tested on the Princeton Engine video-quality metrics suitable for rating video quality on a 5-point subjective scale.

- Added a third staff member during the third quarter of FY 92 for the flat-panel modeling and testing component of the project. Developed and implemented on the Princeton Engine a model of a flat-panel display in which the electro-optically active picture elements switch with the characteristics of the Kerr effect.

\section{FY 93 Plans}

- Continue to develop collaborations with industry to apply the Princeton Engine to modeling and simulation of problems related to data compression, video standards interoperability, and flat-panel operation. In particular, successfully conclude the present collaboration with PBS.

- Continue support for (D)ARPA contractors, including training and software development as necessary.

- Expand vine video quality metrics through a continuing collaboration with the National Telecommunications Information Administration (NTIA).

- Develop more advanced models for flat-panel displays as necessary and create a laboratory for the photometric testing of flat-panel displays.

- Continue collaborations with the SMPTE Task Force on Digital Image Architecture, particularly in demonstrating interoperability problems and solutions associated with frame rate, display rate, and acquisition rate conversions.

\section{Recognition}

- Representatives from the Advanced Television Test Center (ATTC) have approached NIST about cooperating in analysis of test material generated at the ATTC as a result of the recent tests of HDTV proponent systems.

- Software developed at NIST to demonstrate the characteristics of a Kerr Effect Flat Panel Display has been requested by the David Sarnoff Research Center for use in their research and development on flat panel displays.

- NIST Staff member invited to become a member of the IEEE Gigabit Networking Technical Committee. 


\section{Project: DIGITAL INFORMATION PROCESSING}

\begin{tabular}{|c|c|c|c|c|c|}
\hline FISCAL YEARS & 93 & 94 & 95 & 95 & 97 \\
\hline $\begin{array}{l}\text { Develop more extensive evaluation tests } \\
\text { for data compression algorithms (video } \\
\text { quality metrics). [STRS] }\end{array}$ & & & & & \\
\hline $\begin{array}{l}\text { Provide support for DARPA contractors. } \\
\text { [STRS, OA-DARPA] }\end{array}$ & & & & & \\
\hline $\begin{array}{l}\text { Develop short term collaborations with } \\
\text { industry researchers as necessary. [OA] }\end{array}$ & & & & & \\
\hline $\begin{array}{l}\text { Continue active involvement in voluntary } \\
\text { video and digital imaging standards } \\
\text { committees. [STRS] }\end{array}$ & & & & & \\
\hline $\begin{array}{l}\text { Replace the Princeton Engine with a state- } \\
\text { of-the-art video processing system. } \\
\text { [STRS, OA] }\end{array}$ & & & & & \\
\hline $\begin{array}{l}\text { Develop more advanced models for flat } \\
\text { panel displays as necessary. [ATP] }\end{array}$ & & & & & \\
\hline $\begin{array}{l}\text { Determine photometric flat panel testing } \\
\text { requirements and develop a testing } \\
\text { laboratory. [STRS, ATP] }\end{array}$ & & & & & \\
\hline
\end{tabular}




\section{Project: POWER QUALITY}

FY 92 Fund Sources: STRS; OA: NRC, EPRI, PEAC

Staff (1.0 staff-years)

\begin{tabular}{|c||l|l|l|l|}
\hline Professional & F. MARTZLOFF & & & \\
\hline name in capital letters = project leader; & $=$ person works on project part time
\end{tabular}

Objective: To develop the measurement techniques required to characterize the quality of the ac power delivered by electric utilities to end-users. Apply the results to improve mitigation techniques, in particular surge protection.

Significance: Increased sophistication of electronic systems combined with increased dependence on their interference-free operation have made users and electric utilities more conscious of power-quality issues. Accurate measurements on the disturbances that affect power quality are needed to determine if the sources contributing to poor or unacceptable power quality are local or a function of the distribution system. Users and utilities also need NIST to help them develop a more comprehensive set of voluntary standards.

\section{FY 92 Accomplishments}

- Completed and published report on cable aging tests by partial discharge.

- Edited the second draft of the EPRI-Sponsored Power Quality Book.

- Supported an EPRI-sponsored project to monitor power quality by electric utilities.

- Notified of IEEE approval for publication of a major revision of Guide (C62.45) describing surge testing methods (earlier made major contributions to the development of this document).

- Completed and published two co-authored papers on International Standards in the proceedings of the Second International Conference on Power Quality.

- Participated in the work of the Technical Committee 77 on Electromagnetic Compatibility resulting in appointment as Chair of Subcommittee 77B on High-Frequency disturbances.

- Transferred technology to the Power Electronics Application Center (PEAC) on Electrical Fast Transient test and measurement procedures, resulting in the completion of two test protocols.

\section{FY 93 Plans}

- Complete the editing of a textbook on power quality, sponsored by EPRI. Draft due to sponsor in March 1992.

- Obtain additional data following initial studies on the aging of metal-oxide varistors when subjected to swells.

- Provide technology transfer to PEAC and EPRI on surge testing and measurements through drafting documents to be published by PEAC; conduct joint test programs for surge characterization.

- Provide peer-review of the Systems Compatibility test protocols developed by PEAC. 
- Provide final editing of an IEEE Recommended Practice on Powering and Grounding Sensitive Loads.

- Provide expanded participation of U.S. in developing international power-quality related electromagnetic compatibility standards.

\section{Impact}

- New national standards for measuring disturbances that affect power quality incorporate NIST results. IEEE and IEC standards for measurement and characterization of transient disturbances are in place as a result of leadership provided by NIST.

\section{Related Developments}

- Power Quality is emerging as a major topic at IEEE, industry, and academic forums. Electric utilities are becoming active in this field for two major reasons: 1) as a defensive move in response to increasing expectations from their customers, 2 ) as an opportunity to offer improved power quality as a new service for increased revenue.

- A new approach has been taken by EPRI through the development of performance criteria that are used by PEAC in a generic test program to assess system compatibility of emerging power electronic devices. 


\section{Project: POWER QUALITY}

\begin{tabular}{|c|c|c|c|c|c|}
\hline FISCAL YEARS & 93 & 94 & 95 & 96 & 97 \\
\hline \multicolumn{6}{|l|}{ POWER QUALITY ISSUES } \\
\hline \multicolumn{6}{|l|}{$\begin{array}{l}\text { Provide improved measurement methods } \\
\text { for surveying power quality parameters. }\end{array}$} \\
\hline & & & & & \\
\hline \multicolumn{6}{|l|}{$\begin{array}{l}\text { Provide leadership in transfer of } \\
\text { technology through editing a textbook on }\end{array}$} \\
\hline power quality. [STRS, OA-EPRI] & & & & & \\
\hline \multirow{2}{*}{\multicolumn{6}{|c|}{$\begin{array}{l}\text { Provide more effective participation of } \\
\text { U.S. in international standards. [STRS] }\end{array}$}} \\
\hline & & & & & \\
\hline \multicolumn{6}{|l|}{ MEASUREMENT TECHNIQUES } \\
\hline \multicolumn{6}{|l|}{$\begin{array}{l}\text { Effects of repeated temporary } \\
\text { overvoltages on varistors. [STRS] }\end{array}$} \\
\hline \multicolumn{6}{|l|}{$\begin{array}{l}\text { Determine response of varistors to fast } \\
\text { pulses. [STRS, OA] }\end{array}$} \\
\hline \multicolumn{6}{|l|}{$\begin{array}{l}\text { Provide transfer of technology on surge } \\
\text { test methods. [STRS, OA] }\end{array}$} \\
\hline \multicolumn{6}{|l|}{ STANDARDS DEVELOPMENT } \\
\hline \multicolumn{6}{|l|}{$\begin{array}{l}\text { Develop standards on surge testing. } \\
\text { [STRS, OA] }\end{array}$} \\
\hline $\begin{array}{l}\text { Develop standards for power quality } \\
\text { monitoring instruments. [STRS, OA] }\end{array}$ & & & & & \\
\hline
\end{tabular}




\section{Project: PULSED POWER MEASUREMENTS}

FY 92 Fund Sources: STRS; OA: TVA, Navy

Staff (2.5 staff-years)

\begin{tabular}{|l||l|l|l|l|}
\hline Professional & G. FITZPATRICK & J. Lagnese & J. Ramboz* & E. Simmon \\
\hline Technician & J. Pitt* & & & \\
\hline
\end{tabular}

name in capital letters = project leader; = person works on project part time

Objective: To develop technology to measure pulses having characteristic times between one millisecond and one nanosecond, voltages greater than $10 \mathrm{kV}$, and/or currents greater than $10 \mathrm{kA}$. Specifically: develop measurement systems and techniques to reduce uncertainties in pulsed high-voltage and high-current measurements; provide support to development of impulse measurement standards; provide measurement support to high-voltage and pulsed power laboratories.

Significance: Improved accuracy and reliability of pulsed power measurements resulting from NIST work will provide a basis for the measurement of standard pulses used in research, development, and procurement by the electric power industry and enhance the development and operation of pulse power machines used for fusion research, space power sources, nuclear weapons simulation, etc.

\section{FY 92 Accomplishments}

- Developed software for rapid determination of Kerr cell constants from digitized data with greater precision. Reported results at the International Symposium on Digital Techniques in High-Voltage Measurements. Found that variations in the Kerr cell constants determined over a range of voltages corresponding to fringe numbers from 3 to 35 could be reduced by an order of magnitude to less than $0.2 \%$ by using a least-squares curve-fitting technique.

- Designed and built an all-fiber optical current transducer (OCT) for current measurements in the $20 \mathrm{~A}$ $10 \mathrm{kA}$ range for both impulse and steady-state currents. Configured signal-processing electronics specifically for power-frequency current measurements (the development of this OCT provides NIST with a reference device for studies of the performance of commercially-available OCTs and for the development of calibration techniques for them).

- Developed an electrostatic filtration system to improve Kerr liquid purity to reduce the problems of liquid heating and space charge effects under direct voltage. Found that the Kerr liquid's resistivity could be increased by about an order of magnitude over that purified through an alumina column, but only temporarily, so that reduction of space charge under dc high-voltage conditions was not achieved in the long term.

- Performed special on-site in-situ calibrations of high-current shunts used in resistance welders, using test currents of 3.5 and $35 \mathrm{kA}$ for durations of a minimum of $150 \mathrm{~ms}$. Employed multipositional testing process to lower measurement uncertainties more than one order of magnitude.

- Developed method based on laser cutting for producing NIST-designed single-layer Rogowski coils used to measure very high currents.

- Develop techniques for deconvolution of high-voltage impulse waveforms based upon circuit models for 
the impulse generator and voltage measurement system. The approach will enable evaluation of voltage divider measurement errors by determining the input voltage to the divider with much smaller uncertainties than those of other deconvolution methods highly sensitive to small levels of noise in the measurement.

- Evaluate the performance and develop techniques for the calibration of OCTs. Studies will be made for both impulse and steady-state current measurements over a wide dynamic range. Calibration techniques will be tested in support of development of a standard for OCTs in electric power system applications.

- Develop and calibrate probes for use in 500-3000 V range for use in the qualification of digitizers and other high-voltage dividers in accordance with IEEE Standard :1122 on Digital Recorders for HighVoltage Impulse Measurements and IEEE Standard 4 (Standard Techniques for High-Voltage Testing).

- Fabricate and test machinable Rogowski coils. Calibrate coils as precision mutual inductors for use as standards for high-pulsed-current calibrations and measurements.

- Investigate use of electrodialytic membranes for filtration of Kerr liquids and other techniques to permit Kerr cell calibration under dc conditions.

\section{Impact}

- Comparative techniques will be emphasized for qualifying impulse voltage dividers according to an updated version of IEEE Standard 4 on Standard Techniques for High-Voltage Testing, as a result of NIST participation in a round-robin study of high-voltage impulse dividers with the IEEE High-Voltage Test Techniques Committee (HVTT). The NIST reference divider was circulated among twelve industrial, university, and government laboratories. The study indicated that dividers used for many years in some of the laboratories had significant measurement errors. Subsequent studies performed at the National Research Council of Canada showed the NIST divider being much less susceptible to radiated pickup than another reference voltage divider circulated in the test. Study results were also reported to a CIGRE Working Group responsible for the International Electrotechnical Commission's (IEC) standard on high-voltage measurements.

\section{Recognition}

- A CRADA is being arranged with a manufacturer of electrical equipment to characterize the company's optical current transducer (OCT) with $60 \mathrm{~Hz}$ currents and with pulsed currents up to $80 \mathrm{kA}$.

- The Tennessee Valley Authority has requested that NIST develop measurement support for optical current transducers.

- G. J. FitzPatrick has served on the Technical Program Committees for both the International Symposium on Electrical Insulation and Conference on Electrical Insulation and Dielectric Phenomena. E. Simmon is a member of the Optical Sensors Users/Manufacturers Group.

\section{Related Developments}

- The IEEE Subcommittee on Emerging Technologies has begun writing a standard on optical current transducers in electric powar applications. The group is considering proposed calibration techniques and NIST's work in this are sisuld be important to the JCT standard. 
Project: PULSED POWER MEASUREMENTS

\begin{tabular}{|c|c|c|c|c|c|}
\hline FISCAL YEARS & 93 & 94 & 95 & 96 & 97 \\
\hline \multicolumn{6}{|l|}{$\begin{array}{l}\text { Develop techniques for impulse waveform } \\
\text { analysis with improved accuracy. [STRS] }\end{array}$} \\
\hline \multicolumn{6}{|l|}{$\begin{array}{l}\text { Fabricate and calibrate machinable } \\
\text { Rogowski coils. [STRS, OA] }\end{array}$} \\
\hline \multicolumn{6}{|l|}{$\begin{array}{l}\text { Develop improved calibration techniques } \\
\text { for Kerr Cell Systems using direct voltage. } \\
\text { [STRS] }\end{array}$} \\
\hline \multicolumn{6}{|l|}{$\begin{array}{l}\text { Investigate electro-optic and magneto- } \\
\text { optic sensors. [STRS, OA] }\end{array}$} \\
\hline \multicolumn{6}{|l|}{$\begin{array}{l}\text { Investigate reliability of complementary } \\
\text { sensors. [STRS] }\end{array}$} \\
\hline \multicolumn{6}{|l|}{$\begin{array}{l}\text { Develop and characterize systems used to } \\
\text { measure pulses required in international } \\
\text { commerce in electrical power equipment. } \\
\text { [STRS] }\end{array}$} \\
\hline $\begin{array}{l}\text { Develop transportable reference voltage } \\
\text { measurement systems in support of } \\
\text { international standards. [STRS] }\end{array}$ & & & & & \\
\hline
\end{tabular}




\section{Project: PLASMA CHEMISTRY - PLASMA PROCESSING}

\section{FY 92 Fund Sources: STRS}

\section{Staff (1.5 staff-years)}

\begin{tabular}{|l||l|l|l|l|}
\hline Professional & R. VAN BRUNT & J. K. Olthof** & J. R. Roberts* & M. Sobolewski* \\
\cline { 2 - 5 } & J. R. Whetstone* & S. Radovanov & & \\
\hline
\end{tabular}

name in capital letters = project leader; $=$ person works on project part time; Roberts is a member of the Physics Laboratory; Sobolewski and Whetstone are in the Chemical Science and Technology Laboratory.

Objective: To develop fundamental reference data, reference discharge cells, and advanced measurement methods such as mass spectrometry and optical spectroscopy that can be used for control and diagnostics of low-temperature glow-discharge reactors employed for plasma processing of semiconductors, e.g., plasma etching and deposition of silicon.

Significance: To achieve the goal of reduced feature size in advanced integrated circuit design, the semiconductor electronics industry is forced to replace older surface etching techniques that use wet chemistry with more advanced and complex plasma etching techniques. As greater demands are placed upon plasma etching processes, improved control and characterization of the etching plasma become essential. NIST measurements of kinetic-energy distributions of mass identified ions correlated with optical emission, Langmuir probe, and laser-induced fluorescence measurements can provide the refined information needed for a more complete understanding of the etching process. In order to advance plasma processing techniques, it has become necessary to consider development of reference discharges such as the Gaseous Electronics Conference (GEC) radio frequency (rf) Reference Cell now being tested at NIST and in numerous other laboratories which can be used to calibrate diagnostic measurements, test chemical kinetics models of the process, and learn about the inherent physical characteristics of the discharge that determine the limitations on reproducibility.

\section{FY 92 Accomplishments}

- Measured kinetic energy distributions of ions sampled from $\mathrm{Ar} / \mathrm{O}_{2}$ and $\mathrm{Ar} / \mathrm{He}$ rf discharges in the GEC If reference cell under various plasma conditions. Observed correlations when the measured ion energies were compared with voltage and current measurements and measurements made with a Langmuir probe. Found that ion-energy data indicated the possibility of surface charging on the aluminum electrodes. Presented preliminary results at the 1992 Gas Discharge Conference.

- Mounted a new mass spectrometer with an ion-energy analyzer on the GEC rf Reference Cell in such a way that ions could be sampled through the grounded electrode. Checked system by measuring ion kinetic energy distributions from argon plasmas. Found results confirmed earlier measurements made in this laboratory with a different experimental set up (the new apparans provides capacity to monitor plasmas over a much wider range of pressures, and to detect ions with very low concentrations).

- Measured kineti gy distributions for ions sampled from argon and nitrogen diffuse, high E/N, dc discharges $(\mathbb{E} / \mathbf{A}$ collisional cond to the quotient of the electric field and the plasma number density and under distributions ag predictions from measured cross sections, and at higher $E / N$, the distributions exhibit a non-N $\mathbb{N}_{\text {ata }}$ wellian distribution. Presented results on the argon discharges in a conference paper at the 1992 Gas Discharge Conference. 
- Prepared an archival paper documenting results from off-axis measurements of the positive ion kineticenergy distributions from if plasmas in argon generated using the GEC Reference Cell (paper accepted for publication in the Journal of Applied Physics).

- Measured a set of spatially- and temporally-resolved optical emissions data for argon plasmas in the GEC If Reference Cell. Found that the plasma conditions were the same as the "standard" settings used for the initial comparison of GEC Reference Cell data. Calibrated the magnitude of the optical emission against an absolute scale, thus making this data set uniquely suited for comparison with plasma models (report of results accepted for publication in the NIST Journal of Research).

- Submitted an archival paper documenting the electrical characterization of the GEC rf Reference Cell and the intercomparison of measurements made at various laboratories to the Review of Scientific Instruments.

\section{FY 93 Plans}

- Prepare an archival paper documenting the results obtained from measurements made with the new mass spectrometer system of kinetic energies of ions sampled through the grounded electrode of the GEC reference cell.

- Complete measurements of kinetic-energy distributions for ions sampled from argon and nitrogen diffuse, high-E/N, dc discharges. Results will be presented in an archival publication.

- Complete measurements of $\mathrm{K}+$ ion energy distributions in the uniform-field drift tube and compare with results of Monte-Carlo simulations.

- Continue investigations of ion kinetic-energy distributions and attempt to delineate the effects of surface charging on the plasma.

\section{Impact}

- The group at NIST has played a leading role in the development and evaluation of the reference discharge-cell concept. The GEC cell used at NIST is now an object of investigation in numerous research laboratories in the United States, which include the Sandia National Laboratory, University of New Mexico, Air Force Aeropropulsion Laboratory, AT\&T Bell Laboratories, IBM T. J. Watson Research Center, University of Michigan, University of California, Massachusetts Institute of Technology, and University of Illinois.

\section{Recognition}

- R. J. Van Brunt was elected Secretary of the Gaseous Electronics Conference which will be held at NIST in 1994. 


\section{Project: PLASMA CHEMISTRY - PLASMA PROCESSING}

\begin{tabular}{|c|c|c|c|c|c|}
\hline FISCAL YEARS & 93 & 94 & 95 & 95 & 97 \\
\hline $\begin{array}{l}\text { Document measured ion kinetic energy } \\
\text { distributions for positive ions from argon } \\
\text { plasma in GEC Reference Cell. [STRS] }\end{array}$ & & & & & \\
\hline $\begin{array}{l}\text { Measure optical emission profiles and ion } \\
\text { energy distributions from rf discharges in } \\
\mathrm{GEC} \text { reference cell for } \mathrm{Ar}+\mathrm{O}_{2} \mathrm{Ar}+\mathrm{He} \text {, } \\
\text { and } \mathrm{Ar}+\mathrm{H}_{2} \text { mixtures. [STRS] }\end{array}$ & & & & & \\
\hline $\begin{array}{l}\text { Measure } \mathrm{K}+\text { ion energy distributions in } \\
\text { drift tube using energy selector-mass } \\
\text { spectrometer and compare with } \\
\text { simulations. [STRS] }\end{array}$ & & & & & \\
\hline $\begin{array}{l}\text { Measure ion energy distributions from } \\
\text { FY } 96 \text { reactive etching plasmas using } \\
\mathrm{SF}_{6}+\mathrm{O}_{2} \text { and } \mathrm{CF}_{4}+\mathrm{O}_{2} \text { gas mixtures. } \\
\text { [STRS] }\end{array}$ & & & & & \\
\hline $\begin{array}{l}\text { Develop and test system to perform } \\
\text { phase-resolved ion energy distribution } \\
\text { measurements at the discharge } \\
\text { electrodes. [STRS] }\end{array}$ & & & & & \\
\hline $\begin{array}{l}\text { Measure kinetic energy distributions of } \\
\text { ions sampled from dc Townsend } \\
\text { discharges and compare with Monte-Carlo } \\
\text { calculations. [STRS] }\end{array}$ & & & & & \\
\hline
\end{tabular}




\section{Project: GASEOUS DIELECTRICS RESEARCH}

\section{FY 92 Fund Sources: DOE; EPRI}

\section{Staff (1.5 staff-years)}

\begin{tabular}{|l||l|l|l|l|}
\hline \multirow{2}{*}{ Professional } & R. VAN BRUNT & J. T. Herron* & J. K. Olthof** & K. L. Stricklett* \\
\cline { 2 - 5 } & D. Wheeler & & & \\
\hline
\end{tabular}

name in capital letters $=$ project leader; $=$ person works on project part time

Objective: To provide fundamental information and data needed to evaluate gaseous insulation in future high-voltage power systems with emphasis on measurement and modelling of basic chemical processes leading to the formation of toxic and corrosive by-products in electrical discharges.

Significance: Safety concerns relating to the nation's electric power transmission and distribution systems include the presence of toxic materials and the production of toxic materials as a result of service. Information developed and then disseminated by NIST permits design of better tests to assure safe, reliable operation of $\mathrm{SF}_{6}$-insulated high-voltage systems now widely used by the electric power industry. In particular, NIST is developing highly sensitive analytical techniques and measuring the rates for chemical processes to promote reliable detection of decomposition products that are indicators of insulation failure and potential health hazards.

\section{FY 92 Accomplishments}

- Completed measurements of the production rate for $\mathrm{S}_{2} \mathrm{~F}_{10}$ in corona discharges as a function of discharge current and gas pressure; included results in a conference paper presented at the 1992 IEEE International Symposium on Electrical Insulation and presented at the 10th International Conference on Gas Discharges and their application. Identified both $\mathrm{S}_{2} \mathrm{~F}_{10}$ and $\mathrm{S}_{2} \mathrm{O}_{2} \mathrm{~F}_{10}$ as by-products of negative corona discharges in $\mathrm{SF}_{6}$ and estimated their production rates.

- Prepared an archival publication reporting cross sections for electron scattering and electron attachment to $\mathrm{SF}_{6}$ and some of its discharge by-products $\left(\mathrm{SOF}_{2}, \mathrm{SOF}_{4}, \mathrm{SO}_{2}, \mathrm{SO}_{2} \mathrm{~F}_{2}\right.$ and $\left.\mathrm{SF}_{4}\right)$; paper accepted for publication in Plasma Chemistry and Plasma Processing. Measured the absolute dissociative electroncapture cross sections for the molecules $\mathrm{S}_{2} \mathrm{O}_{2} \mathrm{~F}_{10}, \mathrm{~S}_{2} \mathrm{OF}_{10}$ and $\mathrm{S}_{2} \mathrm{~F}_{10}$ in collaboration with the University of Maryland. Found that both $\mathrm{S}_{2} \mathrm{O}_{2} \mathrm{~F}_{10}$ and $\mathrm{S}_{2} \mathrm{OF}_{10}$ have anomalously large cross sections. Also identified the negative ions formed from these compounds identified in a collaborative experiment with the Oak Ridge National Laboratory. Prepared the results from both experiments for archival publication.

- Measured the $\mathrm{S}_{2} \mathrm{~F}_{10}$ concentration in an $\mathrm{SF}_{6}$ sample obtained from an arc test at Ontario Hydro using the gas chromatograph/mass spectrometer (GC/MS) technique. Observed that the large concentration of $\mathrm{SOF}_{2}$ in the sample reduces our $\mathrm{S}_{2} \mathrm{~F}_{10}$ detection sensitivity and suggests further investigations to improve the technique. Found $\mathrm{S}_{2} \mathrm{~F}_{10}$ content of filtered, arc-decomposed $\mathrm{SF}_{6}$ from Ontario Hydro to be below $10 \mathrm{ppb}$.

- Performed tests that verified the presence of trace $\mathrm{S}_{2} \mathrm{~F}_{10}$ in some commercially available $\mathrm{SF}_{6}$ and showed the presence of an unknown contaminant that can interfere with detection of $S_{2} F_{10}$. Applied appropriate mass spectrometric and pyrolysis tests to distinguish the unknown from $S_{2} F_{10}$. Also evaluated the effects of $\mathrm{SOF}_{2}$ interference on $\mathrm{S}_{2} \mathrm{~F}_{10}$ detection in $\mathrm{SF}_{6}$ by the NIST GC/MS technique. 


\section{FY 93 Plans}

- Prepare an archival paper on the production of $\mathrm{S}_{2} \mathrm{~F}_{10}$ in negative glow-type corona discharges.

- Document the analytical procedure developed at NIST for detecting trace levels of $S_{2} F_{10}$ in $S_{6}$ and test an extended version of the method that utilizes a compact capillary chromatographic column that can be readily interfaced with any mass spectrometer.

- Measure the appearance potentials of the positive ions formed by collision of electrons with $\mathrm{SF}_{4}, \mathrm{SF}_{6}$, $\mathrm{SOF}_{2}, \mathrm{SOF}_{4}, \mathrm{~S}_{2} \mathrm{OF}_{10}, \mathrm{~S}_{2} \mathrm{O}_{2} \mathrm{~F}_{10}$, and $\mathrm{S}_{2} \mathrm{~F}_{10}$.

- Measure the production rates for oxyfluorides and $S_{2} F_{10}$ formed by $x$-ray photolysis of $S_{6}$.

\section{Recognition}

- As a result of the power industry's vital interest in the subject, a cooperative research and development agreement (CRADA) was formed to address the problems of detecting $S_{2} F_{10}$ in $S F_{6}$ and of understanding the conditions under which this compound can be formed in power systems. The research is being conducted at NIST, Oak Ridge National Laboratory, and the Ontario Hydro Research Laboratory. NIST receives support for this work from DOE and EPRI. Specific assistance was requested and obtained from major U.S. SF 6 manufacturers in analyzing their products for the presence of undesirable contaminants.

- A CRADA was formed between a manufacturer and NIST to investigate decomposition of $\mathrm{SF}_{6}$ used as an insulating gas in the company's portable $x$-ray units. NIST was able to show the company that the decomposition of $\mathrm{SF}_{6}$ results in formation of corrosive by-products that ultimately cause failure manifested by internal electrical breakdown.

- R. J. Van Brunt served as General Chairman of the 1992 IEEE International Symposium on Electrical Insulation and serves as Secretary of the 1994 Gaseous Electronics Conference, an annual special topics conference of the American Physical Society. Van Brunt is also on the Organizing Committee for the 1992 Tenth International Conference on Gas Discharges and Their Applications, on the Advisory Committee for the 1993 8th International Swarm Seminar, and is Chairman of the IEEE Technical Committee S-32-11 on Gaseous Dielectrics. He was recently elected to serve on the Administrative Committee of the IEEE Dielectrics and Insulation Society. 
Project: GASEOUS DIELECTRICS RESEARCH

\begin{tabular}{|c|c|c|c|c|c|}
\hline FISCAL YEARS & 93 & 94 & 96 & 96 & 97 \\
\hline \multicolumn{6}{|l|}{$\begin{array}{l}\text { Document results from measurement of } \\
\mathrm{S}_{2} \mathrm{~F}_{10} \text { production rates for negative- } \\
\text { corona discharges in compressed } \mathrm{SF}_{6} \text {. } \\
\text { [CRADA] }\end{array}$} \\
\hline \multirow{2}{*}{\multicolumn{6}{|c|}{$\begin{array}{l}\text { Measure production rates for negative } \\
\text { corona discharge generated } \mathrm{S}_{2} \mathrm{~F}_{10} \text { in } \\
\mathrm{SF}_{6}+\mathrm{O}_{2}, \mathrm{SF}_{6}+\mathrm{N}_{2}, \mathrm{SF}_{6}+\mathrm{H}_{2} \mathrm{O} \text { mixtures. } \\
\text { [CRADA] }\end{array}$}} \\
\hline & & & & & \\
\hline \multicolumn{6}{|l|}{$\begin{array}{l}\text { Measure appearance potentials of positive } \\
\text { ions in mass specra of } \mathrm{SF}_{4}, \mathrm{~S}_{2} \mathrm{~F}_{10}, \mathrm{SF}_{6} \text {, } \\
\mathrm{SOF}_{2}, \mathrm{SOF}_{4}, \mathrm{~S}_{2} \mathrm{OF}_{10}, \text { and } \mathrm{S}_{2} \mathrm{O}_{2} \mathrm{~F}_{10} \text {. } \\
\text { [CRADA] }\end{array}$} \\
\hline \multicolumn{6}{|l|}{$\begin{array}{l}\text { Measure rates for formation of } \mathrm{SOF}_{2} \text {, } \\
\mathrm{SOF}_{4}, \mathrm{SO}_{2} \mathrm{~F}_{2}, \mathrm{~S}_{2} \mathrm{O}_{2} \mathrm{~F}_{10} \text { and } \mathrm{S}_{2} \mathrm{~F}_{10} \text { from } \mathrm{x}- \\
\text { ray photolysis of } \mathrm{SF}_{6} \text {. [CRADA] }\end{array}$} \\
\hline \multicolumn{6}{|l|}{$\begin{array}{l}\text { Assess influence of other } \mathrm{SF}_{6} \\
\text { decomposition products on sensitivity of } \\
\text { GC/MS method for } \mathrm{S}_{2} \mathrm{~F}_{10} \text { detection in } \\
\mathrm{SF}_{6} \text {. [CRADA] }\end{array}$} \\
\hline \multicolumn{6}{|l|}{$\begin{array}{l}\text { Measure rates for } \mathrm{S}_{2} \mathrm{~F}_{10} \text { production from } \\
\text { positive corona-discharges in } \mathrm{SF}_{6} \text {. } \\
\text { [CRADA] }\end{array}$} \\
\hline $\begin{array}{l}\text { Build and test capillary column coupled to } \\
\text { thermal conversion tube plus MS for } \\
\text { detection of } S_{2} F_{10} \text { in } \mathrm{SF}_{6} \text {. [CRADA] }\end{array}$ & & & & & \\
\hline
\end{tabular}




\title{
Project: AUTOMATED ELECTRONIC MANUFACTURING
}

\author{
FY 92 Fund Sources: STRS; ATP; OA: U.S. Navy
}

Staff (2.1 staff-years)

\begin{tabular}{|l||l|l|l|l|}
\hline Professional & B. GOLDSTEIN & W. Anderson * & M. J. McLay & C. H. Parks \\
\hline
\end{tabular}

Objective: Work with industry and other government laboratories to develop a program to promote the transfer of technical information between the manufacturers of electronic parts and those that need parts for the design, manufacture, and repair of electronic systems. Promote electronic commerce, more specifically, contribute toward the technology development for a neutral product data exchange specification called STEP (Standard for the Exchange of Product Model Data); to provide an impartial forum to resolve conflicts among competing and conflicting standardization efforts on the exchange of product data by the electronics industry.

Significance: Integral to the electronics industry are product standards and specifications that enable the design, manufacture, documentation, procurement, and support of modern electronics. Computer-aided design (CAD) and computer-aided manufacturing (CAM) systems are heavily dependent on such standards and specifications. The traditional forums for capturing designs and manufacturing information engineering drawings and paper specifications - are being replaced by digital formats. The information must be correct, complete, unambiguous, and efficient. Among the technical challenges is the development of adequate information models that describe the essential characteristics of electrical and electronic products. The digita? information must be unified and tested to ensure that it will lead to the manufacture of the desired product. Currently, there are at least four established standards which can be used to transfer data among automated tools for fabricating electronic products. The industry's complaint is that these standards are not fully capable of expressing designs unambiguously and that "harmonization" with NIST in a key role is needed to avoid costly waste in design and manufacturing. Further, industry needs NIST to facilitate the development of universal protocols for transferring information among members of a "virtual enterprise" across nationally accessible networks.

\section{FY 92 Accomplishments}

- Hosted meeting for Electrical Application Protocol Coordination for the Office of the Secretary of Defense Computer-aided Acquisition and Logistic Support office.

- Participated in ANSI Harmonization of Digital Product Data (HPS) Workshop. Developed a first- draft harmonized model for net list connectivity and defined about 20 terms associated with the model.

- Delivered the Initial Graphics Exchange Specification (IGES) Application Protocol for Hybrid microelectronic assemblies to the Naval Ocean Systems Center.

- Participated in the PDES, Inc. EE (electronics, electrical) project software development effort.

- Provided guidance related to EE product data standards for the tri-services Microwave and Millimeterwave Advanced Computational Environment project.

- Attended the first meetings of the ISO/IEC STEP JWG9 for Electronic and Electrical Products. Signed up to provide JWG9 with document archival services. 
- Developed requirements for a testbed to support the Automated Electronic Manufacturing project.

- Attended a meeting sponsored by the National Initiative on Product Data Exchange (NIPDE) on Electronic Commerce of Component Information (ECCI), in which NIST was asked to take the lead in moving the ECCI project forward.

\section{FY 93 Plans}

- Continue the development of a testbed to examine interoperability problems in electrical and electronic standards.

- Establish a special working group on Test, Validation, and Qualification of International Electronic Product Data Exchange Standards within IEC Technical Committee 93, Design Automation. The working group will provide a forum through which representatives of various testbeds interact to determine common testing requirements.

- Participate in development/testing/validation activities for evolving harmonized electrical standards. In this effort NIST will work in cooperation with PDES, Inc and ISO/IEC Joint Working Group 9.

- Support development of product data standards in the development, fabrication, testing, and support of millimeter and microwave tubes. Provide expertise and sponsor standards workshops.

- Work with Sandia National Laboratories to lead participants in the NIPDE fast-track ECCI demonstration.

- Manage four projects in concurrent engineering and collaborative technology administered by the (Defense) Advanced Research Projects Agency Initiative in Concurrent Engineering (DICE).

- Provide assistance to the NIST Computer Systems Lab with the Federal Information Processing Standard for Integrated Computer-Aided Manufacturing Definition Language (IDEF).

\section{Recognition}

- NIST has been requested by organizations responsible for product data standards (IEEE, EIA, IPC, ASME) to provide a testbed to establish a formal testing activity for the verification of the interoperability of four electronic description standards.

- PDES, Inc. has asked NIST to support its efforts in this area by contributing some staff time to PDES harmonization work.

- Curt Parks was re-elected to serve as an industry observer on the IDEF Steering Committee. He was also asked to stand in as chair of the ISO Product Functionality Committee during the ISO meeting in Oslo, January 1992.

- Curt Parks has been asked to be the principal modeler of the STEP Activity Model by the ISO TC 184/SC 4 Project Management Advisory Group.

- Barbara Goldstein has resumed her role as chair of the HPS Tools and Technology Council.

\section{Related Developments}

- NIST has been invited to manage four (D)ARPA DICE projects, one of which is directly related to standardization of microwave and millimeter-wave product data. 


\section{Project: AUTOMATED ELECTRONIC MANUFACTURING}

\begin{tabular}{|c|c|c|c|c|c|}
\hline FISCAL YEARS & 93 & 94 & 95 & 96 & 97 \\
\hline $\begin{array}{l}\text { HARMONIZATION OF ELECTRONIC } \\
\text { PRODUCT DATA STANDARDS }\end{array}$ & & & & & \\
\hline $\begin{array}{l}\text { Serve as the secretariat to the Councils } \\
\text { and chair of the Tools \& Technology } \\
\text { Council of the HPS. [STRS] }\end{array}$ & & & & & \\
\hline $\begin{array}{l}\text { Plan testing/validation activity. [STRS, } \\
\text { ATP] }\end{array}$ & & & & & \\
\hline $\begin{array}{l}\text { Test/validate interoperability of standards. } \\
\text { [STRS, ATP] }\end{array}$ & & & & & \\
\hline $\begin{array}{l}\text { Aid in development of electrical product } \\
\text { data standards. [STRS, ATP] }\end{array}$ & & & & & \\
\hline $\begin{array}{l}\text { SUPPORT TO DEFINE DATA FOR HYBRID } \\
\text { MICROCIRCUITS }\end{array}$ & & & & & \\
\hline $\begin{array}{l}\text { Develop a plan for transforming the IGES } \\
\text { hybrid applications protocol into a layered } \\
\text { electrical product AP. [STRS] }\end{array}$ & & & & & \\
\hline $\begin{array}{l}\text { ACTIVITIES TO PROMOTE INDUSTRY } \\
\text { USE OF ELECTRONIC PRODUCT DATA }\end{array}$ & & & & & \\
\hline $\begin{array}{l}\text { Establish a cooperative program between } \\
\text { NIST/EEEL and universities. [STRS] }\end{array}$ & & & & & \\
\hline $\begin{array}{l}\text { Cooperate with the DOD CIM/CALS effort } \\
\text { in transitioning new knowledge in } \\
\text { automated manufacturing and testing of } \\
\text { electronic products. [STRS] }\end{array}$ & & & & & \\
\hline $\begin{array}{l}\text { Establish the information requirements } \\
\text { necessary for describing electronic } \\
\text { components in support of a component } \\
\text { library. [STRS] }\end{array}$ & & & & & \\
\hline $\begin{array}{l}\text { Serve as IGES Change Control Secretary. } \\
\text { [STRS] }\end{array}$ & & & & & \\
\hline Manage three DARPA DICE projects. [OA] & & & & & \\
\hline
\end{tabular}




\section{Project: AUTOMATED ELECTRONIC MANUFACTURING (concluded)}

\begin{tabular}{|l|c|c|c|c|c|}
\hline FISCAL YEARS & 93 & 94 & 95 & 96 & 97 \\
\hline $\begin{array}{l}\text { SUPPORT TO NAVY PROGRAM TO } \\
\text { DEFINE DATA FOR MICROWAVE AND } \\
\text { MILLIMETER-WAVE TUBE LIFE-CYCLE }\end{array}$ & & & & & \\
\hline Sponsor standards workshops. [OA] & & & & & \\
\hline $\begin{array}{l}\text { Aid in definition of data requirements. } \\
\text { [OA] }\end{array}$ & & & & & \\
\hline
\end{tabular}




\section{Project: MEASUREMENTS FOR COMPLEX ELECTRONIC SYSTEMS.}

\section{FY 92 Fund Sources: STRS; OA: Army TMDE Support Group}

\section{Staff (2.5 staff-years)}

\begin{tabular}{|l||l|l|l|l|}
\hline Professional & T. SOUDERS* & G. Stenbakken* & A. D. Koffman * & B. A. Bell* \\
\hline Technician & R. H. Palm* & P. S. Hetrick* & & \\
\hline
\end{tabular}

name in capital letters $=$ project leader; ${ }^{*}=$ person works on project part time

Objective: Promote greater efficiency and confidence in testing and calibration of complex electronic systems. This includes development of mathematical models, algorithms, and test procedures for the selection of optimal test points, signals and sequences, and the estimation of confidence and test coverage in a given calibration or test procedure.

Significance: With the growing complexity of electronic instrumentation, testing and calibration costs have become a dominant factor in total instrument life-cycle costs. Confidence levels, test coverage, and test and calibration procedures are often inadequate to assure the extremely low defect levels that are now required. NIST developments are needed by industry to address these issues. This is a collaborative project with the Computing and Applied Mathematics Laboratory. The work sponsored by the Army is in support of its goal to provide adequate calibration support for automatic test systems.

\section{FY 92 Accomplishments}

- Completed development of an error model and efficient test plan for a multirange thermal transfer standard based on 139 sets of test data from the manufacturer. Developed a 20-parameter model using a singular value decomposition approach to selecting empirical model vectors and selected 50 test points from a total of 255. Found that predictions made from measurement data at these test points had an rms error of only $2.7 \%$ of the manufacturer's specified uncertainty, for all 39 instruments (al most 10,000 data points) in the validation set.

- Developed new insight into conditions for optimality of empirical models generated using the singular value decomposition. Showed through extensive simulations, together with a mathematical analysis, how the optimum dimension of the model (which gives the lowest prediction errors) can be selected based on knowledge of the measurement noise incorporated in the model data, and on the singular values. Presented a paper on this work at the 1992 Midwest Symposium on Circuits and Systems in August.

- Began study of self-calibrating systems. Performed literature search of over 460 citations and developed organizational framework for study.

- Published NIST Interagency Report on Integrated Family of Test Equipment calibration support.

- Conducted second workshop on Testing Strategies for Analog and Mixed-Signal Products, with 11 attendees, principally from industry.

\section{FY 93 Plans}

- Prepare paper (coauthored with instrument manufacturer) on the application of testing strategies to a multirange thermal transfer instrument.

- Develop prototype high-level representation scheme (data characteristics and information flow) for 
describing self-calibrating systems. Begin development of an analysis engine to extract information on completeness, underlying assumptions, and coverage of verification tests.

- Develop a mathematical framework for assessing the risk of undetected model error using the NISTdeveloped testing strategies for mixed-signal devices.

- Begin feasibility study for on-line error detection in analog systems using less hardware overhead than required by conventional redundancy methods.

\section{Impact}

- At least two semiconductor manufacturers are currently using the NIST testing strategies in routine production line testing, and several others are involved in pilot tests.

- A major ATE manufacturer has developed applications software for use by its customers to expedite the implementation of the NIST approach.

\section{Related Developments}

- The development of application-specific integrated circuits (ASICs) is creating an increasingly complex mix of analog and digital functions to test ("ASICs Drive Demand for Sophisticated Test Systems," Electronic Engineering Times, May 30,1988). The growth of mixed signal Ics is now predicted to reach $\$ 12.6$ billion by 1993 ("Mixed-Signal IC Market is Booming," Electronics Test, September, 1989). 
Project: MEASUREMENTS FOR COMPLEX ELECTRONIC SYSTEMS.

\begin{tabular}{|c|c|c|c|c|c|}
\hline FISCAL YEARS & 93 & 94 & 95 & 95 & 97 \\
\hline TESTING STRATEGIES & & & & & \\
\hline $\begin{array}{l}\text { Develop mathematical framework for } \\
\text { assessing risks (e.g., undetected model } \\
\text { error) using NIST approach. [STRS] }\end{array}$ & & & & & \\
\hline $\begin{array}{l}\text { Apply empirical modeling techniques to } \\
\text { efficient testing strategies for multi- } \\
\text { range/multifunction instruments. [STRS, } \\
\text { OA] }\end{array}$ & & & & & \\
\hline $\begin{array}{l}\text { Develop a theory for self-calibrating } \\
\text { systems: develop a high level } \\
\text { representation scheme and analysis } \\
\text { engine for describing and analyzing S-C } \\
\text { systems. [STRS] }\end{array}$ & & & & & \\
\hline DEVICEISYSTEM ANALYSIS & & & & & \\
\hline $\begin{array}{l}\text { Develop hardware-efficient approaches to } \\
\text { on-line fault detection in analog and } \\
\text { mixed-signal systems. [STRS] }\end{array}$ & & & & & \\
\hline
\end{tabular}




\section{Project: WAVEFORM ACQUISITION DEVICES AND STANDARDS}

\section{FY 92 Fund Sources: STRS; Calibrations}

Staff (4.1 staff-years)

\begin{tabular}{|l||l|l|l|l|}
\hline \multirow{2}{*}{ Professional } & T. M. SOUDERS* & O. B. Laug* & J.P. Deyst & A. D. Kaufman* \\
\cline { 2 - 5 } & W. L. Gans* & A. G. Perrey* & W. L. Gans* & \\
\hline Technician & P. S. Hetrick* & R. H. Palm* & & \\
\hline
\end{tabular}

name in capital letters = project leader; $=$ person works on project part time

Objective: Develop techniques, physical standards, measurement methods and test apparatus for signal acquisition and analysis. Develop pulse waveform standards that will provide industry and government with a vehicle for pulse-waveform parameter comparability and traceability to NIST.

Significance: A broad spectrum of applications from production line testing to medical and chemical analyses to digital communications and pulse power research increasingly depends on the performance of accurate signal acquisition, conversion, and recording equipment. The number of waveform recorder manufacturers alone has grown from several a decade ago to over 30 today; however, standards and test methods to verify waveform recorder performance are lagging. NIST is filling such needs by proving metrology support for data converters ( $\$ 1.1$ billion sales in 1990) and waveform recorders and analyzers ( $\$ 24.2$ billion sales in 1990$)$.

\section{FY 92 Accomplishments}

- Successfully tested NIST-developed application-specific integrated circuit (ASIC) comparator operating in a sampling probe test fixture. Found that the following measured characteristics met virtually all design goals: transition duration of $140 \mathrm{ps}(2.5-\mathrm{GHz}$ equivalent bandwidth); settling time to $0.1 \%$ in 2 ns and to $0.02 \%$ in $10 \mathrm{~ns}$; rms input noise of $400 \mu \mathrm{V}$; and gain flatness errors ranging from $60 \mathrm{ppm}$ at $1 \mathrm{Mhz}$ to $0.3 \%$ at $100 \mathrm{Mhz}(0.1 \%$ at $50 \mathrm{Mhz})$. Presented paper on this development at the 1992 Instrumentation and Measurement Technology Conference.

- Installed automatic waveform analysis and measurement system in shielded enclosure to perform specialtest measurements of fast pulse parameters, pulse-time delay, and impulse spectrum amplitude.

- Participated in a Sampling Oscilloscope Calibration Workshop conducted by an instrument manufacturer, focusing on the novel "nose-to-nose" technique developed by the company to measure the impulse response of high speed (20- to 50- Ghz) sampling oscilloscopes.

- Completed plans for first phase (nanosecond regime) of pulse measurement intercomparison program: outlined methodology, selected participating labs, developed data processing approaches, and designed pulse transfer instrument.

- Developed frequency-domain approach to compensate for deviations from linear response in the magnitude response spectra of sampling channels. Generated a higher-order rational polynomial approximation; then designed like-order compensating filters having infinite impulse response; results flattened response over the pass band by $20 \mathrm{~dB}$ of greater.

\section{FY 93 Plans}

- Develop a $\pm 10-\mathrm{V}$ sampling probe for low frequency applications (to $1 \mathrm{Mhz}$ ), with target accuracy of 
$100 \mathrm{ppm}$ (gain flatness) to $1 \mathrm{Mhz}$.

- Begin development of an improved time base for use with the NIST sampling comparator probes to maximize throughput at low frequencies $(<10 \mathrm{Khz})$.

- Complete development of pulse generator transfer instrument and begin first phase of round-robin intercomparisons of pulse waveform measurement capability.

- Implement and evaluate "nose-to-nose" impulse response measurement approach using $20 \mathrm{Ghz}$ sampling oscilloscopes.

- Perform error analyses of single-shot vs. repetitive tests of sampling systems, and quantify main sources of uncertainty in sine fit methods.

\section{Impact}

- The IEEE Std. 1057, "Trial Use Standard for Digitizing Waveform Recorders" includes several NISTdeveloped test methods. IEEE reports over 300 copies of the standard have been sold.

\section{Recognition}

- Fifteen laboratories have asked to participate in the pulse measurement intercomparison program being initiated by NIST.

\section{Related Developments}

- The IEEE Instrumentation and Measurement Society's TC-10 now has formed a subcommittee for developing a performance standard on analog-to-digital converters.

- Use of sampling voltage tracker (SVT) technology is proliferating: It is used by several mixed-signal ATE vendors; a major semiconductor manufacturer offers a hybrid circuit version; a complete instrument employing SVT technology is available; and many IC manufacturers use the SVT approach in production line testing Each of these applications could easily incorporate the new NIST-developed ASIC comparator. 
Project: WAVEFORM ACQUISITION DEVICES AND STANDARDS

\begin{tabular}{|c|c|c|c|c|c|}
\hline FISCAL YEARS & 93 & 94 & 96 & 96 & 97 \\
\hline $\begin{array}{l}\text { DATA CONVERTER/WAVEFORM } \\
\text { RECORDER TESTING }\end{array}$ & & & & & \\
\hline $\begin{array}{l}\text { Perform error analyses of test methods in } \\
\text { IEEE Std. 1057. [STRS, OA-Sandial }\end{array}$ & & & & & \\
\hline $\begin{array}{l}\text { Propose and develop test methods for } \\
\text { IEEE TC-10 subcommittee on A/Ds. } \\
\text { [STRS] }\end{array}$ & & & & & \\
\hline $\begin{array}{l}\text { Conduct round-robin pulse measurement } \\
\text { intercomparisons (for ns and ps regimes). } \\
\text { [STRS] }\end{array}$ & & & & & \\
\hline $\begin{array}{l}\text { Develop standard test methods for } \\
\text { characterizing arbitrary waveform } \\
\text { generators. [STRS] }\end{array}$ & & & & & \\
\hline SAMPLING COMPARATOR SYSTEMS & & & & & \\
\hline $\begin{array}{l}\text { Develop low frequency (to } 1 \mathrm{MHz} \text { ) } \\
\pm 10-V \text { sampling probe for rms, } \\
\text { impedance and power applications. } \\
\text { [STRS, OA-AF] }\end{array}$ & & & & & \\
\hline $\begin{array}{l}\text { Develop new time base and control } \\
\text { instrumentation for use with sampling } \\
\text { probes. [STRS, OA-AF] }\end{array}$ & & & & & \\
\hline $\begin{array}{l}\text { Develop reference waveform system } \\
\text { suitable for verifying settling time } \\
\text { measurements in } 1-1000 \text { ns range. } \\
\text { [STRS] }\end{array}$ & & & & & \\
\hline PULSE MEASUREMENT SERVICES & & & & & \\
\hline $\begin{array}{l}\text { Implement and evaluate HP nose-to-nose } \\
\text { impulse response measurement approach. } \\
\text { ISTRS, OA-AF. }\end{array}$ & & & & & \\
\hline $\begin{array}{l}\text { Update pulse measurement software and } \\
\text { provide CALCOM documentation for } \\
\text { SP250 measurement services } \\
\text { (BW }=20 \mathrm{GHz} \text {. [STRS] }\end{array}$ & & & & & \\
\hline $\begin{array}{l}\text { Develop special test system for measuring } \\
\text { pulse parameters down to } t_{p}=5 \text { ps. } \\
\text { (BW }=50 \mathrm{GHz} \text { ). [STRS, OA-DOD] }\end{array}$ & & & & & \\
\hline
\end{tabular}




\section{Project: GENERATION AND MEASUREMENT OF PRECISE SIGNALS.}

\section{FY 92 Fund Sources: STRS; OA: Navy, AF, NASA; Calibration fees}

\section{Staff (5.0 staff-years)}

\begin{tabular}{|l||l|l|l|l|}
\hline Professional & N, M, OLDHAM* & B. A. Bell* & A. D. Koffman * & O. B. Laug* \\
\cline { 2 - 5 } & B. C. Waltrip & A. G. Perrey * & & \\
\hline Technician & P. S. Hetrick & R. H. Palm* & M. E. Parker & \\
\hline
\end{tabular}

name in capital letters $=$ project leader; $=$ person works on project part time

Objective: Develop techniques for generating and measuring voltage and current waveforms over the frequency range from dc to $100 \mathrm{MHz}$ having rms amplitude accuracies from $5 \mathrm{ppm}$ to 1 percent in order to meet future calibration requirements. Develop automatic inductive dividers and digital synthesis and sampling approaches to calibrate inductive divider ratios to $100 \mathrm{kHz}$ and to measure generalized impedances in the dc to $1 \mathrm{MHz}$ range.

Significance: Industrial, university, and government laboratories have calibration requirements for basic instrumentation standards that span wide frequency and voltage ranges to support calibrators, digital multimeters (DMMs), impedance (LCR) meters, and signal generators and analyzers. New waveform generation and measurement capability at NIST will support the basic quantities of ac voltage, current, resistance, and impedance, as well as special calibration services in the Electricity Division that have highaccuracy requirements (e.g., electrical power/energy calibration services that depend on \pm 5 -ppm ac voltage measurements.) NIST traceability for five electrical quantities is now provided via high-accuracy DMMs.

\section{FY 92 Accomplishments}

\section{AC Voltage/Current Measurements}

- Breadboarded an improved model of the digitally synthesized source (DSS-5) that is programmable in amplitude, frequency, and waveform via the IEEE 488 bus.

- Evaluated a high speed, 12-bit digital-to-analog converter for use with the DSS-5 to generate highfrequency signals above $100 \mathrm{kHz}$.

- Conducted a trial Measurement Assurance Program to support the Primary Navy Standards Lab for ac voltage from $100 \mathrm{mV}$ to $1 \mathrm{kV}, 10 \mathrm{~Hz}$ to $1 \mathrm{MHz}$ using a \pm 20 -ppm digital voltmeter.

- Assembled and tested a new current source for operation up to the 2-A rms level that will be incorporated into the DSS-5.

\section{Impedance Measurements}

- Developed a prototype impedance bridge used to compare an inductor to a known resistor (from $10 \mathrm{~Hz}$ to $10 \mathrm{kHz}$ ) with a midrange uncertainty smaller than $\pm 100 \mathrm{ppm}$.

- Developed a dual-channel source with improved resolution for use with the new impedance bridge.

- Completed successful inductive voltage divider tests for NASA, where a differential linearity of 1 part in $10^{8}$ was required around ratios of 0.5 .

- Completed the hardware for a second general purpose bridge for calibrating programmable inductive 
voltage dividers.

\section{FY 93 Plans}

- Complete the DSS-5 modification and deliver units to the Navy and Sandia National Laboratories.

- Complete and deliver to the Electrical Reference Standards Group, an automatic digital impedance bridge capable of calibrating standard inductors, based on known ac resistors, from $10 \mathrm{~Hz}$ to $20 \mathrm{kHz}$ ( $\pm 20 \mathrm{ppm}$ in the midrange).

- Complete and deliver to the Electrical Reference Standards Group, a bridge for cal ibrating programmable inductive voltage dividers from $10 \mathrm{~Hz}$ to $100 \mathrm{kHz}( \pm 0.1 \mathrm{ppm}$ in the midrange).

- Design a new dual-channel digitally synthesized source that may be readily duplicated or commercialized to replace the generators presently used in a number of calibration facilities in the Electricity Division.

- Construct a new calculable current source based on the DSS-5 and a 2-A current cell.

\section{Impact}

- An NIST license to Guildline Instrument has resulted in the commercialization of the NIST 20-A wideband transconductance amplifier and the previous model of the NIST digitally synthesized source.

\section{Recognition}

- Licenses for the DSS-5 and the NIST binary inductive voltage divider have been formally requested.

- U. S. patents were issued to Laug for the design of the NIST Transconductance Amplifier, and to Oldham for claims used in the design of the digitally synthesized source.

\section{Related Developments}

- High-accuracy DMMs are presently used to provide NIST traceability for five electrical quantities.

- There is growing interest in accreditation programs for industrial electrical measurements and calibrations. The NIST response will depend in part on the use of DMMs and impedance meters to transfer standards for demonstrating proficiency.

- The market for DMMs, calibrators, phase meters (for which there are existing NIST calibration services), and LCR meters (NIST calibration is being considered) is now estimated to be over $\$ 500$ million annually. 


\section{Project: GENERATION AND MEASUREMENT OF PRECISE SIGNALS}

\begin{tabular}{|c|c|c|c|c|c|}
\hline FISCAL YEARS & 93 & 94 & 95 & 96 & 97 \\
\hline $\begin{array}{l}\text { AC VOLTAGE/CURRENT } \\
\text { STANDARDS/SYSTEMS }\end{array}$ & & & & & \\
\hline $\begin{array}{l}\text { Complete DSS-5 and deliver units to } \\
\text { sponsors [OA-Sandia] }\end{array}$ & & & & & \\
\hline $\begin{array}{l}\text { Provide a CALCOM-type Tech Note for } \\
\text { routine calibrations of DMMs. [STRS] }\end{array}$ & & & & & \\
\hline $\begin{array}{l}\text { Establish a routine calibration service for } \\
\text { all DMM functions. [STRS] }\end{array}$ & & & & & \\
\hline $\begin{array}{l}\text { Develop a multifunction transportable } \\
\text { source for disseminating } 10 \text { or more } \\
\text { electrical quantities. [STRS, OA] }\end{array}$ & & & & & \\
\hline IMPEDANCE STANDARDS & & & & & \\
\hline $\begin{array}{l}\text { Complete an automatic Digital Impedance } \\
\text { Bridge for calibrating standard inductors. } \\
\text { [STRS, Cal surcharge, OA-AF] }\end{array}$ & & & & & \\
\hline $\begin{array}{l}\text { Complete an automatic bridge for } \\
\text { calibrating IVDs. [STRS, OA-AF, NASA] }\end{array}$ & & & & & \\
\hline $\begin{array}{l}\text { Extend the Digital Impedance Bridge to } \\
\text { calibrate capacitor losses out to } 20 \mathrm{kHz} \text {. } \\
\text { [STRS, OA-AF] }\end{array}$ & & & & & \\
\hline $\begin{array}{l}\text { Develop a new dual-channel digital source } \\
\text { for calibration facilities. [STRS, OA-AF] }\end{array}$ & & & & & \\
\hline $\begin{array}{l}\text { Develop a technique using a sampling } \\
\text { voltage tracker for measuring impedances } \\
\text { from } 100 \mathrm{~Hz} \text { to } 100 \mathrm{kHz} \text {. [STRS, OA-AF] }\end{array}$ & & & & & \\
\hline $\begin{array}{l}\text { Document the new special test for } \\
\text { inductors and capacitors in a NIST Tech } \\
\text { Note. [STRS] }\end{array}$ & & . & & & \\
\hline $\begin{array}{l}\text { Offer a special test for high accuracy LCR } \\
\text { meters. [STRS] }\end{array}$ & & & & & \\
\hline
\end{tabular}




\section{Project: PHASE ANGLE AND POWER/ENERGY STANDARDS \\ [See also Power/Energy and AC/DC High Voltage and High \\ Current Measurements, AEM Group]}

FY 92 Fund Sources: STRS; Calibrations

Staff (2.3 staff-years)

\begin{tabular}{|l||l|l|l|l|}
\hline Professional & N. M. OLDHAM* & T. L. Nelson* & B. C. Waltrip* & \\
\hline Technician & P. S. Hetrick * & R. H. Palm* & M. E. Parker * & \\
\hline
\end{tabular}

name in capital letters = project leader; $\quad=$ person works on project part time

Objective: Develop automatic phase and power/energy calibration systems capable of routine calibrations for phase from $2 \mathrm{~Hz}$ to $100 \mathrm{kHz}$ and for power from $50 \mathrm{~Hz}$ to $10 \mathrm{kHz}$, with Special Tests for phase up to $20 \mathrm{MHz}$ (accuracies of 5 to $5000 \mu \mathrm{rads}$ ) and for power from dc to $200 \mathrm{kHz}$ with uncertainties from $10 \mathrm{ppm}$ to 1 percent.

Significance: Utilities need high accuracy watt/watthour and var/varhour calibrations to equitably distribute the $\$ 170$ billion of electric energy generated annually. High accuracy power measurements for large electrical equipment are required to determine their efficiency during development and manufacture, and for quality control. Measurements have been complicated by new "alternate" energy generation and highly nonlinear loads, which produce nonsinusoidal waveforms with frequency components in excess of 100 $\mathbf{k H z}$. The power industry and its regulators legally require NIST traceability at the highest accuracy. They also need NIST services to resolve disputes that involve measurements.

\section{FY 92 Accomplishments}

Phase Measurements

- Extended the NIST phase measurement capability from $50 \mathrm{kHz}$ to $100 \mathrm{kHz}$ using a dual channel waveform sampler analyzer and a data analysis technique that was described in papers presented at the Conference on Precision Electromagnetic Measurements and at the annual meeting of the National Conference of Standards Laboratories.

- Performed additional measurements on the limitations imposed by phase meters used in interferometry; the results incorporated in a paper to be published in the transactions of the American Society for Precision Engineering.

- Developed a method for characterizing the phase linearity of a dual-channel synthesizer, out to $20 \mathrm{MHz}$, using a phase meter and a data analysis technique. The method was described in a paper that has been accepted for publication in the IEEE Transactions on Instrumentation and Measurements.

\section{Power/Energy Measurements}

- Extended the capability of a dual-channel, 16-bit sampling analyzer to measure power at zero power factor out to $100 \mathrm{kHz}( \pm 0.1 \%)$.

- Constructed and evaluated a prototype power-frequency sampling wattmeter (with uncertainties $<50 \mathrm{ppm}$ from $50 \mathrm{~Hz}$ to $1 \mathrm{kHz}$ ) and described this wattmeter in a paper presented at the 1992 International Measurement Techniques Conference. 


\section{FY 93 Plans}

- Develop software for calibrating high-speed phase meters using a time-interval analyzer and computer operating the VXIbus (IEEE P1155).

- Develop a transportable power frequency bridge to improve the accuracy and stability of power comparisons between the Electronic Instrumentation and Metrology and Applied Electrical Measurements Groups and for use in international comparisons.

- Complete the NIST Technical Note describing the power frequency sampling wattmeter.

- Design a high-frequency power bridge to provide active power measurement to $\pm 2 \%$ at $400 \mathrm{kHz}$.

\section{Recognition}

- NIST is now asked for calibration uncertainties below $\pm 50 \mathrm{ppm}$, although in response to industry need, routine calibration uncertainties from NIST for wattmeters and watthour meters have been reduced from $\pm 500 \mathrm{ppm}$ to $\pm 100 \mathrm{ppm}$ over the past 5 years.

- New wattmeters that operate up to $400 \mathrm{kHz}$ are now commercially available, and NIST has been asked to calibrate them.

\section{Related Developments}

- Switching-mode power supplies and load controllers constitute an increasing portion of the U.S. consumption of electrical energy. The new NIST audio frequency Power Bridge and sampling wattmeter developments will support the efficiency measurements that are needed for best utilizing this equipment.

- Every three years semiconductor storage capability increases by a factor of four, requiring advanced lithography tools. These include wafer steppers and scanners that are controlled by phase-measuring heterodyne interferometers. The precision of the next generation of steppers (a $\$ 1$ billion industry) will rely on high-speed phase angle measurements with uncertainties $<0.3$ degree at frequencies from 1 to $20 \mathrm{MHz}$. 


\section{Project: PHASE ANGLE AND POWER/ENERGY STANDARDS}

\begin{tabular}{|c|c|c|c|c|c|}
\hline FISCAL YEARS & 93 & 94 & 95 & 95 & 97 \\
\hline \multicolumn{6}{|l|}{ PHASE ANGLE STANDARDS } \\
\hline \multicolumn{6}{|l|}{$\begin{array}{l}\text { Extend present NIST } 50 \mathrm{kHz} \text { phase meter } \\
\text { calibration service to } 100 \mathrm{kHz} \text {. [STRS] }\end{array}$} \\
\hline \multicolumn{6}{|l|}{$\begin{array}{l}\text { Develop software for calibrating high } \\
\text { speed phase meters using a VXI system. } \\
\text { [STRS, OA-Army] }\end{array}$} \\
\hline \multicolumn{6}{|l|}{$\begin{array}{l}\text { Document NIST phase angle calibration } \\
\text { capabilities }(1 \mathrm{~Hz} \text { to } 20 \mathrm{MHz}) \text {. [STRS] }\end{array}$} \\
\hline \multicolumn{6}{|l|}{ POWER/ENERGY STANDARDS } \\
\hline \multicolumn{6}{|l|}{$\begin{array}{l}\text { Develop a } 10-p p m \text { transportable power } \\
\text { frequency bridge for use in international } \\
\text { comparisons. [STRS] }\end{array}$} \\
\hline \multicolumn{6}{|l|}{$\begin{array}{l}\text { Develop a wideband power measurement } \\
\text { method that operates out to } 400 \mathrm{kHz} \text { at a } \\
\text { basic accuracy of } 1-2 \% \text {. [STRS] }\end{array}$} \\
\hline $\begin{array}{l}\text { Update the documentation of the NIST } \\
\text { Power/Energy Special Tests (dc-400 kHz). } \\
\text { [STRS] }\end{array}$ & & & & & \\
\hline
\end{tabular}




\section{Project: OPTOELECTRONIC/ELECTROOPTIC TECHNOLOGY}

\section{FY 92 Fund Sources: STRS, OA: Air Force}

\section{Staff (1.5 staff-years)}

\begin{tabular}{|l||l|l|l|l|}
\hline Professional & N. G. PAULTER & W. L. Gans* & A. G. Perrey * & \\
\hline Technician & R. H. Palm & & & \\
\hline
\end{tabular}

name in capital letters $=$ project leader; $"=$ person works on project part time

Objective: Conduct research on, and develop: laser systems, optoelectronic (OE), and electrooptic (EO) techniques, devices, and apparatus that will be used for ultrafast signal sampling and pulse generation, contactless switching, and electric-field probing. Using OE and EO techniques and short- pulse laser systems, develop a fast-transient sampling system with an equivalent frequency bandwidth of $300 \mathrm{GHz}$ or greater. Investigate and develop OE devices for applications such as switches, couplers, dividers, etc. Investigate and develop EO devices and techniques to support the noninvasive measurement of electric-field strength in a variety of circuit configurations, particularly those used by both the electronics and the electricpower industries.

Significance: Very high-speed sampling and noninvasive measurement techniques required to measure ultrafast electrical signals often cannot be accomplished with conventional electronic instrumentation; the use of short-pulse lasers and OE/EO technology is being applied for this purpose. Industry needs NIST measurement developments and standards as a basis for this new technology, which is especially important to the advancement and development of state-of-the-art electronic devices (such as the high-electron mobility transistor, the heterojunction bipolar transistor, and similar quantum effect devices, and materials (semiconductor heterostructures, superlattices, multilayer dielectrics, etc.) presently being utilized by the microwave, telecommunications, computer, electronics, and test equipment industries. Similarly, applying this technology can result in accurate and noninvasive measurements of electric field strength in high-voltage devices and systems that in turn can el iminate the requirement for off-line system analysis, thereby reducing system development time, cost, and operating down-time.

\section{FY 92 Accomplishments}

- Configured laboratory for ANSI-defined class 4 laser system.

- Installed Nd:YAG laser system and associated diagnostic components.

- Designed, built, and tested an autocorrelator for measuring the pulsewidth of the YAG laser optical pulses. Found pulsewidth to be approximately $53 \mathrm{ps}$.

- Designed and fabricated high-speed photoconductive circuits. Performed preliminary tests on dynamic and steady state photoresponses.

- Investigated the feasibility of fabricating novel photoactivated, heterostructure-gated switches. Identified material system (employing fast photoresponse, low-temperature GaAs) that can be grown by the Semiconductor Electronics Division. Began design of prototype circuits and associated fabrication steps.

\section{FY 93 Plans}

- Identify and locate a reliable source of photoconductive devices and/or a fabrication facility and assess the quality of these devices. Develop in-house processing if a reliable source is not identified. 
* Complete assembly of the laser-based sampling system, including assembly of the requisite optical and electronic components and the installation of the pulse compressor/frequency doubler and its diagnostic instrumentation.

- Modify the YAG autocorrelator to measure abnormally wide pulses, such as those encountered when the YAG is improperly tuned.

- Examine electrooptic light modulation as a technique for rms voltage measurements.

Impact

- A major instrument manufacturer credits its collaborative project with NIST with enabling it to investigate future product concepts at an accelerated pace.

\section{Recognition}

- An official of the Naval Research Laboratory cited the work of NIST staff and his hope that "...NIST will continue its active role in the high-speed measurements field."

\section{Related Developments}

- Recent advances in Si/Si-Ge alloy heterostructure device technology produce devices capable of operating at frequencies in excess of $40 \mathrm{GHz}$. This development will bring low cost Si IC technology to the microwave and high-speed digital electronics communities.

- GaAs heterostructure devices are being developed for microwave and high-speed digital electronic applications that have bandwidths exceeding $200 \mathrm{GHz}$.

- High-speed planar circuits (MMIC, VHSIC, etc.) using multilayer dielectrics, advanced ceramics, etc., are being developed to support the operation of high-speed electronic devices.

- Packaging techniques are being developed to provide low-signal loss, fast signal-transit time, low crosscoupling, and high-density interconnects for circuit-to-circuit, chip-to-chip, and module-to-module interfacing for high-speed digital computers.

- Oscilloscopes with $50 \mathrm{GHz}$ bandwidth are produced by two U.S. manufacturers and NIST has been asked to calibrate their time-domain parameters. However, since NIST presently does not have the capability to provide such measurements to our industry, these are provided by the NPL in the U.K. 


\section{Project: OPTOELECTRONIC/ELECTROOPTIC TECHNOLOGY}

\begin{tabular}{|c|c|c|c|c|c|}
\hline FISCAL YEARS & 93 & 94 & 95 & 96 & 97 \\
\hline $\begin{array}{l}\text { Modify the YAG autocorrelator so that } \\
\text { wide pulses ( }>60 p \text { s FWHM) can be } \\
\text { measured. [STRS] }\end{array}$ & & & & & \\
\hline $\begin{array}{l}\text { Complete assembly of the laser-based } \\
\text { sampling system. [STRS, OA-AF] }\end{array}$ & & & & & \\
\hline $\begin{array}{l}\text { Perform oscilloscope transient response } \\
\text { calibration. [STRS, OA-AF] }\end{array}$ & & & & & \\
\hline $\begin{array}{l}\text { Optimize photoconductor performance: } \\
\text { linearity of photoresponse to applied } \\
\text { incident light intensity (I-V characteristics) } \\
\text { [STRS] }\end{array}$ & & & & & \\
\hline $\begin{array}{l}\text { Design and model an EO probing system } \\
\text { for use in coaxial environments. [STRS] }\end{array}$ & & & & & \\
\hline $\begin{array}{l}\text { Develop a high temporal resolution } \\
\text { ( }<1 \text { ps) sampling system with } 1 \% \\
\text { amplitude uncertainty. [STRS] }\end{array}$ & & & & & \\
\hline
\end{tabular}




\section{Project: AC-DC DIFFERENCE STANDARDS AND MEASUREMENT TECHNIQUES}

FY 92 Fund Sources: STRS; OA: DoD; Calibration Fees

Staff (2.6 staff-years)

\begin{tabular}{|l||l|l|l|l|}
\hline Professional & J. R. KINARD* & T. E. Lipe* & Huang De Xiang $\ddagger$ & \\
\hline Technician & C. B. Childers & & & \\
\hline
\end{tabular}

name in capital letters $=$ project leader; ${ }^{*}=$ person works on project part time

$\ddagger=$ industrial research associate (Ballantine Laboratory)

Objective: Establish and maintain NIST primary and working thermal converter standards of ac-de difference used for the measurement and calibration of ac voltage, current, power, and energy; provide calibration services for thermal current and voltage converters ranging from $2 \mathrm{~Hz}$ to $1 \mathrm{MHz}$ for voltage and $2 \mathrm{~Hz}$ to $100 \mathrm{kHz}$ for current, with uncertainties in the range of 0.8 to $200 \mathrm{ppm}$ depending on device, frequency, and magnitude.

Significance: The calibration services supported by this project provide the nation with the most viable and accurate link between measurements of rms ac voltage, current, and energy, and dc standards by which the electrical units are maintained.

\section{FY 92 Accomplishments}

- Finished designs and photomasks for eight newly conceived devices, integrated thin-film micropotentiometers. Fabricated, mounted, and tested devices; applied resulting data to redesign incorporating the placement of output resistors and heater-to-resistor junctions over the silicon to provide a heat sink; additionally designed three new single-voltage-range micropots with trifilar heaters and one new multirange device.

- Completed production and testing of new low-capacitance, thin-film multijunction thermal converters (MJTCs). Found that the performance of operating devices compares favorably with that of very good conventional standards and is better over certain frequency ranges. Measured the breakdown voltage between the heater and thermocouples to be greater than $200 \mathrm{~V}$ (in turn implying that waveforms with crest factors as high as 10 can be applied to the thin-film MJTCs and measured without damage). Measured MJTC output as a function of pressure down to about $0.1 \mathrm{~Pa}$ (about 1 millitorr) and found it to be nine times higher at low pressure than at atmosphere. Such high thermal efficiency means that voltages as low as $1 \mathrm{mV}$ can be measured and that very wide dynamic range is possible.

- Determined to contract for a limited production run of MJTCs from a commercial fabrication facility with; identified two candidates.

- Continued documentation work on a patent application regarding MJTC composite membrane and integrated micropot structures.

- Carried out a complete recharacterization of the NIST working standard thermal voltage converters using a newly devised scheme for check standard intercomparisons. Began a comprehensive program of these check standard measurements as part of the quality control effort for the ac-dc laboratory.

- Presented two papers at the 1992 Conference on Precision Electromagnetic Measurements, reporting results of (1) an international intercomparison of thermal voltage converters from $100 \mathrm{kHz}$ to $1 \mathrm{MHz}$ 
among NIST; NPL, Great Britain; PTB, Germany; and VSL, the Netherlands, and (2) an international intercomparison of thermal voltage converters from $1 \mathrm{MHz}$ to $100 \mathrm{MHz}$ among NIST; NIM, China; PTB; Shaoxing Industry Research Institute, China; and VSL.

- Began a program intended to determine the practicability of using the Pockel electrooptic effect to make rms measurements of low-level ac voltages (the polarization of incoming laser light in a crystal is varied by an electric field applied to the crystal; the effect is used to produce and measure very short pulses).

FY 93 Plans

- Order and evaluate equipment for evaluation of use of film multijunction thermal converters at cryogenic temperatures.

- Continue improvement of film multijunction thermal converters including establishment of an extra-NIST source of production.

- Draft and submit for review documentation for extended-current calibration service.

- Complete and report results of study of converters at lower frequencies to reduce measurement uncertainties.

- Evaluate silicon-based "foundry-micromachined" converters in support of the Semiconductor Electronics Division.

\section{Impact}

- Eleven hundred fifteen points were calibrated on 32 standards for an income of $\$ 244.3 \mathrm{k}$ during FY92.

\section{Related Developments}

- Three new instruments have been recently introduced that will increase the demand for improved ac-dc difference calibrations. These are intended to support the capabilities of commercial advanced highaccuracy meters having accuracies approaching those of standards a few years ago. 
Project: AC-DC DIFFERENCE STANDARDS AND MEASUREMENT. TECHNIQUES

\begin{tabular}{|c|c|c|c|c|c|}
\hline FISCAL YEARS & 93 & 94 & 95 & 96 & 97 \\
\hline $\begin{array}{l}\text { Produce draft CalCom documentation for } \\
\text { extended current calibrations. [STRS] }\end{array}$ & & & & & \\
\hline $\begin{array}{l}\text { Study converters at lower frequencies to } \\
\text { reduce uncertainties. [STRS] }\end{array}$ & & & & & \\
\hline $\begin{array}{l}\text { Evaluate silicon-based "foundry" RMS } \\
\text { converters. [STRS] }\end{array}$ & & & & & \\
\hline $\begin{array}{l}\text { Acquire and evaluate equipment for } \\
\text { investigating performance of MJTCs at } \\
\text { cryogenic temperatures. [STRS] }\end{array}$ & & & & & \\
\hline $\begin{array}{l}\text { Automate thermal current converter } \\
\text { calibrations. [STRS] }\end{array}$ & & & & & \\
\hline $\begin{array}{l}\text { Investigate exotic thermocouple materials } \\
\text { for film multijunction converters. [OA- } \\
\text { DOD] }\end{array}$ & & & & & \\
\hline $\begin{array}{l}\text { Develop electro-optic based techniques } \\
\text { for ac voltage and ac-dc difference } \\
\text { standards. [STRS] }\end{array}$ & & & & & \\
\hline $\begin{array}{l}\text { Develop a very-low noise comparator } \\
\text { system (SQUID-based) to investigate sub- } \\
\text { ppm phenomena. [STRS] }\end{array}$ & & & & & \\
\hline $\begin{array}{l}\text { Explore the use of superconducting } \\
\text { temperature sensors and detectors for } \\
\text { new primary standards. [STRS] }\end{array}$ & & & & & \\
\hline $\begin{array}{l}\text { Investigate new film converter structures. } \\
\text { [STRS, OA-DOD, CRADA] }\end{array}$ & & & & & $=$ \\
\hline
\end{tabular}




\section{Project: CALIBRATION SERVICES FOR BASIC ELECTRICAL QUANTITIES}

\section{FY 92 Fund Sources: Calibration fees}

\section{Staff (10.1 staff-years)}

\begin{tabular}{|l||l|l|l|l|}
\hline Professional & N. B. BELECKI* & P. A. Boynton* & Y. M. Chang* & R. F. Dziuba* \\
\cline { 2 - 6 } & J. R. Hastings* & D. G. Jarrett* & J. R. Kinard* & T. E. Lipe* \\
\hline & M. R. McCaleb* & J. E. Sims* & R. L. Steiner * & \\
\hline \multirow{2}{*}{ Technician } & C. B. Childers* & C. R. Levy* & T. P. Moore* & J. D. Neal* \\
\cline { 2 - 5 } & J. A. Pitt* & S. B. Tillett* & & \\
\hline Administrative & S. L. Fromm* & D. D. Prather & & \\
\hline
\end{tabular}

name in capital letters $=$ project leader; $=$ person works on project part time

Objective: To maintain national primary and working standards for the basic electrical units and quantities of capacitance, inductance, resistance, voltage, ac-dc difference, and ac ratio and use them to provide calibration and Measurement Assurance Program (MAP) services.

Significance: The provided measurement services are fundamental to the electrical/electronic area and they form the basis of all electrical measurements made in the United States, i.e., the National Electrical Measurement System. These services directly, and indirectly through more derived electrical units, affect the operation of all standards laboratories (over 750). The services are used directly by the metrology community to support engineering, qual ity-control, and production activities throughout American industry - especially in the instrumentation, aerospace, and electronics industries - and science in academia, government, and industry.

\section{FY 92 Accomplishments}

During the past year a total of 2359 calibrations were performed on 859 standards as detailed in the table below. The estimated income was $\$ 1,043,530$.

Resistance

No. of Stds.

No. of Tests

Income

Thomas

$10 \mathrm{~K}$ Specials

$0.0001-1 \mathrm{M} \Omega$

High-Megohm

Shunts

Total $(0.0001-1 \mathrm{~m} \Omega)$

Total Resistance
84

65

221

82

12

370

464
84

65

221

92

60

370

522
$\$ 75,395$

75,171

119,266

71,816

26,826

269.832

$\$ 368,474$

\section{Instruments}

Inductive Voltage Dividers 31

$\$ 46,111$

Impedance

Capacitors

Inductors 
No. of Stds.

Voltage

Saturated Cells

Unsaturated Cells

Zeners

Special handling

Total Voltage

\section{8}

12

47

$\underline{22}$

129
No. of Tests

188

12

161

22

383

Income

$$
\begin{array}{r}
\$ 79,785 \\
3,480 \\
57,420 \\
1 \frac{1,661}{\$ 142,346}
\end{array}
$$

AC-DC

Thermal Transfer Stds

32

1115

$\$ 244,286$

MAPs

Resistance

Voltage

10

9

Total MAP's

19

10

$\$ 14,547$

9

19

27.042

$\$ 41,589$

2359

$\$ 1,043,530$

- Completed a draft document laying out requirements for the competence of calibration laboratories specific to dc voltage. Conducted a session to review this document in a NIST Technical Services workshop on the general process of accrediting standards laboratories, (approximately ten representatives from industry and the National Conference of Standards Laboratories).

- Conducted an Electrical Measurement Assurance Program workshop for forty industrial and government personnel.

\section{FY 93 Plans}

- Continue to maintain national electrical standards and measurement services at the highest level of quality and effectiveness.

- Lay the groundwork for support of a national accreditation service covering dc and low-frequency measurements for calibration laboratories developing technical criteria for the quality of dc and lowfrequency calibrations.

- Complete development of database to track shipping and receiving.

\section{Impact}

- The activity supports the calibration and maintenance of over 5 million items of test equipment used throughout U.S. industry for quality assurance, process control, and product development purposes. Results of these calibrations are used to ensure compatibility of electronic components and sub-assemblies purchased from various vendors to produce finished electronic systems and other products.

\section{Related Developments}

- The National Conference of Standards Laboratories Committee on Calibration Systems Requirements is spearheading an effort to obtain agreement among Federal agencies on acceptable criteria for calibration laboratory operations. This step may lead to a system of laboratory accreditation which will result in major changes for calibration services and in the direction of future metrology staff activities at NIST. 


\section{Project: RESISTANCE STANDARDS AND MEASUREMENT METHODS}

\section{FY 92 Fund Sources: STRS; OA: DoD; Calibration Fees; Calibration Project}

\section{Staff (3.8 staff-years)}

\begin{tabular}{|l||l|l|l|l|}
\hline Professional & P. A. Boynton * & R. F. DZIUBA & R. E. Elmquist & D. G. Jarrett \\
\hline Technician & T. P. Moore & J. D. Neal* & & \\
\hline
\end{tabular}

name in capital letters $=$ project leader; $\$=$ person works on project part time

Objective: To maintain the U.S. legal ohm, support the Division's resistance calibration services, and develop new resistance standards and measurement techniques. To provide necessary links between the ohm and experiments to realize the SI ohm via the calculable capacitor, measure the SI ampere, and develop the quantum Hall effect as the international standard for resistance.

Significance: New digital multimeters incorporating improved measurement techniques and improved references are increasingly being used throughout industry for resistance measurements in production facilities and testing laboratories. This in turn generates a need for improved resistance standards to support these meters, especially in the resistance range above $10 \mathrm{k} \Omega$. In addition to supporting our calibration services, this project will develop the next generation of standards needed to calibrate future instrumentation. NIST now maintains the ohm by means of the quantum Hall effect. This new standard provides a powerful tool for the development and evaluation of new resistance materials and standards needed to meet advanced industry needs for NIST measurement support.

\section{FY 92 Accomplishments}

- Completed two comparisons of the national working standards of resistance in terms of the quantum Hall effect. Carried out analysis of all intercomparison data since 1983 between quantum Hall measurements and traditional ohm maintenance measurements that showed a difference of 0.02 parts per million (regarded as evidence of reasonable agreement given the variation in measurement conditions).

- Concluded tests of the 100:1 ratios of two cryogenic current comparators by using them to measure Hamon devices; data indicate that the relative ratio errors were $0 \pm 0.01$ parts per million.

- Made the first measurements of three quantum Hall effect specimen devices using the new system installed in the resistance calibration laboratory.

- Completed and tested the new inductive voltage divider bridge for ac resistors. Calibrated the bridge's binary inductive voltage dividers giving corrections less than 0.05 parts per million $(100 \mathrm{~Hz})$ and 0.12 parts per million $(1 \mathrm{kHz})$.

- Completed and tested the new system for calibrating high-current resistance standards (shunts); this system, based on a current-comparator bridge, affords greater sensitivity and precision and increases the NIST current capability from 1 to $2 \mathrm{kA}$.

- Presented three papers at the 1992 Conference on Precision Electromagnetic Measurements: "Automated AC Bridge for the Measurement of Resistors Over the Frequency Range $10 \mathrm{~Hz}$ to $10 \mathrm{kHz}$;" "Detection of Leakage Errors in Cryogenic Current Comparator Bridges;" and "Improvements in Resistance Scaling at NIST Using Cryogenic Current Comparators." 
- Began investigation into the use of Pd-Pt-Au metallic suspensions (pastes) for constructing standards quality resistors for use at liquid-helium temperatures; fabricated experimental resistors on glass substrates by firing the paste at temperatures from $600^{\circ}$ to $1000^{\circ}$.

- Discovered a pressure coefficient of resistance in the sealed 6452.3- $\Omega$ resistors used for quantum Hall measurements. These are similar in construction to $10-\mathrm{k} \Omega$ standards widely used throughout industry. Tests of three such resistors showed that changes of as large as $0.1 \mathrm{ppm}$ might be experienced from an altitude change of $1610 \mathrm{~m}$ ( 1 mile). Such a change is significant since the best laboratories (such as that at Sandia Laboratory, for example) are striving to maintain standards at the $0.2-0.3 \mathrm{ppm}$ level of uncertainty.

- Completed and began tests on Al-Mg alloy cryogenic resistor having small ac-dc differences; tests results indicated significantly reduced inductive effects in the resistor at cryogenic temperatures over the range from $50 \mathrm{~Hz}$ to $100 \mathrm{kHz}$.

\section{FY 93 Plans}

- Maintain the U.S. ohm representation at the $6453.2 \Omega$ level using the new quantum Hall standard.

- Institute a calibration service for resistances greater than 1 teraohm.

- Complete comparator for ac resistances based on an inductive voltage divider in the low-audio-frequency range.

- Design, fabricate, and complete testing of a prototype ac-dc resistor with superconducting shielding.

- Complete implementation of the current comparator bridge system for calibration of 2-kA shunts.

- Finish development of a dc SQUID (superconducting quantum-interference device)/cryogenic current comparator system for scaling between $6453.2 \Omega$ and $100 \Omega$.

\section{Impact}

- Ten resistance MAPs and 522 calibrations were performed on 464 resistance standards for an income of $\$ 383.0 \mathrm{~K}$ in FY 92.

\section{Related Developments}

- New voltmeters and calibrators are now on the market with resistance specifications in the range from 8 to $16 \mathrm{ppm}$. The proliferation of these items will increase the demand for both better standards and improved calibration services.

- Work on the development of film multijunction converters has possible impact on the development of ac resistance standards. 


\section{Project: RESISTANCE STANDARDS AND MEASUREMENT METHODS}

\begin{tabular}{|c|c|c|c|c|c|}
\hline FISCAL YEARS & 93 & 94 & 96 & 96 & 97 \\
\hline $\begin{array}{l}\text { Develop dc SQUID cryogenic current } \\
\text { comparator system for } 6453.2 \Omega / 100 \Omega \\
\text { scaling. [STRS] }\end{array}$ & & & & & \\
\hline $\begin{array}{l}\text { Implement current-comparator bridge } \\
\text { system for 2-kA shunts. [STRS] }\end{array}$ & & & & & \\
\hline $\begin{array}{l}\text { Maintain the U. S. ohm at the } 6453.2-\Omega \\
\text { level. [STRS] }\end{array}$ & & & & & \\
\hline $\begin{array}{l}\text { Institute a calibration service for } \\
\text { resistances }>1 T \Omega \text {. [STRS] }\end{array}$ & & & & & \\
\hline $\begin{array}{l}\text { Complete automation of } 10 \mathrm{k} \Omega \text { bridge. } \\
\text { [STRS] }\end{array}$ & & & & & \\
\hline $\begin{array}{l}\text { Develop ac resistance measurement } \\
\text { capability. [STRS, OA-DOD] }\end{array}$ & & & & & \\
\hline $\begin{array}{l}\text { Develop automated guarded } \\
\text { bridge/scanner for high-resistance } \\
\text { measurements. [STRS] }\end{array}$ & & & & & \\
\hline $\begin{array}{l}\text { Develop improved resistance standards. } \\
\text { [STRS, OA-DOD] }\end{array}$ & & & & & \\
\hline $\begin{array}{l}\text { Evaluate commercial instruments for } \\
\text { measuring resistance in order to support } \\
\text { laboratory accreditation. [STRS] }\end{array}$ & & & & & \\
\hline $\begin{array}{l}\text { Develop system for calibrating ac shunts. } \\
\text { [STRS] }\end{array}$ & & & & & \\
\hline $\begin{array}{l}\text { Develop ac cryogenic current comparator } \\
\text { resistance bridge. [STRS] }\end{array}$ & & & & & \\
\hline $\begin{array}{l}\text { Develop automated cryogenic current } \\
\text { comparator bridge using high-TC } \\
\text { superconductors. [STRS] }\end{array}$ & & & & & \\
\hline
\end{tabular}




\section{Project: IMPEDANCE STANDARDS AND MEASUREMENT METHODS}

FY 92 Fund Sources: STRS; Calibration Fees

Staff (2.0 staff-years)

\begin{tabular}{|l||l|l|l|l|}
\hline Professional & Y. M. CHANG & J. R. Hastings* & & \\
\hline Technician & C. R. Levy* & S. B. Tillett* & & \\
\hline
\end{tabular}

name in capital letters $=$ project leader; $"=$ person works on project part time

Objective: To develop new standards, instrumentation, and measurement techniques in support of the Division's capacitance, inductance, and decade ratio transformer calibration services, to expand the parameter space of those services to include frequencies up to $100 \mathrm{kHz}$, and to establish the capability for routine, highaccuracy measurements of dissipation factor for standard capacitors.

Significance: The national calibration services supported by this project cover capacitance and inductance standards in the audio-frequency range. Approximately 360 such standards are typically calibrated in a year to enable measurements to be made consistently in terms of the U.S. farad and henry. Capacitance standards are used widely across industry for calibration of instruments for quality-control and component testing and to support the development of improved components, integrated circuits, and high-speed measuring circuits. Inductance standards are used to support the manufacturing of magnetic heads for recording purposes. Dissipation factor measurements are vital to the power industry to measure and reduce transmission losses and to the electronics industry for the development and testing of storage capacitors used in sample/hold circuits.

\section{FY 92 Accomplishments}

- Completed an intercomparison of inductance standards with the National Research Council of Canada (NRC). Found differences between NRC and NIST measurements at a frequency of $1 \mathrm{kHz}$ to be as high as $75 \mathrm{ppm}$. (Resolution of the differences has been delayed by the retirement of the NRC metrologist involved).

- Completed a prototype capacitance Measurement Assurance Program (MAP) transfer in the Los Angeles area involving five companies; for $1000 \mathrm{pF}$-standards, the measured values of $F_{\text {lab }}-F_{\text {NIST }}$ were less than $2 \mathrm{ppm}$ with an uncertainty of $2 \mathrm{ppm}$; and at $100 \mathrm{pF}$ they were less than $10 \mathrm{ppm}$, with an uncertainty of $2.5 \mathrm{ppm}$.

- Announced a pilot MAP transfer service at the 1992 national meeting of the National Conference of Standards Laboratories.

- Put into operation a refurbished oil bath used to house fused-silica local references in the impedance calibration laboratory to eliminate dependence on the availability of a transfer standard for the calibration of commercial fused-silica standards and to improve the precision of calibrations. Developed a measurement procedure to monitor the behavior of these fused silica capacitors in the oil bath.

- Began an investigation into the use of a precision impedance meter as a comparator to replace the Western Electric Type 12 bridge, used since the early 1950s for the calibration of two-terminal capacitance standards. Obtained two commercial capacitance standards to complete the NIST secondary reference set of standards for these measurements. 


\section{FY 93 Plans}

- Implement a procedure for accruing history and using it as a quality tool for capacitance calibrations.

- Determine differences and ertors associated with two-and three-terminal measurements made with the Western Electric Type 12 bridge and with the high-accuracy digital bridges and meters used for impedance comparisons.

- Evaluate and document performance of an automated inductive voltage divider calibration system to be supplied by the Electronic Instrumentation and Metrology Group.

- Assess the uncertainties associated with the realization of the henry with the Maxwell-Wien bridge.

\section{Impact}

- Visits to two private-sector organizations reinforced the need for NIST to re-establish capacitance MAP services and to improve the measurement of impedance standards in the range from $10 \mathrm{kHz}$ to $10 \mathrm{MHz}$. One of the companies is using 15 year-old data as a basis for their capacitance measurements for fear of moving their standards. Both companies are supporting high-frequency impedance bridges by extrapolating from low-frequency standards and spot checks via calibrations from Electromagnetic Fields Division. This process is inadequate to support the specifications of newer meters. This is expressed in the DoD-Calibration Coordination Group "Brown Book" as a proposal for future funding and in the National Conference of Standards Laboratories National Measurement Requirements Committee reports on studies of metrology needs.

- Income from impedance calibrations was $\$ 200.7 \mathrm{k}$ in FY92; a total of 433 calibrations were performed on 278 standards.

\section{Related Developments}

- The electronic instrumentation industry is developing new generations of impedance meters having specifications that challenge the capabilities of in-house metrology support and in turn of services available from NIST. Both the National Conference of Standards Laboratories and the Department of Defense Calibration Coordination Group have identified needs for NIST support to meet these needs, including advertised capacitance MAP service and improved impedance services in the range $10 \mathrm{kHz}$ to $10 \mathrm{MHz}$. 


\section{Project: IMPEDANCE STANDARDS AND MEASUREMENT METHODS}

\begin{tabular}{|c|c|c|c|c|c|}
\hline FISCAL YEARS & 93 & 94 & 95 & 96 & 97 \\
\hline $\begin{array}{l}\text { Implement a procedure for accruing } \\
\text { history on all capacitance standards. } \\
\text { [STRS] }\end{array}$ & & & & & \\
\hline $\begin{array}{l}\text { Determine differences and errors of } 2 \text { - } \\
\text { and } 3 \text {-terminal measurements of the } \\
\text { Type } 12 \text { bridge and digital impedance } \\
\text { meter. [STRS] }\end{array}$ & & & & & \\
\hline $\begin{array}{l}\text { Evaluate the automated bridge/test set } \\
\text { from } 811.02 \text { for calibrating programmable } \\
\text { IVDs between } 20 \text { and } 20 \mathrm{kHz} \text {. [STRS] }\end{array}$ & & & & & \\
\hline $\begin{array}{l}\text { Complete draft CalCom document for } \\
\text { inductance calibrations. [STRS] }\end{array}$ & & & & & \\
\hline $\begin{array}{l}\text { Evaluate the automated Digital Impedance } \\
\text { Bridge (DIB) from } 811.02 \text { for inductance } \\
\text { calibrations. [STRS] }\end{array}$ & & & & & \\
\hline $\begin{array}{l}\text { Complete documentation for IVD and } \\
\text { capacitance calibrations. [STRS] }\end{array}$ & & & & & \\
\hline $\begin{array}{l}\text { Evaluate use of a modified DIB for } \\
\text { capacitive loss measurements. [STRS] }\end{array}$ & & & & & \\
\hline $\begin{array}{l}\text { Develop dissipation-factor calibration } \\
\text { capability based on the DIB. [STRS] }\end{array}$ & & & & & \\
\hline $\begin{array}{l}\text { Evaluate voltage tracker system for high- } \\
\text { frequency impedance measurements ( } 20 \text { - } \\
100 \mathrm{kHZ} \text { ). [STRS] }\end{array}$ & & & & & \\
\hline $\begin{array}{l}\text { Extend frequency range of NIST } \\
\text { capacitance calibrations to } 100 \mathrm{kHz} \text {. } \\
\text { [STRS] }\end{array}$ & & & & & \\
\hline $\begin{array}{l}\text { Develop apparatus and procedures for } \\
\text { calibration of high-accuracy LCR meters. } \\
\text { [STRS] }\end{array}$ & & & & & \\
\hline
\end{tabular}

NOTE: Fundamental development work in impedance measurements is to be found under the projects

"Generation and Measurement of Precise Signals" (81.02) and "SI Farad and Ohm and the Quantum Hall Effect (811.04). This is the final application of that work to the improvement of NIST calibration services. 


\title{
Project: DC VOLTAGE STANDARDS AND MEASUREMENT METHODS
}

\author{
FY 92 Fund Sources: STRS; OA; DoD; Calibration fees
}

Staff (5.2 staff-years)

\begin{tabular}{|l||l|l|l|l|}
\hline \multirow{2}{*}{ Professional } & A. F. CLARK & N. B. Belecki* & T. Early & M. R. McCaleb* \\
\cline { 2 - 5 } & J. E. Sims & R. L. Steiner & & \\
\hline
\end{tabular}

name in capital letters $=$ project leader; $"=$ person works on project part time

Objective: Maintain the U.S. legal volt; support the Division's voltage calibration services; and develop new voltage and scaling standards, measurement techniques, and means of disseminating the volt. Specifically: Develop a portable Josephson array system to ensure uniformity at the highest accuracy levels of Josephson array voltage standards systems; exploit the attributes of the Josephson array for other critical measurements; improve the quality and efficiency of the dc voltage calibration services.

Significance: The services supported by this project provide the basis for accuracy and compatibility for all voltage measurements made throughout U.S. industry, technology, and science. The ac NIST Josephson junction array has not only provided a superior means of maintaining the volt, but an ideal tool for the development of new standards and a basis for new, automated measurement and scaling systems, as well. In addition, the availability of Zener diodes of highly stable and low noise outputs has promoted the development of totally solid-state voltage standards with performance approaching that of saturated standard cells, the traditional voltage standard. This work links these two developments in order to improve the Division's MAP (measurement assurance program) and calibration services.

\section{FY 92 Accomplishments}

- Compared the U.S. National Volt as realized by the 1 volt Josephson array directly with a similar system from the International Bureau of Weights and Measures (BIPM) and showed their equivalence to be better than one part in $10^{10}$.

- Carried out a transfer using a solid-state transport standard with the Navy Primary Standards Lab-East to foliow up on the array-to-array intercomparison done last fall. This resulted in the identification of noise sources which were affecting their measurements.

- Completed tests of the switching system used for standard cell calibrations in the Volt Facility. Measured continuity, contact resistances, leakage resistances, and thermal emf's for all 344 circuits; documented results and techniques used.

- Measured the properties of Josephson junctions made from high-temperature superconductors in order to evaluate their characteristics for a precision determination of the voltage step size. Observed good quality characteristics and appropriate dependance on microwave power.

- Made and studied the first observation of "half-integral" voltage step: in Josephson junctions fabricated from the new high-temperature superconductors. Found steps to occ.: at exactly one-half the expected voltage value for those normally induced by microwaves and used for voltage standards in conventional superconducting materials. Fabricated grain boundary junctions in 20- to 50- micrometer widths from YBCO; determined the microwave power and magnetic-field dependence of the step widths.

- Developed a procedure using $1-m V$ incremental steps generated by a Josephson-junction array standard to investigate the linearity of high-precision digital voltmeters. Applied procedure to specimen 
commercial voltmeter and discovered nonlinear "jump" in its response in one voltage range.

- Provided continuing consultations to the Singapore Institute of Standards and Industrial Research on the establishment of an array-based voltage calibration network for southeast Asia.

\section{FY 93 Plans}

- Determine voltage step characteristics of high-temperature-superconductor Josephson junctions.

- Extend the capacity of the system for the calibration of solid-state standards.

- Complete documentation of the data analysis software used in support of the voltage calibration services.

- Establish criteria for using high-accuracy digital voltmeters for ratio calibrations.

- Develop model for half-integral voltage steps and compare model predictions with empirical data.

\section{Impact}

- A total of 361 voltage standards were calibrated for an income of $\$ 169.3 \mathrm{k}$ in FY 92.

- A major instrument manufacturer credits NIST design and performance criteria in the development of a solid-state voltage reference now in the market.

\section{Related Developments}

- Digital voltmeters and calibrators currently on the market have claimed accuracies from \pm 2 to $\pm 10 \mathrm{ppm}$ depending upon range and length of calibration interval, and a precision nearing $0.05 \mathrm{ppm}$. 


\section{Project: DC VOLTAGE STANDARDS AND MEASUREMENT METHODS}

\begin{tabular}{|c|c|c|c|c|c|}
\hline FISCAL YEARS & 93 & 94 & 95 & 96 & 97 \\
\hline $\begin{array}{l}\text { Establish criteria for using high-accuracy } \\
\text { DVMs for ratio calibrations. [STRS] }\end{array}$ & & & & & \\
\hline $\begin{array}{l}\text { Plar expansion of dc voltage calibration } \\
\text { services beyond } 10 \mathrm{~V} \text {. [STRS] }\end{array}$ & & & & & \\
\hline $\begin{array}{l}\text { Determine voltage-step characteristics of } \\
\text { high TC Josephson junctions. [OA-DOD] }\end{array}$ & & & & & \\
\hline $\begin{array}{l}\text { Extend the capacity of the system for the } \\
\text { calibration of solid-state standards. } \\
\text { [STRS] }\end{array}$ & & & & & \\
\hline $\begin{array}{l}\text { Install and test } 10-\mathrm{V} \text { array system to } \\
\text { support all dc voltage calibrations. [STRS] }\end{array}$ & & & & & \\
\hline $\begin{array}{l}\text { Investigate noise and stability of zener } \\
\text { references to determine reliability limits } \\
\text { for accreditation. [STRS] }\end{array}$ & & & & & \\
\hline $\begin{array}{l}\text { Improve and expand zener calibration } \\
\text { system and begin phase-out of standard } \\
\text { cell calibrations. [STRS] }\end{array}$ & & & & & \\
\hline $\begin{array}{l}\text { Study array physics, frequency } \\
\text { dependance, and potential use as an ac } \\
\text { voltage standard. [STRS] }\end{array}$ & & & & & \\
\hline $\begin{array}{l}\text { Investigate the underlying uncertainty } \\
\text { structure ultimately limiting the } \\
\text { performance of voltage references. } \\
\text { [STRS] }\end{array}$ & & & & & \\
\hline
\end{tabular}




\section{Project: SI FARAD AND OHM AND THE QUANTUM HALL EFFECT}

FY 92 Fund Sources: STRS; OA: DoD, CCG

Staff (6.5 staff-years)

\begin{tabular}{|l||l|l|l|l|}
\hline \multirow{2}{*}{ Professional } & M. E. CAGE & A. F. Clark* & R. F. Dziuba* & K. C. Lee \\
\cline { 2 - 5 } & E. Palm & J. Q. Shields & C. T. Van Degrift & \\
\hline Technician & L. H. Lee & & & \\
\hline
\end{tabular}

name in capital letters = project leader; " = person works on project part time

Objective: Maintain the U.S. legal farad; realize the SI farad and ohm and support the Division's impedance and resistance calibration services; investigate the physics of two-dimensional electron gases, measure the ratio $\mathrm{h} / \mathrm{e}^{2}$, and apply the resulting knowledge to the development. of a system for the maintenance of the U.S. legal ohm via the quantum Hall effect; fabricate developmental quantum Hall devices and investigate the effects of heterostructures and alloy contacts on quantum Hall resistance values; and investigate the frequency dependence of standard capacitance measurement systems.

Significance: The research work being done in this project is the key to tying the U.S. legal system of units to the SI system of units. To provide the nation with the world's best basis for electrical measurements, NIST depends on this project to conduct measurements of the SI ohm and farad that have smaller uncertainties than any others, recognized internationally. The activities of this project underlie the future development of not only the electrical measurement services provided to industry by NIST but also commercial high-precision instrumentation needed by industry to support advances in electronics. NIST's maintenance of the ohm by the quantum Hall effect - a resistance standard dependent on only the values of fundamental constants of nature - provides a basis for NIST and industry to explore and implement new measurement schemes. Methods developed by NIST for scaling of resistance and impdeance measurements at the highest levels of accuracy in a manner that preserves that level will provide needed capbabilities for extending ranges of parameters in industry and other government laboratories.

\section{FY 92 Accomplishments}

- Maintained the ohm via the quantum Hall effect; carried out incremental improvements for the research quantum Hall system.

- Measured and compared results from specimen devices of gallium arsenide and silicon (MOSFET). Found values of resistance to be the same with a precision of 4 parts in $10^{10}$.

- Developed a new technique for making ultra-low-resistance ohmic contacts to GaAs/AlGaAs heterostructures used to make the quantum Hall resistance devices, providing contacts needed for standards-quality devices.

- Analyzed additional QHE breakdown data and showed that the voltage quantization is a function of magnetic field, implying that the fraction of electrons making the transition between Landau levels is quite large, as much as 40 percent. Confirmed earlier conclusions about the quantized nature of the breakdown as a function of magnetic field. Presented colloquium at Nottingham University, England.

- Continued fabrication and testing of fused-silica reference capacitors. Completed new capacitor bank and oil bath capacitor calibrations. 
- Completed two determinations of the SI farad with the calculable capacitor with the additional goal of determining the error introduced by the piezoelectric control of the movable element. Conducted series of calibrations for measurements linking the ohm and the capacitor banks.

\section{FY 93 Plans}

- Maintain the NIST ohm with the quantum Hall effect.

- Construct a new impedance bridge for measuring the dissipation factor and broadening the frequency range of capacitance measurements.

- Complete a definition of the SI ohm from the calculable capacitor.

- Fabricate GaAs devices having constrictions in the two-dimensional electron gas to study the physics of the breakdown phenomena in the quantum Hall effect.

- Investigate the effect of impurities in the edge of specimen devices on precision Hall measurements.

\section{Impact}

- NIST made contributions essential to the 1990 International Adjustment of the Electrical Units through four key experiments linking the SI definitions of the electrical units to NIST national standards at unprecedented levels of accuracy. The results were the determining factor for the value of the von Klitzing constant, permitting a new means of maintaining the ohm using the quantum Hall effect, and a major factor in the determination of the new value of the Josephson constant, the basis for a new magnitude of the volt. The existence of consistent electrical standards worldwide has depended significantly on NIST work.

\section{Recognition}

- Prof. O. Heinonen, U. C. Florida, has developed a new QHE theory based on NIST data.

- Cage has been invited to PTB in Germany to work on breakdown ideas. 
Project: SI FARAD AND OHM AND THE QUANTUM HALL EFFECT

\begin{tabular}{|c|c|c|c|c|c|}
\hline FISCAL YEARS & 93 & 94 & 95 & 96 & 97 \\
\hline $\begin{array}{l}\text { Complete a measurement of the U.S. } \\
\text { ohm for the calculable capacitor. [STRS] }\end{array}$ & & & & & \\
\hline $\begin{array}{l}\text { Complete a determination of the NIST } \\
\text { quantum Hall resistance. [STRS] }\end{array}$ & & & & & \\
\hline $\begin{array}{l}\text { Construct a new bridge to broaden the } \\
\text { frequency range of capacitance } \\
\text { measurements. [STRS] }\end{array}$ & & & & & \\
\hline $\begin{array}{l}\text { Measure the effect of contact resistance } \\
\text { on different QHE hetrostructures. [STRS, } \\
\text { OA-DOD] }\end{array}$ & & & & & \\
\hline $\begin{array}{l}\text { Investigate frequency response of various } \\
\text { types of standard capacitors. [STRS] }\end{array}$ & & & & & \\
\hline $\begin{array}{l}\text { Design extended frequency-range } \\
\text { impedance calibration service. [STRS] }\end{array}$ & & & & & \\
\hline $\begin{array}{l}\text { Design experiment to observe phonon } \\
\text { emission from } Q H E \text { breakdown. [STRS, } \\
\text { OA-DOD] }\end{array}$ & & & & & \\
\hline $\begin{array}{l}\text { Provide calibration at multiple frequencies } \\
\text { of a laboratory-standard capacitor based } \\
\text { on the calculable capacitor. [STRS] }\end{array}$ & & & & & \\
\hline
\end{tabular}




\section{Project: SI AMPERE AND GYROMAGNETIC RATIO OF THE PROTON $\left(r_{p}\right)$}

\section{FY 92 Fund Sources: STRS: OA: CCG}

Staff (4.2 staff-years)

\begin{tabular}{|l||l|l|l|l|}
\hline Professional & P. T. OLSEN & A. F. Clark & R. N. Ghosh & G. R. Jones* \\
\cline { 2 - 5 } & R. L. Steiner & W. E. Tew* & E. E. Williams* & \\
\hline
\end{tabular}

name in capital letters $=$ project leader; $=$ person works on project part time

Objective: Measure the U.S. unit of current as established from national resistance and voltage standards in terms of the SI ampere; determine the gyromagnetic ratio of the proton $\left(\gamma_{\mathrm{p}}\right)$ in terms of the U.S. electrical units; apply the physics of these measurements and other new phenomena such as single- electron tunneling, to the development of improved standards and measurement techniques, especially for constantcurrent standards.

Significance: The results of the NIST ampere measurements in terms of SI units are coupled with those of SI ohm determinations to obtain values to be used with Josephson and quantum Hall measurements as means of achieving drift-free, high precision national standards for the volt and ohm. The new superconducting version of the ampere apparatus now installed has already increased the precision of the ampere experiment by more than an order of magnitude and has the potential for much more. As a result, the ampere experiment holds promise of being a viable means of redefining the kilogram, thus doing away with the final base SI unit defined by an artifact. With the volt and ohm now defined by the Josephson and quantum Hall effects, the ampere can be described in terms of $2 \mathrm{e} / \mathrm{h}$ and $\mathrm{h} / \mathrm{e}^{2}$. Force measurements would then determine the kilogram as a function of these constants. A significantly enhanced ability to perform mass ratio measurements would also result. Accurate measurement of $\gamma_{p}^{\prime}$, possible only with direct access to national electrical standards, leads to an SI value for the ohm and thus the von Klitzing constant and also leads to a value of the fine-structure constant.

In addition to these fundamental metrological considerations, the measurement of both of these quantities at high accuracy requires development of sophisticated techniques for creating uniform and well-known magnetic fields and the measurement of magnetic field strength at high accuracy, methodology then available for other purposes, including generating or stabilizing currents to 3 or 4 parts in $10^{9}$.

\section{FY 92 Accomplishments}

- Fabricated several electrometer samples for single-electron tunneling in the Cryoelectronic Methodology Group's facility at NIST Boulder and two 0.6-pF capacitors on quartz disks. Made additional electrometers with more complex capacitor designs. Tested one electrometer in the NIST dilution refrigerator.

- Made improvements in the balance apparatus to reduce uncertainties in the determination of the NIST watt to about 0.1 parts million, three times better than the previous determination.

- Measured the solenoid dimensions in the $\gamma_{\mathrm{p}}{ }_{\mathrm{p}}$ experiment finding to confirm that no significant change in dimensions had occurred.

- Demonstrated that the nuclear magnetic resonance-controlled current source could be used as an $0.1 \mathrm{ppm}$ current/voltage source. Showed source could be turned off then on again with changes less than 0.05 parts per million. 


\section{FY 93 Plans}

- Conduct zero-field experiments to evaluate the contributions by the balance knife edges and by any magnetic materials present to the systematic uncertainties of the Watt determination.

- Reduce the effects from the mixing of polarization states to improve the multiple path laser interferometer used in the balance apparats velocity-measuring system.

- Make new nuclear magnetic resonance measurements using the $\gamma_{p}^{\prime}$ coil and evaluate systematic errors.

- Analyze the discrepancy between the fine structure constant values from the absolute capacitance experiment and the $\gamma_{\mathrm{p}}$ experiment.

\section{Impact}

- The Committee on Data for Science and Technology Task Group on Fundamental Constants has stated that the results of NIST experiments to measure the ampere and the gyromagnetic ratio of the proton are key in determining new values of the fundamental constants.

\section{Related Developments}

- In an article on the "Recommended Values of Fundamental Constants", B. N. Taylor has indicated that improvements in the $\gamma_{\mathrm{p}}$, determination leading to the fine structure constant is one of the three most critical experiments for improving the understanding of the constants underlying all of physics.

- Terry Quinn, director of BIPM has decided that BIPM should become involved in electronic kilogram experiments. BIPM plans to start by studying how to move a flexure balance at a uniform velocity and is studying making a small version of either the U. K. National Physical Laboratory magnets, or the NIST superconducting magnet. 


\section{Project: SI AMPERE AND GYROMAGNETIC RATIO OF THE PROTON $\left(r_{p}\right)$}

\begin{tabular}{|c|c|c|c|c|c|}
\hline FISCAL YEARS & 93 & 93 & 95 & 96 & 97 \\
\hline $\begin{array}{l}\text { Complete new NMR measurements for } \\
\text { the } r^{\prime} \text { p experiment. [STRS] }\end{array}$ & & & & & \\
\hline $\begin{array}{l}\text { Reduce the phase-shift error in the } \\
\text { multiple-laser interferometer for the } \\
\text { ampere balance. [STRS] }\end{array}$ & & & & & \\
\hline $\begin{array}{l}\text { Determine the NIST watt and ampere in } \\
\text { terms of the SI units. [STRS] }\end{array}$ & & & & & \\
\hline $\begin{array}{l}\text { Develop methods for eliminating index of } \\
\text { refraction errors in the ampere } \\
\text { experiment. [STRS] }\end{array}$ & & & & & \\
\hline $\begin{array}{l}\text { Develop procedures for realizing an } \\
\text { electronic kilogram. [STRS] }\end{array}$ & & & & & \\
\hline $\begin{array}{l}\text { Monitor kilogram for extended time with } \\
\text { ampere balance. [STRS] }\end{array}$ & & & & & \\
\hline $\begin{array}{l}\text { Investigate the use of single-electron } \\
\text { tunneling to determine the fine-structure } \\
\text { constant and as a current standard. } \\
\text { [STRS] }\end{array}$ & & & & & \\
\hline
\end{tabular}


SEMICONDUCTOR ELECTRONICS DIVISION 


\section{Project: MBE GROWTH TECHNOLOGY}

\section{FY 92 Fund Sources: STRS-Reserve; OA-CNVEO}

\section{Staff (3.5 staff-years)}

\begin{tabular}{|l||l|l|l|l|}
\hline Professional & J. COMAS* & W. Miller (GS) & J. Pellegrino & W. Tseng \\
\hline Technician & D. Monk* & & & \\
\hline
\end{tabular}

name in capital letters $=$ project leader; ${ }^{*}=$ person works on project part time

Objective: Provide NIST with state-of-the-art capability for producing compound semiconductor epitaxial films and structures to develop and calibrate measurement tools needed by the semiconductor industry. Specifically, develop methods, tools, reference-qual ity data, and materials to improve state of the art in growth and characterization of compound semiconductors, conduct research in surface science and crystal growth kinetics, and fabricate devices for research and standards.

Significance: The ability to control precisely the thickness, doping, and composition of III-V compound semiconductor layers by molecular beam epitaxial (MBE) growth has great potential in the fabrication of electronic, optical, and optoelectronic devices. Ultrathin layers and superlattice-based structures represent a new class of artificial semiconductor materials with properties which do not exist in bulk form. NIST's development of needed measurement tools will provide detailed understanding of the material, optical, and electrical properties of III-V MBE layers which is critical for military and commercial applications in electronic and optoelectronic devices. NIST also provides unique structures for other NIST basic standards programs.

\section{FY 92 Accomplishments}

- Characterized interface roughness in low-order AlAs/GaAs superlattices and determined the influence of the GaAs buffer layer thickness on the subsequent superlattice interface quality. Inferred that surface roughening by islanding may be promoted by GaAs buffer layers that are 10 to $100 \mathrm{~nm}$ thick; smoother interfaces were obtained in samples with buffer layers $250 \mathrm{~nm}$ and greater. Studied quality of superlattice interfaces by high-resolution X-ray diffraction and found that the quality of the superlattice interfaces is markedly affected by the growth technique. Also found interfaces were sharper in a mimration-enhanced epitaxy sample than in an equivalent superlattice sample grown by the interruptecis wh technique.

- Correlated the degree of interface roughness occurring in short-period III-V superlattices with the behavior of confined optical phonons obtained from Raman measurements. Observed a consistent, reproducible, broadening of the optical phonon peak at $295 \mathrm{~cm}^{-1}$ in superlattices with disordered interfaces.

- Grew and fabricated GaAs photoconductive switches for pulse generation. [collaboration with the Electricity Division]

- Designed and grew five surface-emitting laser structures for the joint laser project with NIST/Boulder. Showed outpui linewidths were less than $0.3 \mathrm{~nm}$, and wavelengths ranged from $835 \mathrm{~nm}$ to $851 \mathrm{~nm}$ over the wafer. [collaboration with the Electromagnetic Technology Division]

- Grew high-quality GaAs samples for the quantum-Hall resistance standard. Made quantum-Hall effect measurements on an InGaAs heterostructure grown on an InP substrate. Observed no steps in the Hall 
voltage, a condition attributed to the high electron channel concentration. [collaboration with the Electricity Division]

- Studied nanometer-scale oxides patterned by means of scanning tunneling microscopy (STM) and showed they are readily generated in an air ambient, easily imaged by scanning electron microscopy and other microprobe techniques, capable of surviving realistic processing environments, and useful as masks for etching and selective area growths.

- Designed a new series of hetero $n-i-p-i$ and low-order superlattice structures to increase the confinement of the optically produced carriers and obtain stronger exciton peaks. Obtained highresolution X-ray diffraction measurements from GaAs/AIGaAs superlattice structures that exhibited well-defined superlattice, buffer, and substrate peaks (these samples are now at lowa for optical transmission studies). [collaboration with the University of Iowa]

\section{FY 93 Plans}

Note: In FY 93, this project will be combined with parts of the Electrical Characterization and GOES Projects to form the Nanoelectronics Project.

- Grow specialized MBE structures such as GaAs on Si with the Army Research Laboratory. Apply $\mathrm{X}$-ray diffraction and standing waves to the analysis of interfaces, in collaboration with the Ceramics Division, Materials Science and Engineering Laboratory. Develop X-ray-fluorescence technique to monitor alloy composition during MBE growth.

- Develop heterostructure-based photonic devices, in collaboration with University of Iowa; develop improved growth techniques and diagnosics for vertical-cavity surface-emitting distributed-structure lasers, in collaboration with the Electromagnetic Technology Division.

- Conduct feasibility demonstration of STM lithography for ultra-fine structures, in collaboration with the Electricity Division, and the Precision Engineering Division, Manufacturing Engineering Laboratory; fabricate artifacts such as quantum-Hall devices, quantum wires, and quantum dots incorporating two-, one- and zero-dimensional electron gases.

\section{Impact}

- A recently established device manufacturer credits its status as the first company to market verticalcavity lasers for sale to joint assistance from NIST's Electromagnetic Technology and Semiconductor Electronics Divisions.

\section{Recognition}

- Pellegrino participated in a panel review of small business research initiative (SBRI) proposals held at the National Science Foundation.

- Comas served on the August review panel for the Office of Naval Technology Postdoctoral Fellowship Program which is administered by the American Society for Engineering Education.

\section{Related Developments}

- Tseng and J. A. Dagata (Precision Engineering Division) were invited to participate in an Army Research Office Workshop on Nanostructures for Optoelectronics and gave talks on their results from nanometer-scale STM pattern generation of ultrathin oxide masks on silicon and GaAs, and results on novel methods of GaAs surface passivation and etch damage repair, and STM-based I-V spectroscopy of III-V alloys under ambient conditions. 


\section{Project: CHARACTERIZATION AND EVALUATION OF HgCdTe INFRARED DETECTORS}

\section{FY 92 Fund Sources: STRS; NOAA}

Staff (3.0 staff-years)

\begin{tabular}{|l||l|l|l|l|}
\hline Professional & D. SEILER* & D. Berning* & G. Harman* & J. Kopanski* \\
\cline { 2 - 5 } & J. Lowney * & W. Thurber* & & \\
\hline Technician & M. Edelstein * & D. Ricks* & & \\
\hline
\end{tabular}

name in capital letters = project leader; $=$ person works on project part time

Objective: Carry out technical analyses of the characteristics and performance of the photoconductive $\mathrm{HgCdTe}$ infrared detectors used on the GOES-NEXT and TIROS weather satellites in support of NOAA. Evaluate status and reliability of detector devices. Attend reviews and evaluation meetings as requested by NOAA/NASA.

Significance: As the dramatic weather events of 1992 emphasized, the nation has become critically dependent on weather information from satellites of the National Oceanic and Atmospheric Administration (NOAA). To meet these needs, NOAA is charged with the responsibility for producing, launching, and operating a multiple Geostationary Operational Environmental Satellite (GOES) system. The data obtained by the GOES satellites provide information needed for severe storm detection, monitoring, and tracking, wind measurements from cloud motion, sea surface thermal features, precipitation estimates, frost monitoring, rescue operations, and research. Serious concerns have arisen over apparent signal reductions or instabilities found in a number of $\mathrm{HgCdTe}$ infrared detectors. NIST was asked by NOAA to investigate, and NIST identified serious problems in detector processing and made recommendations to address them. At NOAA's request, NIST will provide measurement expertise needed by the agency and industry to characterize and evaluate future detectors.

\section{FY 92 Accomplishments}

- Participated on the GOES Detector Evaluation Team (Harman and Seiler). Visited GOES detector vendors, along with the principal contractor, and held selective reviews of their GOES detector work. Briefed NASA/NOAA on January 24,1992 , at NASA.

- Performed visual and SEM measurements at NIST on a packaged GOES detector. Developed a set of Recommended Practices (guidelines) for packaging NOAA space sensors (detectors) and dist: to appropriate organizations. Conducted several laboratory studies to evaluate contractor-sin iied detectors, from the standpoint of workmanship, reliability, and reproducibility. Studied the exrects of molecular cleaning methods on $\mathrm{HgCdTe}$ packaged detectors (to improve the reliability of bonding). Carried out experiments to improve yield and reliability of bonding and packaging at two contractor sites having ultraviolet ozone cleaning equipment.

- Performed oscillatory magnetotransport, i.e., Shubnikov-de Haas (SdH), measurements on a statistically significant number of infrared detectors from the suppliers for the GOES and TIROS programs. Found that two different passivation procedures gave rise distinctly different $\mathrm{SdH}$ signatures. Verified that the SdH oscillations were coming only from the thin (two-dimensional) accumulation layers produced by the surface passivation.

- Wrote code for the NIST Cray supercomputer for calculating the accumulation layer subband densities, cyclotron effective masses, and Fermi energies and confirmed linear dependence of subband 
density on total density, which has been observed experimentally. Compared results of theory and Shubnikov-de Haas measurements for an anodically oxidized sample; found agreement within experimental error. However, found large differences between theory and experiment for a heavily accumulated surface which had been processed differently; concluded that the accumulation-layer potential is different from that of the model. This code furnishes NIST with the ability to analyze Shubnikov-de Haas data in terms of first-principles band structure.

- Completed a survey and review of current applications of test structures as they are applied in the infrared detector industry. Also completed a parallel tutorial on the methodology of applications of test structures to silicon integrated circuits and GaAs monolithic microwave integrated circuits. Reviewed test structures for the measurement of material parameters of wafers at various levels of processing.

\section{FY 93 Plans}

Note: During FY 93, this project will be combined with the Molecular Beam Epitaxy Project and portions of the Electrical Characterization Project to form the Nanoelectronics Project.

- Develop evaluation methods and models for materials parameters critical to device quality and reliability for such devices as infrared detectors and lasers.

- Hold Workshop on Measurement Techniques for Characterization of $\mathrm{HgCdTe}$ Materials, Processing, and Detectors. Edit Proceedings to be published in Semiconductor Science and Technology in June 1993.

- Communicate results of survey on current applications of test structures to infrared detector industry through final report, presentations, and an invited review paper.

\section{Impact}

- Launch of the first GOES-NEXT with detectors of questionable reliability would probably have become a major technical and economic embarrassment to the United States. NIST's careful and timely analysis revealed problems that led to a strong recommendation not to launch these detectors, even though they had previously been judged flight worthy.

- One GOES supplier expressed strong appreciation to NIST for the magnetotransport measurements that have shown one of its fabrication processes to have formed accumulation layers.

\section{Recognition}

- Kopanski and Schuster were invited to present the work on test structures applied to infrared detectors at the Measurement Techniques for Characterization of $\mathrm{HgCdTe}$ Materials, Processing, and Detectors Workshop, Boston, Mass., October 1992.

\section{Related Development}

- It is widely recognized that the ability to grow $\mathrm{HgCdTe}$ materials and structures has outgrown the ability to characterize today's materials and devices. The Characterization Workshop is enthusiastically supported by industry and (D)ARPA and will attempt to summarize the state of the art in characterization techniques. 


\section{Project: NANOELECTRONICS}

\begin{tabular}{|c|c|c|c|c|c|}
\hline FISCAL YEARS & 93 & 94 & 95 & 96 & 97 \\
\hline \multirow{2}{*}{$\begin{array}{l}\text { Conduct research on MBE growth } \\
\text { kinetics, dopant incorporation, and lattice } \\
\text { mismatch strain effects. [STRS, OA- } \\
\text { (D)ARPA, ARL] }\end{array}$} & & & & & \\
\hline & & & & & \\
\hline \multicolumn{6}{|l|}{$\begin{array}{l}\text { Develop SRMs for } \mathrm{Al} \text { and in mole- } \\
\text { fractions in } \mathrm{AlGaAs} \text { and InGaAs layers, }\end{array}$} \\
\hline $\begin{array}{l}\text { respectively, using X-ray RHEED, and } \\
\text { optical techniques. [STRS-SRMPO] }\end{array}$ & & & & & \\
\hline \multirow{2}{*}{\multicolumn{6}{|c|}{$\begin{array}{l}\text { Develop migration-enhanced-epitaxy and } \\
\text { atomic-layer-epitaxy growth techniques } \\
\text { for interface layer sharpness, quantum- } \\
\text { confinement applications, and }\end{array}$}} \\
\hline & & & & & \\
\hline $\begin{array}{l}\text { improvement of quantum-Hall-effect } \\
\text { devices for the standard ohm. [STRS, } \\
\text { STRS-Director's Reserve] }\end{array}$ & & & & & \\
\hline \multicolumn{6}{|l|}{$\begin{array}{l}\text { Correlate MBE materials properties and } \\
\text { interface information with device }\end{array}$} \\
\hline performance. [OA-CCG, OA-NVL] & & & & & \\
\hline \multirow{2}{*}{\multicolumn{6}{|c|}{$\begin{array}{l}\text { Design, grow, and characterize optical } \\
\text { waveguides, laser structures, and multiple } \\
\text { quantum-well structures for NIST/Boulder } \\
\text { projects. [STRS] }\end{array}$}} \\
\hline & & & & & \\
\hline \multirow{2}{*}{\multicolumn{6}{|c|}{$\begin{array}{l}\text { Continue collaborative program with } \\
\text { University of lowa on photonic, } \\
\text { electronic, and physical properties of III-V } \\
\text { heterostructure-based devices. [OA- } \\
\text { (D)ARPA] }\end{array}$}} \\
\hline & & & & & \\
\hline \multirow{2}{*}{\multicolumn{6}{|c|}{$\begin{array}{l}\text { Develop X-ray fluorescence as a } \\
\text { technique to monitor alloy composition. } \\
\text { [STRS, STRS-Director's Reserve] }\end{array}$}} \\
\hline & & & & & \\
\hline \multirow{2}{*}{\multicolumn{6}{|c|}{$\begin{array}{l}\text { Develop STM lithography with Divs. } 821 \\
\text { and } 811 \text { to pattern and study ultra-small }\end{array}$}} \\
\hline & & & & & \\
\hline \multirow{2}{*}{$\begin{array}{l}\text { Develop and apply scanning capacitance } \\
\text { microscopy to wafer mapping of electrical } \\
\text { properies of silicon and compound } \\
\text { semiconductors. [STRS, STRS-OMP] }\end{array}$} & & & & & \\
\hline & & & & & \\
\hline
\end{tabular}


Project: NANOELECTRONICS (concluded)

\begin{tabular}{|c|c|c|c|c|c|}
\hline FISCAL YEARS & 93 & 94 & 95 & 95 & 97 \\
\hline $\begin{array}{l}\text { Provide needed consulting services related } \\
\text { to detector characterization, packaging, } \\
\text { bonding, and metallization. [OA-NOAA] }\end{array}$ & & & & & \\
\hline $\begin{array}{l}\text { Develop and implement Shubnikov-de } \\
\text { Haas effect as a tool to evaluate and } \\
\text { characterize two-dimensional electronic } \\
\text { properties of accumulation layers } \\
\text { produced by passivation processes for } \\
\text { infrared detectors. [STRS, OA-NOAA] }\end{array}$ & & & & & \\
\hline
\end{tabular}




\section{Project: ELECTRICAL CHARACTERIZATION}

\section{FY 92 Fund Sources: STRS-OMP, WCT-SRMP; NOAA; (D)ARPA}

\section{Staff (6.0 staff-years)}

\begin{tabular}{|l||l|l|l|l|}
\hline \multirow{2}{*}{ Professional } & J. EHRSTEIN & J. Kim & J. Kopanski* & S. Mayo* \\
\cline { 2 - 5 } & J. LOWNEY* & D. Seiler* & W. Thurber* & D. Novotny* \\
\hline Technician & D. Ricks* & R. Russell* & J. Thomas & \\
\hline
\end{tabular}

name in capital letters $=$ project leader; $=$ person works on project part time

Objective: Develop methods, tools, and artifacts to improve the state of the art in electrical-characterization metrology for semiconductor materials. Specifically, provide silicon device manufacturers with bulk resistivity standards with better than $1 \%$ accuracy, and implant dose/sheet resistance standards with $1 \%$ accuracy. Provide compound-semiconductor device manufacturers with improved metrology and models to enhance device performance and reliability.

Significance: The yield and reliability of semiconductor devices depend critically on the characteristics of the materials and processes that are used to manufacture them. The electronics industry needs the methodology provided by NIST to evaluate these materials and processes. Industry also needs standard measurement methods and artifacts to make verifiable measurements of materials parameters as a wafer is processed. As an example, resistivity is one of the most important parameters for silicon, and in response to industrial needs, NIST is providing state-of-the-art resistivity SRMs. Improved materials understanding and evaluation techniques are needed by the compound-semiconductor industry to make useful and reliable devices.

\section{FY 92 Accomplishments}

- Developed small-diameter silicon resistivity SRMs having characteristic radial variation of resistivity reduced to about $2 \%$ (previous material had spikes to 5\%); certified 140 wafers of improved uniformity having resistivities of 180 or $1 \mathrm{ohm}-\mathrm{cm}$.

- Received a custom-built chamber and refurbished an existing cold-chuck and adapted it to the patterned-contact, resistivity micro-mapping instrument; upgrades enable mapping over a range of temperatures so that carrier activation may be studied. Demonstrated the fine detail that can be obtained on $\mathrm{HgCdTe}$ with room-temperature maps on wafers supplied by a manufacturer with patterned contacts. Began work on mapping GaAs wafers and on silicon patterned with implanted resolution stripes. [industrial collaboration]

- Prepared detailed specifications for a scanning tunneling/atomic force microscope for scanning capacitance microscopy (SCM); the microscope will be one of the first to be made with a large sample stage, compatible with semiconc or wafers with diameters to $250 \mathrm{~mm}$. Began development of the capacitance-sensitive circuit and thrin'setical modeling of the SCM measurement (delivery and installation expected in early December 1992). (OMP)

- Developed and applied to both $\mathrm{HgCdTe}$ and III-V test samples a general technique for analyzing multicarrier conduction. Made extensive Hall and resistivity measurements on several GaAs-based HEMT structures for a paper on multicarrier characterization methods. 
- Wrote computer codes to enable analysis of high-field magneto-transport measurements of thin semiconductor layers, such as the accumulation layers of $\mathrm{HgCdTe}$ detectors.

- Demonstrated by capacitance-voltage measurements that characteristics of SiC MOS capacitors were as good as those obtainable on silicon, and that a degree of activation for ion-implanted boron into commercially supplied $\mathrm{SiC}$ (having $6 \mathrm{H}$ crystal structure) was greater than previously observed. This latter observation may encourage use of boron, rather than aluminum, as the preferred p-type dopant for $\mathrm{SiC}$ microelectronics.

- Completed the survey on characterization techniques used by the $\mathrm{HgCdTe}$ community for various material parameters, analyzed data, and prepared paper for the 1992 Workshop on Measurement Techniques for Characterization of $\mathrm{HgCdTe}$ Materials, Processing and Detectors in Danvers, Mass.

\section{FY 93 Plans}

Note: In FY 93, portions of this project will be combined with the Optical Characterization Project to form the Semiconductor Characterization Technology Project, and portions combined with the Molecular Beam Epitaxy and GOES Projects to form the Nanoelectronics Project.

- Certify and deliver sufficient quantities of 100-mm silicon resistivity SRMs to meet industry's needs; publish documentation of the certification process.

- Develop improved understanding of the industry's needs for silicon or compound semiconductor-based SRMs, and improve collaboration with the industry for more effective development of such SRMs.

- Extend resistivity-mapping capability to low temperature and develop system and theory for scanning capacitance microscopy. Apply to silicon, HgCdTe, and III-V wafers. (OMP)

- Install and bring on line superconducting magnet system for magneto-transport and magneto-optical measurements on semiconductors. (OMP)

\section{Impact}

- As a result of Kopanski's confirmation of higher electrical activation for boron implanted into SiC, renewed study of boron as a p-type dopant in $\mathrm{SiC}$ has been stimulated at two major manufacturers. NIST's help has been acknowledged in letters from one of these.

\section{Recognition}

- Kopanski was invited to write a chapter on Oxidation of SiC for a commercial publisher.

\section{Related Developments}

- The Defense Procurement Act Title III authorization for very-high-purity silicon and other activities was passed by the Legislative Branch at the end of FY 1992. In anticipation, preparations were made for very-high-purity silicon characterization under Title III during FY 1993.

- Ehrstein received a letter from a manufacturer expressing interest in fabricating samples and performing auxiliary measurements to aid the development of ion implant dosimetry SRMs.

- The Ion-Implant Users Group has provided recommendations for a standard process for dosimetry reference material; to date, two instrument manufacturers have expressed interest in supporting the R\&D effort. 


\section{Project: OPTICAL CHARACTERIZATION}

\section{FY 92 Fund Sources: STRS-ATP; (D)ARPA}

Staff (5.5 staff-years)

\begin{tabular}{|l||l|l|l|}
\hline Professional & P. AMIRTHARAJ & D. Chandler-Horowitz & N. Nguyen \\
\cline { 2 - 5 } & J. Marchiando & D. McKeown* & B. Rennex * \\
\hline & D. Seiler & & \\
\hline
\end{tabular}

name in capital letters = project leader; $=$ person works on project part time

Objective: Develop optical characterization measurements geared to addressing key materials, processing, and device issues in the semiconductor industry while improving standards needed by the industry. Specifically, establish a state-of-the-art spectroscopic facility for a high-resolution and high-sensitivity Fourier transform photoluminescence (FTPL) system for quantitative and impurity-specific analysis of trace levels of impurities in high purity $\mathrm{Si}$, with concentrations of the order of $10^{10} / \mathrm{cm}^{3}$, which are beyond the analytical range of electrical measurements. Establish Raman, conventional photoluminescence, modulation and absorption spectroscopies, and ellipsometry for materials characterization, in order to provide industry with needed standards and improved measurement methods.

Significance: Spectroscopic techniques are both powerful and attractive for semiconductor materials characterization since they are nondestructive, contactless, and possess spatial-mapping capability and nearsurface-region sensitivity. There is an immediate need for quantitative detection of impurities in high-purity silicon for the fabrication of power devices, and FTPL is the major tool for fulfilling it. NIST will use its facility to help industry adapt, improve, and optimize the FTPL technique and to provide standards. Also, the use of photoreflectance (PR) in the semiconductor industry as a routine characterization tool will be significantly advanced by the developments at NIST. Direct inputs are being provided to both the users of PR and the manufacturers of PR measurement equipment.

\section{FY 92 Accomplishments}

- Completed installation of high-resolution Fourier transform photoluminescence system and initiated measurements in high-purity $\mathrm{Si}$ (doped with $\mathrm{P}$ at $10^{12} \mathrm{~cm}^{-3}$ ).

- Optimized (noise, repeatability and stability) high-stability Fourier transform infrared absorption system for SRM measurements.

- Mailed to major semiconductor companies the OMB-approved questionnaire regarding the use of optical characterization techniques for materials and device analysis by the semiconductor industry (responses are being collected).

- Provided (D)ARPA with metrologic support for the X-ray lithography mask program and expert consultation and optical characterization for the infrared materials program.

- Completed Raman scattering measurements and analysis on CdTe as a function of temperature to obtain the first set of reliable optical phonon frequencies, needed to understand impurity-related vibrational behavior for infrared detector materials.

- Observed effects of interface roughness in short-period GaAs/AlAs superlattices using spectroscopic ellipsometry for the first time. 
- Observed in real time, using spectroscopic ellipsometry, the growth of thin native oxide on MBE-grown GaAs layers. Applied the near-monolayer sensitivity to follow the initial stages of native oxide growth on MBE GaAs. Found that the oxide growth followed a logarithmic law for the first 1500 minutes to a thickness of $1.4 \mathrm{~nm}$, followed by a power-law growth behavior.

- Upgraded the spectroscopic ellipsometer with ultraviolet grade polarizers to expand the energy range to $6 \mathrm{eV}$, which substantially increases the ability to study surface-related effects in most semiconductors.

- Completed and tested double-modulation system to perform photoreflectance measurements; method significantly adds to the in-house capability for PR measurements by extending the range of materials that can be examined.

\section{FY 93 Plans}

Note: In FY 93, this project will be combined with portions of the Electrical Characterization Project to form the Semiconductor Characterization Technology Project.

- Develop PL, FTIR, and Raman methods for material and impurity analysis in Si and compound semiconductors. (OMP)

- Develop the system and theory for a new double modulation photoreflectance technique for the characterization of microstructures and compound semiconductors.

- Improve the understanding of the optical properties of $\mathrm{SiO}_{2}$ on $\mathrm{Si}$ thin oxides and interfaces and improve the measurement accuracy for thin layer thicknesses $(<15 \mathrm{~nm})$. (OMP)

- Complete survey and analysis of optical characterization techniques used in the semiconductor industry.

- Complete invited chapter on "Optical Properties of Semiconductors" for the Handbook of Optics.

- Complete certification of oxygen-in-silicon SRMs and continue to improve accuracy of Group's Fourier transform infrared spectrometer.

\section{Impact}

- Computer software developed by Marchiando is reported by several companies to enhance their use of ellipsometric data in process evaluation; at least one company has incorporated NIST codes in its ellipsometric system designed and built to assist in the manufacture of electronic components.

\section{Recognition}

- Chandler-Horowitz was invited to present a tutorial review of ellipsometric analysis at DEC, Inc., in Hudson, Mass.

- Chandler-Horowitz will serve on the International Scientific Committee for the First International Conference on Spectroscopic Ellipsometry, to take place in Paris, January 11-14, 1993.

- SEMI Compound Semiconductor Committee and ASTM F1.15 Compound Semiconductor Subcommittee are becoming active in the development of measurement techniques and artifacts for characterization of compound semiconductors; SEMI Committee has requested NIST involvement. 


\section{Project: SEMICONDUCTOR CHARACTERIZATION}

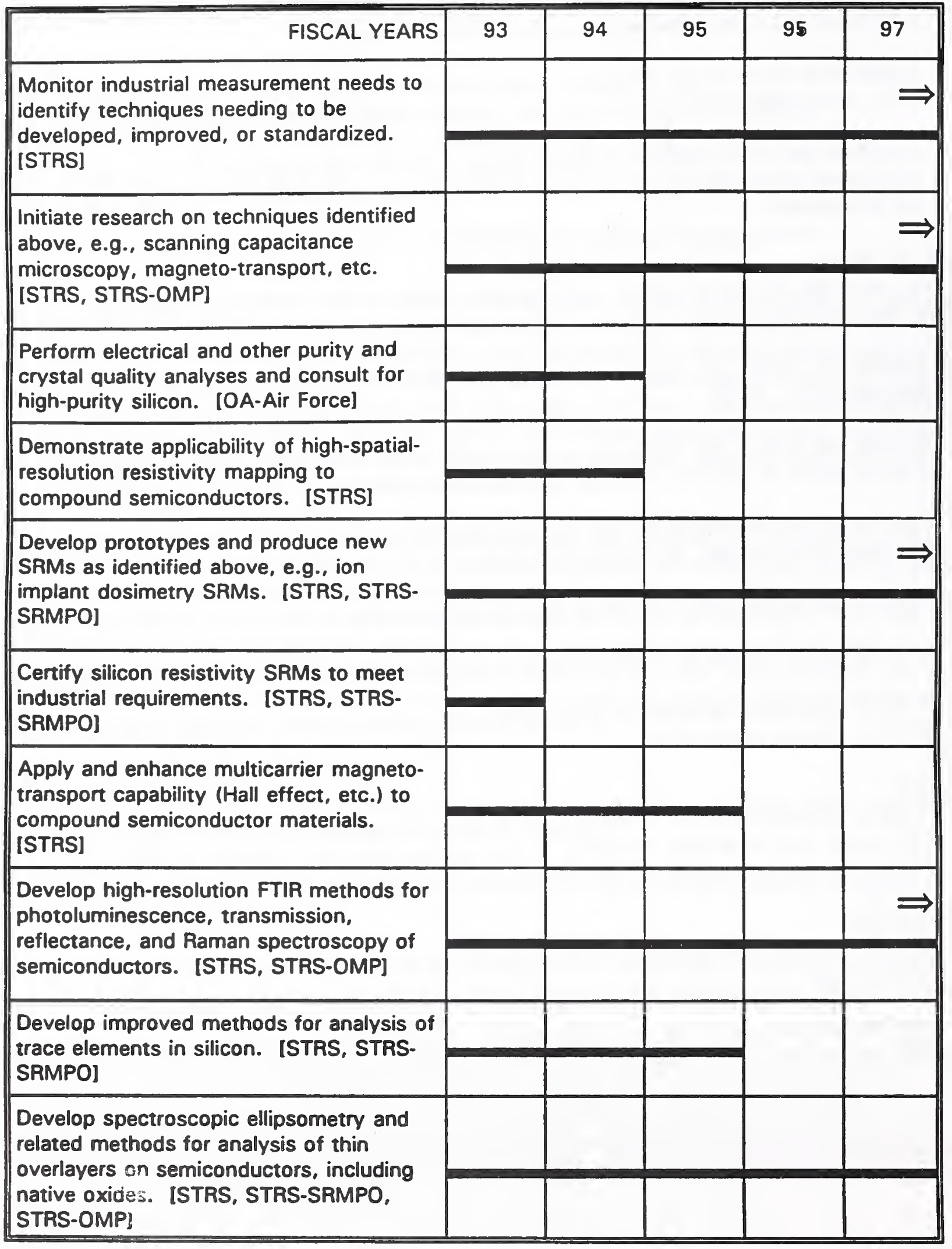


Project: SEMICONDUCTOR CHARACTERIZATION (concluded)

\begin{tabular}{|c|c|c|c|c|c|}
\hline FISCAL YEARS & 93 & 94 & 95 & 96 & 97 \\
\hline $\begin{array}{l}\text { Survey and analyze optical } \\
\text { characterization methods used in the } \\
\text { semiconductor industry. [STRS] }\end{array}$ & & & & & \\
\hline $\begin{array}{l}\text { Complete certification of oxygen-in-silicon } \\
\text { SRMs. [STRS, STRS-SRMPO] }\end{array}$ & & & & & \\
\hline $\begin{array}{l}\text { Explore wafer-level spectroscopic } \\
\text { mapping techniques for compound } \\
\text { semiconductors. [STRS, STRS-OMP, OA] }\end{array}$ & & & & & \\
\hline $\begin{array}{l}\text { Explore in-situ spectroscopic analytical } \\
\text { procedures for semiconductor growth and } \\
\text { processing. [STRS, STRS-OMP, OA] }\end{array}$ & & & & & \\
\hline $\begin{array}{l}\text { Continue interaction with MSEL to } \\
\text { develop X-ray synchrotron techniques for } \\
\text { semiconductor materials analysis. [STRS] }\end{array}$ & & & & & \\
\hline
\end{tabular}




\section{Project: THIN-FILM SRMS}

\section{FY 92 Fund Sources: STRS, SRMP}

\section{Staff (2.8 staff-years)}

\begin{tabular}{|l||l|l|l|l|}
\hline Professional & P. ROITMAN* & D. Blackburn* & J. Geist* & R. Mattis* \\
\hline Technician & B. Belzer & M. Edelstein * & M. Miller & \\
\hline
\end{tabular}

name in capital letters $=$ project leader; $"=$ person works on project part time

Objective: Develop, improve, and produce calibration standards of importance to the microelectronics industry. Apply optical techniques such as ellipsometry and reflectometry to the characterization of thin films and layered structures which can be used to calibrate film thickness and index of refraction and, in cross-section, microscope magnification. Produce thin films and layered structures of sufficient quality to be used as standards.

Significance: The electronics industry needs optical characterization techniques for critical measurements at a number of different stages in the production of integrated circuits and in other areas of semiconductor electronics. Quantitative submicrometer microscopy becomes increasingly important as the fabricated components of integrated circuits have submicrometer dimensions. For quality control and technology transfer, industry needs NIST to provide the metrology essential to support fabrication processes.

\section{FY 92 Accomplishments}

- Completed change in procedures to measure and certify unpatterned wafers as 2530 Series thin-film thickness SRMs; series features include simplified processing, oxide thicknesses of 14 to $200 \mathrm{~nm}$, and compatibility with industrial fixturing.

- Developed capability to produce certifiable 2530 Series SRMs at the NIST processing facility. Fabricated oxides of 25- to 200-nm thickness fabricated on a regular basis to reduce SRM backorders to zero.

- Developed 25-nm and 14-nm-thick oxides as new additions to the 2530 Series (as 2534 and 2535) of thinoxide SRMs.

- Fabricated preliminary $14-\mathrm{nm}$ oxide artifacts. Began study of effects of oxide growth temperature on certification analysis.

- Documented procedure for magnification standard certification; published in NIST Journal of Research.

- Completed development of two "front-end" programs for user-friendly input to MAIN1 ellipsometric analyses program and published as two NISTIRs.

\section{FY 93 Plans}

Note: In FY 93, this project will be combined with the SOI Material and Device Measurements Project to form the Thin Film Characterization Project.

- Begin certifying as SRMs $14-\mathrm{nm}$ oxides grown at JIST.

- Establish feasibility of growing at NIST and certifying 10-nm-thick oxides. 
- Organize and conduct workshop with SEMATECH on thin-film metrology.

- Continue effort to improve definition of the interfacial region in the current SRMs (as well as in other oxide/silicon systems) in regards to thickness and composition through various ellipsometric and complementary methods (cross-sectional and high-resolution transmission electron microscopy, atomic force microscopy, scanning tunneling microscopy, etc.).

\section{Impact}

- Reports indicate that the 2530 Series oxide thickness SRMs are meeting industry needs to improve the reliability of oxide-thickness measurements. One manufacturer is sectioning these standards and using them as magnification standards.

\section{Recognition}

- Belzer, Miller, and Roitman received Measurement Service Awards from the NIST Standard Reference Materials Program in recognition of their work on the thin-film thickness standards.

\section{Related Developments}

- SEMATECH has loaned NIST (long-term) an "excess" ellipsometer for quickly mapping the oxide/thickness on wafers.

- Several staff members have made industrial visits to various major U.S. manufacturers at the request of SEMATECH to gather information on oxide thickness metrology.

- Project staff participated in NIST/DEC Semiconductor Metrology Tutorial Series. Talks given on ellipsometry fundamentals and applications, including certification of SRMs. 


\section{Project: SOI MATERIAL AND DEVICE MEASUREMENTS}

FY 92 Fund Sources: STRS; OA-DNA, -Army (SDC)

Staff (3.1 staff-years)

\begin{tabular}{|l||l|l|l|l|}
\hline Professional & P. ROITMAN & J. Marshall & D. Novotny * & S. Mayo* \\
\hline Technician & M. Edelstein * & G. Krepps* & J. Luther * & R. Russell* \\
\hline
\end{tabular}

name in capital letters $=$ project leader; ${ }^{\star}=$ person works on project part time

Objective: Develop and evaluate material and device characterization tools for SOI structures. Use these tools to evaluate and improve the quality of the silicon and buried oxide. Specifically, develop and evaluate methods for investigating defects and dislocations in SIMOX material, design and fabricate test chip for testing the process sequence and for extracting device modeling parameters, and use these and other tools for improving SOI material and device processing.

Significance: SOI (silicon on insulator) is an emerging technology which offers combined performance benefits in speed, high-temperature operation, resistance to ionizing radiation, and suitability for use in integrated-circuit power device fabrication. Industry needs improved material characterization and analysis tools from NIST to control the quality of SOI material in order to exploit these benefits in a variety of applications. NIST also works with other government agencies to provide technical assistance to government programs developing and using SOI materials.

\section{FY 92 Accomplishments}

- Presented four papers on SOI work in which NIST is involved at the October IEEE SOI Conference.

- Developed a processing variation which reduces the defect density in the silicon film by a factor of as much as fifty.

- Evaluated buried oxides from a commercial supplier using CV and leakage current measurements (mask set NIS Tos was used to fabricate the capacitors). Conduction and breakdown mechanisms for the buried oxides were identified.

- Completed new mask design for SIMOX (separation by implanted oxygen) test chip for fabrication in the Division's processing facility.

\section{FY 93 Plans}

Note: In FY 93, this project will be combined with the Thin Film SRMs Project to form the Thin Film Characterization Project.

- Establish correlation between SOI process parameters and defect density.

- Determine nature of defects in SOI and their effect on electrical parameters.

- Fabricate SIMOX test chips; conduct studies to determine origin of process-induced defects.

\section{Impact}

- Two manufacturers are applying the NIST-developed technique to reduce defects in the silicon film in SOI material. 


\section{Recognition}

- Roitman received best paper award as co-author at 1992 IEEE Nuclear and Space Radiation Effects Conference.

- Roitman received a DoC Bronze Medal for his work in SIMOX.

- Roitman is serving on the paper selection committees for the IEEE SOI Conference, the IEEE Nuclear and Space Radiation Conference, and the IEEE Electron Device Conference.

\section{Related Developments}

- Commercial interest in SOI is rising sharply. Several companies are working on automotive applications, including the acceleration sensor for air-bag deployment, but also including processor and control functions. The advantages of SOI for low-voltage, low-power, battery-powered circuits have been recognized and are being vigorously investigated. The scalability of SOI devices below $0.25 \mu \mathrm{m}$ has been demonstrated, and large-scale use of SOI for VLSI in this regime is being explored by the industry leaders. 


\section{Project: THIN-FILM CHARACTERIZATION}

\begin{tabular}{|c|c|c|c|c|c|}
\hline FISCAL YEARS & 93 & 94 & 95 & 96 & 97 \\
\hline $\begin{array}{l}\text { Continue production of oxide thickness } \\
\text { SRMs. [STRS, STRS-SRMPO] }\end{array}$ & & & & & $=$ \\
\hline $\begin{array}{l}\text { Phase in new thicknesses and materials } \\
\text { as research extends capabilities. [STRS, }\end{array}$ & & & & & \\
\hline $10-\mathrm{nm} \mathrm{SiO}_{2}$ & & & & & \\
\hline 7-nm SiO 2 & & & & & \\
\hline 5-nm SiO 2 & & & & & \\
\hline $\begin{array}{l}\text { Develop procedures and techniques for } \\
\text { improving quality of SIMOX silicon (low } \\
\text { defect density) and buried oxide (high } \\
\text { integrity) by careful control, analysis, and } \\
\text { associated measurement of critical post- } \\
\text { implantation processing. [STRS, OA-USA } \\
\text { SDC, OA-USAF Phillips Lab, OA-DNA] }\end{array}$ & & & & & \\
\hline $\begin{array}{l}\text { Develop and evaluate standard } \\
\text { measurement procedures for qualifying } \\
\text { material and for establishing critical } \\
\text { parameters for SOI material. [STRS, OA- } \\
\text { USA SDC, OA-USAF P lips Lab, OA- } \\
\text { DNA] }\end{array}$ & & & & & \\
\hline $\begin{array}{l}\text { Develop measurement service for single } \\
\text { wavelength ellipsometric measurement of } \\
\text { thin films for semiconductor industry. } \\
\text { [STRS, STRS-SRMPO] }\end{array}$ & & & & & \\
\hline $\begin{array}{l}\text { Design and fabricate circuits and } \\
\text { specialized test devices for correlation to } \\
\text { quality/characteristics of starting SOI } \\
\text { material. [STRS, OA-USA SDC, OA-USAF } \\
\text { Phillips Lab, OA-DNA] }\end{array}$ & & & & & \\
\hline
\end{tabular}




\section{Project: POWER DEVICE AND THERMAL MEASUREMENTS}

FY 92 Fund Sources: STRS; MIMIC; PTO; Alliance Technologies; S.C. State Government (Clemson Univ.)

Staff (2.4 staff-years)

\begin{tabular}{|l||l|l|l|l|}
\hline Professional & D. BLACKBURN & J. Albers* & D. Berning & A. Hefner, Jr. \\
\hline
\end{tabular}

name in capital letters $=$ project leader; $=$ person works on project part time

Objective: Develop and evaluate characterization and simulation tools to support the timely, efficient application of power semiconductor devices for power conditioning. Also, apply thermal characterization and analysis capabilities to devices and circuits of all types. Specifically, develop methods for determining the thermal and safe operating properties of power discrete, power ICs and GaAs ICs and implement physical device models into practical power circuits simulators.

Significance: Concerns for efficient use of electrical energy in the United States are driving the development of new semiconductor devices for controlling the flow of power to components, principally to motors, which by themselves consume some $60 \%$ of the $\$ 170$ billion worth of electric power generated domestically each year. Power semiconductor devices operate at higher temperatures, current densities, and voltages than do "nonpower" devices, the characterization and circuit simulation tools developed for nonpower applications are not adequate or relevant for power applications. The NIST program promotes the introduction of power devices by providing industry with improved measurement and circuit simulation tools for new devices. As circuits become more dense and new technologies and devices are introduced, the thermal problems long present in higher-power applications are becoming apparent in many "lowpower" applications. The NIST program builds on NIST's expertise in power thermal problems to develop tools for the thermal characterization of semiconductor devices broadly.

\section{FY 92 Accomplishments}

- Completed development of dynamic electro-thermal model for the insulated-gate bipolar transistor (IGBT) "chip," developed compact thermal component models for a representative silicon chip, package, and heatsink, and implemented the models and concept into a commercial software circuit-simulation package, demonstrating new methodology for electro-thermal simulation of systems. Completed implementation of buffer-layer model for the IGBT into the system simulator.

- Established failure limits and tentatively identified failure mechanisms for bipolar-mode FET. Discovered significant tendency for the structure to be thermally unstable (hot spots) [collaboration with industry and the University of Naples].

- Initiated studies of the failure limits and mechanisms for power and high-voltage ICs [collaboration with industry and Clemson University].

\section{FY 93 Plans}

- Complete development of prototype electro-thermal package model for typical smart, high-power module.

- Initiate and technically support joint project with EPRI for developing a database of verified models and device parameters for power circuit simulators.

- Provide direct assistance to manufacturers in the areas of safe operation of power ICs for flat-panel displays, parameter extraction procedures for high-power IGBTs, and commutating safe operation 
characterization of lateral, integrated power MOSFETs.

- Determine feasibility, via simulation and measurement, of using transient thermal response measurements for determining the die attach integrity of large, complex chips.

- Establish feasibility and determine limitations (e.g., spatial and temperature resolution) of using a micro Raman probe for measuring the temperature of active devices on a micrometer scale.

\section{Impact}

- Analogy, Inc. press release announced availability of NIST IGBT model in their Analogy's SABER system simulator. The company later announced the availability of a circuit model, based on the NIST work, for an IGBT automotive ignition module from Motorola on the same day the module was announced, a first in the simulator world.

- Measurement results on the safe operation of the bipolar-mode FET are being used by manufacturer to redesign structure.

\section{Recognition}

- An NIST ATP awardee has identified the Group as a source of expertise it needs to determine safe operating regions of integrated power FETs used in its products.

- PEAC has requested that NIST provide technical and planning support in establishing a national database for verified power device models and libraries, to be jointly funded by EPRI and NIST.

- Blackburn was elected a Fellow of the IEEE.

- Blackburn was appointed as an Associate Editor for the IEEE Transactions on Components, Hybrids and Manufacturing Technology for thermal characterization.

- Hefner received a best paper award at the 1992 IEEE Industry Applications Society Annual Meeting.

- Hefner was invited to give overview presentation for modeling and simulation at the Electric Power Research Institute's five-year planning workshop.

\section{Related Developments}

- Automobile manufacturers are responding to legislation enacted by California and others by accelerating development programs for electric-drive and hybrid-drive vehicles. Production vehicles will be critically dependent on advanced power semiconductors. 


\section{Project: ELECTRICAL AND THERMAL CHARACTERIZATION}

\begin{tabular}{|c|c|c|c|c|c|}
\hline FISCAL YEARS & 93 & 94 & 96 & 96 & 97 \\
\hline \multicolumn{6}{|l|}{$\begin{array}{l}\text { Develop well-characterized, physics-based } \\
\text { model (including buffer layer) for steady- } \\
\text { state and transient electrical and thermal } \\
\text { characteristics of Insulated Gate Bipolar } \\
\text { Transistor. [STRS, CRADA] }\end{array}$} \\
\hline \multicolumn{6}{|l|}{$\begin{array}{l}\text { Implement IGBT model into relevant } \\
\text { power electronic circuit simulators. } \\
\text { [STRS, CRADA] }\end{array}$} \\
\hline \multicolumn{6}{|l|}{$\begin{array}{l}\text { Develop compact thermal component } \\
\text { models for electro-thermal simulation. } \\
\text { [STRS, STRS-OMP, CRADA] }\end{array}$} \\
\hline $\begin{array}{l}\text { Develop measurement methods for } \\
\text { thermal and electrical properties of power } \\
\text { ICs. [STRS] }\end{array}$ & & & & & $=$ \\
\hline \multirow{2}{*}{\multicolumn{6}{|c|}{$\begin{array}{l}\text { Develop measurement methods for } \\
\text { thermal and electrical properties of }\end{array}$}} \\
\hline & & & & & \\
\hline \multirow{2}{*}{\multicolumn{6}{|c|}{$\begin{array}{l}\text { Develop methods for characterizing the } \\
\text { electrical and thermal properties of } \\
\text { electronic packages, including both } \\
\text { experimental and computer-simulation } \\
\text { methods. [STRS, STRS-OMP] }\end{array}$}} \\
\hline & & & & & \\
\hline \multirow{2}{*}{\multicolumn{6}{|c|}{$\begin{array}{l}\text { Develop methods for characterizing and } \\
\text { extracting parameters for very high power } \\
\text { devices and packages (modules). [STRS, } \\
\text { STRS-OMP, CRADA] }\end{array}$}} \\
\hline & & & & & \\
\hline \multicolumn{6}{|l|}{$\begin{array}{l}\text { Develop high spatial resolution } \\
\text { temperature measured based on Raman } \\
\text { spectroscopy. [STRS, STRS-OMP, OA- } \\
\text { Consortia] }\end{array}$} \\
\hline \multicolumn{6}{|l|}{$\begin{array}{l}\text { Develop methods for measuring important } \\
\text { electrical parameters of ceramic packages } \\
\text { based on TDR, S-parameters, and } \\
\text { network analysis. [STRS, STRS-OMP] }\end{array}$} \\
\hline $\begin{array}{l}\text { Develop methods for measuring thermal } \\
\text { properties of small GaAs and Si devices. } \\
\text { [STRS, STRS-OMP, OA-Consortium] }\end{array}$ & & & & & \\
\hline
\end{tabular}




\title{
Project: INTEGRATED MEASUREMENT SYSTEMS
}

\author{
FY 92 Fund Sources: STRS; OA-Army, -Navy
}

Staff (2.5 staff-years)

\begin{tabular}{|l||l|l|l|l|}
\hline Professional & M. GAITAN & D. Berning* & D. Novotny* & \\
\hline Technician & C. Ellenwood & G. Krepps* & J. Luther* & \\
\hline
\end{tabular}

name in capital letters = project leader; = person works on project part time

Objective: Develop, characterize and evaluate integratable microsensors based upon semiconductor fabrication technology for sensing motion, pressure and temperature. Specifically, introduce and develop a standard cell approach for micromachined sensors to facilitate the integration of the sensors with their control and monitoring functions and to facilitate foundry processing. Apply integrated microsensors to metrology problems for which they present a best or unique solution.

Significance: The development of microsensors, particularly those based upon the micromachining of semiconductors, will have tremendous impact on the ability to control and monitor mechanical, electrical, thermal, chemical, biological and other processes. The integration of these sensors with microelectronic circuits promises to make low-cost, accurate sensors available for a multitude of commercial, industrial, and military functions. The NIST program will help speed the integration of microsensors and provide the industry with sensor characterization tools, and will provide other areas at NIST with the ability to develop unique sensors for metrological problems of interest. The term "micromachining" refers to a fabrication operation using conventional silicon fabrication steps for all but the final step, an etch usually accomplished with relatively inexpensive equipment. By demonstrating that the silicon fabrication can be carried out in a foundry, NIST supports a broad entry into the micromachining field.

\section{FY 92 Accomplishments}

- Submitted to MOSIS Chip 6 which contained pixel structures of various sizes, an inductor circuit (in collaboration with UCLA), and thermal converter structures. Incorporated pixel structures of $20 \mu \mathrm{m}$, $50 \mu \mathrm{m}, 77 \mu \mathrm{m}$, and $144 \mu \mathrm{m}$ to evaluate the smallest possible operational pixel structures and to evaluate their performance as infrared sources and the inductor circuit for use in $90-\mathrm{GHz}$ tuner applications.

- Designed a 16-by-16 array of pixel structures with blocking diodes in order to study the uniformity of the devices, and completed the video interface for the array.

- Designed and submitted to MOSIS micromachine chip designs 7, 8, and 9; included in the new micro hot plates, a 16-by-16 dynamic thermal scene simulator, humidity sensors, inductor elements (in collaboration with UCLA), and 6-by-6 arrays of pixels of various sizes for uniformity testing. Evaluated uniformity of 6-by-6 arrays; preliminary results show $1.2 \%$ uniformity in resistance of the pixel elements. [MOSIS is a silicon foundry operation established by the National Science Foundation and (D)ARPA.]

- Designed and fabricated modified thermal converter structures, with consulatation by the Electricity Division.

- Designed new line structures of key-shaped and zigzag-shaped patterns for low-contrast infrared imaging applications.

- Designed and submitted to MOSIS micromachine chip designs 11 and 12. Incorporated in these chip 
designs new thermal microheater designs, microwave waveguides, and test structures for micromachine design rules.

- Prepared three patents on the micro hot plate and tin oxide gas sensor. [collaboration with the Process Measurements Division, Chemical Science and Technology Laboratory]

\section{FY 93 Plans}

Note: In FY 93, this project will be transferred to the Integrated Circuits Technology Group and will become part of the project on Test Structure Metrology for Advanced Semiconductor Manufacturing.

- Complete design and fabricate small-array thermal flat-panel display for dynamic thermal scene simulation. Begin demonstration of technology by interfacing with video signal source such as VCR.

- Design and begin evaluation of CMOS-compatible silicon micromachined waveguides and thermal converters for precision wide-band power sensors.

\section{Impact}

- A Cooperative Research and Development partner announced its first fabrication of a 4-by-4 dynamic thermal scene simulator chip based on the NIST technology.

- UCLA has reported that the suspended inductor structure, developed in collaboration with NIST, gave increased performance to their 5-GHz amplifier design.

\section{Recognition}

- Gaitan hosted the Micromachine Technology Meeting for DOC in which people from industry, government, and universities were invited to discuss the U.S. response to the new Japan MITI program on micro-electro-mechanical systems (MEMS). He was invited to give a tutorial at the 35th Midwestern Symposium on Circuits and Systems on Commercial CMOS Compatible MEMS and to give talks on his work at UCLA and at Carnegie-Mellon, and at George Washington University on the CMOS-compatible micromachining work.

- Gaitan was asked to announce the availability of the NIST-modified technology file for CMOS foundry micromachining in a column written by the head of the MOSIS Users Group in the IEEE Circuits and Devices Magazine.

- Gaitan served on the Sensors, Detectors, and Displays subcommittee of the IEEE International Electron Devices Meeting (IEDM).

\section{Related Developments}

- There is great excitement for the potential offered by micromachining, and many organizations in the United States are eager to participate. Given access to a silicon foundry, the low cost of the locally carried-out final etch is proving attractive to entrants.

- DTG has been asked by the Navy (with funding) to research the extension of the ac-dc thermal converter in MOSIS to include microwave frequencies. This work is already leading towards a CRADA with RF Microsystems, a San Diego-based company and should complement the work going on in the Microwave Measurements Division in Boulder. 


\section{Project: TEST STRUCTURES FOR RELIABILITY}

\section{FY 92 Fund Sources: STRS-OMP; (D)ARPA MIMIC}

Staff (4.5 staff-years)

\begin{tabular}{|l||l|l|l|l|}
\hline \multirow{2}{*}{ Professional } & H. SCHAFFT & J. Suehle & S. Witczak* & C. Schuster \\
\cline { 2 - 5 } & J. Albers & S. Mayo* & & \\
\hline Technician & L. Buck* & C. Ellenwood* & & \\
\hline
\end{tabular}

name in capital letters = project leader; $=$ person works on project part time

Objective: Develop test methodology needed by industry and government for assuring reliability of complex integrated circuits related primarily to electromigration and oxide integrity. Specifically, develop and promote new concepts for achieving reliability, develop new models for analyzing accelerated stress test data, support and work with industrial standards organizations, and seek to remove existing measurement ambiguities that interfere with the assurance of product reliability. Provide (D)ARPA MIMIC program with guidance in using test structures for reliability assessment in the fabrication of monolithic microwave integrated circuits.

Significance: Electromigration failure of metallization interconnects and failure of oxide integrity are two of the most critical reliability concerns facing the electronics industry for microelectronic devices. Both concerns become more important as feature sizes continue to decrease. Electromigration has been called the "big fear" for the 1990s and is reported to be the primary reliability problem in state-of-the-art memory chips. Competent and unbiased development by NIST is necessary to assure equity between buyer and seller and to enable improved technology transfer between manufacturers.

\section{FY 92 Accomplishments}

- Revised the EIA's Joint Electron Device Engineering Council Standard on measuring and using temperature coefficient of resistance (TCR) of a metallization. (OMP)

- Evaluated a surface-temperature probe and found its performance to meet needs for improved temperature measurement capability identified in first TCR interlaboratory experiment. Purchased a probe and a portable readout system to be sent for cestion purposes with testion the second interlaboratory experiment. [cc.ataration with Rennselaer Polytechnic Institute] (OMP)

- Oversaw the completion of an economic impact study of the electromigration work at NIST, which indicated a substantial saving to industry (see Impact section).

- Showed that the classical electromigration stress test can be used at ultra-high stress levels, but an enhancement, predicted in earlier work, represents a significant interference to making a correlation to use conditions. Discovered an unusually large enhancement of conductor lifetime under pulsed dc stress that depends on current density and oxide thickness.

- Developed a document for Wafer-Level Testing of Thin Dielectrics which was accepted as a EIA/JEDEC Standard. (OMP)

- Characterized the power lognormal distribution for modeling electromigration failure-time data which 
include a quantification of the length dependence and of a worst-case estimate of the early reliability of conductor lines. (OMP)

- Assembled a library, NISTGAAS, consisting of approximately 134 GaAs microwave and millimeter-wave test-structure designs developed under the (D)ARPA MIMIC Program.

- Set up a new measurement system and wrote software to perform constant-current injection experiments which indicated that the breakdown behavior of SIMOX (separation by implantation of oxygen) oxides is different from that of conventional thermal oxides.

- Developed the first monolithic tin oxide gas sensor realized with commercial CMOS by silicon micromachining. [collaboration with the Process Measurements Division, Chemical Science and Technology Laboratory]

- Designed and tested a sensor for in-situ monitoring of the deposition of metallization.

- Developed and used tester code to measure alignment-related test structures on the Wright Laboratory high-density, test-structure wafers and analyzed resulting data.

\section{FY 93 Plans}

Note: In FY 93, this project will be combined with the projects on Intelligent Test Structure Metrology and Test Structures for IC Manufacturing to form the project on Test Structure Metrology for Advanced Semiconductor Manufacturing.

- Conduct experiment on unpassivated metallization for evaluating the power lognormal distribution to model electromigration failure times. (OMP)

- Continue to promote the application of the Building-In Reliability (BIR) Approach in the industry and in NIST. (OMP)

- Conduct second JEDEC interlaboratory experiment to determine the precision of the JEDEC TCR measurement method when a common temperature calibration is available.

- Measure the thermal conductivity of selected oxide films as a function of film thickness and temperature using refined measurement and data analysis techniques.

\section{Impact}

- Impact study of NIST electromigration work showed that an investment of approximately $\$ 1.6$ million by NIST reaped an estimated total cost savings of over $\$ 26.6$ million for semiconductor producers.

\section{Recognition}

- Schafft served as organizer and General Chair of the 1992 Wafer Level Reliability Workshop, and served as the corresponding member of the Technical Program Committee of the 1992 European Symposium on Reliability of Electron Devices, Failures, and Physical Analysis. He presented invited talks on BIR in France and Germany.

- Suehle was asked to assist a manufacturer in replicating the NIST pulsed electromigration test station. Suehle was author/coauthor of three invited papers which appeared in print.

- Schafft was presented a plaque in recognition of 30 years of service to the International Reliability Physics Symposium. He served as the General Chair of IRPS 1992 and is Chair of the Board of Directors of IRPS. 


\section{Project: TEST STRUCTURES FOR IC MANUFACTURING}

\section{FY 92 Fund Sources: STRS-OMP; (D)ARPA}

\section{Staff (3.0 staff-years)}

\begin{tabular}{|l||l|l|l|l|}
\hline Professional & M. CRESSWELL* & A. Allen* & L. Linholm* & \\
\hline Technician & L. Buck* & C. Ellenwood* & J. Owen* & \\
\hline
\end{tabular}

name in capital letters $=$ project leader; $=$ person works on project part time

Objective: Develop test structures and related measurement processing algorithms for extracting critical dimensions of replicated features in the manufacture of advanced integrated circuits and mask reticles. Extend development of a test structure for the measurement of overlay capabilities of advanced lithographic systems approaching the $0.01-\mu \mathrm{m}$ level. Determine feasibility of contactless test-structure metrology in a manufacturing environment. Provide leadership to the (D)ARPA X-Ray Lithography Program Mask Standards Committee.

Significance: Without an accelerated effort, metrology capability will lag the semiconductor indust: s stated needs through the year 2000. In lithography, a critical requirement is feature placement metrology for primary pattern generator electron-beam tools. Measurements capable of distinguishing $10 \mathrm{~nm}$ are needed for control of critical dimensions and overlay during photo-imaging. In pattern transfer, plasma etch process development requires linewidth measurement to $0.12 \mu \mathrm{m}$, with $0.01-\mu \mathrm{m}$ precision and accuracy. In defect control, techniques for measuring the incidence of particles less than $0.1 \mu \mathrm{m}$ in size will be needed for the competitive manufacture of devices such as gigabit memories. NIST is developing advanced test structures for industry use in meeting these needs.

\section{FY 92 Accomplishments}

- Used a modified voltage-dividing potentiometer structure for feature-placement metrology and demonstrated that systematic errors resulting from asymmetrical inside corner rounding can be eliminated by having voltage taps extend across the current bridge. Developed a model of the intersection of two lines with asymmetric inside corner rounding and developed and experimentally verified a measurement technique that extracts the model parameters. Published paper on modeling the effects of asymmetrical inside corner rounding in Solid State Electronics; reported that the resulting test structure performed with better than 7-nm uncertainty. Filed two related applications for U.S. Patents. (OMP)

- Demonstrated that a mathematical model yielded excellent agreement with measurements extracted from a 1000:1 scaled-up capacitively coupled linewidth bridge over the frequency range $10 \mathrm{kHz}$ to $5 \mathrm{MHz}$. Collaborated with an instrument manufacturer in developing a successful proposal to (D)ARPA for applying to fabrication with cluster tooling a noncontact test structure for linewidth measurement via cross-bridge resistor. Developed and documented noncontact approaches using

(a) infrared diffraction grating test structures and (b) resonant inductive/capacitive radiofrequency circuits in preparation for patent application purposes. Also proposed an interdigitated planar capacitor with linewidth-dependent capacitance which may be extracted by capacitative or inductive coupling. (OMP)

- Developed a technique for low-cost feature-placement metrology featuring a test structure that is partially defined with a reusable artifact calibrated with the NIST nanometer-scale coordinate 
measuring system. [collaboration with Precision Engineering Division, Manufacturing Engineering Laboratory] (OMP)

- Revised the proposal on Test Structures for IC Manufacturing and submitted it to SEMATECH. Assisted SEMATECH in the planning and execution of a Yield Management Workshop in Austin.

\section{FY 93 Plans}

Note: In FY 93, this project will be combined with the projects on Intelligent Test Structure Metrology and Test Structures for Reliability to form the project on Test Structure Metrology for Advanced Semiconductor Manufacturing.

- Develop a robust, low-cost, electrical test-structure metrology for primary pattern feature placement and overlay with calibration that is traceable to atomic spacings. [collaboration with Precision Engineering Division] (OMP)

- Model candidate architectures of noncontact radiofrequency test structures for extraction of critical dimensions of replicated features. (OMP)

- Continue present strategy to license the particle sensor patent to the clean-room industry.

- Obtain agreement between the major players in the U.S. X-ray lithography industry infrastructure on the dimensions of a standard membrane support ring.

\section{Recognition}

- The project has been invited to use the services of SEMI-SEMATECH to investigate the use of the project's particle detector invention in photographic, pharmaceutical, and environmental areas.

- Cresswell serves as Chairman of the (D)ARPA X-Ray Program Mask Standards and Resist Modeling Standards Committees, and was General Chairman of the 1992 IEEE International Conference on Microelectronic Test Structures. He has been appointed to the Semiconductor Research Corporation Lithography Thrust Evaluation Team of the Manufacturing Process Sciences Technical Advisory Board and serves on SEMATECH's X-Ray Lithography's Working Group.

- The paper, "Voltage-Dividing Potentiometer Enhancements For High-Precision Feature Placement Metrology," received a Best Paper Award at the IEEE International Conference on Microelectronic Test Structures in March 1992.

\section{Related Developments}

- The NIST-led and -organized (D)ARPA X-Ray Program Mask Standards Committee has agreed upon mask dimensional standards for the manufacturing of ICs by means of X-ray lithography. 


\section{Project: INTELLIGENT TEST STRUCTURE METROLOGY}

\section{FY 92 Fund Sources: STRS, STRS-OMP; (D)ARPA MIMIC}

\section{Staff (1.9 staff-years)}

\begin{tabular}{|l||l|l|l|l|}
\hline \multirow{2}{*}{ Professional } & L. LINHOLM* & R. Allen* & M. Cresswell* & D. Khera* \\
\cline { 2 - 5 } & M. Zaghloul* & & & \\
\hline \multirow{2}{*}{ Technician } & L. Buck* & C. Ellenwood* & J. Owen* & \\
\hline
\end{tabular}

name in capital letters = project leader; $=$ person works on project part time

Objective: Design, develop, and evaluate integrated-circuit test structures and expert-system-based diagnostic analysis techniques for use in rapidly and accurately determining selected semiconductor process parameters required for improving the parameter control, yield potential, and manufacturing throughput of complex integrated circuits.

Significance: Increased complexity of integrated circuits for both military and civilian applications makes complete performance testing impractical or impossible and intensifies the need for measurements that can verify design, performance, and fabrication processes and equipment operation. Integrated-circuit test structures coupled with thoroughly evaluated diagnostic expert systems and machine-learning codes provide a powerful metrological means for meeting this need. Needed are improved structures thoroughly validated as to capabilities, limitations, and interferences, as well as innovative expert system analysis tools for improving test coverage. Competent and unbiased development by NIST is necessary to assure equity between buyer and seller and to enable improved technology transfer between manufacturers.

\section{FY 92 Accomplishments}

- Developed and delivered an initial prototype expert system for determining the feasibility of applying expert system methodology to capacitance-voltage curve diagnosis; developed rules for the system based on heuristic knowledge from industrial and NIST experts. Incorporated revisions to system following reviews. Received support from industrial partner in form of purchase of license for NIST copy of advanced expert system shell software. [collaboration with industry] (OMP)

- Completed initial evaluation of linewidth measurements by a variety of techniques: optical, electrical, and scanning electron microscopy (SEM). Arranged for manufacturer to fabricate initial specimens for these tests, polysilicon on silicon and titanium on quartz; incorporated quartz substrate to enable linewidth measurement via highly accurate optical techniques at NIST. Analyzed initial results and found agreement between SEM and optical methods to be less than $90 \mathrm{~nm}$. Arranged for fabrication of second set of test specimens having improved edge quality. [collaboration with industry and Precision Engineering Division, Manufacturing Engineering Laboratory] (OMP)

- Installed replacement wafer probe station; following training and qualification testing, declared it to be operational in June 1992. (OMP)

\section{FY 93 Plans}

Note: In FY 93, this project will be combined with the projects on Test Structures for IC Manufacturing and Test Structures for Reliability to form the project on Test Structure Metrology for Advanced Semiconductor Manufacturing.

- Continue collaboration with industry to establish correlation between optical and electron-beam-based 
linewidth metrologies and electrical techniques. (OMP)

- Identify a selection of rules for a capacitance-voltage diagnostic expert system by coupling an MOS model to neural network and/or other classification algorithms. (OMP)

\section{Impact}

- A major U.S. semiconductor manufacturer reports using NIST-developed cross-bridge test structures. SEMATECH is utilizing NIST staff to assist in defining yield management strategies.

- NIST staff members Linholm and Cresswell assisted SEMATECH in developing the concept for planning and organizing a Yield Management Workshop, April 14-15, 1992 (results of the Workshop can be found in SEMATECH publication 92051108A-WS).

\section{Recognition}

- Linholm is serving on the GOMAC Steering Committee as Awards Chairman, for the 1992 IEEE International Conference on Microelectronic Test Structure (ICMTS) as Local Arrangements and Steering Committee Chairman, for the 1993 ICMTS as U.S. Representative and Steering Committee Chairman, and as NIST representative to DoD Advisory Group on Electron Devices Working Group B: Microelectronics.

- Linholm and Allen have been invited to participate in an IEEE Workshop describing NIST test structure development at 1993 International Conference on Microelectronic Test Structures.

- Linholm was invited to make presentation to a major computer manufacturer on NIST test-structure research. 


\section{Project: TEST STRUCTURE METROLOGY FOR ADVANCED SEMICONDUCTOR MANUFACTURING}

\begin{tabular}{|c|c|c|c|c|c|}
\hline FISCAL YEARS & 93 & 94 & 95 & 96 & 97 \\
\hline $\begin{array}{l}\text { Establish correlation between optical and } \\
\text { electron-beam-based linewidth } \\
\text { metrologies and electrical techniques. } \\
\text { [STRS-OMP, OA] }\end{array}$ & & & & & \\
\hline $\begin{array}{l}\text { Produce/implement expert system for } \\
\text { evaluating CV data. [STRS, OA-CRADA] }\end{array}$ & & & & & \\
\hline $\begin{array}{l}\text { Identify and apply robust machine-learning } \\
\text { codes for semiconductor data with } \\
\text { industrial collaborator for tool } \\
\text { characterization. [STRS-OMP, OA- } \\
\text { CRADA] }\end{array}$ & & & & & \\
\hline $\begin{array}{l}\text { Demonstrate robust } 10-\mathrm{nm} \text { overlay } \\
\text { metrology for thin conducting films on } \\
\text { quartz substrates. [STRS, STRS-OMP, } \\
\text { OA] }\end{array}$ & & & & & \\
\hline $\begin{array}{l}\text { Develop and demonstrate electrical test } \\
\text { structure based metrology for pattern } \\
\text { feature placement and overlay that is } \\
\text { traceable to MEL M }{ }^{3} \text {. [STRS-OMP, OA, } \\
\text { Director's Reserve] }\end{array}$ & & & & & \\
\hline $\begin{array}{l}\text { Develop on-wafer, multilevel conductor- } \\
\text { compatible overlay metrology with a goal } \\
\text { of better than 20-nm precision. [STRS. } \\
\text { STRS-OMP, OA] }\end{array}$ & & & & & \\
\hline $\begin{array}{l}\text { Develop and implement approaches to the } \\
\text { commercialization and licensing of } \\
\text { selected test structures/methods. [STRS, } \\
\text { OA] }\end{array}$ & & & & & \\
\hline $\begin{array}{l}\text { Characterize reliability of thin oxide films } \\
\text { for ULSI processes. ISTRS, STRS-OMP, } \\
\text { OA] }\end{array}$ & & & & & \\
\hline $\begin{array}{l}\text { Promote implementation of building-in } \\
\text { reliability approach in industry and } \\
\text { government; demonstrate approach for } \\
\text { deposition of thin metal films or integrity } \\
\text { of oxides. [STRS-OMP, OA] }\end{array}$ & & & & & \\
\hline
\end{tabular}




\section{Project: TEST STRUCTURE METROLOGY FOR ADVANCED SEMICONDUCTOR MANUFACTURING (concluded)}

\begin{tabular}{|c|c|c|c|c|c|}
\hline FISCAL YEARS & 93 & 94 & 95 & 96 & 97 \\
\hline \multicolumn{6}{|l|}{$\begin{array}{l}\text { Complete JEDEC interlaboratory } \\
\text { experiment for measuring TCR of } \\
\text { metallizations. [OA-(D)ARPA] }\end{array}$} \\
\hline \multirow{2}{*}{\multicolumn{6}{|c|}{$\begin{array}{l}\text { Develop, characterize, and evaluate } \\
\text { integrated sensor elements for improving } \\
\text { reliability by monitoring in-situ and } \\
\text { controlling deposition of films. [STRS- } \\
\text { OMP, OA] }\end{array}$}} \\
\hline & & & & & \\
\hline \multicolumn{6}{|l|}{$\begin{array}{l}\text { Measuring thermal conductivity of oxide } \\
\text { films as a function of film thickness and } \\
\text { temperature. [STRS-OMP] }\end{array}$} \\
\hline \multicolumn{6}{|l|}{$\begin{array}{l}\text { Design, develop, and evaluate } \\
\text { micromachined structures and associated } \\
\text { drive and control circuitry for dynamic } \\
\text { thermal scene simulation. [OA-Army] }\end{array}$} \\
\hline \multicolumn{6}{|l|}{$\begin{array}{l}\text { Develop methodology for fabricating } \\
\text { micromachined structures in silicon } \\
\text { foundries to point of practical utilization. } \\
\text { [OA-Army] }\end{array}$} \\
\hline \multicolumn{6}{|l|}{$\begin{array}{l}\text { Design, fabricate, help evaluate sensors } \\
\text { important for metrology, calibration, and } \\
\text { standardization through collaboration with } \\
\text { other NIST divisions. [STRS, OA] }\end{array}$} \\
\hline $\begin{array}{l}\text { Develop CMOS-compatible } \\
\text { micromachined waveguides and thermal } \\
\text { converters for precision wide-band } \\
\text { sensors. [OA] }\end{array}$ & & & & & \\
\hline
\end{tabular}


$-132-$ 


\section{ELECTROMAGNETIC FIELDS DIVISION}




\section{Project: POWER STANDARDS AND MEASUREMENTS}

FY 92 Fund Sources: STRS, OA, DOD, Calibration Fees

Staff (8.0 staff-years)

\begin{tabular}{|l||l|l|l|l|}
\hline \multirow{2}{*}{ Professional } & N. LARSEN & F. Clague & J. Jargon* & J. Juroshek* \\
\cline { 2 - 5 } & G. Rebuldela* & D. Walke* & M. Weidman* & D. Williams* \\
\hline Technician & D. LeGolvan * & C. Ondrejka* & A. Monke* & M. Packer * \\
\hline & D. Seibold * & P. Voris & & \\
\hline
\end{tabular}

name in capital letters $=$ project leader; $=$ person works on project part time

Objective: Establish NIST microwave power standards from $10 \mathrm{MHz}$ to $100 \mathrm{GHz}$ in coaxial line, from $18 \mathrm{GHz}$ to $96 \mathrm{GHz}$ in WR-42, $-28,-22,-15$ and -10 waveguides; with uncertainties of 0.1 to 0.5 percent; develop new isothermal microcalorimeters for reference standards in WR-42, WR-22, WR-15, and WR10 waveguide; provide high-power (50 to 1000 watt) measurements and standards from $1 \mathrm{MHz}$ to $1 \mathrm{GHz}$, and to 40 watts near $60 \mathrm{GHz}$ with uncertainties of 1 to 3 percent. Develop and maintain measurement systems and reference standards used in calibration services for power. [Note on waveguide band designations: WR-42 $=18$ to $26 \mathrm{GHz}$; WR-28 $=26.5$ to $40 \mathrm{GHz}$; WR-22 $=33$ to $50 \mathrm{GHz}$; WR-15 $=50$ to $75 \mathrm{GHz}$; WR-10 $=75$ to $110 \mathrm{GHz}$.]

Significance: Microwave power is a fundamental quantity for every commercial and military application of microwave energy - communication, navigation, surveillance, manufacturing, aerospace, medical, defense, entertainment, advanced computing, etc. This program establishes a new generation of NIST microwave power standards to meet vital present and future needs of industry.

\section{FY 92 Accomplishments}

- Initiated negotiations with a manufacturer which may lead to the development of a new type of dcsubstitution detector for use in small-size coax.

- Completed construction of WR-42 and WR-22 microcalorimeters. Completed design of WR-15 microcalorimeter.

- Completed the construction of waveguide transfer standards in WR-42, WR-22 and WR-15.

- Completed evaluation of 7-mm coaxial microcalorimeter. Found measurement uncertainty to be few tenths of a percent.

- Fabricated power head and microwave load for superconducting WR-22 power meter. Determined sources of systematic error and developed strategy to eliminate errors.

- Completed design and delivery of 1-mW, 1-GHz prototype power measurement system to U. S. Air Force.

- Began the new premium calibration service for the special NIST-designed Type CN, 50-MHz to 18GHz coaxial transfer standards to provide the customer accuracy equal to NIST's in-house working standards (transfer standards are calibrated directly in the automated microcalorimeter). 
- Determined that an existing commercial 2.4/3.5-mm power sensor design, with modification, can be the basis for a bolometric type power detector using semiconductor fabrication techniques.

- Established special calibration service for high-power $\mathrm{cw}$ wattmeters; 1 to $30 \mathrm{MHz}$ at 1 to $1000 \mathrm{~W}$ and 30 to $400 \mathrm{MHz}$ at 1 to $500 \mathrm{~W}$.

- Completed evaluation and documentation of two waveguide/mount power meters at 58, 60 and 62 $\mathrm{GHz}$.

\section{FY 93 Plans}

- Pursue development of a new type of dc-substitution detector suitable for use in 2.4-mm line (probably jointly with industry).

- Develop direct comparison system that operates from $50 \mathrm{MHz}$ to $18 \mathrm{GHz}$ for use in power calibration service.

- Establish feasibility of superconducting WR-22 power meter with systematic measurement errors less than 0.02 percent at $4 \mathrm{~K}$ measurement port.

- Begin the evaluations of the WR-42, -22 , and -10 microcalorimeters, completing the WR-22 evaluation if power sources are available.

- Extend present high-power calibrations at Redstone from 1 to $2.5 \mathrm{GHz}$ (1 to $100 \mathrm{~W}$ ).

- Provide power calibration and measurement services.

\section{Impact}

- Newly developed Type $\mathrm{N}$ thermistor mounts matched to the automated microcalorimeter enable NIST customers to have units with same design as NIST working standards, bypassing a transfer step. Customers can thereby have standards as accurate as NIST's. Three major U.S. user companies have already purchased the Type $\mathbf{N}$ transfer standards.

\section{Recognition}

- Customers are purchasing NIST-designed transfer standards and power meters.

\section{Related Developments}

- A major U.S. instrument company, by customer request, is considering establishing a calibration service for thermoelectric and diode based power meters. These are not calibrated by NIST since they lack stability as a power transfer standard. NIST supports the calibrations by providing information and assistance on customer power transfer using calibrated thermistor mounts or mount/adapter combinations. 
Project: POWER STANDARDS AND MEASUREMENTS

\begin{tabular}{|c|c|c|c|c|c|}
\hline FISCAL YEARS. & 93 & 94 & 95 & 95 & 97 \\
\hline MICROCALORIMETER DEVELOPMENT & & & & & \\
\hline $\begin{array}{l}\text { WR-10, }-15,-22,-42 \text { construction. } \\
\text { [STRS] }\end{array}$ & & & & & \\
\hline Coaxial $3.5 \mathrm{~mm}$ and smaller. [STRS, OA] & & & & & \\
\hline $\begin{array}{l}\text { WR-10, }-15,-22,-42 \text { evaluations. [STRS, } \\
\text { OA] }\end{array}$ & & & & & \\
\hline $\begin{array}{l}\text { TRANSFER STANDARDS/CALIBRATION } \\
\text { SYSTEMS DEVELOPMENT }\end{array}$ & & & & & \\
\hline $\begin{array}{l}\text { Develop } 7 \mathrm{~mm} \text { coax transfer standards } \\
<50 \mathrm{MHz} \text {. [OA] }\end{array}$ & & & & & \\
\hline $\begin{array}{l}\text { Evaluate } 7 \mathrm{~mm} \text { coax transfer standards < } \\
50 \mathrm{MHz} \text {. }[\mathrm{OA}]\end{array}$ & & & & & \\
\hline $\begin{array}{l}\text { Develop coax power standards } 5 \mathrm{MHz} \text { to } \\
1 \mathrm{GHz} \text {. [OA] }\end{array}$ & & & & & \\
\hline $\begin{array}{l}\text { Construct coaxial thermistor standards for } \\
\text { DOD and industrial labs. [OA] }\end{array}$ & & & & & \\
\hline $\begin{array}{l}2.4 \text { and } 3.5 \mathrm{~mm} \text { thermistor standards to } \\
50 \mathrm{GHz} \text {. [OA] }\end{array}$ & & & & & \\
\hline $\begin{array}{l}\text { Build/calibrate } 1 \mathrm{GHz} \text { reference power } \\
\text { meters for Air Force. [OA] }\end{array}$ & & & & & \\
\hline $\begin{array}{l}\text { Develop direct comparison measurement } \\
\text { system. [Fees] }\end{array}$ & & & & & \\
\hline
\end{tabular}


Project: POWER STANDARDS AND MEASUREMENTS (continued)

\begin{tabular}{|l|l|l|l|l|l|}
\hline FISCAL YEARS & 93 & 94 & 96 & 96 & 97 \\
\hline WORKING STANDARDS EVALUATION & & & & & \\
\hline Coaxial 7 mm to 18 GHz. [STRS, Fees] & & & & & \\
\hline $\begin{array}{l}\text { WR-42, WR-28, WR-15, WR-10 } \\
\text { thermistor mounts. [STRS, Fees] }\end{array}$ & & & & & \\
\hline SUPERCONDUCTING STANDARDS & & & & & \\
\hline $\begin{array}{l}\text { Feasibility study for WR-22 power } \\
\text { standards. [OA] }\end{array}$ & & & & & \\
\hline $\begin{array}{l}\text { Construct/evaluate device if feasible. } \\
\text { [STRS, OA] }\end{array}$ & & & & & \\
\hline CALIBRATION/MEASUREMENT SERVICES & & & & & \\
\hline $\begin{array}{l}\text { Modify uncertainty statements per NIST } \\
\text { guidelines. [STRS] }\end{array}$ & & & & & \\
\hline Existing calibration services. [Fees] & & & & & \\
\hline
\end{tabular}




\section{Project: IMPEDANCE, ATTENUATION, VOLTAGE STANDARDS AND MEASUREMENTS}

FY 92 Fund Sources: STRS, DOD, Calibration Fees

Staff (6.0 staff-years)

\begin{tabular}{|l||l|l|l|l|}
\hline Professional & G. REBULDELA & G. Free* & R. Ginley* & J. Jargon* \\
\hline Technician & P. Delara & E. Pittman* & G. Sherwood & D. Seibold \\
\hline
\end{tabular}

name in capital letters = project leader; $=$ person works on project part time

Objective: Preserve and improve the NIST physical standards for impedance, reflection coefficient, attenuation, and voltage. Enhance rf/microwave calibration services through continued improvements of standards, measurement systems, and measurement techniques.

Significance: Standards and their connectors must be improved to fully utilize the potential of modern instruments and meet the needs of a rapidly advancing industry and technology. The measurement of power or attenuation is not meaningful without a statement of the impedance of the device under test relative to that of the measuring standard. NIST standards and services provide the basis for U.S. microwave measurements. NIST methodology ensures that these standards and services will meet industry's advancing needs. Examples: (1) Industry is demanding services at higher and higher frequencies. Since higher frequencies require the use of smaller coaxial connectors, their physical characteristics must be determined with tighter tolerances. NIST's dimensional capabilities combined with the mathematical modelling of electrical parameters based on physical measurements are important for the accurate characterization of vector network analyzers. (2) Attenuation measurements in support of the radar and communication industries have long been traceable to a $30 \mathrm{MHz}$ standard. The improvement in the accuracy of $30 \mathrm{MHz}$ piston attenuation measurements to $0.0001 \mathrm{~dB}$ will meet the increasing demands of new systems developed in those industries. (3) Enhanced measurements of dissipation factor will improve quality control for manufacturing capacitors and the development of improved capacitors in the multi-million dollar ceramic capacitor industry.

\section{FY 92 Accomplishments}

- Completed study which showed that the impedance of an air line could be obtained accurately from capacitance measurements, a method that may prove more accurate than traditional dimensional measurements.

- Designed and constructed system to measure inner conductor of airlines using a laser micrometer.

- Improved design of comparison receiver and wrote software to perform automatic null for $30-\mathrm{MHz}$ attenuator system. The resolution is adequate for a $0.0001 \mathrm{~dB}$ uncertainty.

- Constructed and tested a 30-MHz precision linearity system for the 6.02-dB primary step of attenuation.

- Designed and constructed a stepping motor system to adjust variable capacitors in impedance brid ras; accuracy of calibration of variable capacitors improved by an order of magnitude and time g: reduced.

- Designed and constructed low-frequency Twin-Tee bridge (10 $\mathrm{kHz}$ to $5 \mathrm{MHz}$ ) which allows mure accurate measurements of impedance. 
FY 93 Plans

- Complete development of 30-MHz Linear Measurement System and 30-MHz, 6.02-dB primary step attenuation system.

- Document 30-MHz, 6.02-dB primary step system and establish special measurement service.

- Complete documentation of calibration service for thermal voltage converters and micropotentiometers.

- Complete construction and test semi-automated system to measure diameter of air lines on laser micrometer.

- Complete testing and calibration of low-frequency Twin-Tee bridge and establish special measurement services.

- Design and construct new drive mechanism for variable capacitors in Mark III bridge.

- Provide calibration services in voltage $(10 \mathrm{~Hz}$ to $1 \mathrm{GHz})$ and attenuation at $30 \mathrm{MHz}$ and $1.25 \mathrm{Ghz}$.

\section{Related Developments}

- The recent introduction to the commercial market of precision waveguide-below-cutoff standard attenuators with a resolution approaching $0.0001 \mathrm{~dB}$ and a claimed uncertainty of 0.0002 to $0.0003 \mathrm{~dB}$ per 10-dB increment required the 30-MHz piston attenuator system. For example, when the Department of Defense Primary Standards laboratories purchased these attenuators, they turned to NIST for measurments to verify that the claims for accuracy were being met. 
Project: IMPEDANCE, ATTENUATION, VOLTAGE STANDARDS AND MEASUREMENTS

\begin{tabular}{|c|c|c|c|c|c|}
\hline FISCAL YEARS & 93 & 94 & 95 & 96 & 97 \\
\hline $\begin{array}{l}\text { DIMENSIONAL MEASUREMENTS OF AIR } \\
\text { LINE STANDARDS }\end{array}$ & & & & & \\
\hline $\begin{array}{l}\text { Complete air gauge automation, quality } \\
\text { assurance; new software/graphics: three } \\
\text { axis coordination machine. [STRS] }\end{array}$ & & & & & \\
\hline $\begin{array}{l}\text { Construction and evaluation of laser } \\
\text { micrometer to measure } 2.4,2.92 \text { and } \\
1.85 \mathrm{~mm} \text { air lines. [STRS] }\end{array}$ & & & & & \\
\hline $\begin{array}{l}\text { IMPEDANCE STANDARDS } \\
\text { DEVELOPMENT/EVALUATION }\end{array}$ & & & & & \\
\hline $\begin{array}{l}\text { Investigate alternate Z standards (ie; } \\
\text { capacitance). [STRS] }\end{array}$ & & & & & \\
\hline $\begin{array}{l}\text { Evaluate E-formed waveguide standards } \\
\text { for WR-90, }-62,-42,-28,-22,-15,-10 \text {. } \\
\text { [STRS, OA] }\end{array}$ & & & & & \\
\hline $\begin{array}{l}\text { Evaluate connector discontinuities: } \\
\text { coax/wg. [STRS, OA] }\end{array}$ & & & & & \\
\hline $\begin{array}{l}\text { Adapt MMIC planar work to coaxial. } \\
\text { [STRS] }\end{array}$ & & & & & \\
\hline $\begin{array}{l}\text { Develop simulator code for connector } \\
\text { discontinuities. [STRS, OA] }\end{array}$ & & & & & \\
\hline $\begin{array}{l}\text { LOW FREQUENCY IMPEDANCE } \\
\text { MEASUREMENTS }\end{array}$ & & & & & \\
\hline $\begin{array}{l}\text { Publish report of international comparison } \\
\text { of Q-standards. [STRS] }\end{array}$ & & & & & \\
\hline $\begin{array}{l}\text { Develop low frequency impedance } \\
\text { measurement system to } 5 \mathrm{MHz} \text {. [STRS, } \\
\text { OA] }\end{array}$ & & & & & \\
\hline
\end{tabular}


Project: IMPEDANCE, ATTENUATION, VOLTAGE STANDARDS AND MEASUREMENTS (continued)

\begin{tabular}{|c|c|c|c|c|c|}
\hline FISCAL YEARS & 93 & 94 & 95 & 96 & 97 \\
\hline $\begin{array}{l}\text { LOW FREQUENCY IMPEDANCE } \\
\text { MEASUREMENTS (cont'd.) }\end{array}$ & & & & & \\
\hline $\begin{array}{l}\text { Develop Mark III impedance measurement } \\
\text { system from } 5 \mathrm{MHz} \text { to } 250 \mathrm{MHz} \text {. [STRS, } \\
\text { OA] }\end{array}$ & & & & & \\
\hline $\begin{array}{l}\text { Develop four-port capacitance system to } \\
10 \mathrm{MHz} \text {. [STRS, OA] }\end{array}$ & & & & & \\
\hline VOLTAGE MEASUREMENTS & & & & & \\
\hline Document TVC system. [STRS] & & ש & & & \\
\hline Document micropot system. [STRS] & & & & & \\
\hline ATTENUATION STANDARDS (30MHz) & & & & & \\
\hline $\begin{array}{l}\text { Complete and evaluate NIST primary } \\
\text { WBCO standard. [STRS, OA] }\end{array}$ & & & & & \\
\hline $\begin{array}{l}\text { Intercompare NIST standard with British } \\
\text { attenuators. [OA] }\end{array}$ & & & & & \\
\hline Develop 6.02-decibel step standard. [OA] & & & & & \\
\hline Automate 30-MHz WBCO system. [STRS] & & & & & \\
\hline
\end{tabular}


Project: IMPEDANCE, ATTENUATION, VOLTAGE STANDARDS AND MEASUREMENTS (concluded)

\begin{tabular}{|l|l|l|l|l|l|}
\hline FISCAL YEARS & 93 & 94 & 95 & 96 & 97 \\
\hline CALIBRATION/MEASUREMENT SERVICES & & & & & \\
\hline TVC/micropot calibration service. [Fees] & & & & & $\Rightarrow$ \\
\hline $\begin{array}{l}\text { Low frequency impedance, resistance } \\
\text { calibration service.[Fees] }\end{array}$ & & & & & \\
\hline $\begin{array}{l}\text { Convert to uncertainty expressions per } \\
\text { NIST guidelines. [STRS] }\end{array}$ & & & & & \\
\hline
\end{tabular}


Project: NETWORK ANALYSIS AND MEASUREMENTS

FY 92 Fund Sources: STRS, OA, DOD, Calibration Fees

Staff (8.0 staff-years)

\begin{tabular}{|l||l|l|l|l|}
\hline \multirow{2}{*}{ Professional } & R. JUDISH & R. Ginley* & J. Juroshek* & R. Kaiser \\
\cline { 2 - 5 } & J. Major* & G. Rebuldela* & M. Weidman* & \\
\hline Technician & D. LeGolvan* & N. Martinez & A. Monke* & C. Ondrejka* \\
\hline & M. Packer* & D. Seibold* & K. Talley & \\
\hline
\end{tabular}

name in capital letters $=$ project leader; $=$ person works on project part time

Objective: Develop and disseminate efficient and cost effective methods for evaluating and validating the performance of vector automatic network analyzers (VANAs). Maintain NIST developed dual six-ports to support calibration services. Provide traditional calibration services for S-parameters. [Note on waveguide band designations: WR- $42=18$ to $26 \mathrm{GHz}$; WR-28 $=26.5$ to $40 \mathrm{GHz}$; WR-22 $=33$ to $50 \mathrm{GHz}$; WR-15 $=50$ to $75 \mathrm{GHz} ; \mathrm{WR}-10=75$ to $110 \mathrm{GHz}$.]

Significance: Vector Automatic Network Analyzers are becoming the single most important tool in the microwave research and development laboratory. The procedures to characterize and validate VANAs are not well established, and the traditional calibration hierarchy is not applicable for $S$-parameter measurements. The NIST effort to evaluate and validate VANAs is a step toward solving the practical problems to ensure ANAs can be traceable to national standards.

\section{FY 92 Accomplishments}

- Purchased commercial vector network analyzer (VANA) and put on-line for calibration backup; put second VANA supplied by industrial Cooperative Research and Development partner on-line for use in VANA evaluation study.

- Completed documentation for the 7-mm S-parameter calibration service and submitted to NIST approval process.

- Incorporated through-reflect-line-line (TRLL) calibration algorithm into all coaxial/waveguide six-port software; modified auxiliary data processing and reporting software for the TRLL algorithm.

- Installed software system for on-line data management on the calibration network.

- Finalized design for Air Force System II Dual Six-Port Upgrade.

- Assembled and tested three sets of six-port heads (2 to $18 \mathrm{GHz}$ ) for Navy Primary Standards Laboratory to augment existing capability.

- Obtained manually tuned sources to provide dual six-port coverage from 50 to $70 \mathrm{GHz}$.

- WR-42/28 dual six-port completed and delivered to the Navy Primary Standards Lab.

- Developed 18- to 40-GHz all-coaxial dual six-port using diode detectors. 


\section{FY 93 Plans}

- Develop methods to evaluate and validate commercial VANAs. [collaboration with industry]

- Transfer calibration software to commercial VANA and develop Special Test Service for devices with 2.92-mm connectors.

- Initiate development of low frequency dual six-port $(0.1$ to $1 \mathrm{GHz})$ for Air Force Primary Standards Laboratory.

- Obtain narrow band sources for WR-15 to cover the complete band.

- Continue evaluation of WR-10, -15 , and -22 dual six-ports.

- Continue development of dual six-port $(0.25$ to $18 \mathrm{GHz})$ for Air Force Primary Standards Laboratory.

- Convert data bases for check standards from DOS-based platform to UNIX-based platform.

- Provide advertised S-parameter calibration and measurement services.

\section{Related Developments}

- Overall demands for NIST microwave calibrations have remained stable despite increasing costs, shrinking budgets, and curtailed programs.

- Members of the National Council of Standards Laboratories (NCSL) are expressing concerns about the costs of meeting EC 92 requirements and about NIST's role in NIST accreditation.

- NIST clientele are raising calibration related inquiries on measurement methodology, traceability, uncertainties, transfer techniques and measurement assurance, suggesting that NIST must develop alternative approaches to conventional calibrations and new ways to transfer expertise.

- Demand for the IEEE Automatic RadioFrequency Techniques Group (ARFTG) measurement comparison demonstrates a need for alternative and cost-effective measurement services. A modified form of the ARFTG program may provide a basis for accreditation. 
Project: NETWORK ANALYSIS AND MEASUREMENTS

\begin{tabular}{|c|c|c|c|c|c|}
\hline FISCAL YEARS & 93 & 94 & 95 & 96 & 97 \\
\hline SIX-PORT DEVELOPMENT & & & & & \\
\hline $\begin{array}{l}\text { Evaluate diode-based six-port system (18 } \\
\text { to } 40 \mathrm{GHz} \text { ). [STRS] }\end{array}$ & & & & & \\
\hline $\begin{array}{l}\text { Complete fullband systems at } 50 \text { to } 75 \\
\text { and } 75 \text { to } 110 \mathrm{GHz} \text {; refurbish Navy and } \\
\text { Air Force coaxial six-port systems. [OA] }\end{array}$ & & & & & \\
\hline $\begin{array}{l}\text { Complete construction of coaxial six-port } \\
\text { from } 2 \text { to } 18 \mathrm{GHz} \text {. [STRS] }\end{array}$ & & & & & \\
\hline $\begin{array}{l}\text { Complete and deliver coaxial six-port } \\
\text { system ( } 2 \text { to } 18 \mathrm{GHz} \text { ) to Air Force. [OA] }\end{array}$ & & & & & \\
\hline $\begin{array}{l}\text { Upgrade coaxial six-port } 10 \text { to } 1000 \mathrm{MHz} \\
\text { for NIST and Air Force. [OA] }\end{array}$ & & & & & \\
\hline $\begin{array}{l}\text { VNA } \\
\text { CHARACTERIZATION/MEASUREMENT } \\
\text { TECHNIQUES }\end{array}$ & & & & & \\
\hline $\begin{array}{l}\text { Develop procedures to evaluate } \\
\text { commercial VNAs. [STRS, OA] }\end{array}$ & & & & & \\
\hline $\begin{array}{l}\text { Implement calibration procedures using } \\
\text { capacitance standards. [STRS] }\end{array}$ & & & & & \\
\hline $\begin{array}{l}\text { Develop procedures to verify and validate } \\
\text { VNA performance [STRS, OA] }\end{array}$ & & & & & \\
\hline $\begin{array}{l}\text { Calibration procedures with lossy two- } \\
\text { ports. [OA] }\end{array}$ & & & & & \\
\hline $\begin{array}{l}\text { Calibration/verification procedures with } \\
\text { tunable impedance generator. [STRS] }\end{array}$ & & & & & \\
\hline
\end{tabular}


Project: NETWORK ANALYSIS AND MEASUREMENTS

\begin{tabular}{|l|l|l|l|l|l||}
\hline FISCAL YEARS & 93 & 94 & 95 & 95 & 97 \\
\hline CALIBRATION/MEASUREMENT SERVICES & & & & & \\
\hline $\begin{array}{l}\text { Maintain existing S-parameter calibration } \\
\text { service. [Fees] }\end{array}$ & & & & & \\
\hline & & & & & \\
\hline $\begin{array}{l}\text { Convert uncertainty expressions to new } \\
\text { NIST guidelines. [STRS] }\end{array}$ & & & & & \\
\hline Revise and clarify test reports. [STRS] & & & & & \\
\hline MEASUREMENT ASSURANCE & & & & & \\
\hline $\begin{array}{l}\text { Develop quality manual and document } \\
\text { measurement procedures and } \\
\text { uncertainties for all six-port systems. } \\
\text { [STRS] }\end{array}$ & & & & & \\
\hline $\begin{array}{l}\text { ARFTG measurement comparison } \\
\text { program. [STRS] }\end{array}$ & & & & & \\
\hline
\end{tabular}




\section{Project: MMIC STANDARDS AND MEASUREMENTS}

FY 92 Fund Sources: STRS, OA, DOD

Staff (5.0 staff-years)

\begin{tabular}{|l||l|l|l|l|}
\hline Professional & D. WILLIAMS & R. Marks & D. Walker & K. Phillips \\
\hline Technician & N. Morgan & & & \\
\hline
\end{tabular}

name in capital letters = project leader; ${ }^{*}=$ person works on project part time

Objective: Improve theoretical and experimental measurement competence, develop standards and onwafer calibration techniques, and provide support to industry for monolithic microwave intergrated-circuit (MMIC) and related technologies.

Significance: Devices and products based on MMIC technology comprise the fastest growing segment of the international microwave industry. NIST metrology support is critical if the U.S. is to develop commercial MMIC applications and maintain world leadership in this state-of-the-art area.

\section{FY 92 Accomplishments}

- Developed a straightforward technique for determining the measurement errors of lumped element calibrations. Found systematic errors in standard industry calibrations of as much as 10 percent at 40 $\mathrm{GHz}$ in coplanar waveguide (CPW) and 20 percent in microstrip.

- Conducted an internal traceability study which shows that transmission-line-based probe tip calibrations are valid for application within a limited but typical range of measurement situations.

- Completed development of unified circuit theory for lossy transmission lines; published results in NIST Journal of Research.

- Developed a new method for determining the characteristic impedance of transmission lines fabricated on lossy or dispersive dielectrics, applicable to a wide variety of transmission lines used in MMICs, circuit boards, and multichip modules.

- Concluded study of resistor reactance as a function of resistor geometry and resistance. Developed simple model to predict reactance accurately to $40 \mathrm{GHz}$.

- Developed a new photoresist process that offers better linewidth control and is free of photoresist residue, with the result that CPW calibration standards can now be fabricated with consistency and uniformity. Developed a wafer thinning process required for microstrip standards.

- Developed on-wafer noise-parameter calibration algorithms in accordance with the circuit theory for lossy transmission lines. Tested algorithms in a collaboration with the staff of the Noise Measurement and Standards project.

\section{FY 93 Plans}

- Complete development of standard microstrip fabrication process and fabricate prototype microstrip calibration standards. Continue support and improvment of CPW standards.

- Test calibration accuracy assessment techniques both at NIST and in industrial setting. Continue to 
develop a deeper understanding of fundamental wafer-level measurement problems and problems of establishing traceability with lossy transmission lines.

- Test CPW standards to $60 \mathrm{GHz}$ (recent work in industry suggests that the interaction of standards with surface waves may limit the frequency range of CPW standards).

- Explore further the determination of the characteristic impedance of planar transmission lines fabricated on lossy or dispersive dielectrics. This technique is expected to find immediate applications in the characterization of interconnects fabricated on lossy or dispersive dielectrics in multichip modules, characterization of printed circuit boards, and transmission lines fabricated on silicon integrated circuits. The technique also shows promise for approximate but broadband electromagnetic characterization of thin dielectric, metal, and superconducting substrates and films.

- Continue to assist staff of the Noise project in establishing on-wafer noise-parameter measurement capability. Fabricate and evaluate on-wafer test structures, including noise diodes, for the acc:acy evaluation of commercial noise-parameter test sets. Structures may be incorporated in CPW standard sets.

- Continue investigation of on-wafer techniques for measuring electromagnetic parameters of advanced electronic packaging such as multichip modules. Includes study of time-domain measurements and calibrations, characteristic impedance determination on lossy or dispersive dielectrics, and coupling between lossy planar transmission lines.

- Develop cryogenic on-wafer measurement capability. Develop techniques for the characterization of cooled superconducting films, dielectrics, and devices.

\section{Impact}

- Industry and NIST/MMIC Consortium members can now make more reliable measurments in support of MMIC production as a result of NIST theoretical (transmission-line theory) and practical (on-wafer impedance standards) developments.

- The establishment of techniques for determining wafer-level measurement accuracy is resulting in improvements of measurement technique. For example, one instrument company is now recommending certain calibration procedures over others on the basis of these techniques.

\section{Related Developments}

- The development of high-speed digital interconnects for multichip module applications will require the centralized expertise and measurement standards that NIST is currently developing in the MMIC program. 
Project: MMIC STANDARDS AND MEASUREMENTS

\begin{tabular}{|c|c|c|c|c|c|}
\hline FISCAL YEARS & 93 & 94 & 95 & 96 & 97 \\
\hline \multicolumn{6}{|l|}{ S-PARAMETER METROLOGY } \\
\hline \multicolumn{6}{|l|}{$\begin{array}{l}\text { Unified measurement theory: planar } \\
\text { geometries. [STRS] }\end{array}$} \\
\hline \multicolumn{6}{|l|}{ De-embedding theory. [STRS, OA] } \\
\hline $\begin{array}{l}\text { Probing technology (fundamental } \\
\text { limitations). [STRS, OA] }\end{array}$ & & & & & \\
\hline \multicolumn{6}{|l|}{$\begin{array}{l}\text { Develop on-wafer measurement support } \\
\text { to } 60 \mathrm{GHz} \text {. [STRS, OA, Fees] }\end{array}$} \\
\hline \multicolumn{6}{|l|}{$\begin{array}{l}\text { Develop on-wafer noise measurements. } \\
\text { [STRS, OA] }\end{array}$} \\
\hline \multicolumn{6}{|l|}{$\begin{array}{l}\text { Evaluate verification of on-wafer } \\
\text { measurements. [STRS] }\end{array}$} \\
\hline \multicolumn{6}{|l|}{$\begin{array}{l}\text { WAFER LEVEL STANDARDS } \\
\text { DEVELOPMENT }\end{array}$} \\
\hline \multicolumn{6}{|l|}{ Coplanar. [STRS, OA] } \\
\hline $\begin{array}{l}\text { Microstrip \& similar multiplane. [STRS, } \\
\text { OA] }\end{array}$ & & & & & \\
\hline \multicolumn{6}{|l|}{ PLANAR FABRICATION FACILITY } \\
\hline $\begin{array}{l}\text { Equipment acquisition/installation. [STRS, } \\
\text { DE] }\end{array}$ & & & & & \\
\hline
\end{tabular}


Project: MMIC STANDARDS AND MEASUREMENTS (concluded)

\begin{tabular}{|c|c|c|c|c|c|}
\hline FISCAL YEARS & 93 & 94 & 95 & 96 & 97 \\
\hline CRYOGENIC PROBING & & & & & \\
\hline $\begin{array}{l}\text { Construct/evaluate probe system ( } 4 \\
\text { Kelvin). [OA] }\end{array}$ & & & & & \\
\hline Develop high Tc standards. [STRS, OA] & & & & & \\
\hline INTERCONNECT CHARACTERIZATION & & & & & \\
\hline Lossy dielectrics. [STRS, OA] & & & & & \\
\hline Multiple mode propagation. [STRS, OA] & & & & & \\
\hline $\begin{array}{l}\text { On-wafer time domain measurement. } \\
\text { [STRS, OA] }\end{array}$ & & & & & \\
\hline $\begin{array}{l}\text { Discontinuity characterization. [STRS, } \\
\text { OA] }\end{array}$ & & & & & \\
\hline Coupling and crosstalk. [STRS, OA] & & & & & \\
\hline Interconnection standards. [STRS, OA] & & & & & \\
\hline
\end{tabular}




\section{Project: ELECTROMAGNETIC PROPERTIES OF MATERIALS}

FY 92 Fund Sources: STRS, Air Force, CCG, Calibration Fees

Staff (6.0 staff-years)

\begin{tabular}{|l||l|l|l|l|}
\hline Professional & C. M. WEIL & R. G. Geyer & J. Baker-Jarvis & C. A. Jones \\
\cline { 2 - 5 } & E. J. Vanzura & H. E. Bussey $\ddagger$ & & \\
\hline Technician & J. H. Grosvenor & & & \\
\hline
\end{tabular}

name in capital letters $=$ project leader; $\ddagger=$ guest worker

Objective: Implement and evaluate measurement methods to determine the complex permittivity and complex permeability of various dielectric and magnetic materials over the radiofrequency/microwave spectral range $100 \mathrm{kHz}$ to $18 \mathrm{GHz}$. Identify and characterize reference materials. Provide standards and measurement services to industry. Organize round robin intercomparisons with industry.

Significance: Dielectric and magnetic materials have wide application throughout the electronics, microwave, communication and aerospace industries for such applications as printed circuit boards, substrates, electronic and microwave components, sensor windows, antenna radomes and lenses, microwave absorbers, etc.. Accurate characterization data, covering a wide spectral range as well as temperature range, are needed for both existing and new materials in order to improve automated design processes and to ensure optimized performance at greatly reduced cost. To address these issues effectively, industry needs NIST measurement methodology and services.

\section{FY 92 Accomplishments}

- Completed and released measurement software and a user's manual on broadband transmission/reflection (T/R) materials measurements. Documented this work in NIST Technical Note 1355 and two journal articles.

- Characterized on a decade-by-decade basis seven commerical ferrite materials that are being considered for use as magnetic reference materials. Reported work at July 1992 URSI conference.

- Completed the design and fabrication of a stripline resonator suitable for characterizing dielectric and magnetic materials in the frequency range 150 to $3000 \mathrm{MHz}$, in increments of $150 \mathrm{MHz}$.

- Completed the round robin intercomparison measurements for nonmagnetic materials using a 7-mm coaxial line technique. Compiled the data and presented these at the July 1992 URSI conference.

- Completed the design and fabrication of two $80-\mathrm{mm}$ diameter coaxial air lines, as well as other components and procured some $7-$ to $-80-\mathrm{mm}$ transition sections from commercial sources.

- Completed full-field theory and developed software for the "forward" problem for an open-ended coaxial probe with additional boundary conditions, such as air gaps, finite layer thickness, conductor backing.

\section{FY 93 Plans}

- Continue the development of new algorithms and software for broadband T/R material measurements, with emphasis on high-permittivity $(\epsilon>50)$ materials. Provide software to industry. 
- Continue to select and characterize candidate magnetic reference materials. Perform comparison measurements and publish a NIST Internal Report on this work.

- Develop the stripline resonator technique for high-precision measurements of dielectric and magnetic reference materials in the frequency range 150 to $3000 \mathrm{MHz}$.

- Publish report on the round robin intercomparison of 7-mm coaxial line measurements of nonmagnetic materials. Complete a similar intercomparison of magnetic materials, now in progress.

- Initiate a round robin intercomparison on stripline resonator measurements.

- Develop the use of the 80-mm (3.125-inch) fixture for $T / R$ measurements at frequencies below 1500 $\mathrm{MHz}$. Further develop this fixture for measuring thin magnetic films.

- Continue the development of improved theory, software and calibration methods for material measurements using an open-ended coaxial probe, with emphasis on the "inverse" problem.

- Complete the work to characterize absorbing materials suitable for use in feed-through filters and to confirm predictions of the effect on electromagnetic properties of varying compositions (mixing rules). [collaboration with industry]

- Evaluate the full sheet resonance technique for measuring substrate materials.

\section{Impact}

- An instrument manufacturer has recognized that the NIST developed software for open-ended coaxial probes is considerably superior to its own and has expressed a strong interest in acquiring the program.

\section{Recognition}

- Weil received a letter of thanks from the Antenna Measurement Techniques Association for organizing a Workshop on Materials Measurements, held in Chicago, IL last July.

\section{Related Developments}

- Industry has identified needs for the microwave characterization of high-temperature superconductors. Possible collaborations are being explored jointly with the Electromagnetic Technology Division. 
Project: ELECTROMAGNETIC PROPERTIES OF MATERIALS

\begin{tabular}{|c|c|c|c|c|c|}
\hline FISCAL YEARS & 93 & 94 & 95 & 96 & 97 \\
\hline $\begin{array}{l}\text { METROLOGY FOR COMPLEX } \\
\text { PERMITTIVITY AND/OR PERMEABILITY } \\
\text { OF BULK SOLID MATERIALS, VERY LOW } \\
\text { TO HIGH LOSS }\end{array}$ & & & & & \\
\hline $\begin{array}{l}\text { Transmission line methods, } 100 \mathrm{kHz}- \\
18 \mathrm{GHz} \text {. [OA] }\end{array}$ & & & & & \\
\hline Algorithms optimized. [OA] & & & & & \\
\hline $\begin{array}{l}\text { High precision cavity methods for low- } \\
\text { loss dielectric materials, } 8-11 \mathrm{GHz} \text {. } \\
\text { [STRS] }\end{array}$ & & & & & \\
\hline Special test/calibration services. [Fees] & & & & & \\
\hline $\begin{array}{l}\text { Inhomogeneous/anisotropic materials. } \\
\text { [OA] }\end{array}$ & & & & & \\
\hline $\begin{array}{l}\text { IMPLEMENTATION/EVALUATION OF } \\
\text { MEASUREMENT METHODS }\end{array}$ & & & & & \\
\hline $\begin{array}{l}\text { Stripline resonator, } 150-3000 \mathrm{MHz} \\
\text { Loaded waveguide, } 450-750 \mathrm{MHz} \text {. [OA] }\end{array}$ & & & & & \\
\hline $\begin{array}{l}\text { Open-ended coaxial line, } 3.5 \mathrm{~mm} \text {. [STRS, } \\
\text { OA] }\end{array}$ & & & & & \\
\hline $\begin{array}{l}\text { Large diameter }(80 \mathrm{~mm}) \text { coaxial line. } \\
\text { [STRS] }\end{array}$ & & & & & \\
\hline $\begin{array}{l}\text { Non-destructive methods for PCBs and } \\
\text { substrates. [STRS, OA] }\end{array}$ & & & & & \\
\hline
\end{tabular}


Project: ELECTROMAGNETIC PROPERTIES OF MATERIALS (continued)

\begin{tabular}{|c|c|c|c|c|c|}
\hline FISCAL YEARS & 93 & 94 & 95 & 96 & 97 \\
\hline RESEARCH AND REFERENCE MATERIALS & & & & & \\
\hline Nonmagnetic, low loss. [OA] & & & & & \\
\hline $\begin{array}{l}\text { Nonmagnetic, medium to high loss. } \\
\text { [STRS, OA] }\end{array}$ & & & & & \\
\hline Magnetic, medium to high loss. [OA] & & & & & \\
\hline Thin film magnetic. [OA] & & & & & \\
\hline $\begin{array}{l}\text { MICROWAVE CHARACTERIZATION OF } \\
\text { HIGH-TEMPERATURE } \\
\text { SUPERCONDUCTOR (HTS) FILMS AND } \\
\text { SUBSTRATES }\end{array}$ & & & & & \\
\hline $\begin{array}{l}\text { Cavity measurement methods. [STRS, } \\
\text { OA] }\end{array}$ & & & & & \\
\hline $\begin{array}{l}\text { High-precision measurment method for } \\
\text { HTS films and very low-loss substrates. } \\
\text { [STRS] }\end{array}$ & & & & & \\
\hline
\end{tabular}




\section{Project: ELECTROMAGNETIC PROPERTIES OF MATERIALS (concluded)}

\begin{tabular}{|c|c|c|c|c|c|}
\hline FISCAL YEARS & 93 & 94 & 96 & 96 & 97 \\
\hline $\begin{array}{l}\text { REMOTE SENSING OF MATERIAL } \\
\text { PHYSICAL PROPERTIES }\end{array}$ & & & & & \\
\hline Moisture and density sensing. [OA] & & & & & \\
\hline $\begin{array}{l}\text { Detection of microcracks and defects in } \\
\text { polymers and composites. [STRS, OA] }\end{array}$ & & & & & \\
\hline $\begin{array}{l}\text { ROUND ROBIN INTERCOMPARISON } \\
\text { ORGANIZATION }\end{array}$ & & & & & \\
\hline $\begin{array}{l}\text { National intercomparison on coaxial } \\
\text { transmission line measurements of low- } \\
\text { loss nonmagnetic materials. [OA] }\end{array}$ & & & & & \\
\hline $\begin{array}{l}\text { Similar intercomparison of magnetic } \\
\text { materials. }[O A]\end{array}$ & & & & & \\
\hline $\begin{array}{l}\text { National intercomparison of both dielectric } \\
\text { and magnetic materials using the stripline } \\
\text { resonator. [OA] }\end{array}$ & & & & & \\
\hline
\end{tabular}




\section{Project: NOISE MEASUREMENTS AND STANDARDS}

FY 92 Fund Sources: STRS, CCG, SDI, MMIC, Calibration Fees

Staff (8.0 staff-years)

\begin{tabular}{|l||l|l|l|l|}
\hline Professional & J. W. ALLEN & D. F. Wait & S. Perera & W. C. Daywitt \\
\hline Technician & J. M. Smith & J. L. Rice & L. A. Terrell & R. L. Billinger \\
\hline
\end{tabular}

name in capital letters $=$ project leader; ${ }^{*}=$ person works on project part time

Objective: Develop and disseminate standards and techniques required for accurate measurements of noise (electromagnetic thermal noise) and noise-related parameters, and provide calibration/special test services. Specific needs include standards and automated radiometers in the range 2 to $50 \mathrm{GHz}$ bands and the development of noise figure metrology in the range 8 to $12 \mathrm{GHz}$ band. [Note on waveguide band designations: WR-90 $=8$ to $12 \mathrm{GHz}$; WR- $62=12$ to $18 \mathrm{GHz}$; WR-42 $=18$ to $26 \mathrm{GHz}$; WR-28 $=26.5$ to $40 \mathrm{GHz}$; WR-19 = 40 to $60 \mathrm{GHz}$; WR-15 = 50 to $75 \mathrm{GHz}$.]

Significance: Noise is the ultimate limiting factor affecting the performance of a wide range of microwave/electronic products. Industry needs an accurate noise metrology, based on standards developed by NIST, for evaluating component and system performance and developing improved, more competitive products. NIST noise services support U.S. electronic equipment manufacturers, the communications industry, the radio industry, the satellite broadcast industry, low-noise amplifier technology, and space exploration.

\section{FY 92 Accomplishments}

- Completed the development of a noise-figure measurement theory and established an experimental measurement procedure. Conducted tests to demonstrate the viability of this measurement procedure. Completed preliminary error analysis and studied measurement assurance procedures.

- Performed on-wafer monolithic microwave integrated-circuit (MMIC) noise-figure measurements in collaboration with staff of the MMIC Standards and Measurements Project. Validated the newly developed noise-figure measurement procedure, the basis for future on-wafer noise-figure measurements.

- Completed repairs to the WR-15 measurement system and began verification testing (WR-15 service scheduled to be available from first quarter FY 1993).

- Completed implementation of a local-area network capable of connecting project computers to the Ethernet backbone and incorporating a dedicated server. Began development of interfacing software.

- Extended upper frequency limit of WR-42 measurement services from 22 to $26 \mathrm{GHz}$ (enhanced service scheduled to be available from first quarter FY 1993).

- Established an Automated Network Analyzer (ANA) Users Group, a forum exchange information on the many different types of ANAs now available.

\section{FY 93 Plans}

- Establish new special test services in the WR-42, WR-19, and WR-15 waveguide bands.

- Construct a prototype noise figure measurement system. 
- Renovate existing WR-90 and WR-62 waveguide horn standards and establish new special test services in these frequency bands.

- Construct a WR-28 cryogenic horn standard, and begin verification testing of a new WR-28 automated radiometer system.

\section{Impact}

- The metrology laboratories of at least four major U.S. companies have improved their noise measurement capabilities through the employment of cryogenic standard noise sources fabricated in accordance with the design developed by NIST. The introduction of new NIST calibration services at $1-8 \mathrm{GHz}$ and above in 1986 and 1989 resulted in immediate adjustment of calibration factors of commercial noise sources. Much of U.S. industry accommodated the change and is traceable to NIST.

\section{Related Developments}

- The establishment of the MMIC Consortium and progress toward on-wafer standards and measurements has emphasized the need for accurate noise figure measurements and active device metrology. 


\section{Project: NOISE MEASUREMENTS AND STANDARDS}

\begin{tabular}{|l|l|l|l|l|l|}
\hline \multicolumn{1}{|r|}{ FISCAL YEARS } & 93 & 94 & 95 & 96 & 97 \\
\hline $\begin{array}{l}\text { IMPROVEMENTS TO SPECIAL } \\
\text { TEST/CALIBRATION SERVICES }\end{array}$ & & & & & \\
\hline $\begin{array}{l}\text { Automated waveguide radiometers. } \\
\text { [STRS] }\end{array}$ & & & & & \\
\hline Automated coaxial radiometer. [OA] & & & & & \\
\hline Network/server for data collection. [STRS] & & & & & \\
\hline $\begin{array}{l}\text { Real-time statistical control; on-line error } \\
\text { analysis. [STRS] }\end{array}$ & & & & & \\
\hline IMPROVEMENTS TO STANDARDS & & & & & \\
\hline Gold/copper diffusion. [STRS] & & & & & \\
\hline Improved ambient standard. [STRS] & & & & & \\
\hline On-wafer noise source/standard. [OA] & & & & & \\
\hline Pseudo-random noise standard. IOA] & & & & & \\
\hline $\begin{array}{l}\text { Pressure control and/or temp sensors for } \\
\text { cryogen. [OA] }\end{array}$ & & & & & \\
\hline
\end{tabular}


Project: NOISE MEASUREMENTS AND STANDARDS (continued)

\begin{tabular}{|l|l|l|l|l|l||}
\hline FISCAL YEARS & 93 & 94 & 95 & 96 & 97 \\
\hline IMPROVEMENTS TO RADIOMETERS & & & & & \\
\hline Improve temperature control. [STRS] & & & & & \\
\hline Dual radiometer. [OA] & & & & & \\
\hline $\begin{array}{l}\text { NOISE FIGURE METROLOGY.DISCRETE } \\
\text { DEVICES }\end{array}$ & & & & & \\
\hline Noise parameters of a two-port. [OA] & & & & & \\
\hline $\begin{array}{l}\text { Noise figure measurement procedure. } \\
\text { [OA] }\end{array}$ & & & & & \\
\hline Lab accreditation. [STRS] & & & & & \\
\hline Special test services. [OA] & & & & & \\
\hline
\end{tabular}


Project: NOISE MEASUREMENTS AND STANDARDS (concluded)

\begin{tabular}{|l|l|l|l|l|l||}
\hline \multicolumn{1}{|c|}{ FISCAL YEARS } & 93 & 94 & 95 & 96 & 97 \\
\hline $\begin{array}{l}\text { NOISE FIGURE METROLOGY. } \\
\text { INTEGRATED SERVICES (cont'd.) }\end{array}$ & & & & & \\
\hline Special test services. [OA] & & & & & \\
\hline INTERCOMPARISONS/ROUND ROBINS & & & & & \\
\hline $\begin{array}{l}\text { National-industrial, gov't, etc.; } \\
\text { international-PTB, NPL, EC, etc. [STRS] }\end{array}$ & & & & & \\
\hline NOISE DIODE STUDY & & & & & \\
\hline $\begin{array}{l}\text { Preliminary Study of environmental } \\
\text { effects. [STRS] }\end{array}$ & & & & & \\
\hline $\begin{array}{l}\text { NOISE METROLOGY SEMINAR/SHORT } \\
\text { COURSE }\end{array}$ & & & & & \\
\hline \begin{tabular}{l} 
Short course for U.S. industry. [STRS] \\
\cline { 1 - 6 }
\end{tabular} & & & & & \\
\hline $\begin{array}{l}\text { Publication on "Applications of Broadband } \\
\text { Noise." [STRS] }\end{array}$ & & & & & \\
\hline
\end{tabular}




\section{Project: EMISSION AND IMMUNITY METROLOGY}

FY 92 Fund Sources: STRS, Army, Navy, Air Force, LESL, Interior

Staff (11.5 staff-years)

\begin{tabular}{|l||l|l|l|l|}
\hline Professional & M. KANDA & J. Adams & K. Cavcey & M. Crawford \\
\cline { 2 - 5 } & J. Cruz & D. Hill & J. Ladbury & M. Ma \\
\cline { 2 - 5 } & A. Ondrejka & B. Riddle & & \\
\hline Technician & H. Medley & & & \\
\hline
\end{tabular}

Objective: Evaluate the interaction of electromagnetic (EM) fields with devices, components, and systems, and implement practical and reliable testing methods, based on theoretical foundations, for assessing emission and immunity characteristics. Current emphasis includes quantifying emissions from devices and equipment; studying immunity properties of connectors and cables, and developing time-domain techniques for whole system testing.

Significance: Industry and regulatory agencies have requirements for practical yet rigorous measurement techniques in order to characterize and correct problems arising from electromagnetic interference (EMI) and the failure to achieve electromagnetic compatibility (EMC). NIST research, development, and measurement procedures provide needed guidelines and measurement basis for the entire EMC/EMI community.

\section{FY 92 Accomplishments}

- Completed theory and reverberation chamber measurements for EM penetration into an apertured coaxial line and an apertured transverse electromagnetic (TEM) cell. Found reasonably good agreement over a broad frequency range; published a report of the results.

- Completed theory and calculations for radiated-field excitation and current injection of multiconductor transmission lines and submitted report of work for publication. Analyzed separate vs. simultaneous injection testing of multiport systems and submitted report of work for publication.

- Completed measurements on spherical dipole standard radiators from 2 to $1000 \mathrm{MHz}$ at two Navy EMC laboratories. Analyzed data to determine test repeatability.

- Analyzed gradiometer antennas for detecting low-frequency fields radiated by currents on long lines and performed calculations for various cases; published results in a NIST Interagency Report.

- Made and evaluated modifications to the procedure and fixture used in support of ASTM Standard D 4935 for gasket measurements.

- Defined test procedures for evaluating the shielding effectiveness of wiring harnesses and filter assemblies using the NIST TEM/reverberating chamber.

- Completed feasibility study and report on modifying the Naval Air Propulsion Center's 3E engine test cell into a mode-stirred chamber. 
- Completed an economic impact survey of the NIST EMC/EMI program and reported the results, prepared a chapter analyzing industry needs for EMC/EMI measurements, including identification of unmet measurement requirements of the EMC/EMI industry itself, and published an NIST Interagency Report surveying existing formal EMC standards.

- Completed modification of the Rome Labs reverberating chamber into a TEM-driven reverberating chamber. Calculated E-field patterns in chamber and performed continuous-wave (CW) and pulsed measurements.

\section{FY 93 Plans}

- Develop theory and measurement techniques for the shielding effectiveness of airframes, with emphasis on pulsed fields.

- Develop a statistical electromagnetic theory for characterization of reverberation chambers and for evaluation of new methods of mode stirring.

- Develop alternative EM immunity test methods for broadband and pulsed fields and analyze the relationships between $\mathrm{CW}$ measurements and pulsed measurements.

- Measure and analyze the effects of apertures (for air circulation) and lossy materials on the characteristics (such as the Q) of broadband hybrid chambers.

- Evaluate the effectiveness and limitations of broadband noise excitation of reverberation chambers for EMC testing.

\section{Impact}

- NIST measurement developments have provided a basis for improving the nation's capability to cope with the effects of EMI and to establish to what degree EMC has been achieved. For example, NIST work has shown that some previously accepted methods for EMC/EMI measurement were resulting in serious errors.

\section{Recognition}

- Kanda is serving as Editor of the IEEE Transactions on Electromagnetic Compatibility.

\section{Related Developments}

- The European Community 1992 EMC Directive requires the standardization of EMC measurements throughout Community nations.

- The FAA now requires all commercial airplanes to be tested at $200 \mathrm{~V} / \mathrm{m}$ for EMI survivability. 
Project: EMISSION AND IMMUNITY METROLOGY

\begin{tabular}{|c|c|c|c|c|c|}
\hline FISCAL YEARS & 93 & 93 & 95 & 96 & 97 \\
\hline \multicolumn{6}{|l|}{$\begin{array}{l}\text { EMISSION AND IMMUNITY TESTING } \\
\text { METHODOLOGY }\end{array}$} \\
\hline \multicolumn{6}{|l|}{ Reverberating chamber. [OA] } \\
\hline \multicolumn{6}{|l|}{ Ground screen. [OA] } \\
\hline \multicolumn{6}{|l|}{ Near-field phased array.[OA] } \\
\hline \multicolumn{6}{|l|}{ Shielded room. [OA] } \\
\hline \multicolumn{6}{|l|}{ ANALYSIS OF EM FIELDS EFFECTS } \\
\hline \multicolumn{6}{|l|}{$\begin{array}{l}\text { Resonance determination (time domain). } \\
{[O A]}\end{array}$} \\
\hline \multicolumn{6}{|l|}{ Multiple sources. [OA] } \\
\hline \multicolumn{6}{|l|}{$\begin{array}{l}\text { Electrostatic discharge. [Future programs } \\
\text { to be determined.] }\end{array}$} \\
\hline \multicolumn{6}{|l|}{$\begin{array}{l}\text { EM FIELDS COUPLING (Develop } \\
\text { measurement techniques and } \\
\text { instrumentation.) }\end{array}$} \\
\hline \multicolumn{6}{|l|}{ Shielding \& reflectivity of materials. [OA] } \\
\hline $\begin{array}{l}\text { Penetration into systems: connectors; } \\
\text { cables. [OA] }\end{array}$ & & & & & \\
\hline
\end{tabular}




\section{Project: EMISSION AND IMMUNITY METROLOGY (concluded)}

\begin{tabular}{|c|c|c|c|c|c|}
\hline FISCAL YEARS & 93 & 93 & 96 & 96 & 97 \\
\hline \multicolumn{6}{|l|}{$\begin{array}{l}\text { Penetration into systems: enclosures; } \\
\text { devices. [STRS] }\end{array}$} \\
\hline \multicolumn{6}{|l|}{ TEM cells with aperture. [STRS] } \\
\hline \multicolumn{6}{|l|}{ Radiated/conducted EMl: correlation. $[\mathrm{OA}]$} \\
\hline \multicolumn{6}{|l|}{$\begin{array}{l}\text { Radiated/conducted EMI: mechanisms. } \\
{[\mathrm{OA}]}\end{array}$} \\
\hline \multicolumn{6}{|l|}{ Radiated/conducted EMI: sensors. [OA] } \\
\hline \multicolumn{6}{|l|}{$\begin{array}{l}\text { EM ENVIRONMENTAL } \\
\text { CHARACTERIZATION }\end{array}$} \\
\hline \multicolumn{6}{|l|}{$\begin{array}{l}\text { Characterization of EM environments. } \\
\text { [STRS, OA] }\end{array}$} \\
\hline \multicolumn{6}{|l|}{$\begin{array}{l}\text { Methodology for EM environment } \\
\text { measurements. [STRS, OA] }\end{array}$} \\
\hline $\begin{array}{l}\text { Standards for complex EM environments. } \\
\text { [Future programs to be planned.] }\end{array}$ & & & & & \\
\hline & & & & & \\
\hline
\end{tabular}




\section{Project: STANDARD EM FIELDS AND TRANSFER PROBE STANDARDS}

FY 92 Fund Sources: STRS, Measurement Services, Army, Navy

Staff (9.0 staff-years)

\begin{tabular}{|l||l|l|l|l|}
\hline Professional & M. KANDA & D. Camell & R. Johnk & G. Koepke \\
\cline { 2 - 5 } & K. Masterson & D. Melquist & D. Novotny & R. D. Orr \\
\cline { 2 - 5 } & J. Randa & & & \\
\hline Technician & R. Acker & & & \\
\hline
\end{tabular}

name in capital letters $=$ project leader; $"=$ person works on project part time

Objective: Develop methods and techniques for establishing continuous-wave (CW), pulsed, and nonsinusoidal electromagnetic reference fields to $100 \mathrm{GHz}$, for use by NIST; current emphasis is in the frequency range up to $40 \mathrm{GHz}$ and at 60 and $95 \mathrm{GHz}$. Conduct research and development on probes and related systems to measure electromagnetic (EM) fields and power densities; current emphasis includes the development of millimeter-wave electric field sensors up to $110 \mathrm{GHz}$ and photonic sensors up to $40 \mathrm{GHz}$.

Significance: Well-defined EM reference fields are necessary for special test measurements, antenna development work, evaluating EM field probes, and making electromagnetic compatibility (EMC) and electromagnetic interference (EMI) measurements. Commercial antennas and probes are generally unsuitable for metrology purposes, necessitating the development by NIST of probes which can serve as transfer standards necessary for traceability.

\section{FY 92 Accomplishments}

- Developed for the multiprobe system improved electric-field probes having reduced feedline pickup, increased bandwidth, and improved mechanical strength.

- Constructed, tested, and analyzed a 1-m diameter loop antenna with double gaps. Found that loop output matched theoretical predictions and that the frequency response and sensitivity appear to be adequate.

- Completed an investigation of the technical feasibility of using recent probe designs for, and evaluated necessary support instrumentation for, a broadband, isotropic, computer-controlled probe system.

- Finalized the design of the probes ( $300 \mathrm{MHz}$ to $40 \mathrm{GHz}$ ) for the Department of Defense Calibration Coordination Group and placed an order for probe fabrication.

- Analyzed near-field effects in monopole antenna calibrations and derived a correction factor; prepared a paper on the work for the IEEE Transactions on Electromagnetic Compatibility.

- Performed calculation to determine the optimal thickness for the load in the superconducting power meter. Conducted a literature search and provided advice on the geometrical configuration of the load.

- Tested and validated new automation software for standard field and other measurements.

\section{FY 93 Plans}

- Design, build, and test a three-loop antenna with resistively loaded double gaps and laser diode detectors for measurement of EM radiation from devices located within the enclosed volume. 
- Improve the accuracy and repeatability of standard field generation with horns and open-end waveguides in the anechoic chamber and monopoles and dipoles over the ground screen.

- Develop a framework for characterizing anechoic chambers used for EMC testing. Framework should provide the basis for future work to estimate the uncertainty in various EMC tests in anechoic chambers.

- Develop and test software for automating measurements and data processing for calibrations and special tests in anechoic chambers.

\section{Impact}

- DoD Primary Standards Laboratories have decided to use the NIST 6-mm dipole probes as transfer standards.

\section{Recognition}

- Kanda is serving as Chairman of U.S. URSI Commission A.

- Randa, Kanda, and Orr received the IEEE Transactions on Electromagnetic Compatibility 1992 Best Paper Award (given to the top paper published in the Transactions during the preceding year) for the paper, "Thermo-optic designs for electromagnetic-field probes for microwave and millimeter waves."

- G. Koepke, L.D. Driver, K. Cavcey, K. Masterson, R. Johnk, and M. Kanda received the Rothhammer Memorial Best Paper Award at the August 1992 IEEE International Symposium on Electromagnetic Compatibility for the paper, "New spherical dipole source." [This is the fourth such award won by members of the Division since 1982.]

\section{Related Developments}

- The FCC has announced a policy requiring antennas used in EMI tests to be calibrated with traceability to NIST. 
Project: STANDARD EM FIELDS AND TRANSFER PROBE STANDARDS

\begin{tabular}{|c|c|c|c|c|c|}
\hline FISCAL YEARS & 93 & 94 & 96 & 96 & 97 \\
\hline \multicolumn{6}{|l|}{ STANDARD FIELD GENERATION } \\
\hline \multicolumn{6}{|l|}{ MEASUREMENT SERVICES } \\
\hline \multicolumn{6}{|l|}{$\begin{array}{l}\text { Ground screen site (dipole } 25-100 \mathrm{MHz} \text {, } \\
\text { monopole } 30 \mathrm{kHz}-300 \mathrm{MHz} \text { ); TEM cell ( } \\
100 \mathrm{MHz} \text { ); Standard magnetic field loop }\end{array}$} \\
\hline $\begin{array}{l}\text { MHz-18 GHz). Measurement services } \\
\text { provided on request. [Fees] }\end{array}$ & & & & & \\
\hline \multicolumn{6}{|l|}{ ANECHOIC CHAMBER } \\
\hline \multicolumn{6}{|l|}{$250 \mathrm{MHz}-18 \mathrm{GHz}$. [STRS] } \\
\hline \multicolumn{6}{|l|}{$18-26 \mathrm{GHz} ; 26-40 \mathrm{GHz}$. [STRS, DE] } \\
\hline \multicolumn{6}{|l|}{$60 \mathrm{GHz} ; 95 \mathrm{GHz}$. [STRS, DE, OA] } \\
\hline \multicolumn{6}{|l|}{ REVERBERATING CHAMBER } \\
\hline \multicolumn{6}{|l|}{$\begin{array}{l}18 \text { - } 40 \mathrm{GHz} \text {. (Develop automated } \\
\text { system.) [STRS, DE] }\end{array}$} \\
\hline \multicolumn{6}{|l|}{$40-75 \mathrm{GHz}$. [DE, OA] } \\
\hline \multicolumn{6}{|l|}{ Pulse characteristics. [OA] } \\
\hline Combination with TEM cell. [OA] & & & & & \\
\hline
\end{tabular}


Project: STANDARD EM FIELDS AND TRANSFER PROBE STANDARDS (continued)

\begin{tabular}{|c|c|c|c|c|c|}
\hline FISCAL YEARS & 93 & 94 & 96 & 96 & 97 \\
\hline NEAR-FIELD PHASED ARRAY & & & & & \\
\hline $250 \mathrm{MHz} ; 750 \mathrm{MHz} ; 1000 \mathrm{MHz}$. [OA] & & & & & \\
\hline Broadband (octave). [OA] & & & & & \\
\hline $\begin{array}{l}\text { STANDARD TRANSMITTING AND } \\
\text { RECEIVING ANTENNAS }\end{array}$ & & & & & \\
\hline Narrow band, resonant. [STRS, OA] & & & & & \\
\hline $\begin{array}{l}\text { Broadband, nonresonant, phase-linear. } \\
\text { [OA] }\end{array}$ & & & & & \\
\hline $\begin{array}{l}\text { Refurbish ground screen facility (ground } \\
\text { screen cover). [STRS, DE] }\end{array}$ & & & & & \\
\hline $\begin{array}{l}\text { New anechoic chamber (larger than the } \\
\text { existing one). [STRS, DE] }\end{array}$ & & & & & \\
\hline FIELD MEASUREMENT & & & & & \\
\hline $\begin{array}{l}\text { CW ELECTRIC FIELDS ANTENNA } \\
\text { DEVELOPMENT }\end{array}$ & & & & & \\
\hline $\begin{array}{l}100 \mathrm{kHz}-18 \mathrm{GHz} ; 18-26 \mathrm{GHz} ; 26-40 \\
\mathrm{GHz} \text {. [STRS] }\end{array}$ & & & & & \\
\hline $40-75 \mathrm{GHz}^{2} 75-110 \mathrm{GHz}$. [STRS, OA] & & & & & \\
\hline
\end{tabular}


Project: STANDARD EM FIELDS AND TRANSFER PROBE STANDARDS (concluded)

\begin{tabular}{|c|c|c|c|c|c|}
\hline FISCAL YEARS & 93 & 93 & 95 & 96 & 97 \\
\hline $\begin{array}{l}\text { MAGNETIC FIELD ANTENNA } \\
\text { DEVELOPMENT }\end{array}$ & & & & & \\
\hline $\begin{array}{l}\text { Miniature loop antenna (up to } 1 \mathrm{GHz} \text { ). } \\
\text { [STRS] }\end{array}$ & & & & & \\
\hline $\begin{array}{l}\text { Antenna to measure } B \text { and } B \text { (up to } 18 \\
\mathrm{GHz} \text { ). [OA] }\end{array}$ & & & & & \\
\hline $\begin{array}{l}\text { ANTENNA FOR SIMULTANEOUS E AND } \\
\text { H MEASUREMENT }\end{array}$ & & & & & \\
\hline Three elements. [STRS] & & & & & \\
\hline $\begin{array}{l}\text { One element with electro-optic modulator. } \\
\text { [STRS, OA] }\end{array}$ & & & & & \\
\hline PULSED ANTENNA DEVELOPMENT & & & & & \\
\hline $\begin{array}{l}\text { Broadband antenna (time domain). [STRS, } \\
\text { OA] }\end{array}$ & & & & & \\
\hline $\begin{array}{l}\text { Active antenna; optically linked antenna. } \\
\text { [STRS, OA] }\end{array}$ & & & & & \\
\hline $\begin{array}{l}\text { Special EM field monitors: environment, } \\
\text { dosimeter, nonlinear and/or nonisotropic } \\
\text { media. [STRS, OA] }\end{array}$ & & & & & \\
\hline
\end{tabular}




\section{Project: ANTENNA MEASUREMENTS, THEORY, AND APPLICATIONS}

FY 92 Fund Sources: STRS, NASA, Air Force, Army, Navy

Staff (6.6 staff-years)

\begin{tabular}{|l||l|l|l|l|}
\hline Professional & A. G. REPJAR & M. H. Francis* & J. R. Guerrieri* & W. K. Klemperer * \\
\cline { 2 - 5 } & R. L. Lewis* & K. MacReynolds* & L. A. Muth* & C. Stubenrauch* \\
\cline { 2 - 5 } & R. C. Wittmann* & & & \\
\hline Technician & S. Canales & D. N. Dean* & D. P. Kremer * & D. T. Tamura* \\
\hline
\end{tabular}

name in capital letters $=$ project leader; $*$ person works on project part time

Objective: Develop the theoretical foundations, standards, and associated experimental techniques required for accurate measurements of gain, pattern, and polarization of microwave antennas via planar near-field (PNF) scanning from 1 to $90 \mathrm{GHz}$ and spherical near-field (SNF) scanning from 1 to $40 \mathrm{GHz}$. Gain uncertainties of less than $\pm 0.2 \mathrm{~dB}$ are sought. Current emphasis is on millimeter-wave measurement including position error correction, spherical near-field techniques with application to field uniformity assessment, and array diagnostics.

Significance: Spectrum and orbit crowding and the use of higher frequencies require new generations of antennas. Advanced communication and aerospace systems employ complex antennas with demanding requirements for gain, pattern and polarization. Accurate antenna measurements are essential for verifying performance and conventional techniques are often inadequate. While the near-field measurement techniques developed by NIST have already solved many serious measurement problems, new approaches are needed for millimeter-waves, large arrays, and integrated antennas.

\section{FY 92 Accomplishments}

- Completed certification plan published as a NIST Interagency Report for a proposed DoD planar nearfield facility.

- Completed documentation for the mirror-image/self-calibration technique for determination of gain; submitted paper for review.

- Completed and tested the fifth order position-error correction code for planar near-field scanning.

- Completed report on the theory of the spectral merge method for phased-array antenna alignment.

- Began project to develop expertise and address concerns on the accuracy of radar cross-section (RCS) measurements and the reliability of RCS standards.

- Hosted the 13th annual Antenna Measurement Techniques Association (AMTA) symposium in Boulder. (400 participants and 24 exhibitors)

- Documented cylindrical near-field scanning software for Jet Propulsion Laboratory, to be applied to process data describing the performance of an antenna used to determine sea-state parameters. 


\section{FY 93 Plans}

- Complete all programming for operation and control of the new spherical antenna range. Evaluate the facility for extrapolation and pattern measurements using two antennas on hand.

- Complete NIST calibrations on the standard-gain horns to be used in the International Gain Comparison series of interlaboratory measurements; publish a paper on the results.

- Complete evaluation and certification of the NIST new $2.4 \mathrm{~m}$ by $2.4 \mathrm{~m}$ ( 8 foot by 8 foot) scanner and new receiver. Measure selected antennas obtained from other agencies or industry.

- Implement theory of the spectral merge method for alignment of phased-array antennas and demonstrate its utility on an antenna measured on the planar near-field range.

- Upgrade probe-positioning techniques on the planar near-field range to provide calibration services in the millimeter-wave frequency range.

- Complete and evaluate measurements for the mirror-image/self-calibration technique for determination of gain. Include measurements using a polarization-sensitive reflector. Publish results.

\section{Impact}

- Historical: NIST (then NBS) is the inventor of the near-field scanning method for characterizing antenna performance, offering spatial resolution and accuracy unavailable by any other practical method and significant reductions in testing time and costs. As a direct result of NIST efforts, near-field scanning is now the principal method used in the United States for the development, evaluation, and testing of antennas used for communications, navigation, radar, and other transport-related, space, and military applications. The availability of near-field scanning has enhanced the competitive position of U.S. firms seeking to sell products such as communication satellites in the world market. All U.S. near-field installations agencies depend on NIST for calibration of the probes that are an essential part of the method.

\section{Recognition}

- Repjar is serving a three-year term on the Administrative Committee for the IEEE Antennas and Propagation Society. Stubenrauch is serving as Associate Editor of the Society's Transactions.

- Francis serves as editor for the Antenna Measurement Techniques Association (AMTA) Newsletter. He received the AMTA Outstanding Service Award for hosting the 1991 symposium.

\section{Related Developments}

- There is a continuing trend towards use of higher frequency antennas, phased arrays or feeds, and integrated antennas; new, expanded NIST measurement services are required to meet the characterization demands that these advanced antennas pose. 
Project: ANTENNA MEASUREMENTS, THEORY, AND APPLICATIONS

\begin{tabular}{|c|c|c|c|c|c|}
\hline FISCAL YEARS & 93 & 94 & 95 & 95 & 97 \\
\hline $\begin{array}{l}\text { PLANAR NEAR-FIELD (PNF) } \\
\text { MEASUREMENTS }\end{array}$ & & & & & \\
\hline $\begin{array}{l}\text { MEASUREMENT SYSTEM } \\
\text { IMPROVEMENTS }\end{array}$ & & & & & \\
\hline $\begin{array}{l}\text { Update, document and streamline NF } \\
\text { computer libraries. [STRS, OA] }\end{array}$ & & & & & \\
\hline $\begin{array}{l}\text { Improve on-line data processing on NF } \\
\text { range. [STRS, OA] }\end{array}$ & & & & & \\
\hline IMPROVED INSTRUMENTATION & & & & & \\
\hline $\begin{array}{l}\text { Receiver speed, accuracy and dynamic } \\
\text { range. [STRS, OA] }\end{array}$ & & & & & \\
\hline $\begin{array}{l}\text { Improved position control and accuracy. } \\
\text { [STRS] }\end{array}$ & & & & & \\
\hline $\begin{array}{l}\text { PHOTONIC PROBE SENSOR } \\
\text { DEVELOPMENT FOR ANTENNA } \\
\text { SYSTEMS }\end{array}$ & & & & & \\
\hline $\begin{array}{l}\text { Develop technology for a prototype } \\
\text { photonic probe; evaluate probe on PNF } \\
\text { range; dyn. range, mult. relf. [STRS, OA] }\end{array}$ & & & & & \\
\hline $\begin{array}{l}\text { Construct a 1-dimensional array for rapid } \\
\text { scanning; evaluate array in PNF/CNF } \\
\text { measurement situations. [STRS, OA] }\end{array}$ & & & & & \\
\hline $\begin{array}{l}\text { Transfer technology to in-situ } \\
\text { measurement application. [STRS, OA] }\end{array}$ & & & & & \\
\hline $\begin{array}{l}\text { Form consortitm to participate in overall } \\
\text { effort. [STRS, JA] }\end{array}$ & & & & & \\
\hline
\end{tabular}


Project: ANTENNA MEASUREMENTS, THEORY, AND APPLICATIONS (continued)

\begin{tabular}{|c|c|c|c|c|c|}
\hline FISCAL YEARS & 93 & 94 & 95 & 95 & 97 \\
\hline \multicolumn{6}{|l|}{$\begin{array}{l}\text { NON-PLANAR NEAR-FIELD } \\
\text { MEASUREMENTS }\end{array}$} \\
\hline \multirow{2}{*}{\multicolumn{6}{|c|}{$\begin{array}{l}\text { Refine measurement techniques and } \\
\text { develop applications for outdoor in-situ } \\
\text { measurements. [STRS, OA] }\end{array}$}} \\
\hline & & & & & \\
\hline \multicolumn{6}{|l|}{$\begin{array}{l}\text { Develop a permanent facility for non- } \\
\text { planar measurements. [STRS] }\end{array}$} \\
\hline \multicolumn{6}{|l|}{ NON-PLANAR ERROR ANALYSIS } \\
\hline \multicolumn{6}{|l|}{$\begin{array}{l}\text { Derive upper-bound error expressions. } \\
\text { [STRS] }\end{array}$} \\
\hline \multicolumn{6}{|l|}{$\begin{array}{l}\text { Verify expressions through simulation and } \\
\text { tests. [STRS] }\end{array}$} \\
\hline \multicolumn{6}{|l|}{$\begin{array}{l}\text { Develop measurement tests to quantify } \\
\text { actual errors. [STRS, OA] }\end{array}$} \\
\hline \multicolumn{6}{|l|}{ Analytical error correction. [STRS] } \\
\hline \multicolumn{6}{|l|}{ TECHNOLOGY TRANSFER } \\
\hline \multicolumn{6}{|l|}{$\begin{array}{l}\text { Document theoretical and measurement } \\
\text { developments. [STRS, OA] }\end{array}$} \\
\hline \multicolumn{6}{|l|}{$\begin{array}{l}\text { Provide short courses and workshops: } \\
\text { compile planar notes; present short } \\
\text { courses (PNF). [STRS, OA] }\end{array}$} \\
\hline $\begin{array}{l}\text { IEEE/APS National Distinguished Lecturer. } \\
\text { [STRS] }\end{array}$ & & & & & \\
\hline
\end{tabular}


Project: ANTENNA MEASUREMENTS, THEORY, AND APPLICATIONS (concluded)

\begin{tabular}{|c|c|c|c|c|c|}
\hline FISCAL YEARS & 93 & 94 & 95 & 95 & 97 \\
\hline COMPLEX ANTENNAS & & & & & \\
\hline $\begin{array}{l}\text { Develop phased-array alignment } \\
\text { techniques. [OA] }\end{array}$ & & & & & \\
\hline $\begin{array}{l}\text { Develop characterization methods for } \\
\text { advanced millimeter-wave antennas } \\
\text { (quasi-optics, holography). [STRS, OA] }\end{array}$ & & & & & \\
\hline $\begin{array}{l}\text { Emerging antenna technologies longoing } \\
\text { study). [STRS, OA] }\end{array}$ & & & & & \\
\hline $\begin{array}{l}\text { Field testing measurement techniques. } \\
{[\mathrm{OA}]}\end{array}$ & & & & & \\
\hline $\begin{array}{l}\text { Develop testing methods for direct } \\
\text { broadcast, global positioning and } \\
\text { anticollision applications. [STRS, OA] }\end{array}$ & & & & & \\
\hline
\end{tabular}




\section{Project: METROLOGY FOR ANTENNA, RCS, AND SPACE SYSTEMS}

\section{FY 92 Fund Sources: STRS, JPL, Air Force}

Staff (4.0 staff-years)

\begin{tabular}{|l||l|l|l|l|}
\hline Professional & A. G. REPJAR & M. H. Francis* & J. R. Guerrieri* & W. K. Klemperer* \\
\cline { 2 - 5 } & R. L. Lewis & K. MacReynolds* & L. A. Muth* & C. Stubenrauch* \\
\cline { 2 - 5 } & R. C. Wittmann* & & & \\
\hline Technician & S. Canales* & D. P. Kremer* & D. T. Tamura* & \\
\hline
\end{tabular}

name in capital letters $=$ project leader; ${ }^{*}=$ person works on project part time

Objective: Develop standards, measurement techniques, and instrumentation required for measuring critical performance parameters of earth terminals and satellites, and for absolute calibration of the Air Force Satellite Control Network (AFSCN) metrology earth terminal. Critical parameters include noise temperature $(T)$, antenna gain $(G)$, earth terminal figure of merit $(G / T)$, and satellite effective isotropic radiated power (EIRP). Provide technical support to the Government Range Radar Cross Section Measurement Working Group (GRCSRMWG) to improve the quality and reliability of range measurements. Evaluate the measurement processes including error budgets, design and analysis of required artifact standards, and consultation and support in establishing a range certification process.

Significance: Satellite communication is a finely tuned technology requiring accurate measurements of antenna gain, noise temperature, G/T, and EIRP to assure optimum performance. Ground metrology stations needed to monitor performance of commercial and government satellites require traceability to NIST standards. Some stations measure the performance to determine incentive-clause payments to satellite contractors or charges billed to users or lessees. Industry and government own and operate a number of antenna and radar cross section (RCS) test ranges of various types e.g. outdoor static, indoor (compact ranges), and other specialized ranges. Data taken on one range does not always correlate with measurements on another range, even of the same type. In addition, some of these ranges are used for contractual verification of vendor performance. It is necessary that the data produced be of the highest accuracy possible and be repeatable from one facility to another. NIST provides the basis needed for these measurements.

\section{FY 92 Accomplishments}

- Determined the gain of the USAF 18.2-m (60-foot) antenna at Camp Parks using the 1.8-m (6-foot) standard gain antenna previously calibrated on the NIST planar near-field range. Found that results agree with ETMS measurements on the large antenna using the stellar source Cassiopeia A. Constructed error budgets for these two methods and for a third method using the moon as source.

- Provided support to Jet Propulsion Laboratory (JPL) in checking out their Clear Aperture Antenna before extensive measurements are made on radio sources.

- Conducted tests to verify proper system operation of the Air Force G/T system which uses the sun as the standard source.

\section{FY 93 Plans}

- Measure gain of AFSCN Camp Parks large antenna for elevations from 5 to 60 degrees using Cassiopeia $A$ and a calibrated noise source to characterize gain changes as a function of elevation angle. Compare with gains obtained using a gain comparison method, the $1.8-\mathrm{m}$ antenna and a satellite beacon signal. 
- Collaborate with JPL in flux density measurements of extraterrestrial radio noise sources and gain calibrations of the 70-m antenna and others at Goldstone and Owens Valley Radio Observatory.

- Evaluate G/T measurement procedures and results using the sun for McClellan AFB.

- Provide technical support to the government RCS Range Working Group to improve the quality and reliability of range measurements and standards.

\section{Impact}

- The most cost-effective method for measuring key performance parameters of ground stations depends on the use of appropriate well-characterized astronomical radio sources. As a result of the JPL calibration and field measurements, all users of satellite receiving systems operating in the 33- $\mathrm{GHz}$ telemetry band for deep space applications will have accurately calibrated flux densities for Venus and will be able to measure gain and $\mathrm{G} / \mathrm{T}$ of their systems.

- NIST calibration of the moon as a source provides users of the 7- to 8-GHz band with a radio calibration source for their systems; no other astronomical sources are suitable.

\section{Recognition}

- Stubenrauch and Wittmann were commended by the National Aeronautics and Space Administration for their outstanding contribution in support of the Advanced Communications Technology Satellite.

- Repjar was presented the Outstanding Service Award by the Antenna Measurement Techniques Association. He served as President and Vice President of the organization, 1989-91.

\section{Related Developments}

- JPL has recently upgraded the 70-m antenna at Goldstone for determining the flux density of certain extraterrestrial radio sources. NIST will provide traceability to standards.

- NASA has an interest in calibration of an earth terminal to be used in the Advanced Communications Technology Satellite proof-of-concept system. Some of the techniques and measurements developed in the JPL effort will be directly applicable.

- G/T measurements are used to evaluate the operability and accuracy of earth stations. NIST has been asked to evaluate techniques which utilize the sun as a source. 


\section{Project: METROLOGY FOR ANTENNA, RCS, AND SPACE SYSTEMS}

\begin{tabular}{|c|c|c|c|c|c|}
\hline FISCAL YEARS & 93 & 94 & 95 & 95 & 97 \\
\hline EARTH TERMINAL MEASUREMENTS & & & & & \\
\hline $\begin{array}{l}\text { Conduct gain measurements for large } \\
\text { antennas using radio sources and noise } \\
\text { standards. [OA] }\end{array}$ & & & & & \\
\hline $\begin{array}{l}\text { Conduct gain measurements for large } \\
\text { antennas using satellite signals and } \\
\text { transfer standards. [OA] }\end{array}$ & & & & & \\
\hline $\begin{array}{l}\text { Evaluate system temperature } \\
\text { measurements. [OA] }\end{array}$ & & & & & \\
\hline $\begin{array}{l}\text { Update error budgets for gain } \\
\text { measurements. [OA] }\end{array}$ & & & & & \\
\hline SATELLITE MEASUREMENTS & & & & & \\
\hline $\begin{array}{l}\text { Provide calibrations for satellite effective } \\
\text { isotropic radiated power; update hardware } \\
\text { and software for higher frequencies; } \\
\text { further evaluate bit error rate methods for } \\
\text { determining antenna parameters. [OA] }\end{array}$ & & & & & \\
\hline STANDARD SOURCE MEASUREMENTS & & & & & \\
\hline $\begin{array}{l}\text { Perform certification for standard emitters } \\
\text { (radio stars, satellite signals). [STRS, OA] }\end{array}$ & & & & & \\
\hline $\begin{array}{l}\text { CALIBRATION SERVICES FOR LARGE } \\
\text { ANTENNAS }\end{array}$ & & & & & \\
\hline $\begin{array}{l}\text { Develop antenna pattern measurement } \\
\text { capability. [OA] }\end{array}$ & & & & & \\
\hline $\begin{array}{l}\text { Improve holographic methods for antenna } \\
\text { diagnostics; provide a comprehensive } \\
\text { measurement service. [STRS, OA] }\end{array}$ & & & & & \\
\hline
\end{tabular}


Project: METROLOGY FOR ANTENNA, RCS, AND SPACE SYSTEMS (concluded)

\begin{tabular}{|l|l|l|l|l|l||}
\hline FISCAL YEARS & 93 & 94 & 95 & 96 & 97 \\
\hline $\begin{array}{l}\text { RADAR CROSS SECTION } \\
\text { MEASUREMENTS }\end{array}$ & & & & & \\
\hline Visit RCS ranges. [OA] & & & & & \\
\hline Develop plan of error analysis for different \\
ranges. [OA]
\end{tabular}


Project: SPECIAL TESTS, MEASUREMENTS, AND CALIBRATIONS

FY 92 Fund Sources: Calibration Fees

Staff (3.0 staff-years)

\begin{tabular}{|l||l|l|l|l|}
\hline Professional & $\begin{array}{l}\text { C. } \\
\text { STUBENRAUCH }\end{array}$ & M. H. Francis* & J. R. Guerrieri* & R. L. Lewis* \\
\cline { 2 - 5 } & K. MacReynolds* & A. G. Repjar* & & \\
\hline Technician & S. Canales* & D. N. Dean* & D. P. Kremer* & D. T. Tamura* \\
\hline
\end{tabular}

name in capital letters = project leader; $=$ person works on project part time

Objective: (1) Calibrate antennas and near-field probes for use as transfer standards, enabling other organizations to do their own measurements. (2) Perform special test measurements and performance evaluations when the highest accuracy and NIST facilities and expertise are required. (3) Evaluate new measurement theory and methodology. Focus is on millimeter-wave calibrations, circularly polarized antennas, on-line data processing, and improved probe calibration facilities.

Significance: Calibrations and special test measurements provide critical measurement services to industry and government laboratories. When measurements are based on NIST standards the quality of the entire national measurement network is upgraded. Accurate standards ultimately reduce the cost and improve the performance of communication, radar, and other microwave systems and improve the competitive position of U.S. companies.

\section{FY 92 Accomplishments}

- Completed software to obtain data for the spherical pattern, cylindrical, and extrapolation methods. absorber on two thirds of the room; checked the performance of the new laser interferometer system for measuring position of range components.

- Completed calibrations in the 18- to 26- GHz band (WR-42) and 33- to 50-GHz (WR-22). Completed about half the work of calibrating probes covering range 50 to $75 \mathrm{GHz}$ (WR-15, completion scheduled for first quarter FY 1993). Implemented swept-frequency gain measurement services to $75 \mathrm{GHz}$.

- Calibrated four flat phased-array antennas for the Air Force.

- Calibrated a dual-port probe to be used to measure and qualify the Radarsat antenna.

- Calibrated two X-band standard-gain horns.

- Measured two L-band standard gain horns.

- Calibrated two Jet Propulsion Laboratory probes to be used in characterizating an antenna used to determine sea-state parameters.

- For NIST Time and Frequency Division, Physics Laboratory, used spherical pattern range to measure pattern, polarization, and phase center of two antennas intended for receiving signals from groundposition satellites. 


\section{FY 93 Plans}

- Calibrate dual-port circularly polarized horns for the following bands: 55 to $60 \mathrm{GHz}$ and 60 to $75 \mathrm{GHz}$, as a basis for offering of a calibration service for high-precision circularly polarized antennas in these frequency bands.

- Perform special tests and custom measurements on antennas and probes for industry and government using the near-field, extrapolation, and spherical probe ranges.

- Calibrate four sets of probes for commercial customer for use as gain transfer standards.

\section{Impact}

- All of the near-field facilities at $18 \mathrm{U}$. S. companies and government agencies have been established with NIST assistance; all depend on NIST for calibration of the probes that are an essential part of the method.

- NIST provided special high-accuracy measurements of 26 antennas and probes in FY 1992 for industry and government using the near-field, the extrapolation, and the spherical probe ranges.

\section{Recognition}

- Repjar and Stubenrauch serve as members of the IEEE Antenna Standards Committee.

- Francis received the 1992 EEEL Measurement Service Award.

- Stubenrauch is Associate Editor of the IEEE Transactions on Antennas and Propagation Society.

\section{Related Developments}

- The increase in demand for calibrations in the millimeter-wave bands will continue, but initially at a slower rate due to the cutback in the MILSTAR program.

- New near-field facilities are being constricted by a number of laboratories and others are being planned. These new ranges will require NIST calration of the probes used in them.

- Queries have been received from industry regarding NIST certification of antenna measurement facilities. 
Project: SPECIAL TESTS, MEASUREMENTS, AND CALIBRATIONS

\begin{tabular}{|c|c|c|c|c|c|}
\hline FISCAL YEARS & 93 & 93 & 95 & 96 & 97 \\
\hline $\begin{array}{l}\text { EXTRAPOLATION RANGE } \\
\text { MEASUREMENTS }\end{array}$ & & & & & \\
\hline Improve real-time data analysis. [STRS] & & & & & \\
\hline $\begin{array}{l}\text { Evaluate extrapolation data-fitting } \\
\text { techniques. [STRS] }\end{array}$ & & & & & \\
\hline $\begin{array}{l}\text { Obtain and calibrate circularly polarized } \\
\text { check standards. [STRS, OA] }\end{array}$ & & & & & \\
\hline $\begin{array}{l}\text { Develop self-calibration/reflection } \\
\text { technique. [STRS] }\end{array}$ & & & & & \\
\hline $\begin{array}{l}\text { Evaluate swept-frequency polarization } \\
\text { techniques. [STRS] }\end{array}$ & & & & & \\
\hline $\begin{array}{l}\text { Complete international intercomparison of } \\
\text { gain standards. [STRS] }\end{array}$ & & & & & \\
\hline NEAR-FIELD MEASUREMENTS & & & & & \\
\hline $\begin{array}{l}\text { Implement multi-frequency/multi-beam } \\
\text { measurements. [STRS, OA] }\end{array}$ & & & & & \\
\hline $\begin{array}{l}\text { Develop systems and techniques for } \\
\text { millimeter-wave measurements. [STRS, } \\
\text { OA] }\end{array}$ & & & & & \\
\hline $\begin{array}{l}\text { Develop fault analysis techniques for } \\
\text { arrays. [OA] }\end{array}$ & & & & & \\
\hline $\begin{array}{l}\text { Develop minimum scattering probes. } \\
\text { [STRS, OA] }\end{array}$ & & & & & \\
\hline
\end{tabular}


Project: SPECIAL TESTS, MEASUREMENTS, AND CALIBRATIONS (concluded)

\begin{tabular}{|l|l|l|l|l|l|}
\hline FISCAL YEARS & 93 & 94 & 95 & 96 & 97 \\
\hline SPHERICAL RANGE & & & & & \\
\hline $\begin{array}{l}\text { Develop a permanent facility for probe } \\
\text { calibrations. [STRS] }\end{array}$ & & & & & \\
\cline { 1 - 7 } $\begin{array}{l}\text { Develop methods for range evaluation } \\
\text { using spherical measurements. [STRS] }\end{array}$ & & & & & \\
\hline
\end{tabular}




\section{ELECTROMAGNETIC TECHNOLOGY DIVISION}




\section{Project: OPTICAL-FIBER MEASUREMENT SYSTEMS AND STANDARDS}

FY 92 Fund Sources: STRS, Navy

Staff (4.5 staff-years)

\begin{tabular}{|l||l|l|l|l|}
\hline Professional & D. FRANZEN* & B. Danielson & T. Drapela* & P. Hale* \\
\cline { 2 - 5 } & S. Mechels* & M. Young* & J. Schlager* & \\
\hline Technician & R. Juneau & & & \\
\hline
\end{tabular}

name in capital letters $=$ project leader; $"=$ person works on project part time

Objective: Act through the Telecommunications Industry Association (TIA) to develop optical fiber test procedures and Standard Reference Materials for optical fiber geometry, and work with voluntary standards groups to evaluate test procedures. Specifically, develop measurement techniques for optical fibers; where necessary establish standards for traceability; extend geometry work to include connector ferrules; evaluate test procedures for fiber chromatic dispersion; develop metrology to support optical time-domain reflectometers (OTDRs); determine special metrology requirements for high-resolution OTDRs.

Significance: This project provides the measurement base for the U.S. optical fiber industry, which is a major part of the telecommunications industry. Systems developed by NIST provide round robin testing support to the TIA. U.S. manufacturers make use of NIST Standard Reference Materials for fiber geometry in order to improve their international competitive position.

\section{FY 92 Accomplishments}

- Completed an industry-wide round robin comparison of measurement methods for fiber geometry; the round robin revealed systematic offsets among participants and confirmed the need for a NIST Standard Reference Material.

- Evaluated a potential configuration for a fiber geometry Standard Reference Material; members of the TIA helped evaluate design and gave approval.

- Completed a formal internal comparison of the NIST contact micrometer, scanning confocal microscope, and interference microscope for measuring cladding diameter; found agreement better than $50 \mathrm{~nm}$ on fiber having an outer diameter of $125 \mu \mathrm{m}$, well within industry requirements.

- Started round robin among TIA members to evaluate measurement methods for connector ferrule geometry .

- Developed state-of-the-art fiber optic delay line for OTDR calibration.

- Held Symposium on Optical Fiber Measurements with over 200 attendees; ten domestic and international standards groups $m^{2}$ in conjuction with the Symposium; meetings lasted one week.

- Participated in and chaired sever. "... committee meetings; participa: $?$ in TC-86 (OTDR Working Group) of the International Electrc 


\section{FY 93 Plans}

- Meet all internal NIST requirements for providing geometry Standard Reference Materials to industry and supply the NIST Standard Reference Materials Program with a sufficient number for public sale.

- Complete a round robin evaluation of potential TIA measurement methods for connector ferrule geometry; participants include TIA members.

- Initiate an international round robin to evaluate test procedures for fiber geometry; test specimens will be prepared by NIST and housed in the Standard Reference Material containers.

- Develop optical fiber delay line for calibrating the time base of OTDRs and publish results.

- Develop a high resolution OTDR suitable for local area networks and determine the standards needed to support such instruments.

- Develop a highly accurate measurement system for determining optical fiber chromatic dispersion in the 1300 and $1550 \mathrm{~nm}$ spectral regions.

\section{Impact}

- NIST has improved the capability of industry to measure fiber geometry through (1) conducting a round-robin evaluation to determine the degree of agreement in geometry measurements in industry, and (2) developing a responsive Standard Reference Material, approved by the Telecommunication Industry Association, to address the measurement identified by the round robin.

\section{Recognition}

- NIST has a lead role in an international optical fiber geometry round-robin, to begin in FY 1993.

- Franzen was invited to be a program subcommittee member for the annual Laser and ElectroOptics Society meeting, and was a Conference Chair for the SPIE Conference on Optical Materials Reliability and Testing: Benign and Adverse Environments, September 8-9, 1992 in Boston.

- Young was selected to be Assistant Editor of the 1992 Conference on Precision Electromagnetic Measurements (CPEM) Digest. He will become the editor of the next CPEM Digest when it meets in Boulder in 1994. He was also appointed to be Secretary of the CPEM Executive Committee.

- Franzen gave a three-hour short course on single-mode optical fiber measurements at Optical Fiber Conference '92.

\section{Related Developments}

- Next-generation optical fiber systems will operate at higher bit rates and move into the local loop to provide service to homes and businesses. Large numbers of connectors and splices will appear in the local loop; fibers and connectors with more exact dimensions are needed to reduce joint loss.

- In undersea systems, the use of erbium optical fiber amplifiers will result in long transmission lengths with close tolerances on fiber chromatic dispersion.

- OTDRs have the largest market share for test instrumentation; next-generation fiber systems will require OTDRs with improved accuracy and resolution. 


\section{Project: OPTICAL-FIBER MEASUREMENT SYSTEMS AND STANDARDS}

\begin{tabular}{|c|c|c|c|c|c|}
\hline FISCAL YEARS & 93 & 94 & 95 & 96 & 97 \\
\hline \multirow{2}{*}{\multicolumn{6}{|c|}{$\begin{array}{l}\text { Conduct round robin in chromatic } \\
\text { dispersion and develop reference } \\
\text { measurement methods. [STRS] }\end{array}$}} \\
\hline & & & & & \\
\hline \multirow{2}{*}{\multicolumn{6}{|c|}{$\begin{array}{l}\text { Develop consensus standards for Optical } \\
\text { Time Domain Reflectometer. } \\
\text { [STRS \& OA-AF] }\end{array}$}} \\
\hline & & & & & \\
\hline \multicolumn{6}{|l|}{$\begin{array}{l}\text { Participate in standards committees. } \\
\text { [STRS] }\end{array}$} \\
\hline \multirow{2}{*}{\multicolumn{6}{|c|}{$\begin{array}{l}\text { Conduct international round robin for } \\
\text { optical fiber geometry. [STRS, OA-Navy, } \\
\text { OA-TIA] }\end{array}$}} \\
\hline & & & & & \\
\hline \multirow{2}{*}{\multicolumn{6}{|c|}{$\begin{array}{l}\text { Work with CCITT to develop standards } \\
\text { for optical fiber geometry. [STRS] }\end{array}$}} \\
\hline & & & & & \\
\hline \multirow{2}{*}{\multicolumn{6}{|c|}{$\begin{array}{l}\text { Organize optical fiber measurement } \\
\text { symposium. [STRS] }\end{array}$}} \\
\hline & & & & & \\
\hline \multicolumn{6}{|l|}{$\begin{array}{l}\text { Supply fiber geometry SRMs to industry. } \\
\text { [STRS] }\end{array}$} \\
\hline \multicolumn{6}{|l|}{$\begin{array}{l}\text { Develop standards for other optical fiber } \\
\text { test instrumentation. [STRS] }\end{array}$} \\
\hline \multirow{2}{*}{\multicolumn{6}{|c|}{$\begin{array}{l}\text { Establish measurement procedures for } \\
\text { optical fiber amplifiers. [STRS] }\end{array}$}} \\
\hline & & & & & \\
\hline $\begin{array}{l}\text { Investigate and respond to other } \\
\text { measurement problems of Local Area }\end{array}$ & & & & & \\
\hline Networks. [STRS, OA-Navy] & & & & & \\
\hline
\end{tabular}




\section{Project: LASER POWER AND ENERGY MEASUREMENTS}

FY 92 Fund Sources: STRS, Newark, CCG/Navy, CCG/AF, Calibrations

Staff (11.0 staff-years)

\begin{tabular}{|l||l|l|l|l|}
\hline \multirow{2}{*}{ Professional } & T. SCOT & R. Craig & R. Jones & J. Lehman \\
\cline { 2 - 5 } & R. Phelan* & D. Larson* & I. Vayshenker* & M. Young* \\
\cline { 2 - 5 } & A. Sanders* & D. Franzen* & W. Case* & \\
\hline Technician & R. Juneau* & D. Keenan & I. Tobias & \\
\hline
\end{tabular}

name in capital letters $=$ project leader; $*=$ person works on project part time

Objective: Provide calibration and measurement assurance services for laser power and energy as needed by safety regulation, engineering, optical telecommunications, and acceptance testing. Specifically: develop calorimeters for optical fiber power, providing $1 \%$ accuracy at $1 \mu \mathrm{W}$; develop calorimeters and provide measurement services for excimer lasers (1\% accuracy at $1 \mathrm{~J})$, carbon dioxide lasers $(1 \%$ at $1 \mathrm{~kW})$, and $\mathrm{Nd}$ :YAG lasers (1\% at $300 \mathrm{~W})$.

Significance: Lasers constitute a large and growing market: laser sales themselves are $\$ 2$ billion per year, and the worldwide market for laser-based products, such as optical memories, laser printers, and barcode scanners, exceeds $\$ 14$ billion. Lasers are found in nearly all segments of the industrial community. Excimer lasers are widely used in ultraviolet lithography, materials processing, and medical applications; the Food and Drug Administration is expected soon to approve excimer lasers for corneal sculpting. Highpower $\mathrm{Nd}: \mathrm{YAG}$ and $\mathrm{CO}_{2}$ lasers are used increasingly in industrial and medical systems. The NIST program provides essential laser power and energy measurement services to the laser industry for quality control and the regulation of safety.

\section{FY 92 Accomplishments}

- Conducted a laser beam profile round robin involving six US beam analysis equipment manufacturers. Presented the results at an SPIE conference.

- Initiated an optical fiber power round robin involving 16 laboratories from industry and the Department of Defense.

- Completed the design, construction, and delivery of a low-level laser radiometer for the Navy Metrology Center for measuring peak power of Q-switch pulses from laser target designator and rangefinder systems.

- Implemented a system for calibrating optical fiber power meters with fibers/connectors attached.

- Developed additional capability to calibrate optical fiber power meters at 670-nm wavelength range.

- Performed spectral responsivity measurements on several optical fiber power detectors for customers as Special Tests.

- Performed laser transmittance measurements on samples of laser-safety eyewear material at the request of the ANSI laser safety committee. Presented results at the 1993 International Laser Safety Conference. 


\section{FY 93 Plans}

- Develop high-power Nd:YAG laser calibration capability at a wavelength of $1.06 \mu \mathrm{m}$.

- Develop $10.6-\mu \mathrm{m}$ measurement capability at $1 \mathrm{~kW}$ for calibration service.

- Complete optical fiber power round robin and present results at National Conference of Standards Laboratories meeting.

- Incorporate uniformity, linearity, and spectral responsivity measurements into the optical power measurement service program; document entire optical power measurement service program and submit for EEEL approval.

- Build two excimer laser calorimeters to be used as NIST national standards for excimer laser measurements.

- Design, construct, and implement tuneable laser source systems for optical fiber power calibrations at the three nominal wavelengths of 850,1300 , and $1550 \mathrm{~nm}$.

- Conduct second phase of laser beam profile round robin with beam profile system manufacturers.

\section{Impact}

- NIST's immediate response to a special request for calibrations permitted a major U.S. instrument manufacturer to minimize the time one of its production facilities was out of service. Representatives of the manufacturer accompanied the instruments submitted for calibration. NIST has received a letter of appreciation from the manufacturer.

\section{Recognition}

- Scott was selected to be session chairman at the International Laser Safety Conference held in Cincinnati, $\mathrm{OH}$ in December 1992, and was selected to be chairman of the IEC TC 76 Working Group "Laser Safety Measurements" for the conference in Rotterdam, Netherlands.

- Jones was invited to present a paper on the beam analysis round robin for the SPIE conference in Boston, MA in November 1992.

\section{Related Developments}

- The use of high-power Nd:YAG lasers for industrial welding and cutting has increased dramatically this past year. NIST has recently had several urgent requests for high-power $(>300 \mathrm{~W})$ measurements and standards at $1.06-\mu \mathrm{m}$ wavelength because of discrepancies of $30 \%$ or more at industrial laboratories.

- The expanding use of excimer lasers for industrial and medical purposes has increased the need to develop and provide national laser power/energy traceability at all three of the following wavelengths: 193,248 , and $308 \mu \mathrm{m}$. 
Project: LASER POWER AND ENERGY MEASUREMENTS

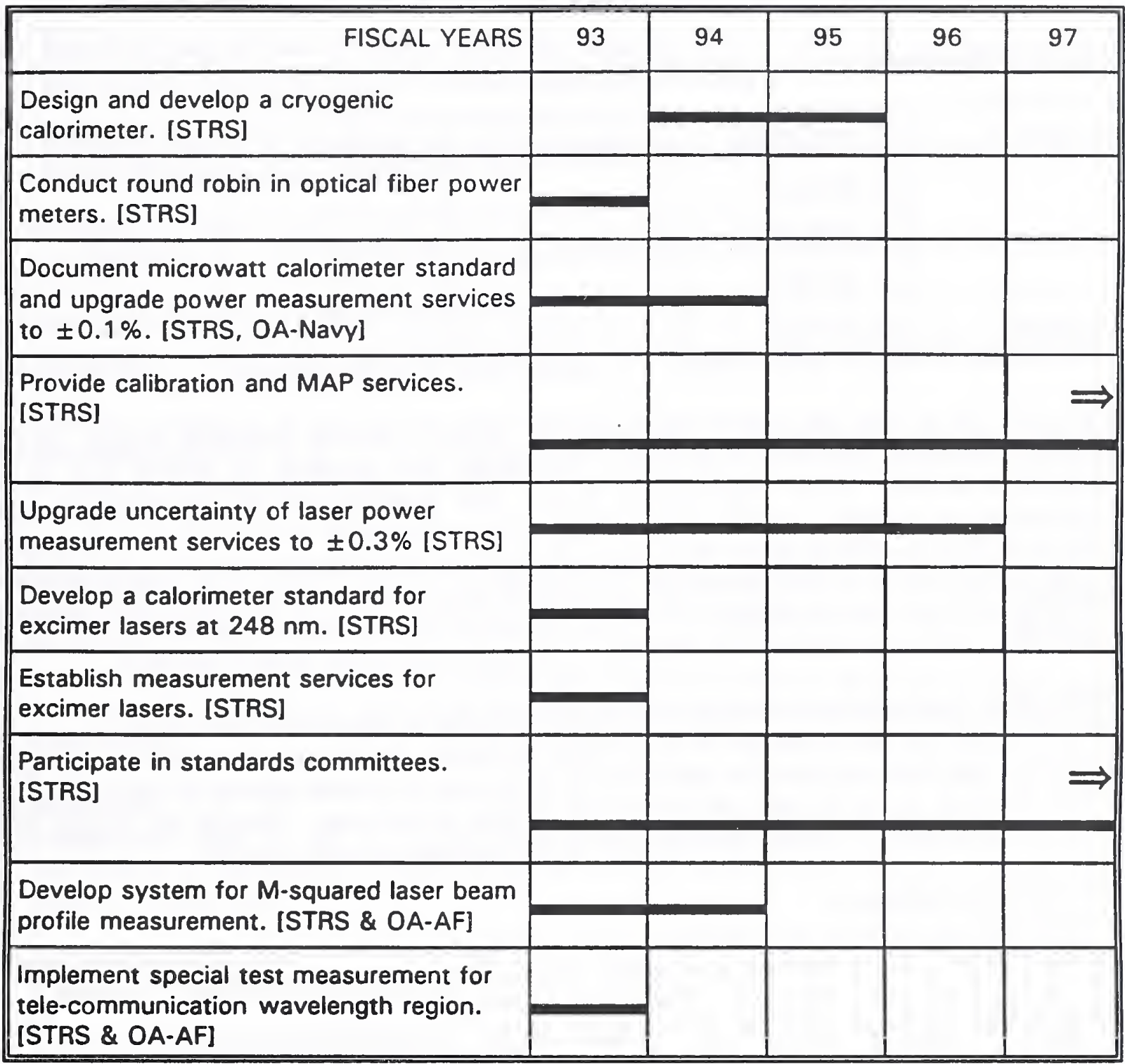




\section{Project: CHARACTERIZATION OF SOURCES AND DETECTORS}

FY 92 Fund Sources: STRS, Navy, Air Force, Calibration Fees

Staff (6.25 staff-years)

\begin{tabular}{|l||l|l|l|l|}
\hline \multirow{2}{*}{ Professional } & D. FRANZEN* & S. Gilbert & T. Drapela* & P. Hale* \\
\cline { 2 - 5 } & J. Schlager* & & & \\
\hline & R. PHELAN* & G. Obarski & D. Larson* & J. Lehman* \\
\hline & A. Sanders* & & & \\
\hline Technician & R. Juneau* & & & \\
\hline
\end{tabular}

name in capital le:ters $=$ project leader; $\quad$ = person works on project part time

Objective: To support the optical communications industry, develop theoretical models, advanced fabrication technology, practical measurement techniques, and standards to specify and measure characteristics of laser diodes, light-emitting diodes, and detectors that are significant in optical telecommunications systems. Specifically: establish in-house fabrication of laser diodes and detectors; develop methods to cha:acterize optical fiber lasers and amplifiers; determine spectral, noise, and modulation properties of laser dioces; develop wavelength standards for laser diodes; develop measurement systems for determining subpicosec nd time response, frequency response to $40 \mathrm{GHz}$, absolute spectral responsivity with $1 \%$ uncertainty, and noise properties of detectors, modulators, and optical network analyzers.

Significance: Fast pulse measurements are particularity needed to support high-performance systems and components which can take advantage of the potential bandwidth of installed optical fiber cables. Moresophisticated transmitters and receivers will allow for an increase in channel capacity by several orders of magnitude thorough higher bit rates and wavelength division multiplexing. Through this project, NIST supports the development of the next generation of optical telecommunication systems.

\section{FY 92 Accomplishments}

- Demonstrated the feasibility of a new highly stable wavelength standard for the $1.5-\mu \mathrm{m}$ region based on hyperfine excited state absorptions in rubidium; constructed atom trap for laser cooling rubidium.

- Completed the design, development and evaluation of a new, spectrally flat reference detector for spectral measurements, which is an order of magnitude more sensitive than previously available.

- Developed a laser heterodyne system for measuring the frequency response of detectors to $30 \mathrm{GHz}$ at a wavelength of $1.3 \mu \mathrm{m}$. Made preliminary measurements on two detectors.

- Acquired 17-ps duration laser diode pulses at $1.3 \mu \mathrm{m}$ by optical sampling with pulses from a 3-ps modelocked erbium fiber laser strobe.

- Demors as the feasibility of a portable wavelength standard for calibrating optical spectrum analyzers at both $1 . .2$ and $1.5 \mu \mathrm{m}$ (better than 0.01-nm accuracy).

- Completed a survey of diode laser manufacturer's specifications to determine need for relative- intensity noise measurements. 


\section{FY 93 Plans}

- Continue development of high-accuracy wavelength standard; lock single-frequency erbium fiber laser to laser cooled rubidium.

- Extend coverage of laser heterodyne system for measuring detector frequency response to $40 \mathrm{GHz}$ and start industry-wide round robin to evaluate measurement methods.

- Determine designs for an electrically calibrated pyroelectric radiometer that will lead to an order-ofmagnitude accuracy improvement.

- Complete the electro-optic sampling system for evaluating detectors and modulators having picosecond time resolution.

- Construct a prototype multi-wavelength standard $(1.3$ and $1.5 \mu \mathrm{m})$ for calibrating optical spectrum analyzers.

- Develop competence in and perform measurements of the relative-intensity noise for diode lasers to determine limitations of present measurement techniques; goal is to contribute to an Electronic Industries Association standard procedure.

\section{Impact}

- NIST's work on frequency response of detectors stimulated a major U.S. instrument manufacturer to offer a state-of-the-art detector to facilitate an industry-wide round robin on frequency response.

- A major instrument manufacturer has entered into a CRADA with NIST to obtain the NIST-developed technology for mid-accuracy wavelength standards for calibration of optical spectrum analyzers and laser diode sources.

\section{Recognition}

- Franzen was asked to give an invited paper on high-speed lightwave measurements (sources and detectors) at the 24th General Assembly of the International Union of Radio Science, to be held in Kyoto, Japan in August 1993.

\section{Related Developments}

- A Japanese company has advanced high-speed system technology with a field trial of a 10-Gbits/s system.

- A major U.S. company has expressed an interest in upgrading existing installed dispersion-unshifted fiber systems by using erbium fiber amplifiers and dense wavelength division multiplexing at $1550 \mathrm{~nm}$ wavelength. This course of action will create a need for new wavelength standards.

- Direct modulation of laser diodes at $25 \mathrm{GHz}$ has been reported by a U.S. company. 


\section{Project: CHARACTERIZATION OF SOURCES AND DETECTORS}

\begin{tabular}{|c|c|c|c|c|c|}
\hline FISCAL YEARS & 93 & 94 & 95 & 96 & 97 \\
\hline SOURCES & & & & & \\
\hline $\begin{array}{l}\text { Develop high and moderate accuracy } \\
\text { wavelength standards at } 1300 \text { and } 1550 \\
\mathrm{~nm} \text { to support needs of optical } \\
\text { communications industry. [STRS] }\end{array}$ & & & & & \\
\hline $\begin{array}{l}\text { Investigate spectral properties of laser } \\
\text { diodes (line-width, noise, etc) [STRS \& } \\
\text { OA-DoD] }\end{array}$ & & & & & \\
\hline $\begin{array}{l}\text { Complete moderate and high accuracy } \\
\text { wavelength standards for laser diodes. } \\
\text { [STRS, OA-AF, OA-Navy] }\end{array}$ & & & & & \\
\hline $\begin{array}{l}\text { Establish in-house fabrication of laser } \\
\text { diodes for study of measurement } \\
\text { problems. [STRS] }\end{array}$ & & & & & \\
\hline $\begin{array}{l}\text { Develop methods to characterize optical } \\
\text { fiber lasers and amplifiers [STRS \& OA- } \\
\text { Navy] }\end{array}$ & & & & & \\
\hline $\begin{array}{l}\text { Develop measurement system for } \\
\text { ris } s \text { me, falltime, and frequency response } \\
\text { of } t \text { : } 5 \text { ser diodes. [STRS \& OA-DOD] }\end{array}$ & & & & & \\
\hline DETECTORS & & & & & \\
\hline $\begin{array}{l}\text { Develop measurement techniques and } \\
\text { services for noise in detectors. [STRS] }\end{array}$ & & & & & \\
\hline $\begin{array}{l}\text { Develop electro-optic sampling system for } \\
\text { measuring response time of detectors and } \\
\text { modulators. [STRS] }\end{array}$ & & & & & \\
\hline $\begin{array}{l}\text { Fabricate detectors for improved } \\
\text { measurement accuracies and for study of } \\
\text { measurement problems. [STRS \& OA- } \\
\text { Navy] }\end{array}$ & & & & & \\
\hline $\begin{array}{l}\text { Establish advanced heterodyne system for } \\
\text { measuring frequency response of } \\
\text { detectors to } 50 \mathrm{GHz} \text { at } 1300 \text { and } 1500 \\
\mathrm{~nm} \text {. [STRS, OA-AF, OA-Navy] }\end{array}$ & & & & & \\
\hline $\begin{array}{l}\text { Establish transfer standard for short } \\
\text { impulse response duration of detectors. } \\
\text { [STRS] }\end{array}$ & & & & & \\
\hline
\end{tabular}




\section{Project: INTEGRATED OPTOELECTRONICS}

\section{FY 92 Fund Sources: STRS}

Staff (8.5 staff-years)

\begin{tabular}{|l||l|l|l|l|}
\hline \multirow{2}{*}{ Professional } & R. PHELAN* & A. Aust & R. Hickernell & J. Hill \\
\cline { 2 - 5 } & E. Johnson & M. McCollum & N. Sanford & R. Gallawa* \\
\cline { 2 - 5 } & D. Larson* & J. Lehman* & M. Young* & D. Veasey \\
\hline Technician & R. Juneau* & & & \\
\hline
\end{tabular}

name in capital letters $=$ project leader; $*=$ person works on project part time

Objective: Support the optical communications, optical information processing, and emerging optical computing industries through advanced metrology in planar waveguides and vertically integrated optoelectronic (10) structures. Specifically: apply state-of-the-art technology and theory to create and package devices made of compound semiconductors or optical crystals and glasses that will lead to advanced measurement techniques; use metrology to evaluate the design of structures; develop methods to measure the power and energy efficiencies, operating wavelengths, switching speeds, attenuation, gain, scattering, coupling, and insertion loss of 10 components.

Significance: Optical fiber cable is an expensive component of an optical telecommunication system, and strenuous research and development efforts are in progress to efficiently use installed and future cables by taking advantage of the enormous bandwidths available through increased bit rate and wavelength multiplexing. Economical distribution of high quality signals to a large number of customers requires integrated optoelectronics. Optical storage and photocopying are major industries that are very likely to become increasingly dependent on 10 components. If optical computing is to become a viable alternative to purely electronic computing, the evaluation and development of the 10 components will be required. Also, NIST must have expertise in this area to support ATP program evaluations.

\section{FY 92 Accomplishments}

- Completed the design of the chemical-beam epitaxy (CBE) system for growing advanced III-V compound semiconductor structures, and installed the machine.

- Extended the NIST-developed optical waveguide model of analysis, based on Galerkin's method, to encompass a new class of problems and new methods of analysis, by using symbolic programming to remove numerical integration from the process for any profile that can be expressed or approximated as a power series (an important case); extended the method to account for waveguide losses for arbitrary complex refractive index.

- Compared and demonstrated the utility of photoluminescence spectroscopy, photoreflectance reflectance spectroscopy, reflectance spectroscopy, scanning electron microscopy, transmission electron microscopy, and double crystal X-ray diffractometry for evaluating laser cavities, Bragg mirror layer thicknesses and alloy compositions of semiconductor structures (in collaboration with the Semiconductor Electronics Division and industry).

- Demonstrated and published a description of the first waveguide laser in $\mathrm{Nd}: \mathrm{LiTaO}_{3}$; these waveguide lasers advance the potential for truly integrated-optic structures. 
- Completed a study of pump-induced dispersion of erbium-doped fibers; study provides information meeded to design practical high-speed amplifiers.

- Refined the localized plasma etching process to create planar waveguide polarizers that are highly selective for either TE or TM polarizations. Published description of unique etching process and applied for patent.

\section{FY 93 Plans}

- Develop optical in situ characterization methods that will provide quantitative information on the kinetics and thermodynamics of growth. Real-time chemical analysis of the source beams will considerably speed up the creation of new structures by making it possible to adjust continuously the growth process and control the epitaxial composition with a resolution of a few atomic layers.

- Extend the measurement capabilities for characterizing GaAs and InP related compound semiconductor materials and novel device structures.

- Grow layers of low-temperature GaAs or InGaAs on the CBE system and evaluate these materials for ultra-high-speed detectors and switches to be applied to detector and modulator measurements. Demonstrate the capability to grow laser-quality InGaAs structures for optical communication wavelengths.

- Continue research on the theory of optical waveguides in integrated structures, extending the work to include the prediction of loss in passive integrated optical components.

- Measure the absorption and emission spectra of a series of ion-exchanged waveguides in rare-earth-doped glass to study the effect of glass composition on performance of waveguide lasers and amplifiers, and demonstrate a $1.3-\mu \mathrm{m}$ waveguide laser.

- Develop domain-reversed segments in rare-earth-doped $\mathrm{LiTaO}_{3}$ and evaluate structures for simultaneous lasing and intra-cavity sum-frequency generation.

\section{Impact}

- A recently established device manufacturer credits its status as the first company to market vertical-cavity lasers for sale to joint assistance from NIST's Electromagnetic Technology Division and Semiconductor Electronics Division.

\section{Recognition}

- Sanford gave invited papers on rare-earth-doped waveguide lasers at the OSA conference on Compact Blue-Green Lasers in Santa Fe, and at the 1992 OSA Annual Meeting in Albuquerque. He was also invited to participate in a workshop on Integrated Optical Solid State Lasers and Quasi-Phasematched Nonlinear Devices at Paderborn, Germany.

- The Chairman of the Electrical Engineering Department and the Dean of the School of Engineering of the University of Oklahoma have indicated their intention to transfer the technology of localized plasma processing to the University. This method is an invention of Veasey and Larson; a patent application has been filed.

\section{Related Developments}

- A Japanese company is reported to be using lithium niobate external modulators in its 10-Gbit/s lightwave systems to avoid chirping problems of laser diodes. 


\section{Project: INTEGRATED OPTOELECTRONICS}

\begin{tabular}{|c|c|c|c|c|c|}
\hline FISCAL YEARS & 93 & 94 & 95 & 96 & 97 \\
\hline $\begin{array}{l}\text { Establish in-house waveguide fabrication } \\
\text { in passive substrates. [STRS] }\end{array}$ & & & & & \\
\hline $\begin{array}{l}\text { Establish in-house waveguide fabrication } \\
\text { in III-V compound semiconductors. [STRS] }\end{array}$ & & & & & \\
\hline $\begin{array}{l}\text { Conduct theoretical studies in } \\
\text { propagation, loss, coupling, and WDM } \\
\text { applications. [STRS] }\end{array}$ & & & & & \\
\hline $\begin{array}{l}\text { Improve instrumentation for measuring } \\
\text { polarization of modes in optical } \\
\text { waveguides. [STRS] }\end{array}$ & & & & & \\
\hline $\begin{array}{l}\text { Develop measurement methods for } 1 \mathrm{II}-\mathrm{V} \\
\text { compound semiconductor waveguides. } \\
\text { [STRS \& OA-DoD] }\end{array}$ & & & & & \\
\hline $\begin{array}{l}\text { Develop methods for on-chip } \\
\text { characterization of integrated optical } \\
\text { devices. [STRS \& OA-DoD] }\end{array}$ & & & & & \\
\hline $\begin{array}{l}\text { Test coupler theory for linear and curved } \\
\text { optical waveguides. [STRS] }\end{array}$ & & & & & \\
\hline $\begin{array}{l}\text { Participate in standards committees. } \\
\text { [STRS] }\end{array}$ & & & & & $\Rightarrow$ \\
\hline $\begin{array}{l}\text { Develop surface emitting laser with } \\
\text { internal modulation. [STRS] }\end{array}$ & & & & & \\
\hline Transfer technology to industry. [STRS] & & & & & $\Rightarrow$ \\
\hline $\begin{array}{l}\text { Evaluate potential areas for NIST } \\
\text { contributions to optical computing } \\
\text { metrology. [STRS] }\end{array}$ & & & & & \\
\hline
\end{tabular}




\section{Project: OPTICAL-FIBER SENSORS}

FY 92 Fund Sources: STRS, Navy, NASA, DNA, NSA, LANL, CCG

Staff (8.0 staff-years)

\begin{tabular}{|l||l|l|l|l|}
\hline \multirow{2}{*}{ Professional } & G. DAY & M. Deeter & K. Rochford & A. Rose \\
\cline { 2 - 5 } & R. Craig & J. Wyss & P. Williams & E. Simmon \\
\hline Technician & S. Etzel & R. Juneau & & \\
\hline
\end{tabular}

name in capital letters $=$ project leader; $*=$ person works on project part time

Objective: To support the optical fiber sensor industry and government and industry-wide laboratories: develop measurement technology for materials and components used in sensors; develop reference data on materials; study fundamental and practical limitations to sensor performance; develop generic calibration technology; assist in development of standards; develop new fiber sensor technology, especially for electromagnetic measurements. Specific objectives include: conduct an interlaboratory comparison of $h$ parameter measurements on high-birefringence fiber; develop a new type of magnetometer based on Faraday effect; develop techniques for making sensors self-calibrating.

Significance: Optical fiber technology brings to metrology many of the same benefits that it has provided for optical communications; particularly significant among these are the relative immunity to electromagnetic interference and reductions in size and weight. Several sectors of the technology are showing commercial success, especially sensors for position measurements, sensors for use in medicine, and optical fiber gyroscopes. Sales of sensors in 1990 were about $\$ 165$ million and are projected to be over $\$ 900$ million in 1996. NIST developments provide metrology support needed by industry for this activity.

\section{FY 92 Accomplishments}

- Developed a new type of fiber current sensor, based on the Faraday effect in four pieces of YIG, which demonstrated a noise equivalent current of $220 \mathrm{nANHz}$ (1000 times better than previously reported values) and having bandwidth of $2.5 \mathrm{MHz}$ (sensitivity-bandwidth product ten times better).

- Demonstrated and filed a patent disclosure for the use of as snetic flux concentration with the Faraday effect in a high-permeability material, to reduce the minimum detectable field of such a sensor by a factor of as much as 100 .

- Developed a technique whereby a polarimetric temperature sensor can be made self-calibrating.

- Improved the temperature stability of fiber current sensors: latest result on a packaged sensor is a normalized stability of $1.7 \times 10^{-4} / \mathrm{K}$ over the range $-65^{\circ} \mathrm{C}$ to $+125^{\circ} \mathrm{C}$.

- Began an interlaboratory comparison of h-parameter measurements in high-hirefringence optical fiber.

- Investigated ionizing radiation effects in iron garnets; found them generally to suffer only about a factor of two greater darkening than fused silica, which makes them more suitable than most materials for use in sensors for high-radiation environments. 


\section{FY 93 Plans}

- Complete and publish h-parameter interlaboratory comparison.

- Complete investigation of the effect of flux concentration on garnet magnetic field sensors.

- Complete temperature sensor incorporating self calibration (a demonstration instrument).

- Design and develop a second-generation YIG current sensor to evaluate sensitivity-bandwidth limitations.

- Complete system for characterization of optical fiber couplers.

\section{Impact}

- A U.S. company is marketing an instrument based directly on NIST technology; at least seven companies or laboratories are known to be using technology developed in the Group.

\section{Recognition}

- Day received the Federal Laboratories Consortium "Excellence in Technology Transfer Award" for transferring NIST annealed-coil technology to industry.

- Day was a member of the Program Committee for the 8th International Conference on Optical Fiber Sensors and was appointed to be (1) North American Co-Chair for OFS-9 and to the Steering Committee for future conferences, (2) co-chair of the IEEE workshop "Challenges in Opto-electronic Packaging," (3) as government liaison to the Optoelectronic Industry Development Association Roadmap Committee, and (4) to the program committee for the next European Optical Fiber Measurement Conference. He also presented an invited paper, "Faraday Effect Sensors" at the Chinese International Conference on Optical Fiber Sensors.

- Deeter was invited to present a paper on magneto-optic effects in iron garnets at the next International Optical Fiber Sensor Conference; his work on magnetic field sensors was described in articles in the trade magazines Design News and Microwaves.

- Rose was appointed a cochair of the SPIE conference "Application of Fiber Optic-Based Sensors in Industry".

\section{Related Developments}

- Certain areas of fiber sensor technology are showing excellent progress. One medical electronics company is known to be producing 50,000 disposable pressure sensors per year. Another company is producing 5,000 temperature sensors per year. The next large passenger plane to be produced in the U.S. will use optical fiber gyroscopes.

- Commercially available Faraday effect current sensors for use at high voltage ( $>100 \mathrm{kV})$ are now priced competitively with conventional current transformers. One major European supplier to the power industry has indicated that it believes the market for Faraday effect current sensors will be substantial within a few years and has re-established product development after stopping for nearly a decade.

- The use of magneto-optic technology for rotation sensing in such environments as automotive transmissions and antilock brakes and aircraft engines is drawing substantial interest. Four companies are known to have initiated development programs within the last two years. 
Project: OPTICAL-FIBER SENSORS

\begin{tabular}{|c|c|c|c|c|c|}
\hline FISCAL YEARS & 93 & 94 & 95 & 96 & 97 \\
\hline $\begin{array}{l}\text { Develop measurement techniques and } \\
\text { standards for birefringence and beat- } \\
\text { length. [STRS] }\end{array}$ & & & & & \\
\hline $\begin{array}{l}\text { Develop current and voltage sensors with } \\
\text { high temperature stability. } \\
\text { [OA-Navy, OA-NASA] }\end{array}$ & & & & & \\
\hline $\begin{array}{l}\text { Develop low-noise optical fiber current } \\
\text { sensor. [STRS, OA-Navy] }\end{array}$ & & & & & \\
\hline $\begin{array}{l}\text { Transfer current sensor technology to } \\
\text { industry. [STRS] }\end{array}$ & & & & & \\
\hline $\begin{array}{l}\text { Extend frequency range and sensitivity of } \\
\text { magnetic field sensors. [OA-DoE (Sandia), } \\
\text { OA-NASA] }\end{array}$ & & & & & \\
\hline $\begin{array}{l}\text { Investigate improved materials for electro- } \\
\text { optic and magneto-optic sensing. } \\
\text { [OA-DoE, OA-Navy] }\end{array}$ & & & & & \\
\hline $\begin{array}{l}\text { Develop optical measurement methods for } \\
\text { magnetic materials (with SMM Group). } \\
\text { [OA-DoE, OA-Navy] }\end{array}$ & & & & & \\
\hline $\begin{array}{l}\text { Extend integrated optics technology to } \\
\text { optical fiber sensors. [STRS, OA-Navy] }\end{array}$ & & & & & \\
\hline $\begin{array}{l}\text { Develop self-calibration technology for } \\
\text { optical fiber sensors. [OA-Navy] }\end{array}$ & & & & & \\
\hline $\begin{array}{l}\text { Establish measurement techniques for } \\
\text { optical fiber couplers. [STRS] }\end{array}$ & & & & & \\
\hline $\begin{array}{l}\text { Participate in standards committees. } \\
\text { [STRS] }\end{array}$ & & & & & \\
\hline $\begin{array}{l}\text { Develop improved packaging for optical } \\
\text { fiber sensors. [STRS, OA-DoE, OA-DoD, } \\
\text { OA-NASA] }\end{array}$ & & & & & \\
\hline
\end{tabular}




\section{Project: CRYOELECTRONIC METROLOGY}

\section{FY 92 Fund Sources: STRS, ONR, CCG}

Staff (6.85 staff-years)

\begin{tabular}{|l||l|l|l|l|}
\hline Professional & J. MARTINIS & R. Kautz & M. Devoret* & A. Johnson \\
\cline { 2 - 5 } & M. Nahum & T. Eiles & R. Welty & \\
\cline { 2 - 5 } & R. Harris & & & \\
\hline Technician & G. Wallace* & M. Crews & & \\
\hline
\end{tabular}

name in capital letters = project leader; $*$ person works on project part time

Objective: Develop measuring devices and standards for fundamental metrology of superior accuracy, sensitivity, and performance. Perform fundamental background research in support of this effort. Specifically develop electronic charge and capacitance standards, new techniques for measuring the fine structure constant, and new microwave power standards. In addition, examine cryoelectronic technology beyond that which is superconducting for new areas of work which will enhance the competitiveness of the U.S. electronics industry.

Significance: Ultra-small electronic devices are fundamental to a new class of electronic devices for metrological application. The demonstrated performance of an electrometer and charge pump at NIST gives credibility to future metrological devices based on this forefront technology. In a few years the singleelectron devices may produce a better value of the fine structure constant and eventual charge and capacitance standards in integrated circuit form. This NIST project is designed to meet future needs in an area of prime NIST responsibility by providing standards and establishing measurement techniques to support new developments in industrial, military, and scientific technology.

\section{FY 92 Accomplishments}

- Measured the temperature dependence of co-tunneling of electrons through a submicrometer superconducting island connected to two normal metal leads by ultra-small tunnel junctions, and submitted a paper to Physical Review Letters.

- Demonstrated successful operation of a charge pump driven at both 4 and $8 \mathrm{MHz}$, showing respectively about 4 and 8 million electrons per second. This is the first step in an experiment to measure the fine structure constant in a new way, that is, in terms of SI units.

- Finished calculations of error rates in a charge pump, and developed analytic formulas for these rates; prepared detailed and lengthy publication.

- Fabricated and tested the first chip with integrated charge pump, electrometer, and capacitor, necessary for the experiment to measure the fine structure constant.

- Showed with a normal state electrometer - a single-electron counting apparatus operating in the millikelvin range of temperature - the existence of one quasiparticle above a sea of $10^{10}$ paired electrons in a superconducting island between two normal metals. This is the first direct observation of a quasiparticle existing at the energy gap above paired electrons in a superconductor; submitted a paper to Physical Review Letters. 
- Discovered much-reduced low frequency charge noise by using sapphire rather than silicon substrates.

- Invented a new bolometer design for the microwave power standard which greatly simplifies its modeling, construction, and ultimate accuracy. Subsequently fabricated a dummy $\mathrm{Nb}-\mathrm{Cu}$ superconducting bolometer mount, demonstrating sufficiently low loss for use as a microwave power standard; presented results at the 1992 Applied Superconductivity Conference.

- Wrote computer programs to analyze the effect of heating on the Coulomb blockade electrometer, compared the results with data to prove the viability of the model, and published the results.

- Built a two-stage integrated SQUID (superconducting quantum interference device) amplifier with bandwidth of about $0.5 \mathrm{MHz}$; published results at the 1992 Applied Superconductivity Conference.

\section{FY 93 Plans}

- Demonstrate on the same chip an integrated charge pump and electrometer.

- Demonstrate accurate electron counting.

- Continue to explore low frequency noise arising from substrates and other sources.

- Measure noise in two-dimensional electron-gas single-electronic devices.

- Attempt to observe localized charges at the metal-insulator transition in two-dimensional electron gases.

- Write a book on chaotic behavior with many examples from the Josephson effect.

- Prepare white papers and proposals describing extended research by the Cryoelectronic Metrology Group involving low-temperature devices which are non-superconducting.

\section{Recognition}

- Martinis was Experimentalist for the Week at the Institute for Advanced Study, University of California at Santa Barbara, and was invited by the American Physical Society to write a simple article for the public explaining single electronics.

\section{Related Developments}

- Researchers at Saclay, France and elsewhere are actively pursuing single-electronics for both its scientific and potential technological interest. 
Project: CRYOELECTRONIC METROLOGY

\begin{tabular}{||r|r|r|r|r|r||}
\hline FISCAL YEARS & 93 & 94 & 95 & 96 & 97 \\
\hline $\begin{array}{l}\text { Perform initial experiments to measure } \\
\text { fine-structure constant. [STRS, OA-ONR] }\end{array}$ & & & & & \\
\hline $\begin{array}{l}\text { Demonstrate accurate electron counting } \\
\text { with electrometer. [STRS] }\end{array}$ & & & & & \\
\hline
\end{tabular}




\section{Project: SUPERCONDUCTING METROLOGY}

FY 92 Fund Sources: STRS, CCG/Army, Stanford, Navy/URI,

Staff (6.0 staff-years)

\begin{tabular}{|l||l|l|l|l|}
\hline \multirow{2}{*}{ Professional } & C. HAMILTON & C. Burroughs & S. Benz & P. Booi \\
\cline { 2 - 5 } & K. Gilbert & M. CROMAR* & R. Harris* & \\
\hline \multirow{2}{*}{ Technician } & G. Wallace* & M. Crews* & C. Livingston * & \\
\hline
\end{tabular}

name in capital letters $=$ project leader; $"=$ person works on project part time

Objective: To support industrial needs for precision measurements, use superconductive integrated circuit technology to develop measuring devices and standards for fundamental metrology having superior accuracy, sensitivity, and performance. Specifically, develop improved voltage standards (all niobium, programmable), ultra-low-noise SQUIDs (superconducting quantum interference devices), measurement techniques for ultrahigh-speed digital circuits, and millimeter wave sources.

Significance: Superconductive technology makes possible voltage standards and sensitive magnetic flux measurement at the fundamental performance limit. No other technology is capable of this performance. Most of the major national standards laboratories in the world depend on NIST for voltage standards. Moreover, advances in electronics for fundamental scientific research, telecommunications, radar, data processing, etc. will demand higher-speed measurement than is now possible. This NIST project is designed to meet future needs in an area of prime NIST responsibility by providing standards and establishing measurement techniques to support new developments in industrial, military, and scientific technology.

\section{FY 92 Accomplishments}

- Developed a new process which substantially increased the yield of $10-\mathrm{V}$ chips and eliminated the backlog of requests for these devices, now at 32 different standards laboratories (collaboration with industry).

- Supported U.S. companies in developing commercial components and systems for Josephson voltage standards. NIST supplied designs, chip layouts, consultation, documentation, sample chips, and test apparatus.

- Published a proposal for a rapidly programmable voltmeter source with the full accuracy of the Josephson standard. Realization of this idea will make possible ac voltage measurements based directly on the Josephson volt.

- Developed and delivered SQUIDs to the Stanford Gravity Probe-B project for low-temperature and verylow-frequency testing.

- Measured coherent and incoherent radiation from a two-dimensional array superconducting millimeter wave generator which has high efficiency and output power for frequencies from 50 to $210 \mathrm{GHz}$.

- Published a margin analysis of single flux quantum logic and presented several invited talks on the subject.

- Completed the NIST automated Josephson IC tester; this system has now been duplicated at four other organizations. 
- Fabricated a family of single-flux-quantum logic gates and demonstrated their operation at low speeds.

\section{FY 93 Plans}

- Design, fabricate, and test developmental circuits for the rapidly programmable voltage source; analyze resulting data for design of the full circuit.

- Continue to participate in the Conductus, TRW, NIST, Berkeley, Hewlett-Packard, Stanford consortium to demonstrate a superconductive work-station by 1997.

- Continue to cooperate with industry to develop and enhance U.S. commercial sources for Josephson voltage standard systems and components. Continue to supply Josephson voltage standard chips until a commercial supplier markets chips.

- Continue in the role of consultant to participants of the URI superconductive electronics project (SUNY Stony Brook, University of Rochester, University of California at Berkeley). Provide NIST-developed technology for cryoprobes and hardware, and software for automated testing.

- Continue the development of low-temperature SQUIDs tailored to the needs of the Stanford Gravity Probe-B program; report the effects of junction size and type and the effects of $\mathrm{SiO}_{2}$ insulation.

- Collaborate with industry on the development of low-temperature SQUIDs for neuromagnetometry.

\section{Impact}

- More than 30 national, commercial, and military standards laboratories worldwide rely on NIST Josephson voltage standard chips. Four U.S. companies are using NIST chips to evaluate and improve commercial products.

\section{Recognition}

- Hamilton is Associate Editor of the IEEE Transactions on Applied Superconductivity, and on the NCSL Intrinsic Standards Committee for the volt.

- Benz was awarded U.S. Patent 5,114,912 for "Two-dimensional, Josephson-array, Voltage-tunable, Highfrequency Oscillator."

\section{Related Developments}

- The Army has a contract with a U.S. company to develop capability to manufacture voltage standard chips. 


\section{Project: SUPERCONDUCTING METROLOGY}

\begin{tabular}{|c|c|c|c|c|c|}
\hline FISCAL YEARS & 93 & 94 & 95 & 96 & 97 \\
\hline $\begin{array}{l}\text { Establish practical } 10-V \text { chip fabrication. } \\
\text { [STRS, OA-CCG] }\end{array}$ & & & & & \\
\hline $\begin{array}{l}\text { Develop all-Nb voltage standard chip. } \\
\text { [STRS, OA-CCG] }\end{array}$ & & & & & \\
\hline $\begin{array}{l}\text { Develop low frequency (and less } \\
\text { expensive) standards of voltage. [STRS] }\end{array}$ & & & & & \\
\hline $\begin{array}{l}\text { Provide advice to standards laboratories. } \\
\text { [STRS, OA-CCG] }\end{array}$ & & & & & \\
\hline $\begin{array}{l}\text { Assist private commercial system } \\
\text { development. [STRS] }\end{array}$ & & & & & \\
\hline $\begin{array}{l}\text { Participate as a full partner in the } \\
\text { Conductus, et al consortium to } \\
\text { demonstrate a superconductive work- } \\
\text { station. [STRS, ATP] }\end{array}$ & & & & & \\
\hline $\begin{array}{l}\text { Develop LTS SQUIDs for Stanford Gravity } \\
\text { Probe-B program. Study effects of } \\
\text { junction size and type, and effects of } \\
\mathrm{SiO}_{2} \text { insulation. [OA-Stanford U.] }\end{array}$ & & & & & \\
\hline $\begin{array}{l}\text { Develop } 2 \mathrm{D} \text { Josephson arrays as } \\
\text { microwave sources. [STRS, OA-AF] }\end{array}$ & & & & & \\
\hline $\begin{array}{l}\text { Install } \mathrm{SiO}_{2} \text { deposition system and } \\
\text { develop associated processes. [STRS] }\end{array}$ & & & & & \\
\hline $\begin{array}{l}\text { Fabricate practical devices with Nb } \\
\text { junction technology. [STRS] }\end{array}$ & & & & & \\
\hline
\end{tabular}




\section{Project: FAR-INFRARED TECHNOLOGY}

FY 92 Fund Sources: STRS, NASA, ONR, SDIO, AF

Staff (4.0 staff-years)

\begin{tabular}{|l||l|l|l|l|}
\hline Professional & D. MCDONALD & J. Sauvageau & E. Grossman & J. Koch* \\
\cline { 2 - 5 } & R. Harris* & & & \\
\hline Technician & G. Wallace & M. Crews* & & \\
\hline
\end{tabular}

name in capital letters $=$ project leader; $=$ person works on project part time

Objective: To support industrial and military need for standards quality and manufacturable infrared detectors, develop infrared standards and sensors for fundamental metrology of superior accuracy, sensitivity, and performance. Specifically, develop the NIST standard radiometer, as well as pixel-sized infrared sensors of superior sensitivity and manufacturability. Extend this infrared technology to other domains of metrology as appropriate; e.g., study the feasibility of an audio frequency and radiofrequency thermal converter, based on a kinetic-inductance thermometer, for a new national standard ac voltmeter. Also explore the application of superconducting kinetic-inductance thermometers to the measurement of $\mathrm{x}$-ray energies.

Significance: The physical foundation of this work is the use of superconducting inductors, coupled to a SQUID (superconducting quantum interference device), as a fundamental measurement device. The temperature dependence of inductance provides the world's most sensitive thermometer (with sensitivity of a few parts in $10^{9}$ ) for power measurements. Industry depends on NIST as a source of quantum-based power standards development as well as to establish and maintain national standards at the highest levels of accuracy. The kinetic-inductance thermometer can be the basis for power standards at audio, radio, microwave, and infrared frequencies, as well as for the visible, ultraviolet, and $x$-ray portions of the spectrum. Used in a different mode, it can be a sensitive detector of ionizing (pair breaking) radiation. Both direct and heterodyne detectors are anticipated.

\section{FY 92 Accomplishments}

- Reported, in Applied Physics Letters, the extension of lithographed antennas to the infrared.

- Developed working radiometer chip with built-in imbalance of $2 \%$, for the national infrared standard radiometer; tested the radiometer (chip with cone) and observed no excess noise due to the cone.

- Constructed and put into operation a deposition system for niobium alloys with critical temperatures $\left(T_{c}\right)$ in the range of $4.5 \mathrm{~K}$ to $8 \mathrm{~K}$. Produced $\mathrm{NbTa}$ films with $\mathrm{T}_{c}$ of about $5.6 \mathrm{~K}$. This and other kineticinductance-based thermal converter projects benefit from using such superconductors having critical temperatures closer to the liquid-helium bath temperature.

- Fabricated, assembled, and tested a single-mode $\mathrm{CO}_{2}$ laser for the far-infrared antenna project. Confirmed to have sufficient power for pumping alcohol lasers at the longer far-infrared wavelengths.

- Completed specification for the new electron cyclotron resonance $\mathrm{SiO}_{2}$ deposition system. 


\section{FY 93 Plans}

- Finish chip fabrication, construction, and testing of the national standard infrared radiometer.

- Develop kinetic inductors of $\mathrm{Nb}$-Ta alloys for operation near 5 kelvin.

- Install $\mathrm{SiO}_{2}$ deposition system and integrate into routine fabrication processes for low-temperature superconductors.

- Experimentally demonstrate antenna-coupled SQUID-based infrared detectors.

- Measure infrared response of high-temperature-superconductor antenna-coupled Josephson junctions.

- Design and fabricate an initial kinetic-inductance-based ac/dc thermal converter for the audio-frequency and radiofrequency ranges.

\section{Recognition}

- The physics of the NIST kinetic-inductance sensor led NIST to extend the use of microantennas to much shorter wavelengths than heretofore, i.e., to the thermal infrared. These antennas are the smallest ever made and are 52\% efficient. This work was subsequently publicized in Scientific American, Business Week, Rocky Mountain News, Denver TV Channel 6. Science News, Los Angeles Times, Chicago Tribune, and some dozen other publications.

- Substantive recognition has come from those agencies that support the development of new metrological instruments. This work is presently financially supported by two agencies in the Department of Defense and two agencies in the National Aeronautics and Space Administration, at a combined level of about $650 \mathrm{~K} \$$ per year.

\section{Related Developments}

- It has become recognized that detectors on long-life (a decade or more) satellites, such as the proposed Earth Observation Satellite series, will require calibration by on-board systems having accuracies better than one percent. NIST developments in the realm of kinetic-inductance sensors may offer a solution to this challenging problem. 


\section{Project: FAR-INFRARED TECHNOLOGY}

\begin{tabular}{|c|c|c|c|c|c|}
\hline FISCAL YEARS & 93 & 94 & 95 & 96 & 97 \\
\hline $\begin{array}{l}\text { Develop infrared standards grade } \\
\text { radiometer. [OA-CCG (SDI)] }\end{array}$ & & & & & \\
\hline $\begin{array}{l}\text { Develop infrared focal plane array } \\
\text { elements. [OA-ONR] }\end{array}$ & & & & & \\
\hline $\begin{array}{l}\text { Determine feasibility of IR heterodyne } \\
\text { receiver. [OA-NASA] }\end{array}$ & & & & & \\
\hline $\begin{array}{l}\text { Design and fabricate an initial kinetic- } \\
\text { inductance-based ac/dc thermal } \\
\text { converter. [Dir. Reserve] }\end{array}$ & & & & & \\
\hline
\end{tabular}




\section{Project: HIGH-TEMPERATURE SUPERCONDUCTING FILMS AND ELECTRONIC DEVICES}

FY 92 Fund Sources: STRS, NASA, DARPA

Staff (8.25 staff-years)

\begin{tabular}{|l||l|l|l|l|}
\hline \multirow{2}{*}{ Professional } & M. CROMAR* & D. RUDMAN & J. Beall & R. Ono \\
\cline { 2 - 5 } & L. Vale & T. Harvey & P. Rosenthal & R. Harris* \\
\cline { 2 - 5 } & N. Missert & J. Rice* & & \\
\hline Technician & G. Wallace * & M. Crews* & H. Beck* & K. Kimminau* \\
\hline
\end{tabular}

name in capital letters $=$ project leader; $=$ person works on project part time

Objective: Develop the basic science, establish the technology, and develop high temperature superconductor (HTS) electronic devices for metrological and commercial use. Transfer this technology to commercial manufacturers. Specifically, develop and refine processes for fabricating Josephson junction devices between HTS films, and for fabricating microwave and infrared detector components. Demonstrate prototype devices of commercial interest.

Significance: The potential impact of HTS on electronics is enormous, but a practical technology must be developed to realize it. Progress on HTS thin-film technology has been rapid, setting the stage for the fabrication of devices to determine the most promising opportunities for this technology. The Cryoelectronic Metrology Group has developed all the components required for HTS integrated circuits and is beginning work on specific devices. This project is part of a nationwide research and development effort to reach that goal.

\section{FY 92 Accomplishments}

- Produced pinhole-free insulating layers of $\mathrm{CeO}_{2}$ on YBCO, and epitaxial films of $\mathrm{SrTiO}_{3}$ on YBCO (necessary for fabricating multilevel HTS circuits).

- Completed measurements and analysis of radiofrequency-induced step heights as a function of magnetic field in YBCO superconductor-normal-superconductor (SNS) junctions. Published paper on these results showing agreement of the data with the resistively-shunted-junction model.

- Compared surface morphology of YBCO films made under a variety of deposition conditions. Analyzed results to find that surface morphology can be controlled by adjusting substrate temperature, oxygen pressure, and film growth rate. [Joint activity with the Superconductor and Magnetic Measurements Group]

- Processed steps for SNS junctions on deposited $\mathrm{SrTiO}_{3}$ and $\mathrm{CeO}_{2}$ dual layers; patterned a step down to the underlying YBCO, and imaged it with an atomic force microscope. [Joint activity with the Superconductor and Magnetic Measurements Group]

- Fabricated 1- $\mu \mathrm{m}$ wide, $375-\mu \mathrm{m}$ long, YBCO lines with very high critical current density $\left(J_{c}>8 \times 10^{6}\right.$ $\mathrm{A} / \mathrm{cm}^{2}$ ) at $78 \mathrm{~K}$. Tested lines for use in a proprietary design microwave phase shifter. [Collaboration with industry] 
- Fabricated and measured the capacitance of thin insulating films $\left(\mathrm{SrTiO}_{3}\right.$ and $\left.\mathrm{CeO}_{2}+\mathrm{SrTiO}_{3}\right)$ between YBCO films. Found the insulating $\mathrm{SrTiO}_{3}$ films to have nearly bulk-like dielectric properties (among the best of those presented at the Applied Superconductivity Conference in August). Measured the dielectric constant of the multilayer composite and found it was an order of magnitude lower that of pure $\mathrm{SrTiO}_{3}$.

- Found that measured normal-state resistance values for the fabricated SNS devices have a much smaller spread than do the critical current values. Predicted such an effect in a model calculation which suggests that the spread in critical current can be reduced by using a lower-resistivity normal metal, such as silver.

- Made YBCO on $\mathrm{LaAlO}_{3}$ having surface resistance of 50 micro-ohms, and fabricated 5-GHz resonators for tunable matching network applications. [Collaboration with the University of Colorado]

\section{FY 93 Plans}

- Fabricate and test electrically small, tunable antennas with low-loss YBCO films. [Collaboration with the University of Colorado]

- Investigate techniques for increasing the normal resistance of step-edge SNS junctions; investigate and improve the predictability and reproducibility of YBCO step-edge SNS Josephson Junctions. Assess manufacturability of these junctions.

- Measure the response of step-edge SNS junctions to terahertz radiation and evaluate their performance as detectors of infrared radiation.

- Continue development of multilayer YBCO Josephson devices for use in detectors and logic applications.

- Investigate the feasibility of a series-array voltage standard based on BSCCO and/or TBCCO thin films. [Collaboration with industry]

- Compare the noise in single layer, multilayer, and high-resistance SNS Josephson junctions and SQUIDs; measure the noise of SQUIDs incorporating step-edge SNS junctions.

\section{Recognition}

- The designation of the Cryoelectronic Metrology Group as a national Superconductivity Research Center for Applications to Electronics was a recognition that the Group's expertise in fabricating lowtemperature superconducting microcircuits is a valuable asset of the national HTS electronics program.

- Ono was named Co-chair and Program Chair for the International Superconductive Electronics Conference for 1993.

- Rudman was elected to the Board of the Applied Superconductivity Conference.

\section{Related Developments}

- Several U.S. companies have begun marketing HTS products, including integrated HTS SQUIDs on a chip, thin films, and microwave components. 


\section{Project: HIGH-TEMPERATURE SUPERCONDUCTING FILMS AND ELECTRONIC DEVICES}

\begin{tabular}{|c|c|c|c|c|c|}
\hline FISCAL YEARS & 93 & 94 & 95 & 96 & 97 \\
\hline $\begin{array}{l}\text { Improve in situ film growth by laser } \\
\text { ablation. [STRS] }\end{array}$ & & & & & \\
\hline $\begin{array}{l}\text { Investigate new film/substrate } \\
\text { combinations. [STRS] }\end{array}$ & & & & & \\
\hline $\begin{array}{l}\text { Develop crossover and multilayer } \\
\text { technology. [STRS] }\end{array}$ & & & & & \\
\hline $\begin{array}{l}\text { Develop Josephson effect devices. } \\
\text { [STRS] }\end{array}$ & & & & & \\
\hline $\begin{array}{l}\text { Investigate microwave characteristics and } \\
\text { applications of HTS. [STRS, OA-DOD } \\
\text { (DARPA)] }\end{array}$ & & & & & \\
\hline Fabricate HTS integrated circuits. [STRS] & & & & & \\
\hline $\begin{array}{l}\text { Develop practical circuits and devices. } \\
\text { [STRS] }\end{array}$ & & & & & \\
\hline $\begin{array}{l}\text { Develop HTS devices at highest possible } \\
\text { frequency. [STRS] }\end{array}$ & & & & & \\
\hline
\end{tabular}




\section{Project: SUPERCONDUCTOR STANDARDS}

\section{FY 92 Fund Sources: STRS}

Staff (4.0 staff-years)

\begin{tabular}{|l||l|l|l|l|}
\hline \multirow{2}{*}{ Professional } & L. GOODRICH & F. Fickett* & R. Goldfarb* & J. Ekin * \\
\cline { 2 - 5 } & A. Srivastava* & & & \\
\hline Technician & T. Stauffer & & & \\
\hline
\end{tabular}

name in capital letters $=$ project leader; $*$ = person works on project part time

Objective: To support the superconductor wire and other superconductor component manufacturing industries, and to support the superconductor materials development industries, develop basic understanding of superconducting materials and measurements to enable standardization of measurement techniques. Specifically: provide standards of critical current and ac loss, round-robin testing of standards, and other reference devices such as a current simulator, for commerce in practical superconductor materials through U.S. organizations such as the American Society for Testing and Materials (ASTM), and international standards organizations such as the International Electrotechnical Commission (IEC) and the Versailles Project on Advanced Materials and Standards (VAMAS).

Significance: Present diversity of measurement methods results in large uncertainty in critical current of large low-temperature superconductivity (LTS) conductors. Design of large magnet systems requires five percent uncertainty or less. Large cable conductors have new problems in degradation of current caused by the cabling. High-temperature superconductivity (HTS) materials represent a new and difficult challenge in measurement science; their approaching commercialization requires rapid development of acceptable measurement methods. NIST supports industry in dealing with these problems by the establishment of standards and measurement methods, and through its international standards activities protects U.S. interests in international trade.

\section{FY 92 Accomplishments}

- Made changes to the $\mathrm{Nb}-\mathrm{Ti}$ critical current IEC standard as a result of comments received from Working Group-2 members of TC-90, ASTM, and others in the United States who are involved in LTS and HTS research.

- Collaborated, in Tsukuba, Japan, with co-workers at the National Research Institute for Metals (NRIM) on problems in critical current standards; participated in VAMAS activities at Tokyo.

- Developed a 10-A critical-current measuring system for Bi-based oxide tape conductors; measured the current of ten specimens at $4.0 \mathrm{~K}$ in magnetic fields from 0 to $12 \mathrm{~T}$. Found best specimen to have a critical current of $275 \mathrm{~A}$ in zero field and $146 \mathrm{~A}$ at $12 \mathrm{~T}$. Used high-current pressure contacts, developed at NIST, for the measurements. [Collaboration with industry]

- Submitted drafts of a chapter and appendix for the VAMAS final report on the $\mathrm{Nb}_{3} \mathrm{Sn}$ critical current interlaboratory comparisons; presided over the discussion of a standard measurement method for the critical current of $\mathrm{Nb}_{3} \mathrm{Sn}$ wires at a VAMAS meeting.

- Worked on a joint project to develop critical-current Reference Devices using bismuth tapes supplied by NRIM, as part of the U.S./Japan Agreement on Cooperation. Developed the design; NRIM supplied about 30 specimens accordingly. 


\section{FY 93 Plans}

- Complete development of standard measurement technique for critical current of large superconductors, including cables. Final form will depend on industry needs, especially those of the Superconducting Super Collider. Develop Standard Reference Material. Coordinate a round-robin evaluation of the method and initiate the process of adoption by ASTM.

- Provide leadership of national (ASTM, IEEE) and international (VAMAS, IEC) standards activities in superconductivity by directing U.S. coordination and participation in standards setting and in interlaboratory comparisons.

- Develop critical current standards for bulk high-temperature superconductors including measurement methods, superconductor simulators, and HTS reference devices. Maintain calibration of four hybrid simulators and promote their availability to U.S. superconductor manufacturers.

- Complete construction and testing of NIST high current variable temperature critical current measurement system. Interact with U.S. manufacturers and national laboratories to develop the NIST device as the primary precision measurement system in the 20 to $76 \mathrm{~K}$ region.

\section{Impact}

- NIST standards work has been and is used in all planning and conductor procurement for fusion energy, high-energy physics, and magnets for medical imaging. The design specifications for the conductors in the Superconducting Super Collider have depended on NIST work.

\section{Recognition}

- DoE has requested NIST participation in their program on HTS standards for large scale applications such as superconducting magnetic energy storage, power transmission, motors, shielding, and bearings.

- Goodrich is the Convenor of Working Group 2 (standards of measurement) of IEC TC-90 (superconductivity). He is also Chairman of ASTM committee B01.08. Goodrich presented invited lectures in Japan and participated in VAMAS activities there.

- Ekin presented an invited talk on superconductor measurements and standards at the March APS meeting.

\section{Related Developments}

- There is a general recognition of the need for standards and education in the measurement of the superconducting characteristics of HTS. International competition in the superconductor industry, even for supplying U.S. government projects, is fierce. 


\section{Project: SUPERCONDUCTOR STANDARDS}

\begin{tabular}{|c|c|c|c|c|c|}
\hline FISCAL YEARS & 93 & 94 & 95 & 96 & 97 \\
\hline $\begin{array}{l}\text { Develop standard reference material and } \\
\text { measurement techniques for critical } \\
\text { current of large superconductors; } \\
\text { coordinate round-robin evaluation and } \\
\text { initiate adoption by ASTM. [STRS] }\end{array}$ & & & & & \\
\hline $\begin{array}{l}\text { Participate in international } \\
\text { intercomparisons of critical current and ac } \\
\text { loss measurements. [STRS] }\end{array}$ & & & & & \\
\hline $\begin{array}{l}\text { Support national standards activities by } \\
\text { coordinating U.S. interlaboratory } \\
\text { comparisons. [STRS] }\end{array}$ & & & & & \\
\hline $\begin{array}{l}\text { Provide leadership of national (ASTM, } \\
\text { IEEE) and international (VAMAS, IEC) } \\
\text { standards activities in superconductivity. } \\
\text { [STRS] }\end{array}$ & & & & & \\
\hline $\begin{array}{l}\text { Develop critical current standards for bulk } \\
\text { HTS, including measurement methods, } \\
\text { superconductor simulators, and HTS } \\
\text { reference devices; promote availability to } \\
\text { U.S. manufacturers. [STRS] }\end{array}$ & & & & & \\
\hline $\begin{array}{l}\text { Complete variable temperature, high } \\
\text { critical current measurement system; } \\
\text { interact with U.S. manufacturers and } \\
\text { national laboratories to develop device as } \\
\text { primary precision measurement system in } \\
20-76 \mathrm{~K} \text { region. [STRS] }\end{array}$ & & & & & \\
\hline
\end{tabular}




\section{Project: CONDUCTOR SYSTEMS}

FY 92 Fund Sources: STRS, DoE, ICA, Navy/DTRC, Army

Staff (6.0 staff-years)

\begin{tabular}{|l||l|l|l|l|}
\hline \multirow{2}{*}{ Professional } & F. FICKETT* & S. Bray & L. Dulcie & R. Cross* \\
\cline { 2 - 5 } & J. Ekin* & R. Goldfarb* & C. Thompson* & S. Sanders \\
\cline { 2 - 5 } & M. Coffey * & S. Smith* & & \\
\hline Technician & N. Bergren & & & \\
\hline
\end{tabular}

name in capital letters $=$ project leader; ${ }^{*}=$ person works on project part time

Objective: To support the design, construction, and operation by industry of superconducting and other systems, develop basic understanding of conductors in order to provide generic data, models, and measurement methods. Specifically: emphasize materials and systems in commercial and near-commercial use, such as $\mathrm{NbTi}$ and $\mathrm{Nb}_{3} \mathrm{Sn}$ multifilamentary conductors; developmental low-temperature (LTS) materials such as Nb-based intermetallics; and low-resistivity normal conductors used in conjunction with LTS and high-temperature superconductivity (HTS) conductors in engineering applications.

Significance: The SSC will use 12,000 superconducting magnets when completed; the Relativistic Heavy Ion Collider will require 1.8 million feet of superconducting cable; tens of thousands of superconducting magnets are in use in laboratories throughout the world; the growing medical field of magnetic resonance imaging is a major new market. Practical LTS conductors are complex composite materials, and HTS materials are even more complex in structure. This NIST project provides a common base for interaction among system designers, system manufacturers, and materials manufacturers. The unique NIST capabilities are also needed for other electrical measurement in support of industry.

\section{FY 92 Accomplishments}

- Published the paper "Effect of cable and strand twist-pitch coincidence on the critical current of flat, coreless superconductor cables, " describing a concept which can greatly improve the current carrying capacity of superconducting cable (see also section on Impact).

- Made the first fatigue studies on Superconducting Composite Rings (SCCR) samples under radial stress, and submitted to the Navy data on commercial $\mathrm{Nb}-\mathrm{Ti} / \mathrm{Cu}$ and $\mathrm{Nb}-\mathrm{Ti} / \mathrm{Cu} / \mathrm{Al}$ "small-scale" wire used in the SCCR. Found that the fatigue-induced disturbances that cause sample quenches can be quite large - even at operating currents near half the critical current, quench resulted from only a few hundred strain cycles.

- Designed, built, and tested a conductive-fiber tow conductivity measurement system, which detects the presence of a carbon tow (multiple fibers) in a test transducer and allows comparison of tows with varying resistivities.

- Obtained wire drawing dies for drawing copper wire to $25 \mu \mathrm{m}$ (0.001 inch). Measured the residual resistivity ratio (RRR) of high-purity copper and of commercially drawn wires, and developed an anneal process to optimize the RRR of the high-purity wire. 


\section{FY 93 Plans}

- Apply theory of surface superconductivity to design of apparatus using microwave resonance for superconductor characterization. Continue study of microwave resistance. Fabricate $10-\mathrm{GHz}$ stripline resonators for microwave contact studies.

- Develop data base on properties of silver to support its uses in conjunction with HTS practical conductor development. Characterize effect of copper on superconducting behavior of copper-stabilized HTS such as BSCCO tape materials with deposited copper coatings.

- Based on prototype system developed in FY92, construct and demonstrate apparatus for on-line measurement of the electrical properties of a tow of carbon fibers.

- Perform critical current measurements on model wires and full-scale candidate conductors for Navy applications. Measure fatigue effect in Superconducting Composite Rings (SCCR) and measure residual resistivity ratio of SCCRs before and after fatigue testing.

- Measure and create data base of transverse compressive stress effects in $\mathrm{Nb}_{3} \mathrm{Sn}$ cable structures with emphasis on strand crossover behavior.

- Measure strain effect on critical current in experimental compound superconductors at very high magnetic fields. Determine effect of conductor shape and cabling configuration on strain effects.

- Establish capability to measure high critical current densities in HTS.

- Develop a program to determine the behavior of conduction electrons in conductors where the scattering mean free path is significantly limited by conductor dimensions.

\section{Impact}

- The existence of the strain limit on superconductor performance was discovered at NIST. Most large superconducting magnet systems designed subsequently have used these and other NIST results as a basis for conductor specification. NIST has provided industrial, government, and academic organizations consultation on strain effects for both LTS and HTS materials and conductors.

- The Department of Energy is considering making changes in the cabling scheme for the Superconducting SuperCollider as a result of Ekin's discovery of the effect on critical current of cable and strand twistpitch coincidence, to take advantage of potential increased current carrying capacity, and will begin tests with one of its cabling machines.

\section{Recognition}

- Fickett's interaction with Buck Research at a National Technology Initiative meeting was the subject of a two-page article in the premier issue of the magazine Technology Transfer Business.

- Ekin has been named head of the MIT Francis Bitter National Magnet Laboratory User's Committee, which is charged with making recommendations on policy and directions for the Laboratory.

\section{Related Developments}

- Small superconducting magnetic energy storage systems for power quality are now commercially available. They use liquid helium technology.

- Development of wire and tape from HTS materials continues; lengths suitable for magnets may be available within a year. 


\section{Project: CONDUCTOR SYSTEMS}

\begin{tabular}{|c|c|c|c|c|c|}
\hline FISCAL YEARS & 93 & 94 & 95 & 96 & 97 \\
\hline $\begin{array}{l}\text { Investigate transverse stress effects in } \\
\text { experimental superconductors at high } \\
\text { fields. [OA- DoE, Navy] }\end{array}$ & & & & & \\
\hline $\begin{array}{l}\text { Perform tests and evaluations of } \\
\text { conductors for DoE. [OA - DoE] }\end{array}$ & & & & & \\
\hline $\begin{array}{l}\text { Evaluate magneto-mechanical } \\
\text { characteristics of developmental } \\
\text { candidate conductors and composite coils } \\
\text { for Navy ship propulsion. [OA - Navy] }\end{array}$ & & & & & \\
\hline $\begin{array}{l}\text { Investigate stability of practical } \\
\text { superconductors. [STRS] }\end{array}$ & & & & & 1 \\
\hline $\begin{array}{l}\text { Develop data on properties of silver and } \\
\text { silver alloys. [STRS] }\end{array}$ & & & & & \\
\hline $\begin{array}{l}\text { Investigate feasibility of HTS stabilization } \\
\text { using copper. [OA - ICA] }\end{array}$ & & & & & \\
\hline $\begin{array}{l}\text { Develop apparatus for using microwave } \\
\text { resonance in superconductor } \\
\text { characterization; fabricate } 10 \mathrm{GHz} \text { strip } \\
\text { line resonators to study microwave } \\
\text { contact resistance. [STRS] }\end{array}$ & & & & & \\
\hline $\begin{array}{l}\text { Develop system to measure electrical } \\
\text { properties of a tow of carbon fibers; apply } \\
\text { AFM and STM techniques to evaluate } \\
\text { fiber structure and properties. [OA-Army] }\end{array}$ & & & & & \\
\hline $\begin{array}{l}\text { Determine size-limited behavior of } \\
\text { electrons; measure effect of conductor } \\
\text { purity on size-effect limited resistivity. } \\
\text { [ICA] }\end{array}$ & & & & & \\
\hline $\begin{array}{l}\text { Meaure strain effect on critical current in } \\
\text { compound superconductors at very high } \\
\text { magnetic field; determine effect of } \\
\text { conductor shape and cabling configuration } \\
\text { on strain effects. [DoE] }\end{array}$ & & & & & \\
\hline
\end{tabular}




\section{Project: MAGNETICS}

\section{FY 92 Fund Sources: STRS}

Staff (6.0 staff-years)

\begin{tabular}{|l||l|l|l|l|}
\hline \multirow{2}{*}{ Professional } & R. GOLDFARB* & T. Capobianco & R. Cross* & F. Fickett* \\
\cline { 2 - 5 } & A. Kos & J. Moreland* & J. Oti & P. Rice \\
\cline { 2 - 5 } & C. Thompson* & R. Thomson* & O. B. Hyun & \\
\hline Technician & R. Folsom* & & & \\
\hline
\end{tabular}

name in capital letters = project leader; $=$ person works on project part time

Objective: To support the magnetic recording industry and other industries using magnetic materials, develop basic understanding of magnetic properties of materials and structures, and provide sound basis for measurement techniques for applications ranging from fundamental studies in magnetism to magnetic recording media. Specifically: provide improved measurement capability and standards for all aspects of magnetic recording; further develop the capabilities of the various scanned-probe microscopies and other instruments for studying the microscopic magnetic properties of materials.

Significance: Magnetic measurements in the $\$ 52$ billion world wide magnetic information storage industry are an ongoing source of disagreement. The advent of thin film magnetics has resulted in further measurement problems. The rapid increase in magnetic recording density requires development of microscopic measurement techniques. This need is affirmed by an industrial survey and continuing industrial interactions. This NIST project responds to the major U.S. industrial needs for basic magnetic measurements.

\section{FY 92 Accomplishments}

- Fabricated the first set of magnetic multilayer ( $\mathrm{Cr}-\mathrm{CoNi}-\mathrm{Cr}-\mathrm{CoNi}$ ) films, using a commercial computercontrolled four-gun sputtering cluster. Varied the thickness of the $\mathrm{Cr}$ decoupling layers from 5 to $80 \mathrm{~nm}$ to explore the effects of a $\mathrm{Cr}$ decoupling layer in standard magnetic media; determined a complete set of hysteresis data on the films. Applied the NIST micromagnetic model of dual-layer magnetic recording films to these dual-layer media using the measured media parameters; found the modeling predictions to be in qualitative agreement with magnetization hysteresis data.

- Implemented the micromagnetic model to study force interactions between sense probe tips and imaged films in tunneling-stabilized magnetic-force microscopy. Model is capable of simulating different triangular tip shapes and different relative tip/film orientations, and allows for changing magnetization patterns in the tips.

- Completed the new microprobe (probe tip diameters as small as $0.1 \mu \mathrm{m}$ ) system, a voltage-scanning system for micrometer-scale examination of magnetoresistive recording heads to determine domain formation and motion in the heads - a problem of great interest to the recording industry. Conducted initial tests to verify scanning resolution of $0.05 \mu \mathrm{m}$ and $0.1 \mu \mathrm{m}$ bidirectional repeatability.

- Measured the "offset" susceptibility of a superconductor, a new aspect of superconductor magnetization which had been predicted from Fourier analysis but never before measured, largely because it is not detectible with usual pick-up coil techniques (the researchers used a Hall-probe magnetometer developed at NIST to measure magnetization directly rather than by induction). 
- Invented a unique but simple, fast, and repeatable method for creating very small tips for use in scanning magnetic surfaces. Formed tip diameters less than $0.1 \mu \mathrm{m}$ by exciting a wire at variable frequency and amplitude while it is withdrawn slowly out of an etching solution.

\section{FY 93 Plans}

- Apply scanned probe microscopy methods to measurement of nanoscale magnetic systems, concentrating on those systems, such as vertical Bloch line memory, which hold promise for magnetic recording. Develop techniques to image magnetic signatures below the $1 \mu \mathrm{m}$ limit and down to at least $10 \mathrm{~nm}$. Fabricate and incorporate semiconductor micro-Hall probes into scanning system to create a field profiler for measurements of high-density magnetic recording media and associated heads.

- Use micromagnetic model of dual-layer media to study the effects of exchange and magnetostatic interactions on the properties of longitudinal films. Correlate theoretical predictions of behavior of duallayer media with experimental data.

- Image magnetic field structure of magnetic recording heads using tunneling-stabilized magnetic-force microscopy and attempt high resolution imaging of domain walls on magnetic garnet. Develop methods for imaging of permaloy domain structure and apply to commercial memory elements.

- Use magnetoresistance scanning system to measure the effect of local field excitations on magnetoresistive (MR) response in MR thin films. Record two-dimensional MR profiles and corresponding magnetic profiles of MR elements. Determine the field and field-angle dependence of the first domain-wall nucleation field and the annihilation field and compare to theory.

- Develop theory of lower critical field and surface barriers in grain-aligned YBCO using NIST generalized critical state model for magnetization of superconductors.

- Develop a theory of vortex dynamics treating type-II superconductor behavior in linear response, and extend to treat both forward and inverse scattering problems and to a regime of nonlinear response.

\section{Impact}

- Lake Shore Cryotronics, Inc. commercialized the NIST ac susceptometer to make the special capabilities of this instrument available to the research community and industry.

\section{Recognition}

- Goldfarb was one of the five editors for the 1992 Intermag Conference and has been named chairman of the 1993 Intermag Publications Committee.

- Ron Goldfarb, Bill Cross, and John Moreland have each been invited to give talks at the Symposium on Magnetic Measurements at the March 1993 meeting of the APS.

- Moreland was awarded patent 5,103,682 "Ultra-Sensitive Force Detector Employing Servo-Stabilized Tunneling Junction."

\section{Related Developments}

- Rapid advances in magnetic recording make the need for dependable measurement technology on the submicrometer level more pressing. New optical recording technologies may once again challenge magnetic systems. The bit density of conventional magnetic recording continues to increase dramatically. 


\section{Project: MAGNETICS}

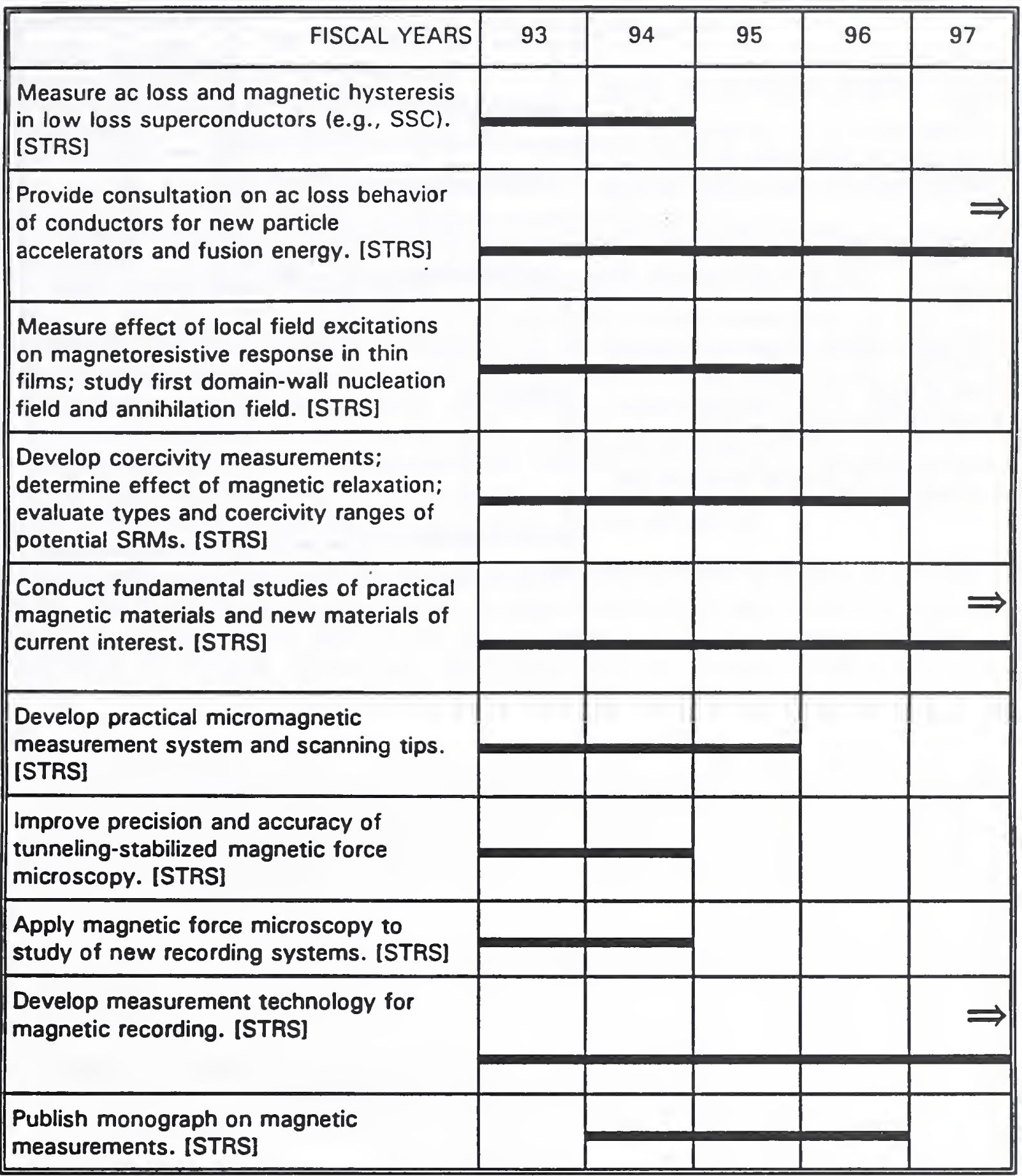




\section{Project: MAGNETICS (concluded)}

\begin{tabular}{|c|c|c|c|c|c|}
\hline FISCAL YEARS & 93 & 94 & 95 & 96 & 97 \\
\hline $\begin{array}{l}\text { Develop multilayer magnetic film model. } \\
\text { [STRS] }\end{array}$ & & & & & \\
\hline $\begin{array}{l}\text { Provide experimental demonstration of } \\
\text { multilayer magnetic film model. [STRS] }\end{array}$ & & & & & \\
\hline $\begin{array}{l}\text { Fabricate semiconductor micro-Hall probe; } \\
\text { study use of probe as a field profiler and } \\
\text { read element. [STRS] }\end{array}$ & & & & & \\
\hline $\begin{array}{l}\text { Develop generalized critical state model } \\
\text { for magnetization of superconductors that } \\
\text { includes effects of surface barrier and } \\
\text { reversible magnetization. [STRS] }\end{array}$ & & & & & \\
\hline $\begin{array}{l}\text { Develop industrial collaborations in the } \\
\text { area of magnetic recording. [STRS] }\end{array}$ & & & & & \\
\hline
\end{tabular}




\section{Project: SUPERCONDUCTOR STRUCTURE AND PROPERTIES}

FY 92 Fund Sources: STRS, DoE, DARPA, AF/WRDC, Navy

Staff (5.0 staff-years)

\begin{tabular}{|l||l|l|l|l|}
\hline \multirow{2}{*}{ Professional } & F. FICKETT* & J. Ekin* & R. Goldfarb* & J. Moreland* \\
\cline { 2 - 5 } & A. Roshko & M. Coffey* & S. Russek* & R. Thomson* \\
\cline { 2 - 5 } & C. Lutgen* & & & \\
\hline Technician & C. Clickner* & R. Folsom* & & \\
\hline
\end{tabular}

name in capital letters $=$ project leader; $=$ person works on project part time

Objective: To support the superconductor materials development industry, develop basic understanding of low-temperature superconductivity (LTS) and high-temperature superconductivity (HTS) materials, perform measurements leading to better understanding of their behavior under conditions typical of superconductor applications, and determine applicability of existing measurement techniques to emerging materials. Specifically: determine the mechanisms responsible for flux pinning, enhanced critical current, and field sensitivity by studying flux lattice structure, growth morphology, grain boundary chemistry, and magnetic field and temperature dependence of superconducting parameters.

Significance: High-temperature superconductivity is one of the major technological advances in recent times. This project makes use of the Group's expertise in conventional superconductivity measurements to contribute solutions industry needs to the new measurement problems associated with HTS materials. Application of emerging measurement technologies, such as scanning-tunneling and atomic-force microscopies, to superconductor evaluation and transfer of this information to industry are major thrusts.

\section{FY 92 Accomplishments}

- Made the first measurements of high-strain tolerance in high-temperature superconductors having high critical current and found acceptable tolerance levels. Measured the high-field axial strain properties of $\mathrm{Ag}$-sheathed bismuth conductors supplied by various organizations and measured a damage threshold for serious electrical degradation of about one order of magnitude greater than that for bulk sintered hightemperature superconductors.

- Found and evaluated several types of correlation between deposition parameters (rate, temperature, and pressure) and the morphology of laser ablated YBCO thin films, information needed for device applications.

- Measured as a function of magnetic field up to $12 \mathrm{~T}$ the transport critical current density of a series of YBCO films deposited at different temperatures. Found that the critical current density of films deposited at lower temperatures is less sensitive to magnetic field than it is for those grown at high temperatures.

- Obtained the first data on the effect of $c$-axis uniaxial stress on $T_{c}$ in single-crystal YBCO materials.

- Completed a study of the influence of $\mathrm{Ag}$ and $\mathrm{AgPt}$ buffer layers on YBCO thick films. Determined that the platinum improved both the flux pinning and transport across grain boundaries without causing texturing in the film. 
- Found, in developing current contacts to YBCO, that pressure contacts can be made with resistance lower than that of soldered contacts (pressure contacts are intrinsically easier to make).

- Completed the construction of the ultra-high-vacuum scanning-tunneling microscope and tested the chamber at a vacuum below $1.3 \times 10^{-8}$ pascal $\left(10^{-10}\right.$ torr $)$.

- Completed construction of the low-temperature scanning-tunneling/tunneling-stabilized magnetic-force microscopy "bathysphere" apparatus capable of rapid turn-around times; tested system successfully at $76 \mathrm{~K}$ and $4 \mathrm{~K}$.

\section{FY 93 Plans}

- Develop tunneling spectroscopy capability for scanning tunneling microscope and apply to HTS.

- Fabricate very thin YBCO films using laser growth on $\mathrm{LaAlO}_{3}, \mathrm{MgO}$, or $\mathrm{SrTiO}_{3}$ substrates. Measure transport critical current density and characterize other superconducting properties. Investigate the surface morphologies of the YBCO film surface for submicrometer features.

- Determine pinning mechanisms in film and bulk HTS and optimize fabrication process for high critical current density. Upgrade deposition and analysis systems.

- Determine the suitability of the $\mathrm{YBCO} / \mathrm{Au} / \mathrm{Pt} / \mathrm{Al}$ multilayer system as an interface to silicon by measuring contact resistance afiry oxygen annealing. Develop an effective method of depositing a dielectric layer, necessary for the contact measurement, which is compatible with $400^{\circ} \mathrm{C}$ oxygen anneals. Fabricate a test structure using photolithography.

- Determine activation energies, surface barriers, pinning potentials, and mechanism of intergranular flus pinning in HTS and investigate how flux structure influences the transport current capability. Measure the anisotropic intergranular coupling properties and lower critical fields of oriented HTS.

- Design and carry out quasiparticle injection experiments on YBCO films and study non-equilibrium quasiparticle properties of YBCO.

- Design and fabricate high-quality contacts to HTS films down to $2 \mu \mathrm{m}$ in size. Develop and optimize both in-situ and ex-situ contact processes.

\section{Recognition}

- A third patent on contacts to high-temperature superconductors has been allowed formally by the Patent Office.

- The Group's expertise in measurements of critical current, strain effects, and magnetic properties such as ac loss, have attracted requests for collaboration from all major U.S. superconductor manufacturers, several national laboratories, and foreign sources, with publications resulting.

- The Superconductor Coordinating Committee for Electric Power, composed of organizations interested in promoting the application of superconductivity to electric power developments, met in Boulder with NIST as host; the Electric Power Research Institute has indicated an interest in NIST work on ac loss.

\section{Related Developments}

- Commercial HTS products are now appearing. A commercial-size electric motor is under development. Designs are being prepared for HTS-based underground power transmission cables which will be direct replacements for existing power lines. 


\section{Project: SUPERCONDUCTOR STRUCTURE AND PROPERTIES}

\begin{tabular}{|c|c|c|c|c|c|}
\hline FISCAL YEARS & 93 & 94 & 95 & 96 & 97 \\
\hline $\begin{array}{l}\text { Develop data base on critical parameters } \\
\text { of new superconductors. [STRS, OA- } \\
\text { Navy] }\end{array}$ & & & & & $\Longrightarrow$ \\
\hline & & & & & \\
\hline $\begin{array}{l}\text { Develop critical current measurement } \\
\text { methods and standards for HTS. [STRS] }\end{array}$ & & & & & \\
\hline $\begin{array}{l}\text { Measure ac loss of HTS bulk material, } \\
\text { wire, and tape. [STRS] }\end{array}$ & & & & & \\
\hline $\begin{array}{l}\text { Extend low-resistance contacts to new } \\
\text { superconductors, large currents, and high } \\
\text { magnetic fields. [OA-Navy] }\end{array}$ & & & & & \\
\hline $\begin{array}{l}\text { Develop low-resistance contacts between } \\
\text { HTS and semiconductors. [OA-DoE] }\end{array}$ & & & & & \\
\hline $\begin{array}{l}\text { Apply magnetic force microscope to flux } \\
\text { lattice imaging. [STRS] }\end{array}$ & & & & & \\
\hline $\begin{array}{l}\text { Determine flux pinning mechanisms in } \\
\text { films and bulk conductors. [STRS \& OA. } \\
\text { DoD (DARPA)] }\end{array}$ & & & & & \\
\hline $\begin{array}{l}\text { Determine effects of grain boundary } \\
\text { structure, chemistry, crystallography, and } \\
\text { microstructure on properties of HTS. } \\
\text { [STRS] }\end{array}$ & & & & & \\
\hline $\begin{array}{l}\text { Investigate superconductor properties of } \\
\text { thin and thick films. [OA-DOD (DARPA)] }\end{array}$ & & & & & \\
\hline $\begin{array}{l}\text { Construct UHV STM with new scanner } \\
\text { and test at low temperatures; measure iN } \\
\text { curves of superconducting fullerenes, } \\
\text { using system. [STRS] }\end{array}$ & & & & & \\
\hline
\end{tabular}




\section{Project: SUPERCONDUCTOR STRUCTURE AND PROPERTIES (concluded)}

\begin{tabular}{|c|c|c|c|c|c|}
\hline FISCAL YEARS & 93 & 94 & 95 & 96 & 97 \\
\hline $\begin{array}{l}\text { Fabricate very thin YBCO films using laser } \\
\text { growth on a variety of substrates and } \\
\text { measure superconducting properties: } \\
\text { investigate film surface for submicrometer } \\
\text { features. [STRS] }\end{array}$ & & & & & \\
\hline $\begin{array}{l}\text { Fabricate ex situ contact chips; evaluate } \\
\text { surfaces with RHEED before and after } \\
\text { exposure to air, and study after cleaning } \\
\text { and regrowth. [OA-DoD (DARPA)] }\end{array}$ & & & & & \\
\hline $\begin{array}{l}\text { Design and fabricate high-quality contacts } \\
\text { to HTS films down to } 2 \mu \mathrm{m} \text {. Develop and } \\
\text { optimize both in situ and ex situ contact } \\
\text { processes. [OA-DoD (DARPA)] }\end{array}$ & & & & & \\
\hline $\begin{array}{l}\text { Examine composition and grain boundary } \\
\text { chemistry of HTS materials by STEM, } \\
\text { AES, or SIMS. Study morphology of thin } \\
\text { films by SEM, STM, and AFM. [STRS] }\end{array}$ & & & & & \\
\hline
\end{tabular}



